\title{
Functional added value of microprocessorcontrolled prosthetic knee joints
}

Citation for published version (APA):

Theeven, PJR. (2012). Functional added value of microprocessorcontrolled prosthetic knee joints.

[Doctoral Thesis, Maastricht University]. Maastricht University. https://doi.org/10.26481/dis.20121004pt

Document status and date:

Published: 01/01/2012

DOI:

10.26481/dis.20121004pt

Document Version:

Publisher's PDF, also known as Version of record

\section{Please check the document version of this publication:}

- A submitted manuscript is the version of the article upon submission and before peer-review. There can be important differences between the submitted version and the official published version of record.

People interested in the research are advised to contact the author for the final version of the publication, or visit the DOI to the publisher's website.

- The final author version and the galley proof are versions of the publication after peer review.

- The final published version features the final layout of the paper including the volume, issue and page numbers.

Link to publication

\footnotetext{
General rights rights.

- You may freely distribute the URL identifying the publication in the public portal. please follow below link for the End User Agreement:

www.umlib.nl/taverne-license

Take down policy

If you believe that this document breaches copyright please contact us at:

repository@maastrichtuniversity.nl

providing details and we will investigate your claim.
}

Copyright and moral rights for the publications made accessible in the public portal are retained by the authors and/or other copyright owners and it is a condition of accessing publications that users recognise and abide by the legal requirements associated with these

- Users may download and print one copy of any publication from the public portal for the purpose of private study or research.

- You may not further distribute the material or use it for any profit-making activity or commercial gain

If the publication is distributed under the terms of Article $25 \mathrm{fa}$ of the Dutch Copyright Act, indicated by the "Taverne" license above, 


\title{
Functional added value of microprocessor- controlled prosthetic knee joints
}

\author{
Patrick J. R. Theeven
}


The financial support that has been kindly provided by Otto Bock HealthCare GmbH, Vienna, Austria, for the studies presented in this thesis and for the publication of the present thesis is gratefully acknowledged.

All studies presented in this thesis were performed at the Centre of Expertise in Rehabilitation and Audiology of Adelante Rehabilitation Centre, Hoensbroek, The Netherlands.

The research presented in this thesis was also conducted at the School for Public Health and Primary Care: CAPHRI, Department of Rehebilitation Medicine, of Maastricht University. CAPHRI participates in The Netherlands School of Primary Care Research CaRe. CAPHRI was classified as 'excellent' by the external evaluation committee of leading international experts that reviewed CAPHRI in December 2010.

ISBN 978-90-9026942-9

Printed in Poland

Cover design \& lay-out: Esther Theeven - van Hinsberg

Theeven, Patrick Jacobus Richard. Functional added value of microprocessor-controlled prosthetic knee joints.

Copyright (C) P.J.R. Theeven, Maastricht 2012

All rights reserved. No part of this publication may be reproduced or transmitted in any form or by any means, electronical or mechanical, including photocopy, recording or any other information storage or retrieval system, without the prior written permission of the copyright owner. 


\title{
Functional added value of microprocessor- controlled prosthetic knee joints
}

\author{
Proefschrift \\ ter verkrijging van de graad van doctor \\ aan de Universiteit Maastricht, \\ op gezag van de Rector Magnificus, \\ Prof. dr. L.L.G. Soete, \\ volgens het besluit van het College van Decanen, \\ in het openbaar te verdedigen \\ op donderdag 4 oktober 2012 om 14.00 uur
}

door

Patrick Jacobus Richard Theeven

Geboren te Sittard, 2 januari 1982 


\section{Promotores}

Prof. dr. R.J.E.M. Smeets

Prof. dr. P.R.G. Brink

\section{Copromotores}

Dr. B. Hemmen

Dr. H.A.M. Seelen

\section{Beoordelingscommissie}

Prof. dr. R.A. de Bie (voorzitter)

Prof. dr. J.H.B. Geertzen (Universitair Medisch Centrum Groningen)

Prof. dr. M.K.C. Hesselink

Prof. dr. G.W.H. Schurink

Prof. dr. H.J. Stam (Erasmus Medisch Centrum Rotterdam) 



\section{Contents}

Chapter 1 General introduction $\ldots$

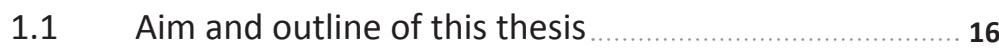

1.2 References 18

Chapter 2 Measures and procedures utilized to determine the added value of microprocessor-controlled prosthetic knee joints ..... 23 Abstract $\ldots \ldots \ldots$

2.1 Introduction $\ldots \ldots$

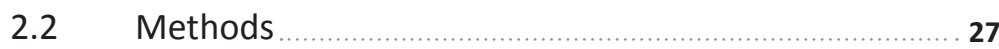

2.3 Results 29

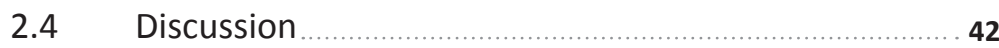

2.5 Conclusions 46

$2.6 \quad$ References $\quad 47$

Chapter 3 Feasibility of a new concept for measuring actual functional performance in daily life of transfemoral amputees _.............. 53

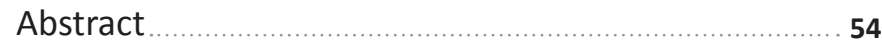

3.1 Introduction 55

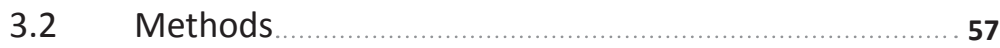

3.3 Results 62

3.4 Discussion $\ldots 6$

3.5 Acknowledgements 70

3.6 References 71

Chapter 4 Functional added value of microprocessor-controlled prosthetic knee joints in daily life performance of Medicare functional classification level-2 amputees $\quad 75$ Abstract 76

4.1 Introduction 77

4.2 Methods 79

$4.3 \quad$ Results 85

4.4 Discussion $\ldots$

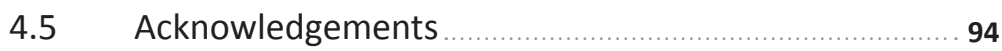

4.6 References.$\ldots \ldots$ 
Chapter 5 Gait perturbation recovery of low-functional transfemoral amputees using microprocessor-controlled prostheses:

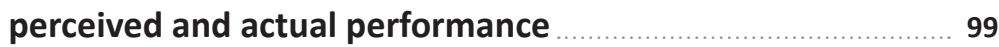

Abstract 100

5.1 Introduction 101

5.2 Methods 102

5.3 Results 107

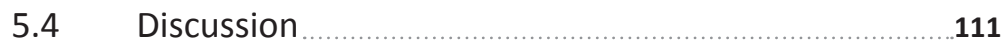

5.5 Acknowledgements 114

5.6 References 115

Chapter 6 Influence of advanced prosthetic knee joints on perceived performance and everyday life activity level of lowfunctional persons with a transfemoral amputation or knee disarticulation 119

Abstract 120

6.1 Introduction 121

6.2 Methods 123

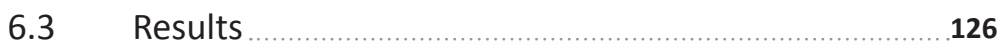

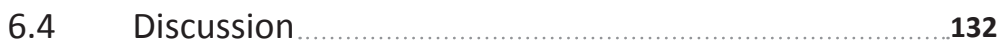

6.5 Acknowledgements _.......................................... 135

6.6 References 136

Chapter $7 \quad$ General discussion

7.1 Scope and aim of this thesis ………………......... 142

7.2 Main research findings 143

7.3 Clinical implications of main research findings ............150

7.4 Methodological considerations _............................. 153

7.5 Recommendations for future research _..................... 156

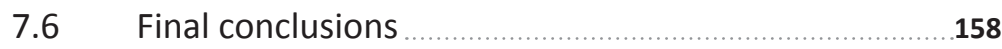

7.7 References 159

Summary 165

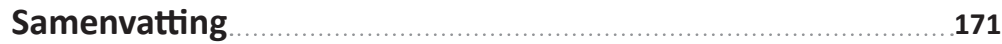

Dankwoord 179

About the author 185

Publications 189 


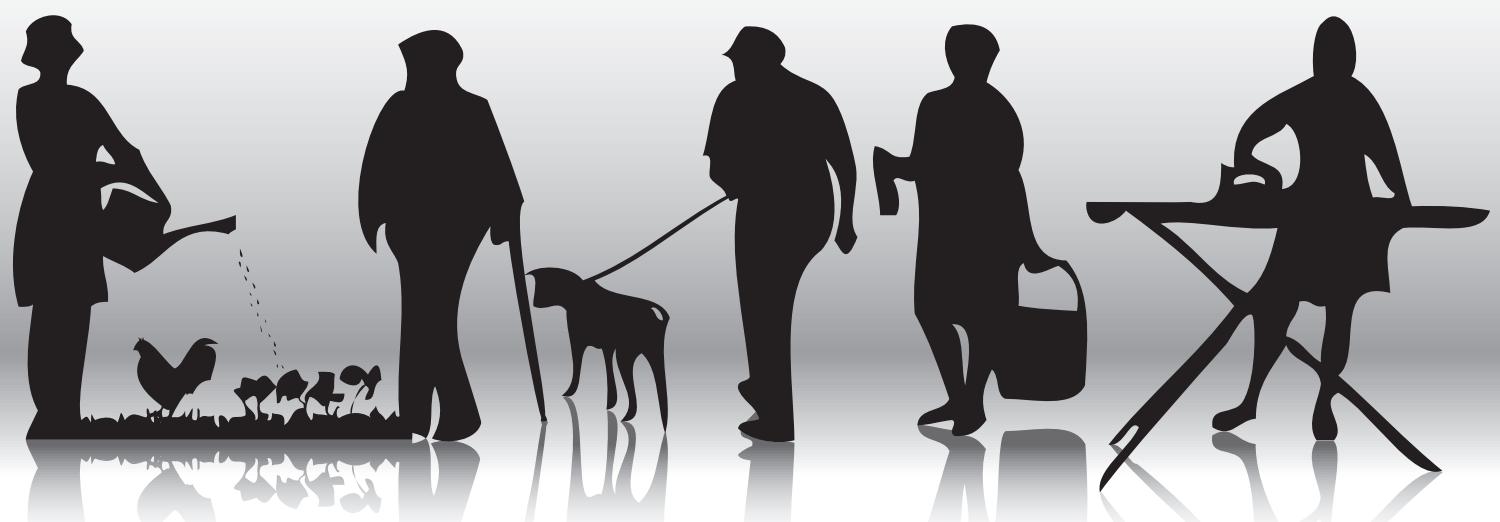




\section{Chapter 1}

General introduction

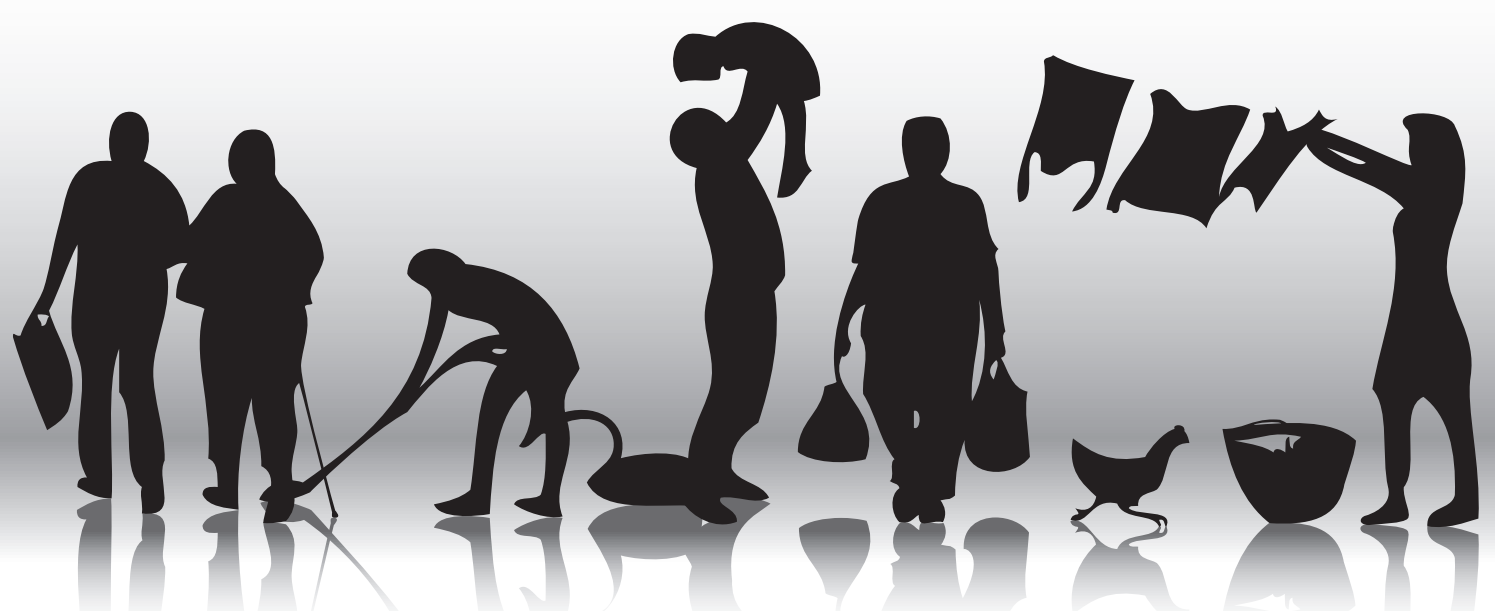




\section{CHAPTER 1}

\section{General introduction}

Lower extremity amputation is believed to be one of the oldest known surgically procedures performed ${ }^{1}$. The earliest literature discussing amputation dates from 1700 $B C^{2}$. An amputation is commonly defined as the removal of a limb through one or more bones ${ }^{2}$. An amputation is referred to as a disarticulation when the limb is removed through the joint ${ }^{2}$. This chapter provides a concise introduction regarding lower extremity amputations and gives a brief view on the intricate link with the fields of rehabilitation and prosthetics.

\section{Epidemiology}

In The Netherlands, approximately 3600 amputations of the lower extremities were performed in $2010^{3}$. The annual incidence in The Netherlands is estimated at 21.5 per 100,000 . About $55 \%$ of all lower extremity amputations are amputations of the toes, $30 \%$ at the below-knee level (transtibial and Syme), and $15 \%$ of the amputations are performed through (knee disarticulation) or above the knee (transfemoral and hip disarticulation) ${ }^{3}$. Almost $90 \%$ of the lower limb amputations are performed in persons over 65 years of age and about $60 \%$ are performed in men ${ }^{3}$. Amputations are generally performed following ischemic peripheral vascular disease, trauma, tumour, infection, or congenital limb deficiency. Rommers et al. ${ }^{4}$ reported that in the early nineties, $94 \%$ of all amputations of the lower extremities performed in the Northern provinces of The Netherlands were due to vascular problems ( $45 \%$ were related to diabetes mellitus ${ }^{5}$ ), about 3\% due to trauma, and 3\% as a result of cancer. These figures are similar to numbers from Denmark as reported by Ebskov et al. ${ }^{6}$. The estimated prevalence of lower limb amputees in the United States in 2005 was about 1 million ${ }^{7}$, and $79 \%$ of the amputations were due to peripheral vascular disease, of which $70 \%$ were caused by diabetes mellitus. Twenty percent of the lower extremities amputations were the result of trauma and $1 \%$ was due to cancer ${ }^{7}$.

\section{International Classification of Functioning, Disability and Health}

An amputation has a considerable influence on a person's health and his level of functioning in everyday life. According to the framework of the International Classification of Functioning, Disability, and Health (ICF) ${ }^{8}$, a person's level of functioning covers three health-related domains, i.e. body functions and body structures (ICF function), activity (ICF activity), and participation (ICF participation). The ICF classifies health and functioning from body, individual, and societal perspectives. The model of the ICF framework is shown in Figure 1. Body functions include the physiological functions of body systems (including 
psychological functions), whereas body structures refer to the anatomical parts of the body, such as organs and limbs. The domain of ICF activity focuses on the execution of tasks or actions by an individual. Participation is associated with the pursuit of different roles by the individual in society ${ }^{8}$.

Figure 1. A model of the ICF framework

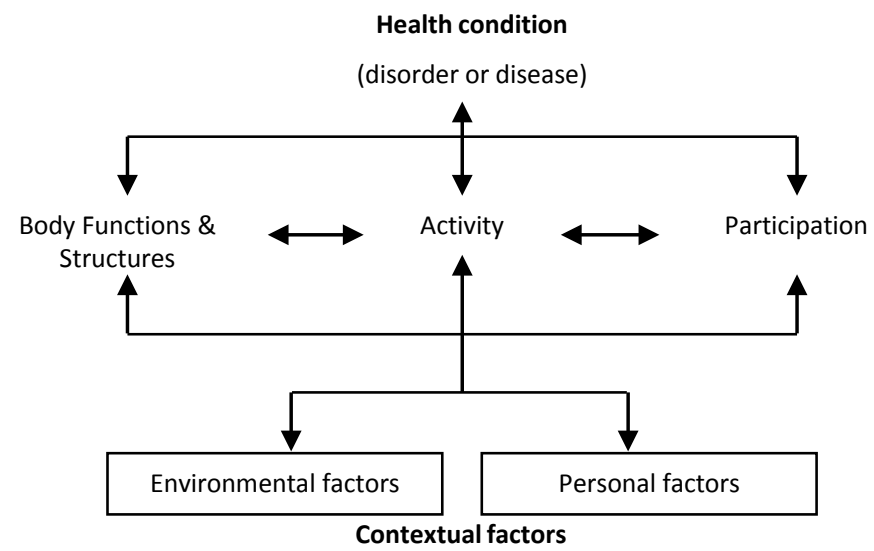

Rehabilitation

Rehabilitation of a person who has undergone a transfemoral amputation or knee disarticulation is aimed at enabling this person to reach and maintain his optimal physical, sensory, psychological and social functional level in order to optimally pursue his roles in society ${ }^{9}$. In The Netherlands, rehabilitation of persons with a transfemoral amputation or knee disarticulation is performed by a multidisciplinary team of health care professionals that includes a rehabilitation physician, a physical therapist, a nurse, a prosthetist, an occupational therapist, and preferably, a psychologist and social worker. The preprosthetic phase focuses on wound healing, control of oedema, prevention of infection, pain control, improving balance, and maintaining, and when necessary, improving the range of motion and strength of both the residual and the contralateral limb ${ }^{10,11}$. Passive and active mobilisation exercises of both limbs as well as balance training are provided by the physiotherapist. If a contracture around the hip joint is present, joint mobilisation needs to be applied. Also, a wheelchair is provided temporarily by the occupational therapist, who will train the amputee in order to master the necessary wheelchair skills. Several methods of reduction of oedema of the residual limb can be used, such as soft gauze elastic dressings, rigid cast dressings, removable rigid dressings, and prefabricated 
pneumatic dressings ${ }^{12}$. Once the oedema of the residual limb is resorbed, the amputee starts with prosthetic gait training. In some clinics, a so-called interim prosthesis is provided early in the rehabilitation process with the aim to (re)learn walking skills as soon as possible ${ }^{10}$. The training will initially focus on the technique of walking on even surface, and gradual reduction of the need for walking aids or the type of walking aid used. Also, instructions about daily care of the stump and the prosthetic components are given. During the course of the rehabilitation process, negotiating different walking surfaces such as uneven terrain, stairs and inclines are trained while the amputee is using the prosthesis. Once the patient has mastered these ambulation skills, household, vocational and leisure activities are trained ${ }^{13}$.

\section{Measuring rehabilitation outcome}

In order to determine whether rehabilitation was successful, the outcome should be measured and compared with the patient's individual goals set at the start of the rehabilitation. Rehabilitation outcome should be measured in all three ICF domains, as performance in the function, activity, and participation domain together determine a patient's level of functioning and quality of life. In measuring a person's functional outcome, a distinction can be made between a person's actual performance and his perceived performance. In this thesis actual performance is defined as the objectively detectable level of functioning of the amputee in a given domain at a given moment, whereas perceived performance is defined as the level of functioning subjectively experienced by the amputee in a given domain at a given moment. The influence of the patient's input into both the prescription of prostheses and the selection of prosthetic knee joints on successful outcomes is well recognized ${ }^{14,15}$. However, the use of selfreported measures introduces potential inaccuracy, which, among others, may stem from the patient's limited recall capacity. Also, social desirability (e.g. a patient provides answers he believes clinicians or researchers like to hear), and the patient's expectations (e.g. the fact that the patient is using an MPK may be enough for him to believe that he is experiencing enhanced function) reduce the validity of subjective tools. By using objective measures that focus on patients' actual level of functioning with the prosthesis, these confounders are avoided and more reliable results may be acquired. To this end, in addition to measures on perceived performance, using measures on objective performance is warranted. 


\section{Prosthetics}

A prosthesis for a person with a through or above the knee amputation generally consists of a socket, a knee joint, a pylon, and a prosthetic foot. The knee joint largely determines the amputee's ability to ambulate safely and efficiently with the prosthesis, because the knee needs to be stabilized and controlled by the amputee. The choice of the knee joint has a considerable influence on the mobility level the amputee will reach. Problems associated with prosthetic ambulation include the occurrence of (injurious) falls and fear of falling ${ }^{16}$, a high energy inefficiency (27\%-49\% more energy is used in comparison with persons who have not undergone an amputation ${ }^{17,18}$ ), and a considerable cognitive effort 19. These problems are highly associated with reduced activity, (general) mobility, and quality of life in amputees ${ }^{20-26}$. As a result of non-use, the amputee's physical capacity and functional abilities may further diminish, which may increase and perpetuate his functional limitations. Fortunately, many of the developments and innovations in prosthetic knee joints are focused on the reduction of these problems. These developments have also resulted in a broad range of prosthetic knee joints presently available. In order for a patient to function optimally and participate in society to his fullest extent, it is important that a prosthetic knee joint is selected that best suits the amputee's characteristics and his needs associated with the societal roles he wishes to perform. Prosthetic knee components may initially be divided into two groups, i.e. those that are exclusively mechanically controlled, and those that include microprocessor control ${ }^{27}$.

\section{Mechanically controlled prosthetic knee joints}

Different principles may be employed to mechanically control the swing and stance phase of a prosthetic knee joint, such as free swing (no control), manual locking, constant friction, weight-activated friction, geometrically locking, pneumatics, or hydraulics. One of the most basic mechanical prosthetic knee joints that is currently used, has a single axis with constant friction, which provides some damping of the swing phase motion ${ }^{27}$. In general, spring-loaded or elastic extension assistance is included to limit heel rise and to force the prosthetic knee joint into full extension just before heel strike ${ }^{27}$. Two major limitations for the use of the single axis constant friction prosthetic knee joint exist. Firstly, this prosthetic knee joint only provides stability when the net ground reaction force passes anterior to the knee axis ${ }^{1}$. Ambulating outdoors or on uneven surfaces requires constant compensation for changes in the ground reaction force to avoid knee collapse. Secondly, a knee prosthesis with constant friction swing control will only swing 


\section{CHAPTER 1}

effectively at one fixed cadence, which hinders the possibility to walk at varying speeds. Nowadays, prostheses featuring hydraulically or pneumatically controlled knee units are more commonly used. Pneumatic or hydraulic dampers that restrict the flow of the air or the liquid they contain, create a very high damping force to control the extension and/ or flexion of the prosthetic knee joint, and, in some cases, also allow variable cadence.

\section{Microprocessor-controlled prosthetic knee joints}

Since the early 1990s, microprocessor-controlled prosthetic knee joints (MPKs) have been available. These knee joints feature a microprocessor that controls the speed and ease of knee extension in the swing phase and, in some cases, also offer variable stance phase control. Microprocessor-controlled prosthetic knee joints are equipped with sensors that continuously detect the position and the angular velocity of the knee joint, as well as the forces that act on the ankle adapter. This allows instantaneous adaptation of the flexion and extension resistance, which facilitates ambulation with varying walking speeds and cadence on different terrains, under various environmental conditions. MPKs feature a variety of systems that may provide resistance, including pneumatics, hydraulics or magneto-rheological systems. The prosthetist can adapt the settings of the MPK by means of software.

\section{Prescription of prosthetic knee joints}

Matching each individual's specific characteristics, capacities, and preferences, with a suitable prosthesis is challenging. Van der Linde et al. ${ }^{28,29}$ state that no uniformity exists concerning prosthetic prescription, as it is primarily based on clinical expertise and experience. To make the prosthetic prescription and reimbursement more efficient, in The Netherlands clinical guidelines are being developed which include a protocol for matching the amputee's characteristics with the functional properties of a prosthetic knee joint ${ }^{30,31}$. Thus far, these guidelines are based on limited evidence available as to the effectiveness of prosthetic knee joints. In order for such a protocol to be effective, it is vital that sufficient objective scientific evidence is available regarding the effects of prosthetic knee joints on the amputee's functioning in all ICF domains. Especially information regarding the domains of activity and participation is of importance, as these levels closely relate to the amputee's daily pursuits. Moreover, such evidence is necessary, because the growing discrepancy between the development of medical technology and the limited financial resources in health care have led to the increasing demand of health care insurers for sound motivation as to the choice for a particular prosthetic knee joint, especially in case of the reimbursement of expensive MPKs. 
It is important to explore whether the effects of prosthetic components on a person's functioning apply to all above knee amputees or solely to specific subgroups of amputees. The United States department of health and human services' centers for Medicare and Medicaid services (CMS) adopted coding modifiers used by the United States Health Care Financing Administration to describe individuals with lower-limb amputation (Table I) 32,33. This classification system is known as the Medicare Functional Classification Level (MFCL) and is widely used in the US, Australia, and Europe. It classifies persons into one of five levels based on their ambulation abilities or ambulatory potential with a prosthesis. In Table I, an overview of these levels is presented.

Table I. Medicare Functional Classification Level (MFCL) descriptions

\begin{tabular}{|c|c|c|}
\hline $\begin{array}{c}\text { HCFA } \\
\text { Modifier }\end{array}$ & \multicolumn{2}{|r|}{ MFCL description } \\
\hline Ко & MFLC-0 - & $\begin{array}{l}\text { Does not have the ability or potential to ambulate or transfer safely with } \\
\text { or without assistance and a prosthesis does not enhance quality of life or } \\
\text { mobility. }\end{array}$ \\
\hline K1 & MFLC-1 - & $\begin{array}{l}\text { Has the ability or potential to use a prosthesis for transfers or ambulation } \\
\text { on level surfaces at fixed cadence. Typical of the limited and unlimited } \\
\text { household ambulator. }\end{array}$ \\
\hline K2 & MFLC-2 - & $\begin{array}{l}\text { Has the ability or potential for ambulation with the ability to traverse low- } \\
\text { level environmental barriers such as curbs, stairs, or uneven surfaces. } \\
\text { Typical of the limited community ambulator. }\end{array}$ \\
\hline K3 & MFLC-3 - & $\begin{array}{l}\text { Has the ability or potential for ambulation with variable cadence. Typical of } \\
\text { the community ambulator who has the ability to traverse most } \\
\text { environmental barriers and may have vocational, therapeutic, or exercise } \\
\text { activity that demands prosthetic utilization beyond simple locomotion. }\end{array}$ \\
\hline K4 & MFLC-4 - & $\begin{array}{l}\text { Has the ability or potential for prosthetic ambulation that exceeds the } \\
\text { basic ambulation skills, exhibiting high impact, stress, or energy levels, } \\
\text { typical of the prosthetic demands of the child, active adult, or athlete. }\end{array}$ \\
\hline 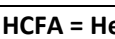 & & ing Administration \\
\hline
\end{tabular}

Although primarily used for reimbursement considerations in the United States, the MFCL classification is also used as an aid in the prescription of prosthetic knee joints. Amputees who have a lower functional level (MFCL-2) are characterised as limited community ambulators'. Compared with individuals classified as MFCL-3/-4, persons classified as MFCL-2 are generally older, may require additional walking aids (e.g. cane or crutches), and have (more) co-morbidities. In this subgroup of amputees a relatively large portion of the persons has been amputated due to the consequences of peripheral vascular disease or diabetes. In The Netherlands, MPKs are typically considered beneficial for amputees with a high functional level (MFCL-3 or MFCL-4), because the MPKs have features that suit the needs of such dynamic ambulators who are able to walk with varying speeds and 
utilize the prosthesis for purposes other than simple locomotion (vocational, therapeutic, leisure, or exercise activity). In contrast, MPKs are not considered eligible for amputees classified as MFCL-2, based on the prevailing supposition that MFCL-2 amputees ambulate less dynamically and therefore do not need or utilize the key performance enhancing features that differentiate the MPK from the mechanically controlled prosthetic knee joints (e.g. adaptive swing phase control to enable varying cadence) ${ }^{34}$. However, this supposition is based on little scientific evidence. MFCL-2 amputees may therefore have been denied an eligible prosthesis solution that would increase their level of functioning. Research seems to typically focus on the effects of MPKs in relatively young, fit, and active prosthetic ambulators ( $\geq \mathrm{MFCL}-3$ ). The reduced muscle strength, muscle coordination, prosthetic control and balance of MFCL-2 amputees underline a pronounced need for a prosthetic knee joint that enables safe ambulation. Safety is paramount for amputees to function optimally in daily life. Specific features in the MPKs, such as an adaptive stance phase control, are intended to provide a high level of safety, which, in turn, may positively affect the amputee's level of functional performance. Hafner \& Smith ${ }^{35}$ and Wetz et al. ${ }^{36}$ have reported significant reductions in MFCL-2 amputees' stumble and fall frequency, improvement of quality of stairs and hill negotiation, improved ability to divide attention during gait, reduced muscle force requirements, and reduced load on the unaffected leg. However, generally, little evidence seems to be available regarding the effects of using an MPK on persons' functioning in the ICF domains activity and participation. In contrast to the assessment of amputees' performance in the ICF domain function, assessing a person's performance in the ICF domains activity and participation relates more to the prosthesis-related problems the amputee encounters in daily life. The present thesis aims to comprehensively investigate the effects of using MPKs in amputees classified as MFCL-2, by typically evaluating the effects from a patient's perspective.

\subsection{Aim and outline of this thesis}

The main aims of the present thesis are:

1. to review the measures that have been utilized to assess the effects of using an MPK, in comparison with a mechanically controlled knee joint, in each of the three ICF domains and to summarize the effects on the functioning of persons with a transfemoral amputation or knee disarticulation;

2. to assess the effects of using an MPK, in comparison with a mechanically controlled knee joint, in persons classified as MFCL-2, concerning:

(i) the functional ability to perform activities of daily living; 
(ii) the functional ability to recover effectively from different types of perturbations in gait;

(iii) the influence on the daily activity level.

In chapter 2 a literature review is reported, exploring how and in which subgroups of amputees the effects of using an MPK, in comparison with a mechanically controlled prosthetic knee joint, have been determined thus far. Additionally, the effects of MPKs on the functioning of persons with a leg amputation are summarized.

In chapter 3 a concept for a new measuring tool is presented that enables objective assessment of amputees' actual ability to perform common daily activities. The feasibility of this concept is analysed and recommendations for a new test are given.

In chapter 4 a clinical study is reported in which the effects of using two types of MPKs, in comparison with mechanically controlled prosthetic knee joints, on the ability to perform activities of daily living in amputees classified as MFCL-2 were analysed using the measuring tool reported on in chapter 3 .

In chapter 5 a clinical study is described in which safety aspects of using an MPK in MFCL-2 amputees have been assessed. The effects of using two types of MPKs on persons' ability to successfully overcome different types of perturbations in gait have been investigated.

In chapter 6 the results of a clinical study are described in which the effects of using two types of MPKs, in comparison with mechanically controlled prosthetic knee joints, on amputees' daily activity level in persons classified as MFCL-2 have been quantified using an accelerometer.

In chapter 7 the findings reported in the previous chapters of this thesis and the clinical implications of our findings are discussed. Also, recommendations for future research are given. 


\section{CHAPTER 1}

\subsection{References}

1. Murdoch G, Wilson ABJ. Amputation: Surgical Practice and Patient Management. St Louis: Butterworth-Heinemann Medical; 1996.

2. Kulkarni GS. Textbook of orthopedics and trauma. 2nd edn. New Delhi: Jaypee Brothers Medical Publishers Ltd.; 2008.

3. Kiwa Prismant. Landelijke Medische Registratie [National Medical Registration]. [December 30, 2011]; Available from: http://cognosserver.prismant.nl/cognos7/cgi-bin/ppdscgi.cgi?DC=Q\&E=/ Prisma-Landelijke-LMR/Landelijke+LMR-informatie+-+Verrichtingen.

4. Rommers GM, Vos LD, Groothoff JW, Schuiling CH, Eisma WH. Epidemiology of lower limb amputees in the north of The Netherlands: aetiology, discharge destination and prosthetic use. Prosthet Orthot Int 1997; 21:92-99.

5. van Houtum WH, Lavery LA. Regional variation in the incidence of diabetes-related amputations in The Netherlands. Diabetes Res Clin Pract 1996; 31:125-132.

6. Ebskov LB. Level of lower limb amputation in relation to etiology: an epidemiological study. Prosthet Orthot Int 1992; 16:163-167.

7. Ziegler-Graham K, MacKenzie EJ, Ephraim PL, Travison TG, Brookmeyer R. Estimating the prevalence of limb loss in the United States: 2005 to 2050. Arch Phys Med Rehabil 2008; 89:422-429.

8. World Health Organisation. International Classification of Functioning, Disability and Health: ICF; 2001.

9. World Health Organisation. Health topics: Rehabilitation. [Accessed February 15, 2012]; Available from: http://www.who.int/topics/rehabilitation/en.

10. Geertzen JHB, Rietman JS. Amputatie en prothesiologie van de onderste extremiteit. Den Haag: Lemma; 2008.

11. Esquenazi A, DiGiacomo R. Rehabilitation after amputation. J Am Podiatr Med Assoc 2001; 91:13-22.

12. Smith DG, McFarland LV, Sangeorzan BJ, Reiber GE, Czerniecki JM. Postoperative dressing and management strategies for transtibial amputations: a critical review. J Rehabil Res Dev 2003; 40:213-224.

13. Deckers JHM, Beckers DML. Ganganalyse en looptraining voor de paramedicus. Houten/Diegem: Bohn Stafleu Van Loghum; 1996.

14. Boone DA, Coleman KL. Use of the Prosthesis Evaluation Questionnaire (PEQ). J Prosthet Orthot 2006; 18:68-79.

15. Legro MW, Reiber GD, Smith DG, del Aguila M, Larsen J, Boone D. Prosthesis evaluation questionnaire for persons with lower limb amputations: assessing prosthesis-related quality of life. Arch Phys Med Rehabil 1998; 79:931-938.

16. Miller WC, Speechley M, Deathe B. The prevalence and risk factors of falling and fear of falling among lower extremity amputees. Arch Phys Med Rehabil 2001; 82:1031-1037. 
17. Gitter A, Czerniecki J, Weaver K. A reassessment of center-of-mass dynamics as a determinate of the metabolic inefficiency of above-knee amputee ambulation. Am J Phys Med Rehabil 1995; 74:332338.

18. Hoffman MD, Sheldahl LM, Buley KJ, Sandford PR. Physiological comparison of walking among bilateral above-knee amputee and able-bodied subjects, and a model to account for the differences in metabolic cost. Arch Phys Med Rehabil 1997; 78:385-392.

19. Pellecchia GL. Postural sway increases with attentional demands of concurrent cognitive task. Gait Posture 2003; 18:29-34.

20. Bussmann JB, Grootscholten EA, Stam HJ. Daily physical activity and heart rate response in people with a unilateral transtibial amputation for vascular disease. Arch Phys Med Rehabil 2004; 85:240244.

21. Bussmann JB, Schrauwen HJ, Stam HJ. Daily physical activity and heart rate response in people with a unilateral traumatic transtibial amputation. Arch Phys Med Rehabil 2008; 89:430-434.

22. Miller WC, Deathe AB, Speechley $M$, Koval J. The influence of falling, fear of falling, and balance confidence on prosthetic mobility and social activity among individuals with a lower extremity amputation. Arch Phys Med Rehabil 2001; 82:1238-1244.

23. Miller WC, Speechley M, Deathe AB. Balance confidence among people with lower-limb amputations. Phys Ther 2002; 82:856-865.

24. Bertera EM, Bertera RL. Fear of falling and activity avoidance in a national sample of older adults in the United States. Health Soc Work 2008; 33:54-62.

25. Delbaere K, Crombez G, Vanderstraeten G, Willems T, Cambier D. Fear-related avoidance of activities, falls and physical frailty. A prospective community-based cohort study. Age Ageing 2004; 33:368373.

26. Fletcher PC, Hirdes JP. Restriction in activity associated with fear of falling among community-based seniors using home care services. Age Ageing 2004; 33:273-279.

27. Michael JW. Modern prosthetic knee mechanisms. Clin Orthop Relat Res 1999; 361:39-47.

28. van der Linde H, Geertzen JHB, Hofstad CJ, van Limbeek J, Postema K. Prosthetic prescription in the Netherlands: An observational study. Prosthet Orthot Int 2003; 27:170-178.

29. Van der Linde H. Prosthetic prescription in lower limb amputation. Development of a clinical guideline in the Netherlands. Thesis (PhD). Rijksuniversiteit Groningen; 2004.

30. Nederlandse Vereniging van Revalidatieartsen (VRA). Conceptrichtlijn Amputatie en Prothesiologie Onderste Extremiteit [Concept Guidelines Amputation and Prosthesiology Lower Extremities]. Available from: http://www.cbo.nl/Downloads/1347/conceptrichtlijn\%20amputatie_definitieve \%20versie\%20voor\%20commentaar_11\%20mei\%202011.pdf.

31. Stuurgroep Protocollering en Prijssystematiek Prothesen. Protocol verstrekkingsproces beenprothesen [Protocol for Prescribing Leg Prostheses]. Available from: http://www.cbo.nl/ 


\section{CHAPTER 1}

Downloads/1348/Protocolverstrekkingsprocesbeenprothesen1november2010.pdf.

32. Medicare Region C DMERC Durable Medical Equipment Prosthetics Orthotics and Supplies (DMEPOS) Supplier Manual. Columbia (SC): Palmetto GBA; 2006.

33. Centers for Medicare and Medicaid Services. U.S. Department of Health and Human Services. HCFA Common Procedure Coding System (HCPCS). Springfield (VA): U.S. Department of Commerce, National Technical Information Service; 2001.

34. Friel K. Componentry for lower extremity prostheses. J Am Acad Orthop Surg 2005; 13:326-335.

35. Hafner BJ, Smith DG. Differences in function and safety between Medicare Functional Classification Level-2 and -3 transfemoral amputees and influence of prosthetic knee joint control. J Rehabil Res Dev 2009; 46:417-433.

36. Wetz HH, Hafkemeyer U, Drerup B. Einfluss des C-Leg-Kniegelenk-Passteiles der Fa. Otto Bock auf die Versorgungsqualität Oberschenkelamputierter. Eine klinisch-biomechanische Studie zur Eingrenzung von Indikationskriterien [The influence of the C-leg knee-shin system from the Otto Bock Company in the care of above-knee amputees. A clinical-biomechanical study to define indications]. Orthopäde 2005; 34:298-319. 



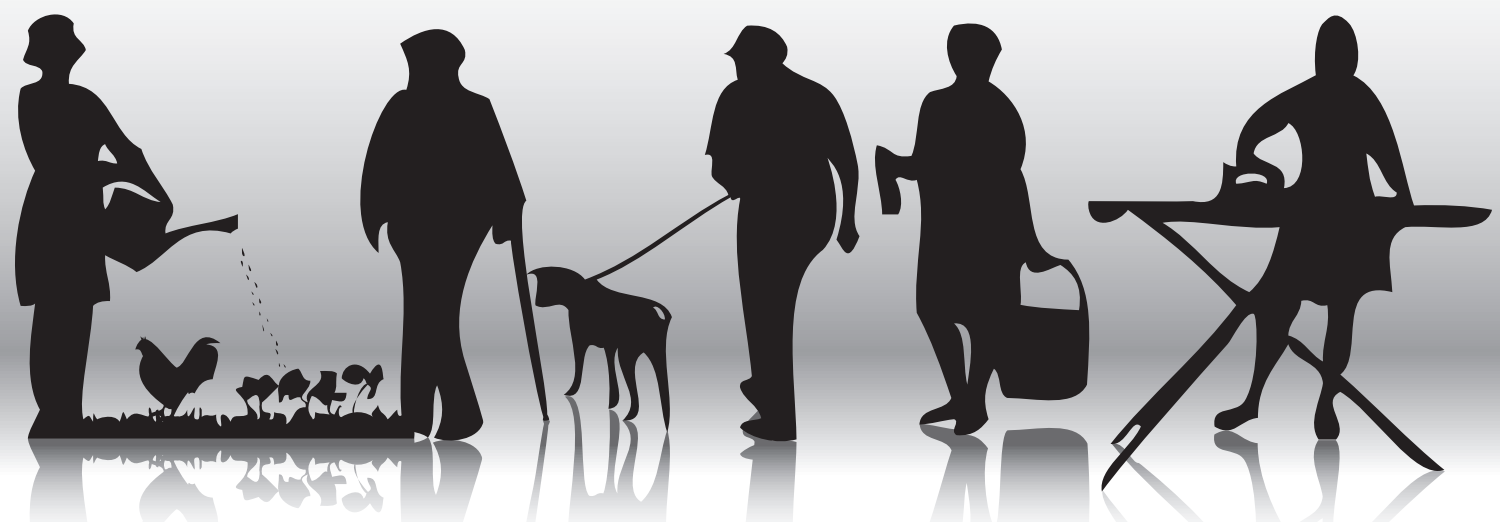




\section{Abstract}

Purpose: investigating how the effects of using a microprocessor-controlled prosthetic knee joint (MPK), in comparison with a mechanically controlled prosthetic knee joint, have been determined thus far.

Method: a systematic literature search in 6 databases (PubMed, CINAHL, Cochrane Library, Embase, Medline and PsychInfo) identified scientific studies that compared the effects of using MPKs with mechanically controlled prosthetic knee joints on persons' functioning. The outcome measures that have been utilized in those studies were extracted and categorized according to the ICF framework. Also, a descriptive analysis regarding all studies has been performed.

Results: a total of 31 studies and 64 outcome measures have been identified. The majority (70\%) of the outcome measures that described the effects of using an MPK on persons' actual performance with the prosthesis covered ICF function level. Only $27 \%$ of the measures on persons' actual performance investigated how an MPK may affect performance in daily life. Research also typically focused on young, fit and active persons. Conclusions: scientifically valid evidence regarding the performance of persons with an MPK in everyday life is limited. Research should specifically focus on ICF activity and participation level to increase our understanding of the possible functional added value of MPKs. 


\subsection{Introduction}

Prosthetic componentry has evolved considerably over the years, incorporating advanced materials and techniques into the modern-day prostheses. Presently, a multitude of prosthetic knee joints exists that, based on how these joints are controlled, can generally be divided into two groups, i.e. prosthetic knee joints with exclusively mechanical control properties, and microprocessor-controlled prosthetic knee joints (MPKs) ${ }^{1}$. Mechanical control of the knee joint during the swing phase of gait is achieved either by constant friction (spring loaded or elastic extension), hydraulic dampening, or pneumatic dampening. Mechanical control during stance phase is obtained by manual locking, a weight-activated friction brake, a polycentric axis, or by hydraulic dampening ${ }^{1}$. MPKs on the other hand, have a built-in microcomputer that continuously controls the flexion and extension resistance of the prosthetic knee during the stance phase and/ or swing phase of each gait cycle. According to its manufacturers, the benefits of using an MPK, in comparison with a mechanically controlled prosthetic knee, are especially associated with the possibility to walk with varying walking speeds due to the adaptive swing phase control, and to walk with a higher level of safety due to the MPKs' adaptive stance phase control. These features may allow persons with an amputation to ambulate with a walking pattern that closely resembles natural gait, which in turn may lead to, for instance, a reduction in metabolic cost and cognitive demand.

From the broad range of available components, rehabilitation professionals have to choose a specific prosthetic knee joint that enables the patient to function optimally with the prosthesis in daily life. This choice is a complicated and challenging task, because every patient is unique in terms of age, gender, body weight, type of amputation, physical condition, cognition, ambulation-related goals regarding activities of daily living, and societal roles (s)he wishes to engage in. It is crucial that a prosthetic knee joint is selected that best meets the patient's characteristics and needs, in order for the patient to reach an optimal level of functioning in daily life. Patients' level of functioning encompasses multiple health and health-related domains that are described in the framework provided by the International Classification of Functioning, Disability and Health (ICF) ${ }^{2}$. The ICF defines three different levels, i.e. function level (aimed at body functions and body structures), activity level (i.e. aimed at skills, task execution, and activity completion), and participation level (aimed at a person's involvement in a life situation). The term 'functioning' encompasses all body functions, activities and participation ${ }^{2}$. The ICF also lists environmental factors that may interact with a person's level of functioning. Additionally, amputees can be classified into subgroups based on 
their level of functioning. The Medicare Functional Classification Level system ${ }^{3}$ (MFCL-0 through MFCL-4; or KO through K4) is an example of such a classification. It classifies individuals based on their ability or potential ability to function with their prosthesis, as is indicated in Table I. Such classification may aid clinicians in the selection of prosthetic knee joints, as the MFLC level of a patient is often associated with specific categories of prosthetic knee joints that are considered suitable for those patients ${ }^{4}$.

Table I. Medicare Functional Classification Level (MFCL) descriptions

\begin{tabular}{cll}
\hline $\begin{array}{c}\text { HCFA } \\
\text { Modifier }\end{array}$ & \multicolumn{1}{c}{ MFCL description } \\
\hline K0 & MFLC-0 - $\begin{array}{l}\text { Does not have the ability or potential to ambulate or transfer safely with } \\
\text { or without assistance and a prosthesis does not enhance quality of life or } \\
\text { mobility. }\end{array}$ \\
\hline K1 & MFLC-1 $-\begin{array}{l}\text { Has the ability or potential to use a prosthesis for transfers or ambulation } \\
\text { on level surfaces at fixed cadence. Typical of the limited and unlimited } \\
\text { household ambulator. }\end{array}$ \\
\hline K2 & MFLC-2 $-\begin{array}{l}\text { Has the ability or potential for ambulation with the ability to traverse low- } \\
\text { level environmental barriers such as curbs, stairs, or uneven surfaces. } \\
\text { Typical of the limited community ambulator. }\end{array}$ \\
\hline K3 & MFLC-3 - $\begin{array}{l}\text { Has the ability or potential for ambulation with variable cadence. Typical of } \\
\text { the community ambulator who has the ability to traverse most } \\
\text { environmental barriers and may have vocational, therapeutic, or exercise } \\
\text { activity that demands prosthetic utilization beyond simple locomotion. }\end{array}$ \\
\hline HCFA = Health Care Financing Administration \\
\hline
\end{tabular}

Ever since the MPKs became available, a debate is ongoing as to what characteristics an amputee should have in order for an MPK to be a more suitable prosthetic solution than a mechanically controlled prosthetic knee joint to function optimally in daily life. Finding an answer to this issue is an important step in streamlining the current prescription guidelines and reimbursement policies regarding the MPKs. Various studies with diverse degrees of quality have been performed that evaluated the possible effects on persons' level of functioning of using the more advanced MPKs in comparison with the mechanically controlled prosthetic knee joints. The effects of using an MPK have been assessed using a variety of outcome measures in a variety of health and health-related domains. However, if the patient is to receive a prosthetic knee joint that enables him to function optimally in daily life, it is vital that the clinician has adequate information about the effects of that particular component on all three ICF domains of persons' functioning. Especially information concerning performance in the domains of activity and participation are of 
high importance, as those domains closely describe the person's ability to function with the prosthesis in daily life. Moreover, information is necessary that describes to what amputee subgroups (e.g. MFCL classes) those effects are applicable. A comprehensive overview of the scientific evidence concerning the differences in the effects of MPKs and mechanically controlled prosthetic knee joints on the functioning of amputees is therefore warranted. A first step in creating such an overview is to investigate how and in which domains of amputees' functioning those effects have been determined thus far.

The present review aims:

(i) to identify the outcome measures that have been utilized to assess the effects of using an MPK in comparison with a mechanically controlled prosthesis in persons with a knee disarticulation or transfemoral amputation, (ii) to classify and structure the outcome measures identified according to the ICF framework, (iii) to evaluate the characteristics and quality of the studies that have been performed to assess the differences between MPKs and mechanically controlled prosthetic knee joints, (iv) to determine possible gaps in the information that is available at the three ICF domains of 'function', 'activity', and 'participation'. For contextual overview, also a short summary per paper identified and included, will be provided.

\subsection{Methods}

\section{Search strategy}

The databases PubMed, CINAHL, Cochrane Library, Embase, Medline and PsychInfo were searched up to June 15,2011 . The search focused on studies that compared the use of any type of MPK to the use of any type of mechanically controlled prosthetic knee joint. The following default Boolean search strategy was used: "prosthe* AND knee AND (amput* OR disarticulation) AND (microprocessor OR active OR electronic* OR magnetorheologic* OR intelligent OR variable-damping OR computerized)". The search was limited to articles written in English, Dutch, French, or German between January 1990 and June 2011. The first MPK became commercially available in 1993. In addition to the database search, the lists of references of all papers included were checked for eligible articles.

\section{Screening}

The papers found in the literature search were independently screened by two researchers (PT and HS), based on title and abstract, and classified as 'relevant', 'not relevant', or 'possibly relevant'. The two researchers resolved any disagreement regarding the classification of papers by assessing the full-text article and discussing on ultimate 
inclusion or exclusion. Subsequently, the full text of all papers, found to be eligible, was reviewed. Papers were included when they met the following inclusion criteria:

(i) Participants are persons with a transfemoral amputation or knee disarticulation;

(ii) Persons' performance using a mechanically controlled knee joint is contrasted to persons' performance using an MPK.

Papers were excluded when one or both of the inclusion criteria were not met, when they focused on endoprosthetic knee joints, or when the primary outcome parameters focused on performance of the prosthetic knee joint and not on the performance of the person using the prosthesis.

\section{Classification of outcome measures identified}

Main outcome parameters were identified in the selected studies and subsequently categorised according to the ICF classification ${ }^{2}$. Each parameter was given an ICF code to indicate which particular function, activity, participation, or environmental factor it measured. Also, a distinction was made between parameters that describe persons' actual performance and persons' self-perceived performance. Actual performance was defined as the objectively detectable level of functioning of the amputee in a given domain at a given moment. Perceived performance was defined as the level of functioning subjectively experienced by the amputee in a given domain at a given moment (self-report).

Furthermore, it was specified to what particular purpose each function, activity, participation, or environmental factor was measured. To this end, eight, so-called, areas of interest were identified, i.e. 'quality of walking', 'energy cost', 'cognitive effort', 'safety', 'activity level', 'activities other than walking', 'prosthetic comfort' and 'other (e.g. health)'. These areas of interest summarize the general topics of the papers included in the present review.

\section{Descriptive analysis of studies included}

A descriptive analysis of the studies included in the present review was performed. Information is provided about the characteristics of the participants included in the studies (i.e. age, aetiology of amputation, reported functional level), and the characteristics of the studies included (sample size, study design, methodological quality). The methodological quality was assessed using the van Tulder's quality assessment system. This scale scores the internal validity (maximum 11 points), the descriptive criteria (maximum 6 points) and the statistical criteria (maximum 2 points) ${ }^{5,6}$. 


\subsection{Results}

Figure 1 represents a schematic overview of the selection process of the studies. A total of 31 articles, in which the use of mechanically controlled prosthetic knee joints was contrasted to the use of MPKs, were included in the final analysis.

Figure 1. Schematic representation of article selection

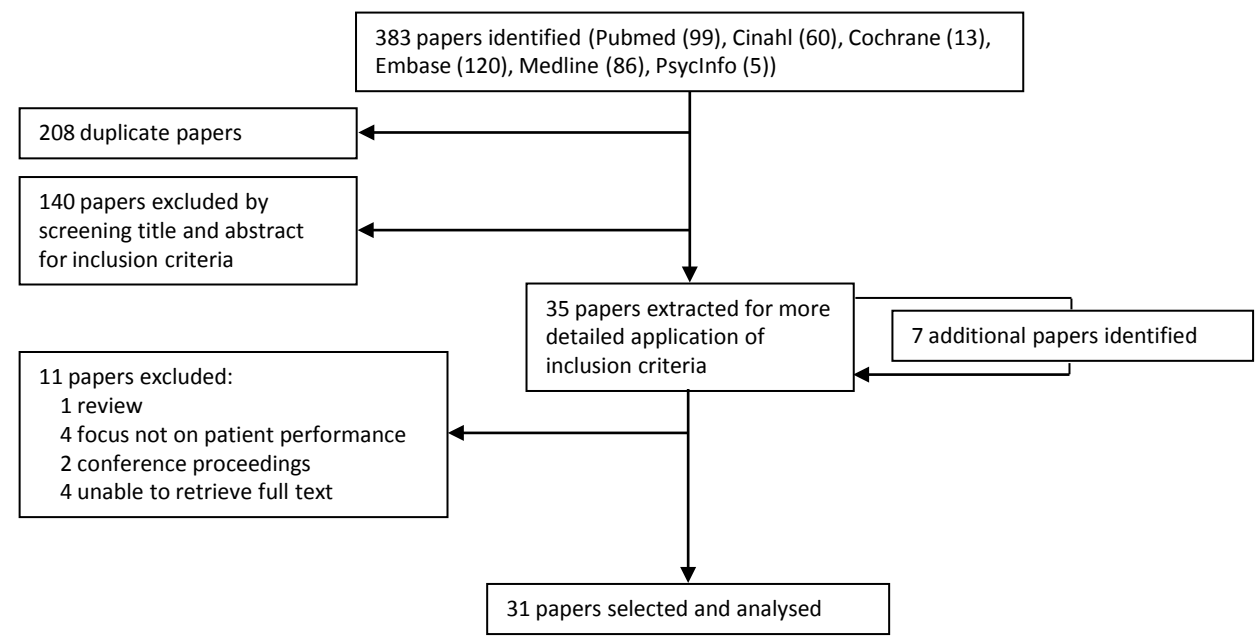

A comprehensive overview of the characteristics of the papers included is presented in Table 2. Papers are sorted in ascending order of publication year.

Classification of outcome measures identified

A detailed description of the main outcome parameters extracted from the articles is shown in Table 3. A total of 64 different outcome parameters were identified. Thirtyfour parameters described participants' actual performance, 27 parameters described participants' self-perceived performance, and 3 parameters assessed both actual performance and perceived performance (indicated in Table 3 with "a-p").

Classification according to the ICF framework demonstrated that $56 \%$ of all outcome parameters assessed the effects of using an MPK at ICF function level, 30\% at ICF activity level, and $3 \%$ at ICF participation level. An additional $11 \%$ of the outcome parameters were classified as environmental factors. In 5 cases, no specific ICF code could be ascribed to the parameter, because of the wide interpretability of those parameters. 
Table 2. Overview of study characteristics, outcome parameters, and results on main outcome parameters

\begin{tabular}{lllllllll} 
Reference & $\begin{array}{l}\text { Sample } \\
\text { size }\end{array}$ & $\begin{array}{l}\text { Age } \pm \text { SD } \\
\text { (range) }\end{array}$ & $\begin{array}{l}\text { Study } \\
\text { design }\end{array}$ & $\begin{array}{l}\text { Study } \\
\text { quality } \\
\text { (VT) }\end{array}$ & $\begin{array}{l}\text { Functional } \\
\text { classification } \\
\text { level reported }\end{array}$ & $\begin{array}{l}\text { Type of } \\
\text { MPK }\end{array}$ & $\begin{array}{l}\text { Type of } \\
\text { mech. knee }\end{array}$ & $\begin{array}{l}\text { Accommo- } \\
\text { dation time } \\
\text { with MPK }\end{array}$ \\
\hline
\end{tabular}

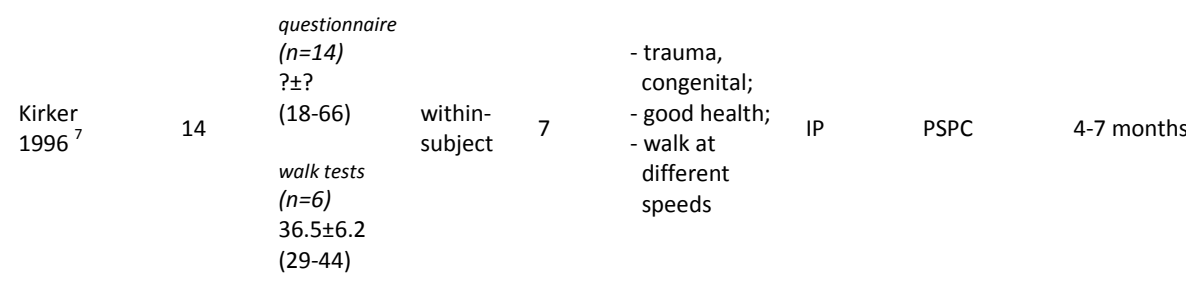

\begin{tabular}{|c|c|c|c|c|c|c|c|c|}
\hline $\begin{array}{l}\text { Taylor } \\
1996^{8}\end{array}$ & 1 & 33 & $\begin{array}{l}\text { within- } \\
\text { subject }\end{array}$ & 7 & $\begin{array}{l}\text { - trauma; } \\
\text { - active }\end{array}$ & IP & $\begin{array}{l}\text { Mauch SNS; } \\
\text { PSPC }\end{array}$ & $\geq 5$ weeks \\
\hline $\begin{array}{l}\text { Buckley } \\
1997^{9}\end{array}$ & 3 & $\begin{array}{l}48.3 \pm 10.1 \\
(39-59)\end{array}$ & $\begin{array}{l}\text { within- } \\
\text { subject }\end{array}$ & 8 & $\begin{array}{l}\text { - trauma; } \\
\text { - fit; } \\
\text { - active }\end{array}$ & IP & PSPC & $?$ \\
\hline
\end{tabular}

\begin{tabular}{|c|c|c|c|c|c|c|c|c|}
\hline $\begin{array}{l}\text { Datta } \\
1998^{10}\end{array}$ & 22 & $\begin{array}{l}39.9 \pm ? \\
(25-76)\end{array}$ & $\begin{array}{l}\text { within- } \\
\text { subject }\end{array}$ & 7 & $\begin{array}{l}\text { - trauma, } \\
\text { - osteomyelitis, } \\
\text { malignancy; } \\
\text { - fit; } \\
\text { - generally } \\
\text { fairly active }\end{array}$ & IP & $\begin{array}{l}\text { ESK } \\
\text { with PSPC }\end{array}$ & 7-41 months \\
\hline
\end{tabular}

\begin{tabular}{|c|c|c|c|c|c|c|c|c|}
\hline $\begin{array}{l}\text { Heller } \\
2000^{11}\end{array}$ & 10 & $\begin{array}{l}38 \pm ? \\
(23-46)\end{array}$ & $\begin{array}{l}\text { within- } \\
\text { subject }\end{array}$ & 8 & $\begin{array}{l}\text { - trauma, } \\
\text { congenital; } \\
\text { - generally fit; } \\
\text { - active }\end{array}$ & IP & ESK & $\geq 6$ weeks \\
\hline $\begin{array}{l}\text { Stinus } \\
2000^{12}\end{array}$ & 15 & $\begin{array}{l}39.6 \pm ? \\
(27-70)\end{array}$ & $\begin{array}{l}\text { within- } \\
\text { subject }\end{array}$ & 7 & $\begin{array}{l}\text { - trauma; } \\
\text { - } 11 \text { subjects } \\
\text { very active }\end{array}$ & C-leg & $\begin{array}{l}\text { 3C1; 3R49; } \\
\text { 3R72; 3R80; } \\
\text { ESK; Teh lin } \\
\text { pneumatic; } \\
\text { Mauch SNS; } \\
\text { ESK IP }\end{array}$ & 6-14 months \\
\hline $\begin{array}{l}\text { Schmalz } \\
2002^{13}\end{array}$ & 6 & $\begin{array}{l}37 \pm 9 \\
(27-53)\end{array}$ & $\begin{array}{l}\text { within- } \\
\text { subject }\end{array}$ & 10 & $\begin{array}{l}\text { - trauma; } \\
\text { - able to walk } \\
5 \mathrm{~km} \text { daily }\end{array}$ & C-leg & $3 C 1$ & $?$ \\
\hline $\begin{array}{l}\text { Perry } \\
2004{ }^{14}\end{array}$ & 1 & $\approx 30$ & $\begin{array}{l}\text { within- } \\
\text { subject }\end{array}$ & 6 & $\begin{array}{l}\text { - infection; } \\
\text { - bilateral } \\
\text { amputation; }\end{array}$ & C-leg & Mauch SNS & $\approx 8$ months \\
\hline $\begin{array}{l}\text { Yokogushi } \\
2004^{15}\end{array}$ & 3 & $\begin{array}{l}28 \pm 1.5 \\
\text { (?-?) }\end{array}$ & $\begin{array}{l}\text { within- } \\
\text { subject }\end{array}$ & 10 & - trauma & $\begin{array}{l}\text { micro- } \\
\text { processor } \\
\text { swing } \\
\text { phase } \\
\text { (4-bar) }\end{array}$ & $3 R 60$ & 30 minutes \\
\hline
\end{tabular}




\begin{tabular}{|c|c|c|}
\hline $\begin{array}{l}\text { - original questionnaire; } \\
\text { - } 100 \mathrm{~m} \text { walk test; } \\
\text { - expired gas analysis during } \\
\text { treadmill walking; } \\
\text { - video recording of treadmill } \\
\text { walking }\end{array}$ & $\begin{array}{l}\text { questionnaire } \\
\text { - effort to walk at varying speeds; } \\
\text { - effort to walk outdoors or at work; } \\
\text { - effort to negotiate stairs; } \\
\text { - effort to negotiate slopes; } \\
\text { - confidence in knee when walking; } \\
\text { - confidence in knee when standing; } \\
\text { - knee preference; } \\
\text { walk tests } \\
\text { - walking speed (self-selected, fast, slow); } \\
\text { - } \mathrm{VO}_{2} ; \\
\text { - symmetry in step length }\end{array}$ & $\begin{array}{l}\text { questionnaire } \\
\text { - less effort with IP at normal and fast } \\
\text { speed (respectively, } p<0.05 \text { and } \\
\text { p<0.01); } \\
\text { - less effort with IP walking outdoors or } \\
\text { at work ( } p<0.01 \text { ); } \\
\text { - less effort walking down slope } \\
\quad(p<0.05) \text {; } \\
\text { - strong preference for IP ( } p<0.01) ; \\
\text { walk tests } \\
\text { - no difference walking speed; } \\
\text { - no difference } \mathrm{VO}_{2} ; \\
\text { - symmetry improved with IP at slow and } \\
\text { fast speeds }(p=0.017)\end{array}$ \\
\hline $\begin{array}{l}\text { - expired gas analysis during } \\
\text { treadmill walking }\end{array}$ & $\begin{array}{l}-\mathrm{VO}_{2} \\
-\mathrm{VCO}_{2}\end{array}$ & $\begin{array}{l}\text { - lower } \mathrm{VO}_{2} \text { with IP }(\approx 10 \%(\mathrm{p}<0.05)) \text { at } \\
\text { higher walking speed }(3.2 \mathrm{~km} / \mathrm{h})\end{array}$ \\
\hline $\begin{array}{l}\text { - expired gas analysis during } \\
\text { treadmill walking }\end{array}$ & $-\mathrm{VO}_{2}$ & $\begin{array}{l}\text { - lower } \mathrm{VO}_{2} \text { with IP (5.6-9.0\%) in } 2 \\
\text { subjects at slow and fast walking } \\
\text { speeds; } \\
\text { - lower } \mathrm{VO}_{2} \text { with IP (2.2-7.0\%) at } \\
\text { constantly varying speeds }\end{array}$ \\
\hline - original questionnaire & $\begin{array}{l}\text { - ability to walk at varying speeds; } \\
\text { - distance able to walk; } \\
\text { - ability to negotiate stairs; } \\
\text { - ability to negotiate slopes; } \\
\text { - ability to walk on uneven underground; } \\
\text { - effort to walk; } \\
\text { - walking style; } \\
\text { - mechanical reliability; } \\
\text { - learning to walk; } \\
\text { - comments by others on walking style }\end{array}$ & $\begin{array}{l}\text { - for all areas of the questionnaire } \geq 59 \% \\
\text { of the subjects reported improvements } \\
\text { regarding the IP }\end{array}$ \\
\hline $\begin{array}{l}\text { - video-based motion analysis } \\
\text { during treadmill walking at } \\
\text { constantly varying walking } \\
\text { speeds }\end{array}$ & $\begin{array}{l}\text { - mean forehead marker displacement } \\
\text { velocity of walking with and without } \\
\text { cognitive dual task }\end{array}$ & $\begin{array}{l}\text { - no difference in sway ratios between IP } \\
\text { and ESK; } \\
\text { - total sway during gait less for IP } \\
(27 \mathrm{~mm} / \mathrm{s} ; \mathrm{p}=0.047)\end{array}$ \\
\hline - original questionnaire & $\begin{array}{l}\text { - perceived stance phase safety; } \\
\text { - perceived swing phase control; } \\
\text { - perceived dynamics of the knee; } \\
\text { - recommendation prosthesis to others; } \\
\text { - continuous duration able to walk; } \\
\text { - continuous distance able to walk }\end{array}$ & $\begin{array}{l}\text { - patients marked the C-leg in nearly all } \\
\text { areas investigated as "very good" }\end{array}$ \\
\hline $\begin{array}{l}\text { - expired gas analysis during } \\
\text { treadmill walking; } \\
\text { - heart rate monitor } \\
\end{array}$ & $\begin{array}{l}-\mathrm{VO}_{2} \\
\text { - heart rate }\end{array}$ & $\begin{array}{l}\text { - lower } \mathrm{VO}_{2} \text { with } \mathrm{C} \text {-leg at medium and } \\
\text { low speeds }(6-7 \% ; p<0.05)\end{array}$ \\
\hline $\begin{array}{l}\text { - expired gas analysis on } \\
\text { outdoor track; } \\
\text { - electrocardiography; } \\
\text { - insoles with compression } \\
\text { closing switches }\end{array}$ & $\begin{array}{l}\text { - stride length; } \\
\text { - cadence; } \\
\text { - walking distance in } 20 \text { minutes; } \\
\text { - walking speed during } 20 \text { minutes; } \\
\text { - } \mathrm{VO}_{2} ; \\
\text { - heart rate }\end{array}$ & $\begin{array}{l}\text { - distance increased with C-leg }(625 \mathrm{~m}) ; \\
\text { - speed increased with C-leg } \\
\text { ( } 30.2 \mathrm{~m} / \mathrm{min}) \text {; } \\
\text { - longer stride length with C-leg; } \\
\text { - lower } \mathrm{VO}_{2} \text { with C-leg; } \\
\text { - heart increased with C-leg; }\end{array}$ \\
\hline $\begin{array}{l}\text { - video-based motion analysis; } \\
\text { - } 2 \text { force platforms }\end{array}$ & $\begin{array}{l}\text { variation with different cadence in: } \\
\text { - stance phase duration (\% of gait cycle); } \\
\text { - peak knee flexion angle (stance+swing); } \\
\text { - peak hip flexion angle; } \\
\text { - peak hip extension moment }\end{array}$ & $\begin{array}{l}\text { - most of the values of the gait } \\
\text { parameters with MPK showed no } \\
\text { significant variation in individuals } \\
\text { walking at different cadences, which } \\
\text { resembles natural gait. This in contrast } \\
\text { to values with 3R60 knee joint }\end{array}$ \\
\hline
\end{tabular}


CHAPTER 2

\begin{tabular}{|c|c|c|c|c|c|c|c|c|}
\hline Reference & $\begin{array}{l}\text { Sample } \\
\text { size } \\
(n)\end{array}$ & $\begin{array}{l}\text { Age } \pm S D \\
\text { (range) }\end{array}$ & $\begin{array}{l}\text { Study } \\
\text { design }\end{array}$ & $\begin{array}{l}\text { Study } \\
\text { quality } \\
\text { (VT) }\end{array}$ & $\begin{array}{l}\text { Functional } \\
\text { classification } \\
\text { level reported }\end{array}$ & $\begin{array}{l}\text { Type of } \\
\text { MPK }\end{array}$ & $\begin{array}{l}\text { Type of } \\
\text { mech. knee }\end{array}$ & $\begin{array}{l}\text { Accommo- } \\
\text { dation time } \\
\text { with MPK }\end{array}$ \\
\hline $\begin{array}{l}\text { Datta } \\
2005^{16}\end{array}$ & 10 & $\begin{array}{l}38 \pm ? \\
(23-46)\end{array}$ & $\begin{array}{l}\text { within- } \\
\text { subject }\end{array}$ & 8 & $\begin{array}{l}\text { - trauma, } \\
\text { congenital, } \\
\text { - generally fit; } \\
\text { - reasonably } \\
\text { high level of } \\
\text { activity }\end{array}$ & IP & ESK & $\geq 6$ weeks \\
\hline
\end{tabular}

\begin{tabular}{|c|c|c|c|c|c|c|c|c|}
\hline $\begin{array}{l}\text { Johansson } \\
2005^{17}\end{array}$ & 8 & $\begin{array}{l}44.3 \pm ? \\
(29-54)\end{array}$ & $\begin{array}{l}\text { within- } \\
\text { subject }\end{array}$ & 11 & $\begin{array}{l}\text { - trauma, } \\
\text { infection, } \\
\text { congenital, } \\
\text { cancer; } \\
\text { - } \geq \text { MFCL-3 }\end{array}$ & $\begin{array}{l}\text { C-leg; } \\
\text { Rheo } \\
\text { knee }\end{array}$ & Mauch SNS & $\begin{array}{l}10 \text { hours/ } \\
\text { knee }\end{array}$ \\
\hline
\end{tabular}

\begin{tabular}{|c|c|c|c|c|c|c|c|}
\hline $\begin{array}{l}\text { Wetz } \\
2005^{18}\end{array}$ & 25 & $\begin{array}{l}45 \pm ? \\
(16-77)\end{array}$ & $\begin{array}{l}\text { within- } \\
\text { subject }\end{array}$ & 7 & $\begin{array}{l}\text { - trauma, } \\
\text { tumour, } \\
\text { malformation, } \\
\text { infection, } \\
\text { PVD; } \\
\text { - MFCL-2 } \\
\text { - MFCL-3 } \\
\text { - MFCL-4 }\end{array}$ & C-leg & $\begin{array}{l}\text { Mauch SNS; } \\
\text { ESK; } \\
\text { Total knee; } \\
\text { Teh Lin; } \\
\text { 3R80; } \\
\text { 3R60; } \\
\text { KP3; } \\
\text { 3R49; } \\
\text { 3R40; }\end{array}$ \\
\hline
\end{tabular}

\begin{tabular}{|c|c|c|c|c|c|c|c|c|}
\hline $\begin{array}{l}\text { Klute } \\
2006^{19}\end{array}$ & 5 & $\begin{array}{l}48 \pm 12 \\
(?-?)\end{array}$ & $\begin{array}{l}\text { within- } \\
\text { subject }\end{array}$ & 11 & $\begin{array}{l}\text { - trauma, } \\
\text { tumour; } \\
\text { - ambulate } \\
\text { without } \\
\text { walking aids }\end{array}$ & C-leg & Mauch SNS & 3 months \\
\hline $\begin{array}{l}\text { Orendurff } \\
2006^{20}\end{array}$ & 8 & $\begin{array}{l}48.5 \pm 10.2 \\
(?-?)\end{array}$ & $\begin{array}{l}\text { within- } \\
\text { subject }\end{array}$ & 10 & $?$ & C-leg & Mauch SNS & 3 months \\
\hline
\end{tabular}

\begin{tabular}{|c|c|c|c|c|c|c|c|c|}
\hline $\begin{array}{l}\text { Segal } \\
2006^{21}\end{array}$ & 8 & $\begin{array}{l}47 \pm 13 \\
(28-60)\end{array}$ & $\begin{array}{l}\text { within- } \\
\text { subject }\end{array}$ & 10 & $\begin{array}{l}\text { - ambulate } \\
\text { without } \\
\text { walking aids } \\
\text { on level } \\
\text { ground, stairs } \\
\text { and inclines }\end{array}$ & C-leg & Mauch SNS & 3 months \\
\hline
\end{tabular}




\begin{tabular}{|c|c|c|}
\hline $\begin{array}{l}\text { - expired gas analysis; } \\
\text { - video observation scale (VAS); } \\
\text { - video-based motion analysis }\end{array}$ & $\begin{array}{l}\text { - } \mathrm{VO}_{2} ; \\
\text { - overall quality of gait; } \\
\text { - walking speed; } \\
\text { - symmetry in stance time; } \\
\text { - symmetry in step distance }\end{array}$ & $\begin{array}{l}\text { - mean } \mathrm{VO}_{2} \text { lower with IP at slow speed } \\
(3 \mathrm{ml} / \mathrm{kg} \cdot \mathrm{m} ; \mathrm{p}<0.01) \\
\text { - no differences in overall gait evaluation } \\
\text { or gait parameters }\end{array}$ \\
\hline $\begin{array}{l}\text { - portable expired gas analysis on } \\
\text { indoor track; } \\
\text { - video-based motion analysis; } \\
\text { - } 2 \text { force plates; } \\
\text { - electromyography; } \\
\text { - accelerometers; }\end{array}$ & $\begin{array}{l}\text { - } \mathrm{VO}_{2} ; \\
\text { - walking speed; } \\
\text { - step time; } \\
\text { - step length; } \\
\text { - single support time; } \\
\text { - double support time; } \\
\text { - joint angles (hip, knee, ankle); } \\
\text { - joint moments (hip, knee, ankle); } \\
\text { - joint power (hip, knee, ankle); } \\
\text { - muscular activity pattern (M. Gluteus } \\
\text { Max+Med); } \\
\text { - jerk (smoothness of motion) }\end{array}$ & $\begin{array}{l}\text { - } \mathrm{VO}_{2} \text { lower with Rheo compared with } \\
\text { Mauch ( } 5 \% ; p=0.009) ; \\
\text { - Rheo generally longer step times than } \\
\text { Mauch and C-leg (respectively, 0.03s; } \\
\mathrm{p}=0.038 \text { and } 0.04 \mathrm{~s} ; \mathrm{p}=0.007) ; \\
\text { - biomechanical advantages with MPK, } \\
\text { including: decrease hip work } \\
\text { production ( } \mathrm{p}<0.05 \text { ); } \\
\text { lower peak hip flexion moment at } \\
\text { terminal swing ( } \mathrm{p}<0.05 \text { ); } \\
\text { reduction peak hip power generation at } \\
\text { toe off ( }<<0.05 \text { ); } \\
\text { - lower muscle activity (M. Gluteus } \\
\text { Med.) with Rheo compared with } \\
\text { Mauch and C-leg ( } p<0.025 \text { ); } \\
\text { - lower jerk RMS with MPK ( } p<0.05 \text { ) }\end{array}$ \\
\hline $\begin{array}{l}\text { - electronic walkway system; } \\
\text { - video-based motion analysis; } \\
\text { - } 2 \text { force plates; } \\
\text { - portable expired gas analysis; } \\
\text { - original questionnaire }\end{array}$ & $\begin{array}{l}\text { - symmetry in step length; } \\
\text { - symmetry in stance phase duration; } \\
\text { - cadence; } \\
\text { - variability in gait pattern; } \\
\text { - walking speed; } \\
\text { - joint angles (hip and knee); } \\
\text { - joint moments (hip and knee); } \\
\text { - VO }{ }_{2} ; \\
\text { - heart rate; } \\
\text { - perceived safety; } \\
\text { - load on non-amputated leg; } \\
\text { - integration into body schema; } \\
\text { - divided attention; } \\
\text { - ability to walk with varying speeds; } \\
\text { - reduction of effort of walking; } \\
\text { - quality of gait; } \\
\text { - use of walking aids }\end{array}$ & $\begin{array}{l}\text { - MFCL-2 subjects may benefit } \\
\text { considerably from the static safety of } \\
\text { the C-leg; } \\
\text { - subjects classified as MFCL-2, MFCL-3, } \\
\text { and MFCL-4 demonstrate a functional } \\
\text { added value from using the C-leg } \\
\text { regarding safety, divided attention, and } \\
\text { reduced muscle force requirements, } \\
\text { and reduced load on non-amputated } \\
\text { leg; } \\
\text { - subjects with a high MFCL level } \\
\text { specifically benefit regarding reduced } \\
\text { muscle force requirements, and } \\
\text { reduced load on non-amputated leg }\end{array}$ \\
\hline
\end{tabular}

\begin{tabular}{|c|c|c|}
\hline - activity monitor & $\begin{array}{l}\text { - activity level (steps/week); } \\
\text { - activity duration (time active/week) }\end{array}$ & - no effects \\
\hline $\begin{array}{l}\text { - portable expired gas analysis on } \\
\text { indoor track; } \\
\text { - velocity-recording cart }\end{array}$ & $\begin{array}{l}-\mathrm{VO}_{2} ; \\
\text { - walking speed (self-selected) }\end{array}$ & $\begin{array}{l}\text { - no differences in } \mathrm{VO}_{2} ; \\
\text { - walking speed (self-selected) faster } \\
\text { with C-leg }(0.1 \mathrm{~m} / \mathrm{s} ; \mathrm{p}=0.046)\end{array}$ \\
\hline $\begin{array}{l}\text { - video-based motion analysis; } \\
\text { - force plate }\end{array}$ & $\begin{array}{l}\text { - walking speed (self-selected); } \\
\text { - step length; } \\
\text { - peak knee flexion angle (stance); } \\
\text { - knee flexion angle at opposite heel } \\
\text { strike; } \\
\text { - peak knee flexion angle (swing); } \\
\text { - peak knee flexion moment; } \\
\text { - peak coronal knee moment of intact I } \\
\text { limb; } \\
\text { - peak sagittal-plane joint power (hip, } \\
\text { knee, ankle); } \\
\text { - maximal vertical ground reaction force } \\
\text { (vGRF) }\end{array}$ & $\begin{array}{l}\text { - walking speed (self-selected) higher } \\
\text { with C-leg }(0.09 \mathrm{~m} / \mathrm{s} ; \mathrm{p} \leq 0.004) ; \\
\text { - step length decreased with C-leg at } \\
\text { controlled walking speed }(0.04 \mathrm{~m} ; \\
\text { p=0.005); } \\
\text { - peak knee flexion angle in swing } \\
\text { smaller with C-leg }\left(9.2^{\circ} ; \mathrm{p}=0.005\right) ; \\
\text { - peak knee flexion moment (early } \\
\text { stance) increased with C-leg } \\
\text { (0.073N.m } / \mathrm{kg} ; \mathrm{p}=0.01) ; \\
\text { - max ankle power of intact limb reduced } \\
\text { with C-leg (0.48W/kg; } \mathrm{p}=0.05) ; \\
\text { - vGRF }(\% \text { body weight) from } 10 \%-30 \% \text { of } \\
\text { gait cycle reduced with C-leg }(4 \% ; \\
\text { p=0.009). }\end{array}$ \\
\hline
\end{tabular}




\section{CHAPTER 2}

\begin{tabular}{|c|c|c|c|c|c|c|c|c|}
\hline Reference & $\begin{array}{l}\text { Sample } \\
\text { size } \\
(n)\end{array}$ & $\begin{array}{l}\text { Age } \pm S D \\
\text { (range) }\end{array}$ & $\begin{array}{l}\text { Study } \\
\text { design }\end{array}$ & $\begin{array}{l}\text { Study } \\
\text { quality } \\
\text { (VT) }\end{array}$ & $\begin{array}{l}\text { Functional } \\
\text { classification } \\
\text { level reported }\end{array}$ & $\begin{array}{l}\text { Type of } \\
\text { MPK }\end{array}$ & $\begin{array}{l}\text { Type of } \\
\text { mech. knee }\end{array}$ & $\begin{array}{l}\text { Accommo- } \\
\text { dation time } \\
\text { with MPK }\end{array}$ \\
\hline $\begin{array}{l}\text { Williams } \\
2006^{22}\end{array}$ & 8 & $\begin{array}{l}48.5 \pm 10.2 \\
(29-61)\end{array}$ & $\begin{array}{l}\text { within- } \\
\text { subject }\end{array}$ & 12 & $\begin{array}{l}\text { - able to walk } \\
3 \text { flights of } \\
\text { stairs and } \\
30 \mathrm{~m} \text { on an } \\
\text { incline without } \\
\text { walking aids }\end{array}$ & C-leg & Mauch SNS & 3 months \\
\hline $\begin{array}{l}\text { Bunce } \\
2007^{23}\end{array}$ & 42 & $\begin{array}{l}45.5 \pm 12.5 \\
\text { (?-?) }\end{array}$ & $\begin{array}{l}\text { within- } \\
\text { subject }\end{array}$ & 10 & $\begin{array}{c}\text { - trauma } \\
(n=30)\end{array}$ & C-leg & $?$ & 6 months \\
\hline $\begin{array}{l}\text { Chin } \\
2007^{24}\end{array}$ & 2 & $\begin{array}{l}78 \pm 4.2 \\
(75-81)\end{array}$ & $\begin{array}{l}\text { within- } \\
\text { subject }\end{array}$ & 7 & $?$ & IP & $\begin{array}{l}\text { 3R15; } \\
\text { 3R40 }\end{array}$ & $\begin{array}{l}12 \text { weeks } \\
\text { training }\end{array}$ \\
\hline
\end{tabular}

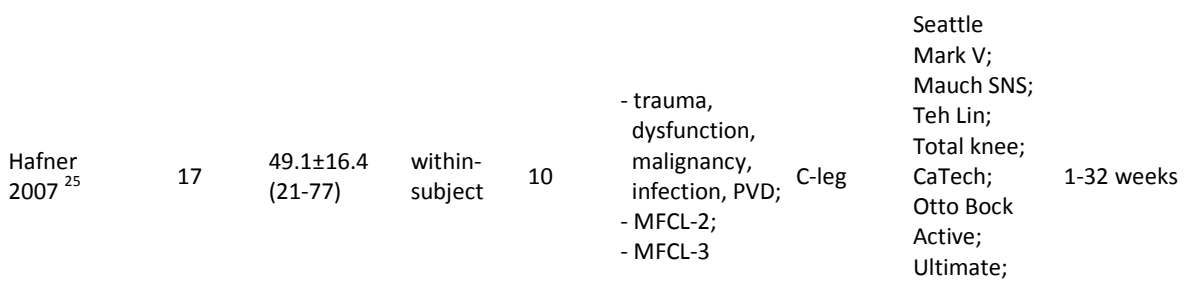

$\begin{array}{llllll}\begin{array}{l}\text { Kaufman } \\ 2007^{26}\end{array} & 15 & \begin{array}{l}42 \pm 9 \\ (26-57)\end{array} & \begin{array}{l}\text { within- } \\ \text { subject }\end{array} & 10 & \begin{array}{l}\text { - trauma, } \\ \text { tumour, PVD, } \\ \text { congenital; } \\ -\geq \text { MFCL-3 }\end{array}\end{array} \quad$ C-leg $\quad \begin{aligned} & \text { Mauch SNS } \\ & \text { or equivalent }\end{aligned}$ 10-39 weeks

\begin{tabular}{|c|c|c|c|c|c|c|c|c|}
\hline $\begin{array}{l}\text { Seymour } \\
2007^{27}\end{array}$ & 13 & $\begin{array}{l}46 \pm 13 \\
(30-75)\end{array}$ & $\begin{array}{l}\text { within- } \\
\text { subject }\end{array}$ & 11 & $\begin{array}{l}\text { - non-vascular; } \\
\text { - MFCL-4 }\end{array}$ & C-leg & $\begin{array}{l}\text { Mauch SNS; } \\
\text { 3R80; } \\
\text { Total knee; } \\
\text { 3R90; } \\
\text { CaTech; } \\
\text { Seattle Fusior }\end{array}$ & $2-44$ months \\
\hline
\end{tabular}




\begin{tabular}{|c|c|}
\hline $\begin{array}{l}\text { - serial subtraction test; } \\
\text { - controlled oral word } \\
\text { - association test; } \\
\text { - category test; } \\
\text { - original questionnaire } \\
\text { - prosthetic cognitive burden } \\
\text { scale }\end{array}$ & $\begin{array}{l}\text { - number of errors; } \\
\text { - total number of unique words; } \\
\text { - total number of unique words; } \\
\text { - attention focused on walking; } \\
\text { - attention focused on thinking of words; } \\
\text { - attention focused on other things.; } \\
\text { - general subjective cognitive burden }\end{array}$ \\
\hline $\begin{array}{l}\text { - amputee body image scale; } \\
\text { - interview }\end{array}$ & $\begin{array}{l}\text { - body appearance; } \\
\text { - body function; } \\
\text { - effective distress; } \\
\text { - behavioural avoidance in social } \\
\text { situations }\end{array}$ \\
\hline - heart rate monitor & $\begin{array}{l}\text { - physiological cost index; } \\
\text { - step length; } \\
\text { - cadence; } \\
\text { - stride length; } \\
\text { - walking speed; } \\
\text { - use of walking aids }\end{array}$ \\
\hline $\begin{array}{l}\text { - activity monitor; } \\
\text { - amputee mobility predictor } \\
\text { - } 36 \text {-item short-form health } \\
\text { survey (SF-36); } \\
\text { - Stair Assessment Index (SAI); } \\
\text { - Hill Assessment Index (HAI); } \\
\text { - 73.2m outdoor obstacle course; } \\
\text { - distracted walking test; } \\
\text { - Prosthesis Evaluation } \\
\text { Questionnaire (PEQ); } \\
\text { - original 14-question PEQ } \\
\text { addendum }\end{array}$ & $\begin{array}{l}\text { - activity level (step frequency + } \\
\text { estimated daily distance travelled); } \\
\text { - basic functional mobility; } \\
\text { - self-reported general health (QoL); } \\
\text { - ability to negotiate stairs (functional } \\
\text { independence and technique); } \\
\text { - ability to negotiate slopes (functional } \\
\text { independence, technique, step length, } \\
\text { speed); } \\
\text { - ability to negotiate uneven terrain } \\
\text { (speed); } \\
\text { - cognitive demand of walking (test speed } \\
\text { and accuracy); } \\
\text { - self-assessed satisfaction; } \\
\text { - self-assessed performance; } \\
\text { - confidence; } \\
\text { - concentration; } \\
\text { - number of stumbles; } \\
\text { - number of falls }\end{array}$ \\
\hline
\end{tabular}

- no differences in (objective) cognitive burden;

- less attention focused on walking with C-leg (1.42; $\mathrm{p}<0.001)$;

- less (subjective) cognitive burden with C-leg

\begin{tabular}{|c|c|c|}
\hline & & $(p<0.05)$ \\
\hline $\begin{array}{l}\text { - video-based motion analysis; } \\
\text { - } 2 \text { force plates; } \\
\text { - sensory organisation test (SOT) }\end{array}$ & $\begin{array}{l}\text { - peak knee extensor moment during } \\
\text { stance; } \\
\text { - postural stability (equilibrium score) }\end{array}$ & $\begin{array}{l}\text { - peak knee angle at initial stance } \\
\text { changed from hyper-extension with } \\
\text { Mauch to flexion with C-leg }\left(\approx-4^{\circ} \text { to }\right. \\
\left.+1^{\circ} ; p<0.01\right) ; \\
\text { - internal knee flexion moment with } \\
\text { Mauch to internal extension moment } \\
\text { with C-leg ( } p<0.01) \text {; } \\
\text { - SOT scores (all conditions) improved } \\
\text { with C-leg ( }<<0.01) \text {; }\end{array}$ \\
\hline $\begin{array}{l}\text { - expired gas analysis during } \\
\text { treadmill walking; } \\
\text { - } 12.2 \mathrm{~m} \text { standardised walking } \\
\text { obstacle course; } \\
\text { - } 36 \text {-item short-form health } \\
\text { survey (SF-36) }\end{array}$ & $\begin{array}{l}-\mathrm{VO}_{2} ; \\
\text { - heart rate; } \\
\text { - ability to negotiate obstacles (speed, } \\
\text { number of steps, number of step-offs } \\
\text { (errors), number of stumbles); } \\
\text { - self-reported general health (QoL) }\end{array}$ & $\begin{array}{l}\text { - } \mathrm{VO}_{2} \text { reduced at typical and fast speeds } \\
\text { with C-leg ( } 0.9 \text { and } 1.2 \mathrm{ml} / \mathrm{kg} / \mathrm{min} \text {; } \\
\mathrm{p} \leq 0.03) \text {; } \\
\text { - reduction in number of steps (1.4; } \\
\mathrm{p}=0.004) \text {, time ( } 1.2 \mathrm{sec} ; \mathrm{p}=0.004) \text {, and } \\
\text { step-offs (errors) }(0.3 ; \mathrm{p}=0.03 \text { ) with C- } \\
\text { leg on obstacle course; } \\
\text { - SF- } 36 \text { scores with C-leg were above the } \\
\text { mean for norms for limitation in the } \\
\text { use of an arm or leg }\end{array}$ \\
\hline
\end{tabular}

- body image more positive with C-leg $(p<0.001)$ - both subjects show reduced $\mathrm{PCl}$ with IP;

- increased speed;

- improved cadence in 1 subject;

- improved stride length; - improved symmetry (step length) - no difference activity level;

- no difference amputee mobility predictor;

- no difference SF-36;

- SAI descent improved with C-leg $(p<0.001)$;

- decline descent time improved with Cleg (15 sec; $p<0.001)$;

- affected-side step length decline descent increased with C-leg $(18 \mathrm{~cm}$; $\mathrm{p}<0.01$ );

- no difference on uneven terrain;

- no difference cognitive performance;

- no differences PEQ;

- stumble frequency (self-report)

improved $(p<0.05)$;

- semi-controlled fall frequency (selfreported) improved $(p<0.05)$;

- uncontrolled fall frequency (self-report) improved $(p<0.05)$;

- multitasking (self-report) improved $(p<0.05)$;

frustration about falling improved $(p<0.05)$

peak knee angle at initial stance changed from hyper-extension with $+1^{\circ} ; \mathrm{p}<0.01$ )

internal knee flexion moment with Mauch to internal extension moment C-leg $(\mathrm{p}<0.01)$ with C-leg $(p<0.01)$

reduced at typical and fa $\mathrm{p} \leq 0.03$ );

reduction in number of steps (1.4; $\mathrm{p}=0.004)$, time (1.2sec; $\mathrm{p}=0.004)$, and step-offs (errors) $(0.3 ; p=0.03)$ with $C$ use of an arm or leg 


\begin{tabular}{lllllllll} 
Reference & $\begin{array}{l}\text { Sample } \\
\text { size } \\
\text { (n) }\end{array}$ & $\begin{array}{l}\text { Age } \pm \text { SD } \\
\text { (range) }\end{array}$ & $\begin{array}{l}\text { Study } \\
\text { design }\end{array}$ & $\begin{array}{l}\text { Study } \\
\text { quality } \\
\text { (VT) }\end{array}$ & $\begin{array}{l}\text { Functional } \\
\text { classification } \\
\text { level reported }\end{array}$ & $\begin{array}{l}\text { Type of } \\
\text { MPK }\end{array}$ & $\begin{array}{l}\text { Type of } \\
\text { mech. knee }\end{array}$ & $\begin{array}{l}\text { Accommo- } \\
\text { dation time } \\
\text { with MPK }\end{array}$ \\
\hline $\begin{array}{l}\text { Stevens } \\
2007^{28}\end{array}$ & 1 & 30 & $\begin{array}{l}\text { within- } \\
\text { subject }\end{array}$ & 8 & $\begin{array}{l}\text { - trauma; } \\
\text { - participates } \\
\text { in running } \\
\text { and cycling }\end{array}$ & C-leg & $3 R 80$ & 9 days \\
\hline
\end{tabular}

\begin{tabular}{|c|c|c|c|c|c|c|c|c|}
\hline $\begin{array}{l}\text { Jepson } \\
2008^{29}\end{array}$ & 5 & $\begin{array}{l}41.2 \pm ? \\
(28.8-55.7)\end{array}$ & $\begin{array}{l}\text { within- } \\
\text { subject }\end{array}$ & 8 & $?$ & Adaptive & CaTech & 8 weeks \\
\hline
\end{tabular}

\begin{tabular}{|c|c|c|c|c|c|c|c|c|}
\hline $\begin{array}{l}\text { Kahle } \\
2008^{30}\end{array}$ & 19 & $\begin{array}{l}51.3 \pm 19.4 \\
(22-83)\end{array}$ & $\begin{array}{l}\text { within- } \\
\text { subject }\end{array}$ & 10 & $\begin{array}{l}\text { - trauma, PVD, } \\
\text { congenital, } \\
\text { diabetes, } \\
\text { tumour; } \\
\text { - MFCL-2; } \\
\text { - MFCL-3; } \\
\text { - MFCL-4; }\end{array}$ & C-leg & $\begin{array}{l}\text { weight- } \\
\text { activated } \\
\text { stance phase } \\
\text { brake with } \\
\text { pneumatic or } \\
\text { friction swing } \\
\text { phase; } \\
\text { Mauch SNS; } \\
\text { Total knee; } \\
\text { 4-bar } \\
\text { hydraulic } \\
\text { swing; } \\
\text { single axis } \\
\text { friction } \\
\end{array}$ & 90 days \\
\hline $\begin{array}{l}\text { Kaufman } \\
2008^{31}\end{array}$ & 15 & $\begin{array}{l}42 \pm 9 \\
(26-57)\end{array}$ & $\begin{array}{l}\text { within- } \\
\text { subject }\end{array}$ & 10 & $\begin{array}{l}\text { - trauma, } \\
\text { tumour, PVD, } \\
\text { congenital; } \\
\text { - MFCL-3 } \\
\text { - MFCL-4 }\end{array}$ & C-leg & $\begin{array}{l}\text { Mauch SNS; } \\
\text { Catech; } \\
\text { Black Max; } \\
\text { Century } 2000\end{array}$ & $10-39$ weeks \\
\hline $\begin{array}{l}\text { Berry } \\
2009^{32}\end{array}$ & 368 & $\begin{array}{l}54.7 \pm 15.6 \\
(15-85)\end{array}$ & $\begin{array}{l}\text { within- } \\
\text { subject }\end{array}$ & 10 & $\begin{array}{l}\text { - trauma, } \\
\text { tumour, PVD, } \\
\text { infection, } \\
\text { congenital, } \\
\text { other; } \\
\text { - MFCL-3 }\end{array}$ & C-leg & $\begin{array}{l}\text { variable } \\
\text { cadence } \\
\text { non-micro- } \\
\text { processor- } \\
\text { controlled }\end{array}$ & 6-9 months \\
\hline $\begin{array}{l}\text { Blumentritt } \\
2009^{33}\end{array}$ & 3 & $\begin{array}{l}36.7 \pm 10.1 \\
(25-43)\end{array}$ & $\begin{array}{l}\text { within- } \\
\text { subject }\end{array}$ & 10 & $\begin{array}{l}\text { - trauma, } \\
\text { tumour; } \\
\text { - MFCL-3; } \\
\text { - MFCL-4 }\end{array}$ & C-leg & $\begin{array}{l}\text { Mauch SNS; } \\
3 \text { R80 }\end{array}$ & 30 minutes \\
\hline
\end{tabular}




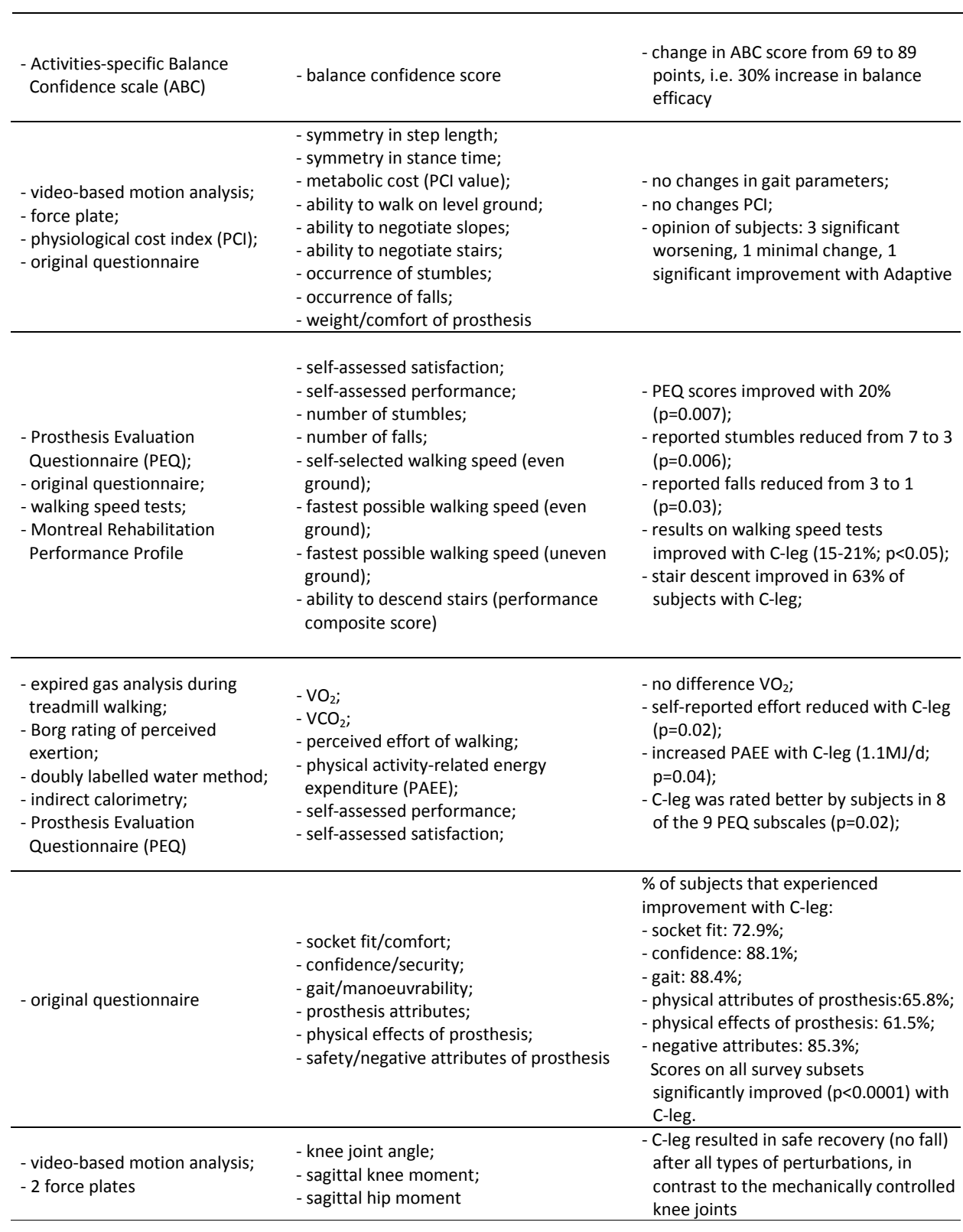




\section{CHAPTER 2}

\begin{tabular}{lllllllll} 
Reference & $\begin{array}{l}\text { Sample } \\
\text { size }\end{array}$ & $\begin{array}{l}\text { Age } \pm \text { SD } \\
\text { (range) }\end{array}$ & $\begin{array}{l}\text { Study } \\
\text { design }\end{array}$ & $\begin{array}{l}\text { Study } \\
\text { quality } \\
\text { (VT) }\end{array}$ & $\begin{array}{l}\text { Functional } \\
\text { classification } \\
\text { level reported }\end{array}$ & $\begin{array}{l}\text { Type of } \\
\text { MPK }\end{array}$ & $\begin{array}{l}\text { Type of } \\
\text { mech. knee }\end{array}$ & $\begin{array}{l}\text { Accommo- } \\
\text { dation time } \\
\text { with MPK }\end{array}$ \\
\hline
\end{tabular}

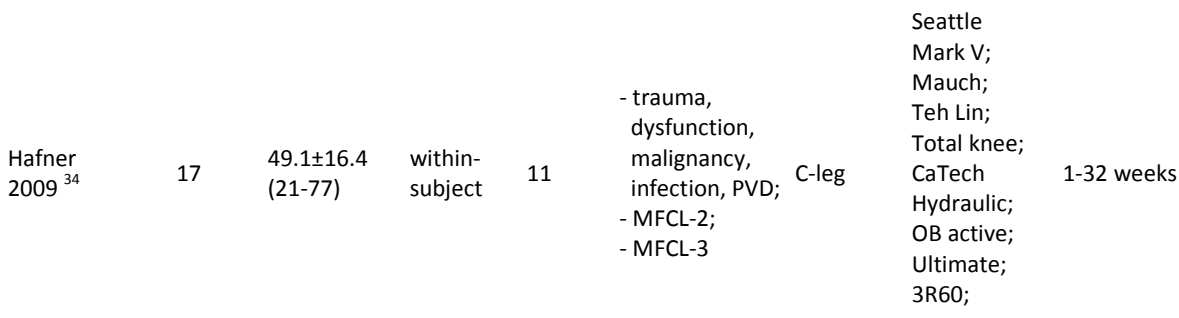

\begin{tabular}{|c|c|c|c|c|c|c|c|}
\hline $\begin{array}{l}\text { Mâaref } \\
2010^{35}\end{array}$ & 29 & $\begin{array}{l}45 \pm 14 \\
(?-?)\end{array}$ & $\begin{array}{l}2 \text { cohorts } \\
\text { retro- } \\
\text { spective }\end{array}$ & 7 & $\begin{array}{l}\text { - trauma, } \\
\text { tumour; } \\
\text { - non-vascular }\end{array}$ & C-leg & $\begin{array}{l}\text { swing phase } \\
\text { control }\end{array}$ \\
\hline
\end{tabular}

\begin{tabular}{|c|c|c|c|c|c|c|c|c|}
\hline $\begin{array}{l}\text { Petersen } \\
2010^{36}\end{array}$ & 5 & $\begin{array}{l}36.6 \pm 8.9 \\
(26-48)\end{array}$ & $\begin{array}{l}\text { within- } \\
\text { subject }\end{array}$ & 10 & $\begin{array}{l}\text { - trauma, } \\
\text { tumour; } \\
\text { - MFCL-3; } \\
\text { - MFCL-4 }\end{array}$ & C-leg & $3 R 60$ & 1 week \\
\hline
\end{tabular}

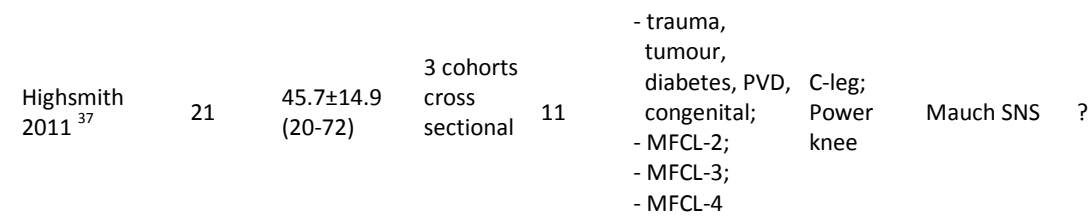




- amputee mobility predictor;
- 36-item short-form health
survey (SF-36);
- Stair Assessment Index (SAI);
- Hill Assessment Index (HAI);
- 73.2m outdoor obstacle course;
- distracted walking test;
- Prosthesis Evaluation
Questionnaire (PEQ);
- original 14-question PEQ
addendum

- basic functional mobility;

- self-reported general health (QoL);

- ability to negotiate stairs (functional

independence and technique);

- ability to negotiate slopes (functional independence, technique, step length, speed);

- ability to negotiate uneven terrain (speed);

- cognitive demand of walking (test speed and accuracy)

- self-assessed satisfaction;

- self-assessed performance;

- confidence;

- concentration;

- number of stumbles;

- number of falls
- SAl improved, MFCL-2 (5.7; $\mathrm{p}=0.008)$ MFCL-3 (5.6; $p=0.004)$;

- HAl improved, MFCL-2 (2.2; $\mathrm{p}=0.008)$;

- hill speed improved, MFCL-2 $(0.46 \mathrm{~m} / \mathrm{s}$; $\mathrm{p}=0.002)$, MFCL-3 $(0.87 \mathrm{~m} / \mathrm{s} ; \mathrm{p}<0.02)$;

- obstacle course speed improved, MFCL-2 $(0.09 \mathrm{~m} / \mathrm{s} ; \mathrm{p}=0.02)$, MFCL-3 $(0.07 \mathrm{~m} / \mathrm{s} ; \mathrm{p}=0.007)$;

- attention speed improved, MFCL-2 (0.1 $\mathrm{m} / \mathrm{s} ; \mathrm{p}=0.02$ )

- PEQ scores improved for satisfaction, ambulation, sounds, and utility in MFCL-3 $(p<0.05)$

- improved confidence in MFCL-3 $(p=0.004)$;

- improved multitasking MFCL-2/3 $(\mathrm{p}<0.05)$;

- improved frustration with falls in MFCL3;

- reduced relative frequency of stumbles, MFCL-2 (15.8\%; $p=0.05)$, MFCL-3 (31\%; $p=0.03)$;

- reduced relative number of falls MFCL-2 (4.5\%; $p=0.01)$;

- reduced fall frequency, MFCL-2 $(80 \%$; $\mathrm{p}=0.01$ );

- walking speed faster with C-leg

- walking speed;

- cadence;

$(0.17 \mathrm{~m} / \mathrm{s} ; \mathrm{p}<0.05)$;

- cadence higher with C-leg

( $\approx 11$ steps/min; $p<0.05$ );

- video-based motion analysis; - stride length;

- 3 force plates

- stance phase duration;

- full knee extension instant;

- latency period (LP)

- LP prosthetic limb shorter with C-leg

(0.041s; $p=0.021$ )

- LP intact limb longer with C-leg (0.013s; $p<0.05$ )

- symmetry of step length

- symmetry of stance phase duration;

- symmetry of vertical ground reaction

no effects - 2 force plates force (butterfly plot)

- duration (stand to sit and sit to stand); - vertical ground reaction force (vGRF);

- joint angle symmetry $\mathrm{l} / \mathrm{r}$ (hip+knee);

- joint force symmetry $\mathrm{l} / \mathrm{r}$ (hip+knee);

- joint moment symmetry $\mathrm{l} / \mathrm{r}$ (hip+knee)
For stand to sit:

- with Mauch SNS greater load on sound leg than with power knee $(1.6 \mathrm{~N} / \mathrm{kg}$. $\mathrm{p}<0.05$ );

- with Mauch SNS smaller load on prosthetic leg than with Power knee $(1.4 \mathrm{~N} / \mathrm{kg} ; \mathrm{p}<0.05)$

- vGRF asysmmetry higher with Mauch compared with Power knee (28\%; $\mathrm{p}<0.01$ );

For sit to stand:

- hip moment asymmetry better for Power knee compared with Mauch SNS $(25 \% ; p<0.05)$

?: not reported by the author; ESK: Endolite Stabilised Knee; IP: Intelligent Prosthesis; I/r: left/right; mech. knee: mechanically controlled prosthetic knee joint; MFCL: Medicare Functional Classification Level; MPK: microprocessor-controlled prosthetic knee joint; PSPC: pneumatic swing phase control; PVD: peripheral vascular disease; QoL: quality of life; SD: standard deviation; VT: Van Tulder score; VO2: rate of oxygen consumption; VCO2: rate of carbon dioxide production. 
Furthermore, $70 \%$ of all parameters that described persons' actual performance are measured at ICF function level, $27 \%$ at ICF activity level, and none at ICF participation level. For parameters that describe persons' perceived performance, 33\% are measured at ICF function level, 37\% at ICF activity level, and 7\% at ICF participation level.

In twenty-eight studies ${ }^{7-11,13-18,20-36}$ (i.e. $90.3 \%$ of all studies), one or more parameters at ICF function level were utilized to assess the differences in performance between an MPK and a mechanically controlled prosthesis. Fifty percent of all parameters at ICF function level, divided over 15 studies 7, 14-18, 20, 21, 24-26, 29, 30, 35, 36 (i.e. 48\% of all studies), targeted persons' quality of walking with the prosthesis on even surface. These parameters typically encompass spatiotemporal parameters, kinematic, and kinetic parameters, measured with standardised gait analysis. An additional $14 \%$ of all parameters at ICF function level, divided over 14 studies $^{7-10,13,14,16-18,20,24,27,29,31}$ (45\% of all studies), focused on the energy cost of walking with the prosthesis. Furthermore, $8 \%$ of the parameters at ICF function level focused on cognitive effort ( 5 studies $^{11,18,22,25,34}$ ), 17\% on safety-related parameters ( 7 studies $7,18,25,28,32-34$ ), 3\% on activities other than walking (i.e. standing) (1 study ${ }^{26}$ ), and $8 \%$ on other parameters ( 2 studies ${ }^{18,23}$ ).

Thirteen studies $7,10,12,16,18,19,25,27,29,30,32,34,37$ measured one or more parameters at ICF activity level to determine the level of performance with the prosthesis. The majority (68\%) of all parameters at ICF activity level described activities other than walking on level ground. These activities included negotiation of stairs, hills, uneven terrain, and obstacles. Also, sitting down and standing up was assessed, as well as a variety of basic mobility tasks.

In five studies $25,27,30,31,34$ the effects on the performance with a prosthesis at the ICF participation level were measured using two measures. Perceived performance with the prosthesis was measured using questionnaires on the overall satisfaction and performance with the prosthesis in daily life (Prosthesis Evaluation Questionnaire ${ }^{38}$ ), and general health and quality of life (36-item Short-Form Health Survey ${ }^{39}{ }^{40}$ ).

\section{Descriptive analysis of studies included}

The MPKs investigated in the studies were the C-leg (Otto Bock HealthCare, Duderstadt, Germany) ( $n=22$ ), Intelligent Prosthesis (Chas A. Blatchford \& Sons Ltd, Basingstoke, UK) $(n=7)$, Rheo knee (Össur, Reykjavik, Iceland) $(n=1)$, Adaptive knee (Chas. A. Blatchford \& Sons Ltd, Basingstoke, UK) ( $n=1)$, Power knee (Össur, Reykjavik, Iceland) ( $n=1)$, and a newly 
Table 3. Overview of outcome parameters identified in studies included in review

\begin{tabular}{|c|c|c|c|c|c|c|c|c|c|c|c|}
\hline & Outcome parameter & $\begin{array}{l}2 \\
8 \\
0 \\
0 \\
\underline{u}\end{array}$ & 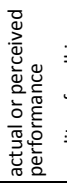 & 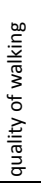 & 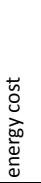 & 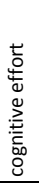 & 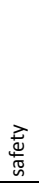 & 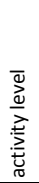 & 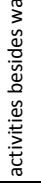 & 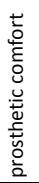 & 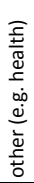 \\
\hline \multirow{34}{*}{$\begin{array}{c}\text { ICF } \\
\text { Function }\end{array}$} & walking speed $^{7,14,16-18,20,21,24,30,35}$ & b770 & a & $\bullet$ & & & & & & & \\
\hline & symmetry (spatial/temporal) $7,16,18,29,36$ & b770 & a & $\bullet$ & & & & & & & \\
\hline & stance phase duration ${ }^{15,35}$ & b770 & a & - & & & & & & & \\
\hline & joint angles ${ }^{15,17,18,21}$ & b770 & a & - & & & & & & & \\
\hline & joint moments ${ }^{15,17,18,21,26}$ & b770 & a & $\bullet$ & & & & & & & \\
\hline & joint power ${ }^{16,20}$ & b770 & a & $\bullet$ & & & & & & & \\
\hline & step time ${ }^{17}$ & b770 & a & - & & & & & & & \\
\hline & step length ${ }^{17,21}$ & b770 & a & - & & & & & & & \\
\hline & single-support time ${ }^{17}$ & b770 & a & - & & & & & & & \\
\hline & double-support time ${ }^{17}$ & b770 & a & - & & & & & & & \\
\hline & jerk $^{17}$ & b770 & a & - & & & & & & & \\
\hline & cadence $^{14,18,24,35}$ & b770 & a & - & & & & & & & \\
\hline & ground reaction force ${ }^{21}$ & b770 & a & - & & & & & & & \\
\hline & stride length $^{14,24,35}$ & b770 & a & - & & & & & & & \\
\hline & knee extension instant ${ }^{35}$ & b770 & a & $\bullet$ & & & & & & & \\
\hline & latency period ${ }^{35}$ & b770 & a & - & & & & & & & \\
\hline & muscular activity pattern ${ }^{17}$ & b760 & a & $\bullet$ & & & & & & & \\
\hline & walking distance $^{14,25}$ & b455 & a & $\bullet$ & & & & & & & \\
\hline & $\mathrm{O}_{2}$ consumption rate ${ }^{7-9,13,14,16-18,20,27,31}$ & b455 & a & & $\bullet$ & & & & & & \\
\hline & heart rate ${ }^{13,14,18,27}$ & b455 & a & & - & & & & & & \\
\hline & physiological cost index ${ }^{24,29}$ & b455 & a & & $\bullet$ & & & & & & \\
\hline & physical activity-related energy expenditure ${ }^{31}$ & b455 & a & & $\bullet$ & & & & & & \\
\hline & effort to walk $7,10,18,31$ & b469 & $\mathrm{p}$ & & $\bullet$ & & & & & & \\
\hline & ability to divide attention ${ }^{18,22}$ & b140 & $\mathrm{p}$ & & & - & & & & & \\
\hline & concentration $^{25,34}$ & b140 & $\mathrm{p}$ & & & $\bullet$ & & & & & \\
\hline & whole body sway ${ }^{11}$ & b755 & a & & & $\bullet$ & & & & & \\
\hline & joint angles/moments (safety potential) ${ }^{33}$ & b770 & a & & & & $\bullet$ & & & & \\
\hline & joint angles (gait pattern variability) ${ }^{18}$ & b770 & a & & & & $\bullet$ & & & & \\
\hline & confidence (walking ${ }^{7,25,32,34} /$ standing $^{7} /$ balance ${ }^{28}$ ) & b126 & $\mathrm{p} / \mathrm{p} / \mathrm{p}$ & & & & $\bullet$ & & & & \\
\hline & perceived safety ${ }^{18,32}$ & b126 & $\mathrm{p}$ & & & & $\bullet$ & & & & \\
\hline & postural stability ${ }^{26}$ & b755/b235 & a & & & & & & • & & \\
\hline & load on non-affected leg ${ }^{18}$ & b780 & $\mathrm{p}$ & & & & & & & & - \\
\hline & integration in body scheme ${ }^{18}$ & b180 & $\mathrm{p}$ & & & & & & & & $\bullet$ \\
\hline & body image ${ }^{23}$ & b180 & $\mathrm{p}$ & & & & & & & & - \\
\hline \multirow{11}{*}{$\begin{array}{c}\text { ICF } \\
\text { Activity }\end{array}$} & $\begin{array}{l}\text { quality }{ }^{10,16,18} / \text { ability }^{10,12,18,29,32} \text { of walking } \\
\text { learning to walk }\end{array}$ & $\begin{array}{l}\mathrm{d} 450 \\
\mathrm{~d} 155\end{array}$ & $a-p / p$ & $\bullet$ & & - & & & & & \\
\hline & stumble frequency ${ }^{25,29,30,34}$ & & $\mathrm{p}$ & & & & - & & & & \\
\hline & fall frequency $25,29,30,34$ & & $\mathrm{p}$ & & & & $\bullet$ & & & & \\
\hline & activity duration ${ }^{19}$ & & a & & & & & $\bullet$ & & & \\
\hline & daily step frequency ${ }^{19,25}$ & $\mathrm{~d} 450$ & a & & & & & $\bullet$ & & & \\
\hline & quality ${ }^{25,34} /$ ability $^{10,18,29,30} /$ effort $^{7}$ of stairs negotiation & d4455 & $a / p / p$ & & & & & & • & & \\
\hline & quality ${ }^{25,34} /$ ability $^{10,18,29} /$ effort $^{7}$ of hill negotiation & $\mathrm{d} 450$ & $a / p / p$ & & & & & & • & & \\
\hline & ability ${ }^{10,25,30,34}$ /effort ${ }^{7}$ to negotiate uneven terrain & $\mathrm{d} 450$ & $a-p / p$ & & & & & & $\bullet$ & & \\
\hline & quality of obstacle negotiation ${ }^{27}$ & $\mathrm{~d} 450$ & a & & & & & & $\bullet$ & & \\
\hline & duration ${ }^{37} /$ symmetry ${ }^{37}$ of sitting down/standing up & $\mathrm{d} 410$ & $a / a$ & & & & & & $\bullet$ & & \\
\hline & basic functional mobility ${ }^{25,34}$ & $\mathrm{~d} 4^{*}$ & a & & & & & & $\bullet$ & & \\
\hline \multirow{2}{*}{$\begin{array}{c}\text { ICF } \\
\text { Participation }\end{array}$} & satisfaction/performance $25,30,31,34$ & & $\mathrm{p}$ & & & & & & & & $\bullet$ \\
\hline & general health/QoL ${ }^{25,27,34}$ & & $\mathrm{p}$ & & & & & & & & \\
\hline \multirow{7}{*}{$\begin{array}{c}\text { ICF } \\
\text { Environmental } \\
\text { factors }\end{array}$} & use of walking aids ${ }^{18,24}$ & e115 & a-p & - & & & & & & & \\
\hline & swing phase control ${ }^{12}$ & e1151 & $\mathrm{p}$ & & & & & & & 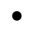 & \\
\hline & knee dynamics $^{12}$ & e1151 & $\mathrm{p}$ & & & & & & & $\bullet$ & \\
\hline & mechanical reliability ${ }^{10}$ & e115 & $\mathrm{p}$ & & & & & & & $\bullet$ & \\
\hline & socket fit ${ }^{30}$ & e1151 & $\mathrm{p}$ & & & & & & & $\bullet$ & \\
\hline & prosthesis attributes ${ }^{29,32}$ & e1151 & $\mathrm{p}$ & & & & & & & - & \\
\hline & physical effects of prosthesis ${ }^{32}$ & e1151 & $\mathrm{p}$ & & & & & & & - & \\
\hline
\end{tabular}

*: applies to multiple paragraphs in chapter 4 (d410-d499); a: actual performance; p: perceived performance; ICF: International Classification of Functioning, Disability and Health. 


\section{CHAPTER 2}

developed polycentric MPK prototype $(n=1)$. Accommodation time for the MPK ranged between 30 minutes to 44 months.

A total of 719 participants have been investigated. The mean age of participants was 43.3 years (SD 9.2 years; range=15-85 years). The most common aetiology of amputation for the participants in the studies were trauma, congenital causes and malignancy $(n=24$ studies) $7-13,15-19,23,25,26,28,30-37$. Participants with an amputation due to peripheral vascular diseases were included in 8 studies 18, 25, 26, 30-32, 34, 37. In 24 7-13, 16-19, 21, 22, 25-28, 30-34, 36, 37 of the 31 studies the participants were described as active and fit individuals. Thirty-two participants (i.e. $4.5 \%$ of total number of subjects) with a reported lower functional level ( $\leq$ MFCL-2) were included, divided over five studies ${ }^{18,25,30,34,37}$. Two of those studies ${ }^{18,34}$ specifically investigated the effects of MPKs in amputees classified as MFCL-2. In seven studies ${ }^{14,15,20,23,24,29,35}$ participants' functional level was not clearly specified.

The mean sample size of participants for all studies included was 23.3 (SD 65.8; range 1-368). The sample size of the study of Berry et al. ${ }^{32}(n=368)$ may be considered a far outlier. The mean sample size without this study was 11.4 (SD 9.5; range 1-42). In 29 7-34, 36 of the 31 studies, a within-subject design was used to test the differences between mechanically controlled prosthetic knees and MPKs. Two studies 35, 37 compared the performance of a cohort of amputees using mechanically controlled prostheses with one or two cohorts of amputees using a particular type of MPK.

The methodological quality of all studies included, indicated by the mean total van Tulder score, was 9.1 (SD 1.7; range 6-12) out of a maximum score of 19. Mean score on the internal validity of the publications was 4.4 (SD 0.8 ) out of 11 . The mean score on descriptive criteria was 3.2 (SD 1.0) out of 6 , and the mean score for the statistical criteria was 1.5 (SD 0.5 ) out of 2 . When using the cut-off value suggested by van Tulder $(50 \%$ of

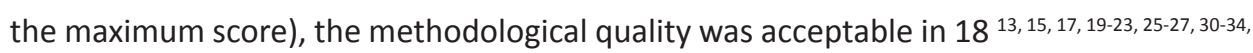
36,37 of the 31 studies.

\subsection{Discussion}

The main aim of the present review was to provide insight in how the effects of using an MPK, in comparison with a mechanically controlled knee joint, have been determined thus far. To this end, an overview of the outcome measures that have been utilized in comparative studies to describe the effects of an MPK on patients' were identified from the literature and subsequently structured according to the ICF framework to provide 
a comprehensive overview of the health and health-related domains that have been assessed. In addition, a descriptive evaluation of the study characteristics, the participant characteristics, and the overall quality of the studies performed, was conducted. The findings indicated that a majority (70\%) of all outcome measures, utilized to assess persons' actual performance, targeted ICF function level, whereas only few measures assessed the effects of using an MPK at activity level (27\%), and no measures at participation level. The outcome measures utilized to evaluate persons' perceived performance with an MPK also typically described the effects at function level and activity level. Thus, the scientific knowledge that is currently available regarding the effects of using an MPK on persons' functional abilities is limited. Additional information is necessary about how the use of an MPK may affect persons' actual ability to perform activities in everyday life and how using an MPK may influence people's participation in society.

The majority of the evidence that is available regarding the effectiveness of using an MPK is primarily based on measures covering ICF function level. Such information is valuable to understand the principles behind how an MPK may contribute to optimizing persons' performance with a prosthesis. However, one of the main reasons to provide an above knee amputee with a prosthesis featuring a specific prosthetic knee joint is to enable that person to reach an optimal level of functioning in daily life. Yet, only few studies have investigated the effects of an MPK in the ICF activity domain and no trials have studied the effects in the ICF participation domain. Information on those domains is more closely related to the problems experienced by amputees in daily life in comparison with measures at function level. For instance, persons with an above-knee amputation are not necessarily interested in whether they consume less millilitres of oxygen per kilogram per meter walked on a treadmill at a constant speed. Instead, it is more important for them to know whether they are (more) able to perform their activities of everyday life, or be involved in life situations when using their prosthesis.

The outcome measures utilized to measure functioning in the activity domain were predominantly based on parameters on perceived performance. As this entails subjective information about persons' performance, it is more sensitive to bias (e.g. response or recall bias) compared with objective measurements. Persons may give answers that are influenced by their own expectations, or because they want to please the researcher. Also, subjective measures are more sensitive to changes in the participants' frame of reference, i.e. their perception may change over time, for instance, because they have put a certain condition or state into perspective. Nevertheless, it is important that, in 
addition to information concerning persons' actual performance level, the level of participants' perceived performance is also included in the process of decision making for a prosthetic knee, as persons' level of (dis)satisfaction with the prosthesis is strongly related to the level of use of the prosthesis ${ }^{41,42}$. Unfortunately, in only 7 of the 31 studies, identified in the current review, parameters were assessed by measuring a combination of both actual and self-perceived performance. The assessment of a combination of both actual and perceived performance measures is strongly recommended for future prosthetic research.

To objectively measure a person's actual performance at the level of activity or participation is difficult, due to the fact that very few (validated) measuring tools are available, that have been designed specifically to be used in persons with an amputation of a lower extremity ${ }^{43}$. Nevertheless, several original tools that objectively measure activities were found in the present review. Hafner et al. ${ }^{25,34}$ used three measures that aim to assess actual performance at ICF activity level. The Stair Assessment Index (SAI) ${ }^{44}$ and Hill Assessment Index (HAI) ${ }^{45}$, that measure persons' overall ability and quality of performance during stairs and hill negotiation, and a distracted walking test, that assesses the level of cognitive load during walking. During the latter test, persons walked outdoor around a busy city block while talking to a researcher on a cell phone. Participants had to repeat series of numbers back to the researcher in reversed order. Datta et al. ${ }^{16}$ used an original video observation scale to evaluate persons' overall gait quality. Also, Seymour et al. ${ }^{27}$ developed a standardised walking obstacle course to determine persons' ability to negotiate obstacles. Although no information is available about the psychometric properties of the aforementioned measures, they seem ecologically valid. Tools that aim to measure participation are typically self-report measures. This is inherent to the definition of participation, as it involves social interaction, which is impossible to measure under standardised conditions.

Although this review focused on how the effects of an MPK were assessed, it should also be noted that the majority $(\approx 77 \%)$ of all studies that investigated the effectiveness of using an MPK included relatively young, fit, and active persons, with an amputation due

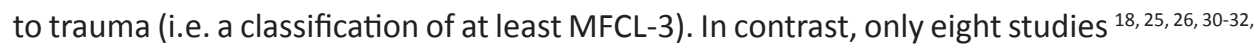
34, 37 included persons with an amputation due to peripheral vascular disease and in only two studies ${ }^{18,34}$ the effects of an MPK were specifically evaluated in amputees classified as MFCL-2. This does not seem to be representative of the total amputee population. The prevalence numbers in, for instance, the United States and The Netherlands, indicate that 
an estimated $42 \%$ and $90 \%$ respectively, of the lower limb amputees are over 65 years old ${ }^{46,47}$, and around $79 \%$ and $94 \%$ respectively, of the amputations are due to peripheral vascular disease ${ }^{47,48}$. The research attention concerning the evaluation of MPKs seems to be more focused on the high profile, well-performing subpopulation. However, it is important to recognise that the ageing of the general population and the increasing prevalence of obesity and cardiovascular disease, are likely to cause the relative number of older persons with an amputation for vascular problems to grow. Persons with a lower functional level might also benefit from using a prosthesis featuring an MPK ${ }^{18,24,}$ ${ }^{34}$. However, additional research is necessary to further increase our knowledge available about the effects of MPKs regarding this subpopulation of prosthesis users.

The average quality of the studies identified in the review was moderate to low. In general, the effects of the MPKs were investigated in a small research population, leading to statistical power problems and affecting the generalizability of the results reported. Also, large variation exists in the length of the accommodation time for the MPK (range 30 minutes to 44 months). Intuitively, a longer accommodation time would result in a better performance on the tests. English et al. ${ }^{49}$ reported that at least one week of functional walking with the prosthesis is necessary for clinical decision making on the suitability of a knee joint, but that three weeks is recommended for research purposes. This recommendation, however, is based on the findings in one subject. To date, no consensus exists on a suitable accommodation period. Additionally, the mean Van Tulder score for all studies incorporated in the review (9.1 out of 19), further underlines the moderate quality. According to Van Tulder ${ }^{5,6}$ the methodological quality of a study is considered adequate with a score of at least 9.5. Especially, the internal validity is scored very low (4.4 out of 11), which may be associated with the lack of blinding in all studies. Blinding of the participants is practically impossible to accomplish, as the different features of the MPKs have to be explained to enable subjects to use the MPK to its full potential. It should also be noted that the Van Tulder's quality assessment system is typically designed to rate randomised controlled trials (RCT) or controlled clinical trials (CCT). The majority of the studies included in the present review were neither. This may have led to an underestimation of the quality of the papers in the review.

\section{Recommendations for future research}

The majority of the comparative studies have objectively investigated the effects of an MPK versus a mechanically controlled prosthesis on walking (quality, physical effort, and cognitive effort). Little information is available about other aspects of functioning 
with a prosthesis. Next to the investigations on negotiating stairs, slopes, and obstacles, no parameters were identified on persons' actual ability to perform activities of daily living ( $A D L$ ). Research should focus more on whether the effects measured in a human movement lab also apply to situations in persons' everyday life, i.e. investigate the functional added value of using a prosthetic knee joint.

Future research should focus on the development of tools that are able to objectively measure actual performance in persons with an above-knee amputation. More specifically, tools that measure at ICF activity level and participation level are necessary to further increase our understanding about the possible effects of using an MPK on persons' functioning. Moreover, a combination with parameters on self-perceived performance is warranted.

Prosthesis research should focus more on the effects of using an MPK in persons with a lower functional level (e.g. amputees classified as MFCL-2). Given their limited physical capacity, these persons might not benefit from using the adaptive swing phase control that should enable them to walk at varying speeds. However, they may possibly benefit from the higher levels of stability of the knee due to the continuous adaptive stance phase control.

\subsection{Conclusions}

Much research has been done on the effects of MPKs. However, the information available provides insight into the effects of using an MPK on only a limited number of health and health-related domains. The effects have been predominantly investigated from the perspective of the body (ICF function level), and so, objective information and scientifically valid evidence regarding the performance of persons with an MPK in everyday life is still fairly limited. Research should therefore specifically focus on ICF activity and ICF participation level, rather than ICF function level.

Also, the information about the effects of MPKs on persons' functioning cannot be generalised for the entire population of persons with an above-knee amputation, as testing of MPKs is almost only performed in healthy, fit, and active persons, who are relatively young. Future research should therefore also aim at the older, less active persons with an amputation to complement the information available so far. 


\section{$2.6 \quad$ References}

1. Michael JW. Modern prosthetic knee mechanisms. Clin Orthop Relat Res 1999; 361:39-47.

2. World Health Organisation. International Classification of Functioning, Disability and Health: ICF; 2001.

3. Centers for Medicare and Medicaid Services. U.S. Department of Health and Human Services. HCFA Common Procedure Coding System (HCPCS). Springfield (VA): U.S. Department of Commerce, National Technical Information Service; 2001.

4. Stuurgroep Protocollering en Prijssystematiek Prothesen. Protocol verstrekkingsproces beenprothesen [Protocol for Prescribing Leg Prostheses]. Available from: http://www.cbo.nl/ Downloads/1348/Protocolverstrekkingsprocesbeenprothesen1november2010.pdf.

5. van Tulder M, Furlan A, Bombardier C, Bouter L. Updated method guidelines for systematic reviews in the cochrane collaboration back review group. Spine (Phila Pa 1976) 2003; 28:1290-1299.

6. van Tulder MW, Assendelft WJ, Koes BW, Bouter LM. Method guidelines for systematic reviews in the Cochrane Collaboration Back Review Group for Spinal Disorders. Spine (Phila Pa 1976) 1997; 22:2323-2330.

7. Kirker S, Keymer S, Talbot J, Lachmann S. An assessment of the intelligent knee prosthesis. Clin Rehabil 1996; 10:267-273.

8. Taylor MB, Clark E, Offord EA, Baxter C. A comparison of energy expenditure by a high level transfemoral amputee using the Intelligent Prosthesis and conventionally damped prosthetic limbs. Prosthet Orthot Int 1996; 20:116-121.

9. Buckley JG, Spence WD, Solomonidis SE. Energy cost of walking: comparison of "intelligent prosthesis" with conventional mechanism. Arch Phys Med Rehabil 1997; 78:330-333.

10. Datta D, Howitt J. Conventional versus microchip controlled pneumatic swing phase control for transfemoral amputees: user's verdict. Prosthet Orthot Int 1998; 22:129-135.

11. Heller BW, Datta D, Howitt J. A pilot study comparing the cognitive demand of walking for transfemoral amputees using the Intelligent Prosthesis with that using conventionally damped knees. Clin Rehabil 2000; 14:518-522.

12. Stinus H. Biomechanik und beurteilung des exoprothesenkniegelenkes C-leg [Biomechanics and evaluation of the microprocessor-controlled C-leg]. Z Orthop Ihre Grenzgeb 2000; 138:278-282.

13. Schmalz T, Blumentritt S, Jarasch R. Energy expenditure and biomechanical characteristics of lower limb amputee gait: the influence of prosthetic alignment and different prosthetic components. Gait Posture 2002; 16:255-263.

14. Perry J, Burnfield JM, Newsam CJ, Conley P. Energy expenditure and gait characteristics of a bilateral amputee walking with C-leg prostheses compared with stubby and conventional articulating prostheses. Arch Phys Med Rehabil 2004; 85:1711-1717.

15. Yokogushi K, Narita H, Uchiyama E, Chiba S, Nosaka T, Yamakoshi KI. Biomechanical and clinical 


\section{CHAPTER 2}

evaluation of a newly designed polycentric knee of transfemoral prosthesis. J Rehabil Res Dev 2004; 41:675-681.

16. Datta D, Heller B, Howitt J. A comparative evaluation of oxygen consumption and gait pattern in amputees using Intelligent Prostheses and conventionally damped knee swing-phase control. Clin Rehabil 2005; 19:398-403.

17. Johansson JL, Sherrill DM, Riley PO, Bonato P, Herr H. A clinical comparison of variable-damping and mechanically passive prosthetic knee devices. Am J Phys Med Rehabil 2005; 84:563-575.

18. Wetz HH, Hafkemeyer U, Drerup B. Einfluss des C-Leg-Kniegelenk-Passteiles der Fa. Otto Bock auf die Versorgungsqualität Oberschenkelamputierter. Eine klinisch-biomechanische Studie zur Eingrenzung von Indikationskriterien [The influence of the C-leg knee-shin system from the Otto Bock Company in the care of above-knee amputees. A clinical-biomechanical study to define indications]. Orthopäde 2005; 34:298-319.

19. Klute GK, Berge JS, Orendurff MS, Williams RM, Czerniecki JM. Prosthetic intervention effects on activity of lower-extremity amputees. Arch Phys Med Rehabil 2006; 87:717-722.

20. Orendurff MS, Segal AD, Klute GK, McDowell ML, Pecoraro JA, Czerniecki JM. Gait efficiency using the C-Leg. J Rehabil Res Dev 2006; 43:239-246

21. Segal AD, Orendurff MS, Klute GK, McDowell ML, Pecoraro JA, Shofer J, Czerniecki JM. Kinematic and kinetic comparisons of transfemoral amputee gait using C-Leg and Mauch SNS prosthetic knees. J Rehabil Res Dev 2006; 43:857-70.

22. Williams RM, Turner AP, Orendurff M, Segal AD, Klute GK, Pecoraro J, Czerniecki J. Does having a computerized prosthetic knee influence cognitive performance during amputee walking? Arch Phys Med Rehabil 2006; 87:989-994.

23. Bunce DJ, Breakey JW. The impact of C-Leg on the physical and psychological adjustment to transfemoral amputation. J Prosthet Orthot 2007; 19:7-14.

24. Chin T, Maeda Y, Sawamura S, Oyabu H, Nagakura Y, Takase I, Machida K. Successful prosthetic fitting of elderly trans-femoral amputees with Intelligent Prosthesis (IP): a clinical pilot study. Prosthet Orthot Int 2007; 31:271-276.

25. Hafner BJ, Willingham LL, Buell NC, Allyn KJ, Smith DG. Evaluation of function, performance, and preference as transfemoral amputees transition from mechanical to microprocessor control of the prosthetic knee. Arch Phys Med Rehabil 2007; 88:207-217.

26. Kaufman KR, Levine JA, Brey RH, Iverson BK, McCrady SK, Padgett DJ, Joyner MJ. Gait and balance of transfemoral amputees using passive mechanical and microprocessor-controlled prosthetic knees. Gait Posture 2007; 26:489-493.

27. Seymour R, Engbretson B, Kott K, Ordway N, Brooks G, Crannell J, Hickernell E, et al. Comparison between the C-leg microprocessor-controlled prosthetic knee and non-microprocessor control prosthetic knees: a preliminary study of energy expenditure, obstacle course performance, and 
quality of life survey. Prosthet Orthot Int 2007; 31:51-61.

28. Stevens PM, Carson R. Case report: Using the Activities-Specific Balance Confidence Scale to quantify the impact of prosthetic knee choice on balance confidence. J Prosthet Orthot 2007; 19:114-116.

29. Jepson F, Datta D, Harris I, Heller B, Howitt J, McLean J. A comparative evaluation of the Adaptive knee and Catech knee joints: a preliminary study. Prosthet Orthot Int 2008; 32:84-92.

30. Kahle JT, Highsmith MJ, Hubbard SL. Comparison of nonmicroprocessor knee mechanism versus C-Leg on Prosthesis Evaluation Questionnaire, stumbles, falls, walking tests, stair descent, and knee preference. J Rehabil Res Dev 2008; 45:1-14.

31. Kaufman KR, Levine JA, Brey RH, McCrady SK, Padgett DJ, Joyner MJ. Energy expenditure and activity of transfemoral amputees using mechanical and microprocessor-controlled prosthetic knees. Arch Phys Med Rehabil 2008; 89:1380-1385.

32. Berry $D$, Olson MD, Larntz K. Perceived stability, function, and satisfaction among transfemoral amputees using microprocessor and nonmicroprocessor controlled prosthetic knees: a multicentre survey. J Prosthet Orthot 2009; 21:32-42.

33. Blumentritt S, Schmalz T, Jarasch R. The safety of C-leg: biomechanical tests. J Prosthet Orthot 2009; 21:2-15.

34. Hafner BJ, Smith DG. Differences in function and safety between Medicare Functional Classification Level-2 and -3 transfemoral amputees and influence of prosthetic knee joint control. J Rehabil Res Dev 2009; 46:417-433.

35. Mâaref K, Martinet N, Grumillier C, Ghannouchi S, Andre JM, Paysant J. Kinematics in the terminal swing phase of unilateral transfemoral amputees: microprocessor-controlled versus swing-phase control prosthetic knees. Arch Phys Med Rehabil 2010; 91:919-925.

36. Petersen AO, Comins J, Alkjaer T. Assessment of gait symmetry in transfemoral amputees using C-leg compared with $3 R 60$ prosthetic knees. J Prosthet Orthot 2010; 22:106-112.

37. Highsmith MJ, Kahle JT, Carey SL, Lura DJ, Dubey RV, Csavina KR, Quillen WS. Kinetic asymmetry in transfemoral amputees while performing sit to stand and stand to sit movements. Gait Posture 2011; 34:86-91.

38. Legro MW, Reiber GD, Smith DG, del Aguila M, Larsen J, Boone D. Prosthesis evaluation questionnaire for persons with lower limb amputations: assessing prosthesis-related quality of life. Arch Phys Med Rehabil 1998; 79:931-938.

39. McHorney CA, Ware JE, Jr., Raczek AE. The MOS 36-Item Short-Form Health Survey (SF-36): II. Psychometric and clinical tests of validity in measuring physical and mental health constructs. Med Care 1993; 31:247-263.

40. Ware JE, Jr., Sherbourne CD. The MOS 36-item short-form health survey (SF-36). I. Conceptual framework and item selection. Med Care 1992; 30:473-483.

41. Phillips B, Zhao H. Predictors of assistive technology abandonment. Assist Technol 1993; 5:36-45. 


\section{CHAPTER 2}

42. Riemer-Reiss ML, Wacker RR. Factors associated with assistive technology discontinuance among individuals with disabilities. J Rehabil 2000; 66:44-50.

43. Condie E, Scott H, Treweek S. Lower limb prosthetic outcome measures: a review of the literature 1995 to 2005. J Prosthet Orthot 2006; 18:13-45.

44. Buell NC, Willingham LL, Allyn KJ, Hafner BJ, Smith DG. Evaluation of gait style to ascend and descend stairs for lower limb amputees. Boone D, editor. 11th World Congress of the International Society of Prosthetics and Orthotics; 2004 Aug 1-6; Hong Kong; 2004. pp. 367.

45. Buell NC, Willingham LL, Allyn KJ, Hafner BJ, Smith DG. Evaluation of gait style for hill descent for lower limb amputees. Boone D, editor. 11th World Congress of the International Society of Prosthetics and Orthotics; 2004 Aug 1-6; Hong Kong; 2004. pp. 53.

46. Kiwa Prismant. Landelijke Medische Registratie [National Medical Registration]. [Accessed December 30, 2011]; Available from: http://cognosserver.prismant.nl/cognos7/cgi-bin/ppdscgi.cgi?DC=Q\&E=/ Prisma-Landelijke-LMR/Landelijke+LMR-informatie+-+Verrichtingen.

47. Ziegler-Graham K, MacKenzie EJ, Ephraim PL, Travison TG, Brookmeyer R. Estimating the prevalence of limb loss in the United States: 2005 to 2050. Arch Phys Med Rehabil 2008; 89:422-429.

48. Rommers GM, Vos LD, Groothoff JW, Schuiling CH, Eisma WH. Epidemiology of lower limb amputees in the north of The Netherlands: aetiology, discharge destination and prosthetic use. Prosthet Orthot Int 1997; 21:92-99.

49. English RD, Hubbard WA, McElroy GK. Establishment of consistent gait after fitting of new components. J Rehabil Res Dev 1995; 32:32-35. 



$$
\operatorname{tin}
$$




\section{Chapter 3}

Feasibility of a new concept for measuring actual functional performance in daily life of transfemoral amputees

P.J.R. Theeven, B. Hemmen, C.H.C. Stevens, E.C. Ilmer, P.R.G. Brink, H.A.M. Seelen / Rehabil Med 2010; 42:744-751

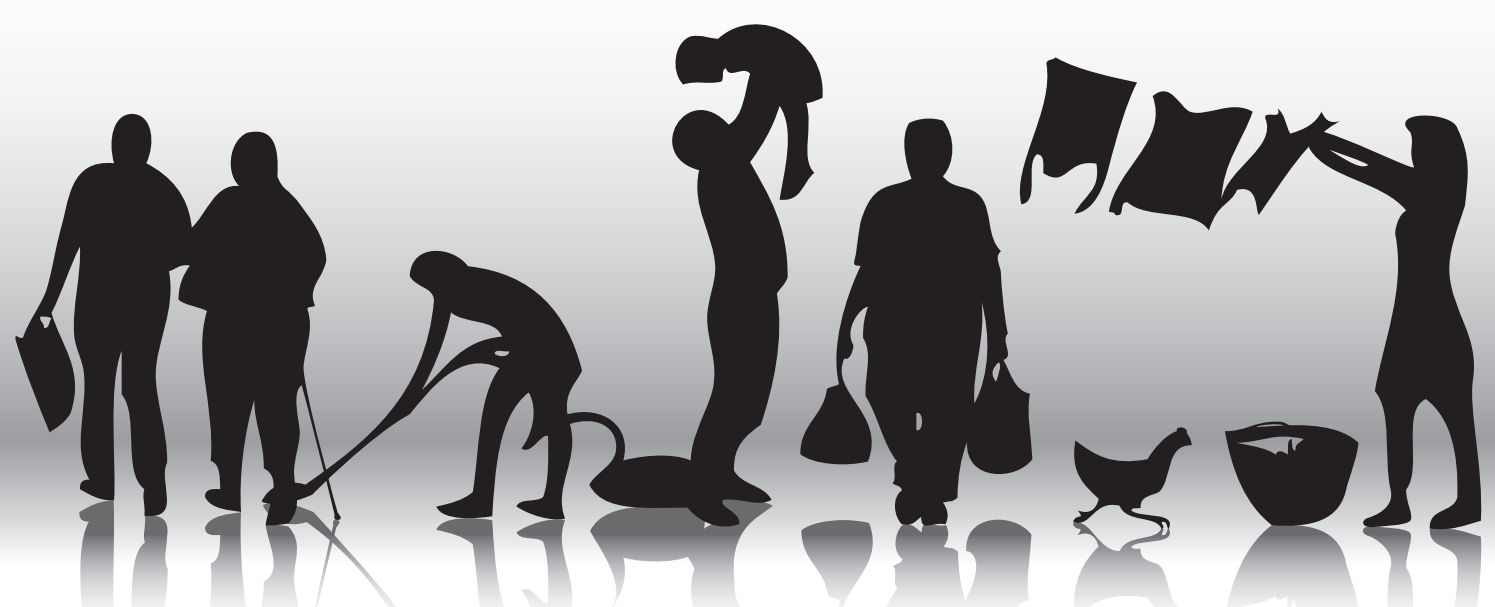




\section{Abstract}

Objective: Determining the feasibility of implementing a new concept to objectively evaluate actual functional abilities of transfemoral amputees into a new measuring tool called "Assessment of Daily Activity Performance in Transfemoral amputees" (ADAPT).

Design: Study 1: cross-sectional design. Study 2: repeated measures design.

Subjects: Study 1 comprised two groups of 10 participants, age range $19-72$ years. One group used microprocessor-controlled knee joints and the other group used mechanically controlled knee joints. Study 2 comprised 20 participants, age 31-68 years.

Methods: Two versions of ADAPT were assessed in the separate studies.

In study 1 performance times on version 1 of ADAPT were compared between groups.

In study 2 participants completed version 2 of ADAPT twice with a 1-hour rest between trials. The Locomotor Capabilities Index was administered. Reliability was determined by calculating correlation coefficients and by Bland-Altman analyses.

Results: In study 1, ADAPT version 1 proved to be sensitive in detecting differences in performance between groups. In study $2,75 \%$ of all correlation coefficients exceeded 0.90 in version 2 of ADAPT. Bland-Altman analyses showed high test-retest agreement.

Conclusion: It is feasible to reliably assess actual functional abilities of transfemoral amputees using standardized simulations of daily activities. This ADAPT concept is able to differentiate between different functional performance levels. 


\subsection{Introduction}

Amputation of a lower limb changes a person's life and diminishes their functional ability to perform activities of daily living ${ }^{1}$. Receiving a prosthesis and completing a rehabilitation programme may partly restore this decreased functional ability. In transfemoral amputation, the type of knee joint fitted to the prosthesis is critical, because the knee needs to be stabilized and controlled by the amputee in order to ambulate effectively and safely ${ }^{1,2}$. To select the most suitable prosthetic knee joint for an individual patient is a challenge, due to the large variety of available prosthetic components, each of which has specific functions and purposes. The effects of different types of prosthetic knee joints on the functioning of transfemoral amputees has been the topic of many studies ${ }^{3-7}$. These studies have typically focused on biomechanical and (neuro)physiological measures, i.e. measures at ICF function level, in order to quantify any possible added value due to prosthetic knee joints. Although important, the effects of prosthetic components should not be assessed solely at ICF function level, as this would disregard the problems that occur at the activity and participation level. From the amputee's perspective, it is more important to be able to resume previous social roles, rather than to be able to, for example, walk $100 \mathrm{~m}$ a few seconds faster.

Several instruments are currently available to evaluate the functional ability of amputees. For example, the Locomotor Capabilities Index $(\mathrm{LCl})^{8}$ and the Functional Measures for Amputees (FMA) ${ }^{9}$. These evaluate the functional ability of amputees using self-report questionnaires and thus rely heavily on the amputee having a realistic self-knowledge, which makes these tests highly subjective. The Special Interest Group of Amputee Medicine (SIGAM) of the British Society of Rehabilitation Medicine has developed a method to assign leg amputees to 1 of 6 mobility classes (A-F) using a 21-item questionnaire in combination with an accompanying algorithm ${ }^{10}$. This test is used in several countries, including The Netherlands (SIGAM-WAP) ${ }^{11}$. Although all the above-mentioned tests are valid and reliable, they all measure perceived functional performance, rather than actual functional performance with a prosthesis. The Amputee Mobility Predictor (with prosthesis) (AMPPRO) ${ }^{12}$ is a more objective 21 -item performance test including transfers, sitting and standing balance, and several gait skills to assess the amputee's mobility and existing or potential functional ambulation with a leg prosthesis. However, this test focuses on individual aspects of performance with a prosthesis (sitting balance, standing balance, minor gait manoeuvres), whereas it would be even more important to focus on the necessary ability of the amputee to combine these different aspects during functional performance in their home situation. 


\section{CHAPTER 3}

A recent search of the literature did not reveal any instruments that objectively quantify the actual functional ability of amputees to perform common daily activities. Such an instrument, however, is important because it could provide information about the effect of a prosthesis component on the functioning of the amputee in daily life. It could therefore help in the selection and prescription of prostheses that best suit the individual's physical abilities and participation aims.

A concept for a new tool that may objectively measure functional performance in daily life was developed. This concept is based on the idea that the most straightforward way to assess an individual's functional performance level is to observe the patient performing the selected set of daily activities that are most common in their life. However, this would mean that a new measuring tool based on this concept should be different for each patient, because each person performs different activities during their daily routine. This would lead to a test with endless variations, which would be highly impractical. In order to limit the number of variations of activities, a series of structured interviews was performed among unilateral transfemoral amputees and experienced occupational therapists with the aim of making an inventory of daily activities perceived by amputees as difficult to perform with a prosthesis. With the information obtained from these interviews, a gross list was composed, listing limiting factors as perceived by persons with a leg amputation in their daily pursuits, such as overhead reaching, bending down, kneeling, turning, maintaining balance, walking, negotiating stairs, descending a sloped surface, pulling/pushing, and carrying objects. From this gross list, a number of common daily situations were identified that were expected to be the most difficult to perform, for example putting a bag of potatoes into a shopping trolley in the supermarket or hanging out laundry on a clothes line.

Ideally, the patient should be assessed in real life circumstances. However, from a research point of view, it is necessary to measure under repeatable circumstances. Therefore, the next step in the development of this new tool to measure functional performance was the operationalization of the identified common daily activities into standardized and measurable test situations or "circuit stations", consisting of simulated representations of these daily activities. This tool would thereby link the experienced disability level with the actual activity level.

The final step of incorporating this concept into a new measuring tool is to select the most suitable and reliable circuit station activities with high sensitivity to detect small changes in functional performance levels from all the simulated daily life activities 
available. Based on two test versions, evaluated in the present study, a final test may be constructed involving a selection of those circuit stations that best simulate daily life situations. This final version will be called the "Assessment of Daily Activity Performance in Transfemoral amputees" (ADAPT) test.

The aim of this study was to evaluate the feasibility of implementing a concept of objectively assessing functional abilities of transfemoral amputees in daily life performance into a new measuring tool (the ADAPT test). Therefore, proof of principle was sought by investigating the ability to differentiate between functional performance levels of two groups of transfemoral amputees, i.e. discriminant validity, and the level of reproducibility, i.e. test-retest reliability, in two different test versions of the ADAPT test.

\subsection{Methods}

In two separate consecutive studies "proof of principle" for implementing the ADAPT test was evaluated.

Study 1 evaluated a first test version of an ADAPT test in terms of the sensitivity to differentiate between functional levels of performance of different groups of users of leg prostheses. A subset of available circuit stations was used in this study, as described in Table I (subset A).

Study 2 assessed a second test version of an ADAPT test in terms of reproducibility. This second test version partly consisted of a selection of circuit stations from subset $A$ that were modified based on the findings in study 1 . Moreover, several newly developed circuit stations were added to the modified selection of subset $A$. All circuit stations together constitute subset $\mathrm{B}$, as is described in Table II.

As shown in Tables I and II, some circuit stations were sometimes subdivided into 2 or 3 categories of activities ranging in difficulty level. The degree of difficulty is determined by several factors, such as the weight of objects used, introduction of a cognitive dual task or the addition of more challenging actions.

Instructions concerning the nature of the tasks were given to the participants by the researcher prior to the start of each circuit station activity. It was stressed that the activities should be performed in the same way that the participant would do normally. A circuit station was repeated if a participant did not carry out the required tasks within a specific circuit station in the correct order. An exception was introduced for activity 12 (subset B) in the case of one or more of the tennis balls dropping from the tray. The balls 
Table I. Description of subset A of the Assessment of Daily Activity Performance in Transfemoral amputees test circuit stations used in study 1

Subset $\boldsymbol{A} \quad$ Circuit station Task description

\begin{tabular}{|c|c|c|}
\hline \multirow{3}{*}{1} & \multirow{3}{*}{ Supermarket } & $\begin{array}{l}18 \text { low-weight }(500 \mathrm{~g}) \text {, easy to handle objects have to be } \\
\text { picked from shelves at different heights and placed into } \\
\text { a shopping trolley. Seven objects are labelled with an } \\
\text { " } A \text { ", } 6 \text { objects with a " } B \text { " and } 5 \text { objects with a " } C \text { ". }\end{array}$ \\
\hline & & $\begin{array}{l}\text { "Moderate": } 4 \text { moderate weight ( } 2 \text { and } 5 \mathrm{~kg} \text { ) objects (labelled with a } \\
\text { "D") have to be picked from the shelves at different } \\
\text { heights and placed into a shopping trolley. }\end{array}$ \\
\hline & & $\begin{array}{l}\text { "Difficult": } 2 \text { large and heavy ( } 6 \mathrm{~kg} \text { ) objects (labelled with an " } \mathrm{E} \text { ") } \\
\text { have to be picked from the shelves at different heights } \\
\text { and placed into a shopping trolley. }\end{array}$ \\
\hline 2 & Shopping bags & $\begin{array}{l}\text { The } 18 \text { "easy" objects (described in circuit station } 1 \text { ) have to be } \\
\text { loaded into } 3 \text { shopping bags with corresponding labels " } A \text { ", " } B \text { ", " } C \text { ", } \\
\text { that are placed on a table. }\end{array}$ \\
\hline \multirow{3}{*}{3} & \multirow{3}{*}{ Kitchen cabinets } & $\begin{array}{l}\text { Unload the shopping bags into kitchen cabinets of a height- } \\
\text { adjustable kitchen at different reaching heights. }\end{array}$ \\
\hline & & $\begin{array}{l}\text { "Easy": } \quad \text { put the } 18 \text { low-weight objects into the designated } \\
\text { cabinets labelled " } A \text { ", " } B \text { " and " } C \text { ". Cabinets " } A \text { " and " } C \text { " } \\
\text { are at eye-level. Cabinet " } B \text { " is at knee level. }\end{array}$ \\
\hline & & 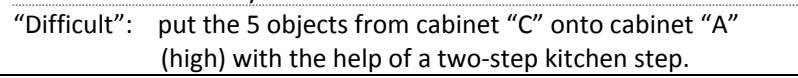 \\
\hline \multirow{3}{*}{4} & \multirow{3}{*}{$\begin{array}{l}\text { Unloading low kitchen } \\
\text { cabinets }\end{array}$} & $\begin{array}{l}\text { Unload objects placed in the front part of a cabinet at } \\
\text { knee height and put them on the floor. }\end{array}$ \\
\hline & & $\begin{array}{l}\text { "Moderate": Unload objects placed in the middle part of a cabinet at } \\
\text { knee height and put them on the floor. }\end{array}$ \\
\hline & & $\begin{array}{l}\text { "Difficult": Unload objects placed in the deep part of a cabinet at } \\
\text { knee height and put them on the floor. }\end{array}$ \\
\hline 5 & Slalom (13 m) & $\begin{array}{l}\text { Short slalom (approximately } 13 \mathrm{~m} \text { ) while holding a serving tray with } 5 \\
\text { plastic cups filled with water. }\end{array}$ \\
\hline \multirow{4}{*}{6} & \multirow{4}{*}{$\begin{array}{l}\text { Get the remote } \\
\text { control }\end{array}$} & $\begin{array}{l}\text { Sit down, stand up, walk to the television set to pick up the remote } \\
\text { control and sit down again. }\end{array}$ \\
\hline & & sit down in an armchair. \\
\hline & & $\begin{array}{l}\text { "Moderate": sit down in the middle of a low sofa without using the } \\
\text { armrests. }\end{array}$ \\
\hline & & "Difficult": sit down on a very low bench. \\
\hline 7 & Car & $\begin{array}{l}\text { Walk towards a small car and get in at the passenger side (distance: } \\
4 \mathrm{~m}) \text {. Get out and walk round the car once, get into and out of the car } \\
\text { again and walk to the place where you started the task. }\end{array}$ \\
\hline \multirow{4}{*}{8} & \multirow{4}{*}{ Stairs descent } & Go down the stairs. \\
\hline & & normal walking. \\
\hline & & $\begin{array}{l}\text { "Moderate": walking while holding a plastic cup of water in one } \\
\text { hand. }\end{array}$ \\
\hline & & "Difficult": walking while holding an empty box in both hands. \\
\hline \multirow{4}{*}{9} & \multirow{4}{*}{$\begin{array}{l}\text { Slope descent and } \\
\text { ascent } \\
(10 \mathrm{~m})\end{array}$} & Walk up and down a slope (length $5 \mathrm{~m}$; height $0.3 \mathrm{~m}$ ). \\
\hline & & normal walking. \\
\hline & & "Moderate": walking while holding a plastic cup of water. \\
\hline & & "Difficult": walking while holding an empty box. \\
\hline
\end{tabular}


Table II. Description of subset B of the Assessment of Daily Activity Performance in Transfemoral amputees test circuit stations used in study 2

Subset B Circuit station Task description

\begin{tabular}{|c|c|c|}
\hline \multirow{3}{*}{10} & \multirow{3}{*}{$\begin{array}{l}\text { Slope descent and } \\
\text { ascent }(72 \mathrm{~m})\end{array}$} & Walk up and down a slope twice (length $18 \mathrm{~m}$; height $2.2 \mathrm{~m}$ ) \\
\hline & & normal walking \\
\hline & & "Moderate": walking combined with a cognitive dual task \\
\hline 11 & Theatre & $\begin{array}{l}\text { Walk sideways between two rows of chairs while holding a cup of } \\
\text { water. Sit down at the last chair, stand up and walk back to the } \\
\text { start/finish line. }\end{array}$ \\
\hline 12 & Slalom (32 m) & $\begin{array}{l}\text { Slalom (approximately } 32 \mathrm{~m} \text { ) while holding a serving tray with } 10 \\
\text { tennis balls. }\end{array}$ \\
\hline 13 & Bedroom & $\begin{array}{l}\text { Sit down on the bed. Take off the prosthesis and lie down; } \\
\text { When on the bed, put on the prosthesis and go to the toilet in the } \\
\text { bathroom (distance: } 15 \mathrm{~m} \text { ); } \\
\text { Strip the bed (eiderdown cover, pillowcase and fitted sheet). }\end{array}$ \\
\hline 14 & Hanging out laundry & $\begin{array}{l}\text { Pick up the towels one by one ( } 8 \text { in total) from a tray on the ground } \\
\text { together with two pins and hang them on the clothes line. The } \\
\text { (adjustable) clothes line is set at wrist level when arms are fully } \\
\text { extended and raised above the head. }\end{array}$ \\
\hline 15 & $\begin{array}{l}\text { Picking up objects } \\
\text { from the floor }\end{array}$ & $\begin{array}{l}\text { Different objects from varying sizes and weight have to be picked up } \\
\text { and moved to their designated locations. }\end{array}$ \\
\hline 16 & Obstacle avoidance & $\begin{array}{l}\text { Walk across a living room and avoid all the obstacles (e.g. toys) on } \\
\text { the ground. }\end{array}$ \\
\hline 17 & $\begin{array}{l}\text { Sitting down and } \\
\text { standing up from the } \\
\text { floor }\end{array}$ & Sit down on the floor and stand up again. \\
\hline 18 & $\begin{array}{l}\text { Dressing and changing } \\
\text { clothes }\end{array}$ & Put on a pair of rain proof trousers and a raincoat. \\
\hline
\end{tabular}

were replaced on the tray by the researcher without interfering in the participant's test performance. This was done to prevent participants from not being able to finish this circuit station.

All participants were selected from the patient database of the Amputation and Traumatology Department of Adelante Rehabilitation Centre. This included patients from the southern regions of The Netherlands and adjacent regions in Belgium and Germany. A total of more than 100 eligible persons were invited to participate in the studies. A group of 20 participants agreed to participate in study 1 and another 20 participants participated in study 2. All participants completed the tests according to the study protocol. The main reasons for not participating were that the travelling distance was too long, that individuals were not able to take a day off work, or that they had no interest in participating in the study. 


\section{CHAPTER 3}

Approval for both studies was obtained from the medical ethics committee of the Rehabilitation Foundation Limburg, Hoensbroek, The Netherlands. Written informed consent was obtained from all subjects prior to their participation.

\section{Study 1}

The aim of study 1 was to test the concept of an ADAPT test, using subset A, in terms of the ability to differentiate between the levels of functional performance of different groups of users of leg prostheses, i.e. people using a leg prosthesis featuring a knee joint with a microprocessor-controlled stance and swing phase and people using a leg prosthesis featuring a mechanically controlled knee joint. It does not aim to prove that a microprocessor-controlled knee joint is advantageous or detrimental compared with a mechanically controlled knee joint.

\section{Participants}

Inclusion criteria for study 1 were: age 18-75 years; use of upper leg prosthesis; completion of the rehabilitation programme; ability to walk at least $500 \mathrm{~m}$. Exclusion criteria were: severe orthopaedic, rheumatologic, neurological or cardiovascular disease that might impede performance; severe perceptual or cognitive disorders; and skin problems of the stump.

Twenty men and women with a unilateral transfemoral amputation participated. They were divided into 2 groups based on the prosthesis they were wearing. One group consisted of 10 persons wearing a prosthesis featuring a microprocessor stance and swing phase controlled knee joint (C-leg (Otto Bock, Vienna, Austria)) (C-group).

The second group consisted of 10 persons wearing a prosthesis featuring a mechanically controlled knee joint (3R80, 3R72 (Otto Bock, Vienna, Austria), Safe Life (Proteval, Valenton, France), Ultimate (Ortho Europe, Oxfordshire, UK), Total Knee (Össur, Reykjavik, Iceland) and Graph-Lite (Teh Lin Prosthetic and Orthopaedics, Kuala Lumpur, Malaysia)) (M-group).

Both groups had comparable functional performance levels and differed only as to the type of knee joint they were using.

\section{Measurements}

All participants completed circuit stations 1-9 (see Table I). For each of the different activities the performance time was recorded using a stopwatch. 


\section{Data analysis}

The performance times on the different circuit stations were analysed using MannWhitney $U$ tests. All statistical analyses were performed using SPSS 14 (SPSS Inc., Houston, Texas, USA).

\section{Study 2}

The aim of study 2 was to evaluate the concept of an ADAPT test in terms of its test-retest reliability, using the activities from subset $B$.

\section{Participants}

Twenty men and women (different from study 1 ) participated in study 2 . The following inclusion criteria had to be met: unilateral transfemoral amputation; age 18-75 years; use of an upper leg prosthesis; completion of the rehabilitation programme; and the ability to walk at least $500 \mathrm{~m}$. Exclusion criteria were: severe orthopaedic, rheumatological, neurological or cardiovascular diseases that might impede performance; perceptual or cognitive disorders; skin problems of the stump; and the use of a manual locking knee.

\section{Measurements}

Participants completed a subset of 9 circuit stations (subset B), i.e. stations 10 through 18 (Table II). After a 1-hour resting period these circuit stations were repeated. Performance time was recorded for all activities of the different circuit stations using a stopwatch. All participants also completed the LCl questionnaire ${ }^{8,13}$.

\section{Data analysis}

Test-retest reliability was determined using Bland-Altman analyses ${ }^{14}$ and by calculating Pearson's correlation coefficients ( $r$ ) between the performance time of the first and second measurement. Analyses were performed using SPSS 14 (SPSS Inc., Houston, Texas, USA).

Table III. Composition of M-group and C-group in study 1

\begin{tabular}{lccccccc}
$\begin{array}{l}\text { Prosthesis } \\
\text { type }\end{array}$ & \multicolumn{2}{c}{ Gender $(n)$} & Age (years) & $\begin{array}{c}\text { Post-amputation } \\
\text { time (years) }\end{array}$ & \multicolumn{2}{c}{ Cause of amputation $(n)$} \\
\hline Male & Female & Mean (SD) & Mean (SD) & Trauma & Vascular & Cancer \\
\hline C-group & 9 & 1 & $52.6(14.3)$ & $14.0(12.0)$ & 5 & 4 & 1 \\
\hline
\end{tabular}

M-group: mechanically controlled knee joint group; C-group: microprocessor-controlled knee joint group; SD: standard deviation 


\section{CHAPTER 3}

\subsection{Results}

Study 1

\section{Participants}

In total 20 participants with either a microprocessor-controlled knee joint (C-group) or a mechanically controlled knee joint (M-group) were included in study 1 . All participants were experienced users of their leg prosthesis and had used the type of knee joint that was assessed for a long period of time. There was no significant difference between the two groups concerning age and post-amputation time. An overview of the composition of both groups is given in Table III.

Table IV. Mean performance time (in s), standard deviation (SD) and median values of 9 circuit stations (study 1)

\begin{tabular}{|c|c|c|c|c|c|c|c|}
\hline & \multirow[b]{2}{*}{ Circuit station } & \multirow[b]{2}{*}{$\begin{array}{l}\text { Level of } \\
\text { difficulty }\end{array}$} & \multicolumn{2}{|c|}{ M-group } & \multicolumn{2}{|c|}{ C-group } & \multirow[b]{2}{*}{ p-value } \\
\hline & & & Mean (SD) & Median & Mean (SD) & Median & \\
\hline \multirow{3}{*}{1} & \multirow{3}{*}{ Supermarket } & "e" & $108.4(29.4)$ & 99.5 & $79.7(11.5)$ & 79.5 & $0.007^{*}$ \\
\hline & & "m" & $41.3(14.2)$ & 37.0 & $30.3(4.6)$ & 30.0 & $0.041^{*}$ \\
\hline & & "d" & $26.4(5.5)$ & 26.0 & $24.1(5.7)$ & 22.5 & 0.328 \\
\hline 2 & Shopping bags & & $130.9(45.7)$ & 123.5 & $91.7(12.6)$ & 89.0 & $0.011 *$ \\
\hline \multirow{2}{*}{3} & \multirow{2}{*}{ Kitchen cabinets } & “e” & $97.4(46.6)$ & 95.0 & $70.1(10.4)$ & 70.0 & $0.041^{*}$ \\
\hline & & "d" & $57.6(4.5)$ & 58.5 & $39.4(9.8)$ & 39.0 & $0.016^{*}$ \\
\hline \multirow{3}{*}{4} & \multirow{3}{*}{$\begin{array}{l}\text { Unloading low kitchen } \\
\text { cabinets }\end{array}$} & "e" & $15.0(5.2)$ & 14.5 & $12.1(2.8)$ & 12.5 & 0.236 \\
\hline & & "m" & $19.6(6.7)$ & 18.0 & $16.1(4.9)$ & 13.5 & 0.110 \\
\hline & & "d" & $30.0(13.4)$ & 28.0 & $24.5(8.7)$ & 22.5 & 0.250 \\
\hline 5 & Slalom (13 m) & & $36.9(12.7)$ & 30.0 & $31.1(7.5)$ & 30.0 & 0.385 \\
\hline \multirow{3}{*}{6} & \multirow{3}{*}{ Get the remote control } & "e" & $23.0(11.9)$ & 18.5 & $15.3(1.9)$ & 15.0 & $0.018^{*}$ \\
\hline & & "m" & $18.7(5.8)$ & 16.0 & $14.1(2.4)$ & 14.0 & 0.063 \\
\hline & & "d" & $29.6(23.6)$ & 20.5 & $17.9(5.3)$ & 16.5 & 0.067 \\
\hline 7 & Car & & $92.7(45.3)$ & 77.0 & $58.8(10.4)$ & 56.5 & $0.017^{*}$ \\
\hline \multirow{3}{*}{8} & \multirow{3}{*}{ Stairs descent } & "e" & $31.3(12.8)$ & 28.5 & $18.4(5.9)$ & 16.5 & $0.012 *$ \\
\hline & & "m" & $32.6(13.9)$ & 29.0 & $22.8(7.0)$ & 23.5 & 0.086 \\
\hline & & "d" & $36.5(15.3)$ & 33.0 & $26.0(2.6)$ & 25.5 & 0.201 \\
\hline \multirow{3}{*}{9} & \multirow{3}{*}{$\begin{array}{l}\text { Slope descent and } \\
\text { ascent }(10 \mathrm{~m})\end{array}$} & “e” & $15.6(5.2)$ & 13.5 & $13.1(2.6)$ & 12.5 & 0.225 \\
\hline & & "m" & $16.3(5.2)$ & 14.5 & $13.7(3.0)$ & 13.0 & 0.226 \\
\hline & & "d" & $15.0(2.3)$ & 14.5 & $13.9(3.6)$ & 12.0 & 0.293 \\
\hline
\end{tabular}

" $e$ ": easy; " $m$ ": moderate; "d": difficult; * statistically significant 


\section{Performance times on the ADAPT test}

An overview of the performance times for both the C-group and the M-group on circuit stations $1-9$ is given in Table IV.

All activities of the circuit stations 1-9 were performed faster by the C-group than the M-group. Filling a shopping trolley in the supermarket (activity 1: easy and moderate level), filling shopping bags (activity 2), putting items in the designated kitchen cabinets (activity 3), sitting down and rising from a low chair (activity 6: easy level), getting in and out of a car (activity 7) and walking down the stairs (activity 8: easy level) were performed significantly faster by the C-group in contrast to the $\mathrm{M}$-group. The performance times on the other circuit stations were also shorter for the C-group compared with the M-group, but these differences did not attain statistical significance.

The mean differences in performance times of the C-group relative to the M-group on the different circuit stations are shown in Figure 1. The mean performance times for all activities of the $\mathrm{M}$-group are used as reference values (set at $0 \%$ ). The vertical bars represent the relative differences in performance time between the C-group and the M-group (1-(PT Microprocessor $_{\text {PT }}$ Pechanical $)$ x 100\%). For example, the activity Supermarket " $e$ ", is performed $26.5 \%$ faster by the C-group compared with the M-group. The C-group is faster on every activity of this test ranging from $7 \%$ to $41 \%$ compared with the M-group.

Figure 1. Mean relative differences in performance time (\%) of the group with a microprocessorcontrolled knee joint (C-group) compared with the group with a mechanically controlled knee joint (M-group) (study 1 )

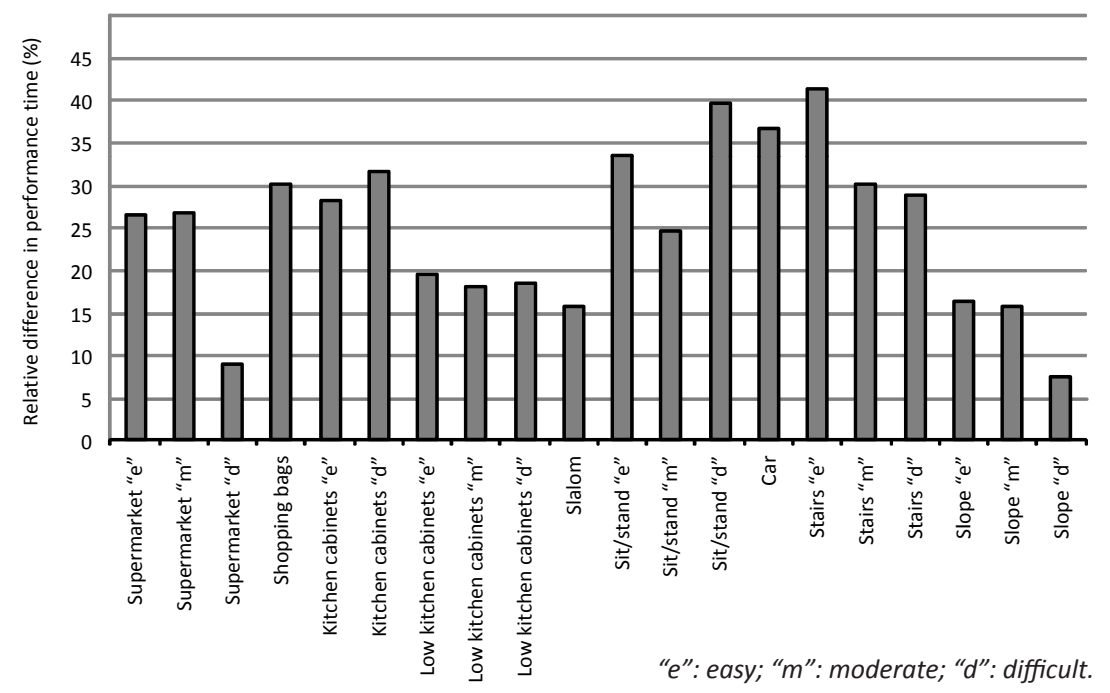




\section{CHAPTER 3}

\section{Study 2}

\section{Participants}

Study 2 included 20 participants. An overview of the group composition is shown in Table V.

Table V. Group composition in study 2

\begin{tabular}{ccccccc}
\multicolumn{2}{c}{ Gender $(n)$} & $\begin{array}{c}\text { Age } \\
\text { (years) }\end{array}$ & $\begin{array}{c}\text { Post-amputation } \\
\text { time (years) }\end{array}$ & \multicolumn{2}{c}{ Cause of amputation $(n)$} \\
\hline Male & Female & Mean (SD) & Mean (SD) & Trauma & Vascular & Cancer \\
\hline 18 & 2 & $50.3(10.7)$ & $15.6(12.3)$ & 12 & 6 & 2 \\
\hline
\end{tabular}

SD: standard deviation

\section{Test-retest reliability}

Participants performed activities 10-18 twice. Mean performance times for both the first and second attempt on these activities are shown in Table VI. Mean differences in performance time between the first and second measurement $(\Delta \mathrm{PT})$ varied between +0.7 and $+11.0 \mathrm{sec}$, depending on the total duration of the circuit station involved.

All correlation coefficients (Pearson's $r$ ) exceeded 0.80 , except for activity $13 c(r=0.69)$. In $75 \%$ of all circuit stations Pearson's $r$ was $\geq 0.90$.

The mean difference in performance time between measurement 1 and 2 was assessed using the Bland-Altman procedure ${ }^{14}$. Figure 2 shows a typical example of a BlandAltman plot. The mean performance times of measurements 1 and 2 for this specific circuit station activity are plotted against the differences in performance times of the two measurements for all participants. Results from the Bland-Altman analyses showed no specific trend between mean time scores on the one hand and test-retest differences in time scores on the other hand.

\section{$\angle C I$ vs ADAPT}

The $\mathrm{LCl}$ values of all participants are represented in Table VII.

It should be noted that in $70 \%$ of all cases $\mathrm{LCl}$ values were maximal, indicating a ceiling effect. On the other hand, the scores on this second test version of ADAPT did not show such effects, i.e. between-subject variation was still observed in ADAPT scores of those 14 participants that scored maximal on the $\mathrm{LCl}$. This is supported by the calculated Coefficient of Variation values (CV) of all ADAPT test circuit stations for the subgroup of these 14 participants. The CV is a normalized measure of dispersion, defined as the ratio 
Table VI. Mean performance times for all circuit stations for both measurements (study 2)

\begin{tabular}{|c|c|c|c|c|c|c|}
\hline & \multicolumn{2}{|c|}{ Circuit station } & \multirow{2}{*}{$\begin{array}{c}\text { Measurement } 1 \\
\text { Mean PT (SD) }\end{array}$} & \multirow{2}{*}{$\begin{array}{r}\text { Measurement } 2 \\
\text { Mean PT (SD) }\end{array}$} & \multirow{2}{*}{$\frac{\Delta \mathrm{PT}}{\text { Mean (SD) }}$} & \multirow[t]{2}{*}{ Pearson's } \\
\hline & & & & & & \\
\hline \multirow{2}{*}{10} & \multirow{2}{*}{$\begin{array}{l}\text { Slope descent and } \\
\text { ascent }(72 \mathrm{~m})\end{array}$} & "Easy" & $91.1(20.5)$ & $88.6(21.4)$ & $2.5(11.2)$ & 0.96 \\
\hline & & "Moderate" & $92.3(19.8)$ & $89.4(18.8)$ & $2.9(13.1)$ & 0.94 \\
\hline 11 & \multicolumn{2}{|l|}{ Theatre } & $47.1(10.6)$ & $40.5(8.1)$ & $6.5(9.2)$ & 0.91 \\
\hline 12 & \multicolumn{2}{|l|}{ Slalom (32 m) } & $86.6(16.7)$ & $80.6(13.6)$ & $6.0(15.0)$ & 0.90 \\
\hline $13 a$ & \multicolumn{2}{|c|}{ a Bedroom - taking off prosthesis } & $36.3(10.3)$ & $33.2(9.7)$ & $3.0(10.0)$ & 0.88 \\
\hline $13 b$ & \multicolumn{2}{|c|}{$\begin{array}{l}\text { Bedroom - putting on prosthesis } \\
\text { + going to toilet }\end{array}$} & $122.9(38.4)$ & $116.4(29.3)$ & $6.5(29.0)$ & 0.94 \\
\hline $13 c$ & \multicolumn{2}{|c|}{ Bedroom - stripping the bed } & $36.1(11.8)$ & $31.1(6.8)$ & $5.0(17.3)$ & 0.69 \\
\hline 14 & \multicolumn{2}{|l|}{ Hanging out laundry } & $127.0(23.2)$ & $116.0(20.2)$ & $11.0(18.9)$ & 0.91 \\
\hline 15 & \multicolumn{2}{|c|}{ Picking up objects from the floor } & $124.0(20.1)$ & $117.7(19.0)$ & $6.3(23.7)$ & 0.82 \\
\hline 16 & \multicolumn{2}{|l|}{ Obstacle avoidance } & $84.2(19.5)$ & $77.6(16.3)$ & $6.6(13.1)$ & 0.95 \\
\hline 17 & \multicolumn{2}{|c|}{$\begin{array}{l}\text { Sitting down and standing up } \\
\text { from the floor }\end{array}$} & $8.6(3.3)$ & $7.9(3.0)$ & $0.7(2.0)$ & 0.95 \\
\hline 18 & \multicolumn{2}{|c|}{ Dressing and changing clothes } & $92.9(38.0)$ & $90.7(36.8)$ & $2.2(26.1)$ & 0.94 \\
\hline
\end{tabular}

PT: performance time (s); $\triangle P T$ : difference in performance time between measurement 1 and measurement 2 (s); SD: standard deviation(s); Pearson's r: correlation coefficient.

Figure 2. Typical example of a Bland-Altman plot for the activity slalom (32 m) (study 2)

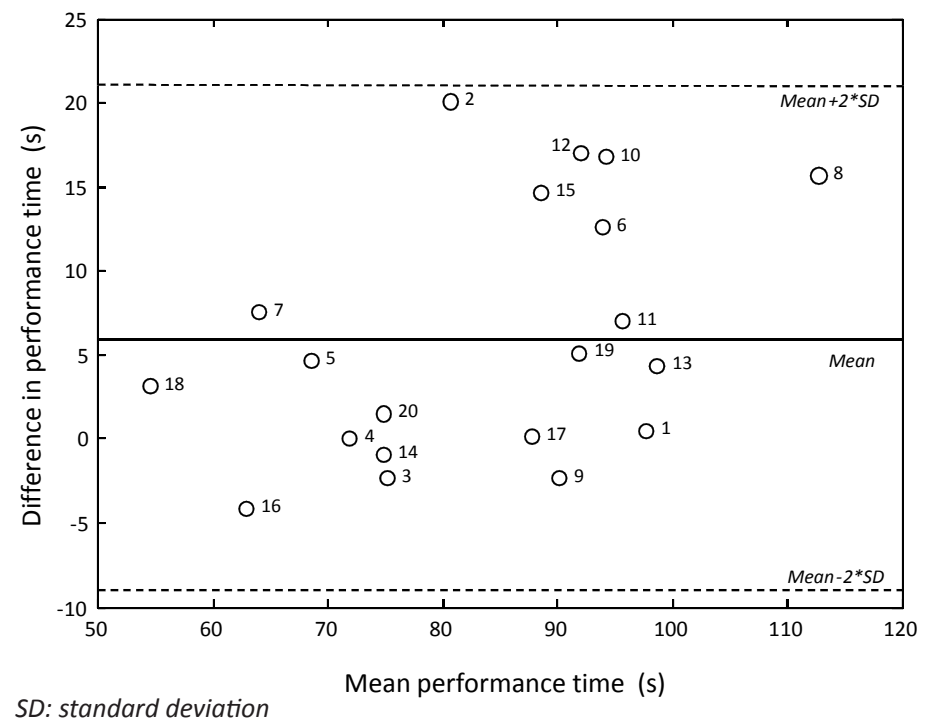




\section{CHAPTER 3}

Table VII. Frequency of Locomotor Capabilities Index scores for all participants in study 2

\begin{tabular}{lcccccccc} 
LCl score & $<36$ & 36 & 37 & 38 & 39 & 40 & 41 & 42 \\
\hline Frequency (\#) & 0 & 3 & 0 & 0 & 1 & 1 & 1 & 14 \\
\hline
\end{tabular}

Figure 3. Typical example of circuit station (Theatre) scores vs Locomotor Capabilities Index scores (study 2)

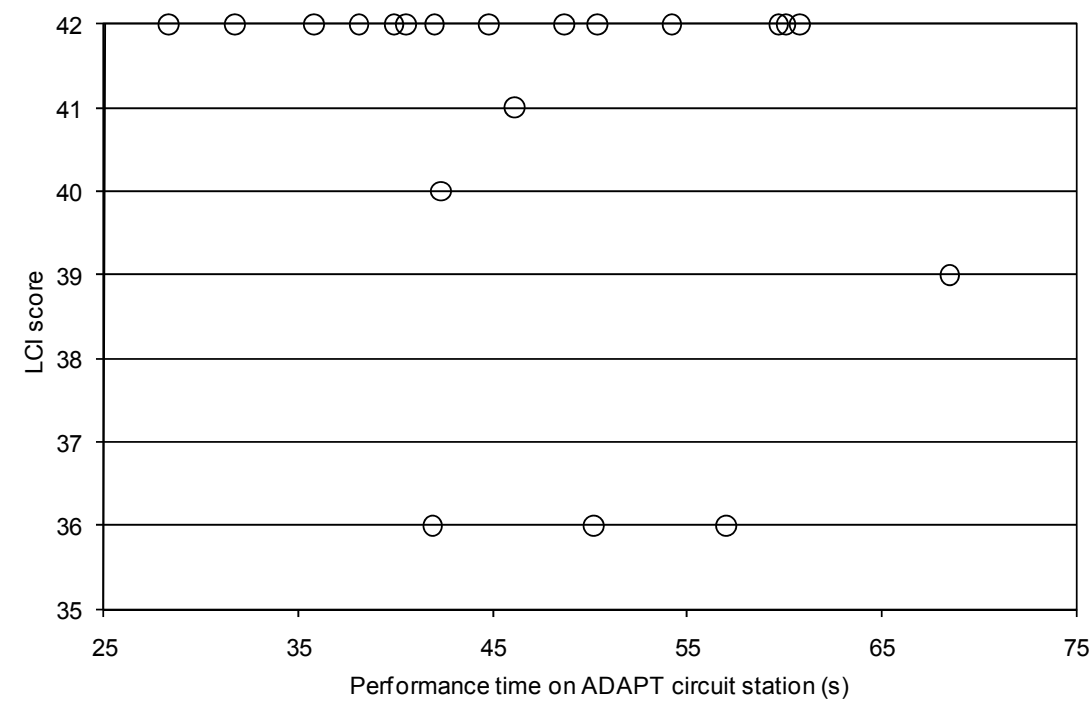

of the standard deviation to the mean $(\sigma / \mu)$. The CV values range from 0.14 to 0.47 for ADAPT, whereas no variation was present in the $\mathrm{LCl}$ for those participants. A typical example of the difference between the LCl scores and the scores on one circuit station is given in Figure 3. The performance times (s) on circuit station "theatre" are plotted against the $\mathrm{LCl}$ scores for all participants.

\subsection{Discussion}

This study evaluated the feasibility of implementing a new concept into a measuring tool to objectively assess functional abilities of transfemoral amputees in daily life performance. The goal was to establish 'proof of principle' of a measuring tool based on this new concept by using two separate consecutive studies in which two important requirements were evaluated, i.e. ability to differentiate between functional performance levels (sensitivity) and the level of reproducibility (test-retest reliability). In each of these two studies a different test version of the ADAPT test was evaluated. 
Study 1 was performed to assess whether the ADAPT concept could detect differences in functional performance levels due to the use of different prosthetic components. The choice to compare mechanically controlled knee joints with microprocessorcontrolled knee joints was made based on the findings of a study by Hafner et al. ${ }^{1}$. They reported advantageous effects of microprocessor-controlled knee joints on functional performance levels during stairs descent, hill descent and obstacle course performance. Moreover, other studies show benefits from using a microprocessorcontrolled knee joint at function level, e.g. positive influence on gait parameters ${ }^{6,7}$, energy consumption ${ }^{15,16}$, stability and balance-related aspects ${ }^{6,17}$ and cognitive load ${ }^{18}$. The results of study 1 showed clear differences in functional performance levels between the group of microprocessor-controlled knee joint users (C-group) compared with the group of mechanically controlled knee joint users (M-group) in favour of the C-group. Statistical testing indicated no significant difference between both groups regarding age and post-amputation time. The ratio between men and women slightly differed between the M-group and the C-group. However, no studies have been found that indicate gender being a factor for performance differences in persons using a leg prosthesis.

The slightly higher number of amputees due to vascular causes in the M-group might also have led, to a certain extent, to the observed differences in performance level between both groups because of the decreased physical fitness of dysvascular patients. The test version of the ADAPT test, consisting of subset A circuit stations, was able to detect differences in functional performance between the two groups of prosthesis users.

Study 1 led to increased insight regarding the design of the circuit stations. Two main factors proved to be important in developing ADAPT test circuit stations. First, a circuit station activity should represent a real-life situation of adequate duration. Including circuit stations of short duration would inevitably lead to larger variances regarding performance time measurements when performing the test multiple times. Secondly, when developing a circuit station it should be taken into account that the number of different ways in which a participant can accomplish the activity is as small as possible. This reduces the level of variance and thus increases the quality of the test. Based on this knowledge some existing circuit stations from subset $A$ were modified and were added to a new set of circuit stations to constitute subset B used in study 2 .

In study 2 the aim was to assess the level of reproducibility of the ADAPT concept. Strong correlations (Pearson's $r$ ) in combination with high levels of agreement (Bland- 


\section{CHAPTER 3}

Altman plots) between the first and second test results for all circuit stations were found. Furthermore, small differences in performance time were seen between the two attempts on this second test version of the ADAPT test. These differences are probably not the result of a definite training effect, since the circuit stations consist of common daily activities. Therefore, these activities have been 'trained' many times before participating in the study. Performance is therefore not expected to improve after only 1 hour. The observed differences will probably be the result of familiarization of the measuring protocol. This effect might be avoided by giving the participant more time to become acquainted with the circumstances of the test by, for instance, introducing a test run prior to the actual measurement. In general, results indicate that the reliability of this version of the ADAPT test is very good.

Evaluation of functional abilities necessary to perform basic or advanced common daily activities is also the goal of the $\mathrm{LCl}^{19}$. To place the ADAPT test results in a broader perspective, they were compared with the $\mathrm{LCl}$ scores. However, $\mathrm{LCl}$ scores were maximal in $70 \%$ of the participants, indicating a ceiling effect. In contrast, the ADAPT test results showed clear differences per circuit station, even in those patients in which the $\mathrm{LCl}$ score was maximal. The $\mathrm{LCl}$ ceiling effect has already been reported by Miller et al. ${ }^{20}$. They stated that, because of the ceiling effect found for the $\mathrm{LCl}$, no change can be observed in higher functioning prosthesis users. They suggest the $\mathrm{LCl}$ is more appropriate for a less active group of amputees with multiple co-morbidities. Franchignoni et al. ${ }^{21}$ imply that the $\mathrm{LCl}$ is suitable to detect differences in locomotor capabilities between persons of different amputation levels, e.g. between transfemoral and trans-tibial amputees. The findings of the studies of Miller et al. ${ }^{20}$ and Franchignoni et al. ${ }^{21}$ further emphasize the need for a test capable to better differentiating between different levels of functional performance. Our findings show that the ADAPT test, in contrast to the $\mathrm{LCl}$, may be more sensitive to small differences and, furthermore, may detect differences within a particular performance domain.

The results of this study indicate that it is feasible to objectively measure functional abilities in daily life in transfemoral amputees using the concept of simulated daily life situations. It is now possible to develop a final version of the ADAPT test, knowing that the concept has proven to be reliable and sensitive to small changes. This final version should encompass a selection of circuit stations tested in this study, which indicated small levels of variance and a high capacity to distinguish between performance levels. Based on these characteristics, recommendations for circuit stations that should be included 
in the final ADAPT test are: supermarket shopping (activities 1 and 2), unloading of the shopping bags into the kitchen cabinets (activity 3 ), fetching the remote control (activity 6), getting into and out of a car (activity 7), negotiating stairs (activity 8) and the long slope (activity 10), going to the theatre (activity 11), picking up and hanging out laundry (activity 14) and avoiding obstacles in the living room (activity 16). Further research is necessary to establish the psychometric properties of the final ADAPT test.

The practical aspects of using an ADAPT test are considered to be clinically feasible. Conducting the test took approximately 45 minutes including resting periods and the time to explain the tasks. An area of approximately $150 \mathrm{~m}^{2}$ is necessary to set up all (indoor) circuit stations.

Currently, decision-making in prosthesis indication in The Netherlands is based mainly on the experience and empirical knowledge of the technical team, consisting of the prosthetist, the rehabilitation physician and the physical therapist ${ }^{22}$. The ADAPT test may assist in this process by generating an individual patient profile showing the performance levels on a selected set of different daily life activities. Such an overview can consist of relative differences in performance level between, for instance, two (or more) trial prostheses (analogous to Figure 1) used by a patient prior to final indication. Applying this 'try-out' approach may provide valuable additional information as to the possible benefit (or, in some cases, detriment) of the use of different types of prosthetic knee joints during certain daily life activities. It may therefore be used, in conjunction with other clinical measures, to make a well-founded, client-specific decision about the choice for a prosthesis in upper leg amputees. Although the use of prosthesis components for trial purposes is not currently possible in many countries, the process of providing the most suitable prosthesis to a patient may further improve if trial fitting could become part of the prescription process. In addition, results of the ADAPT concept provide objective data that may be used in the dialogue between healthcare providers, patients and health insurance companies in, for example, the reimbursement process for a prosthesis.

An important aspect of the ADAPT test is that it measures at a level that is relevant to the patient. The included activities are relevant to the subjects because they are performed on a daily basis. Often, patients report mainly being interested in what they eventually can do with his prosthesis in everyday life and that they are focused on returning to their former social roles. 
The ADAPT test concept might also be used to evaluate different target populations, including, for example, stroke patients. For each target population, adaptations on the existing ADAPT test circuit stations should be considered, because every group of patients has its own specific functional problems (e.g. walking, arm/hand skills or balance). Further research is necessary to expand the number and type of daily activities in the test in order to best suit each target population. Furthermore, a future goal is to create a set of validated circuit stations from which those activities can be chosen that best fit the individual needs of a patient in his home environment. Consequently, a unique test can be created for each individual that focuses on aspects of daily functioning that are perceived to be most important to that patient. It is this concept that has been tested in the current study.

\subsection{Acknowledgements}

The authors would like to thank Peter Schraven and Sven Balk of Adelante Rehabilitation Centre, Hoensbroek, The Netherlands and Frans Rings of Livit Orthopedie, Hoensbroek, The Netherlands for their valuable contribution to this study. 


\subsection{References}

1. Hafner BJ, Willingham LL, Buell NC, Allyn KJ, Smith DG. Evaluation of function, performance, and preference as transfemoral amputees transition from mechanical to microprocessor control of the prosthetic knee. Arch Phys Med Rehabil 2007; 88:207-217.

2. Kaufman KR, Levine JA, Brey RH, McCrady SK, Padgett DJ, Joyner MJ. Energy expenditure and activity of transfemoral amputees using mechanical and microprocessor-controlled prosthetic knees. Arch Phys Med Rehabil 2008; 89:1380-1385.

3. Datta D, Heller B, Howitt J. A comparative evaluation of oxygen consumption and gait pattern in amputees using Intelligent Prostheses and conventionally damped knee swing-phase control. Clin Rehabil 2005; 19:398-403.

4. Heller BW, Datta D, Howitt J. A pilot study comparing the cognitive demand of walking for transfemoral amputees using the Intelligent Prosthesis with that using conventionally damped knees. Clin Rehabil 2000; 14:518-522.

5. Kastner J, Nimmervoll R, Wagner P. What are the benefits of the Otto Bock C-leg? A comparative gait analysis of C-leg, 3R45 and 3R80. Med Orth Tech 1999; 119:131-137.

6. Kaufman KR, Levine JA, Brey RH, Iverson BK, McCrady SK, Padgett DJ, et al. Gait and balance of transfemoral amputees using passive mechanical and microprocessor-controlled prosthetic knees. Gait Posture 2007; 26:489-493.

7. Segal AD, Orendurff MS, Klute GK, McDowell ML, Pecoraro JA, Shofer J, et al. Kinematic and kinetic comparisons of transfemoral amputee gait using C-Leg and Mauch SNS prosthetic knees. J Rehabil Res Dev 2006; 43:857-870.

8. Gauthier-Gagnon C, Grise MC. The locomotor capabilities index: content validity. J Rehabil Outcomes Meas 1998; 2:40-46.

9. Callaghan BG, Sockalingam S, Treweek SP, Condie ME. A post-discharge functional outcome measure for lower limb amputees: test-retest reliability with trans-tibial amputees. Prosthet Orthot Int 2002; 26:113-119.

10. Ryall NH, Eyres SB, Neumann VC, Bhakta BB, Tennant A. The SIGAM mobility grades: a new population-specific measure for lower limb amputees. Disabil Rehabil 2003; 25:833-844.

11. Rommers GM, Ryall NH, Kap A, De Laat F, Van der Linde H. The mobility scale for lower limb amputees: the SIGAM/WAP mobility scale. Disabil Rehabil 2008; 30:1106-1115.

12. Gailey RS, Roach KE, Applegate EB, Cho B, Cunniffe B, Licht S, et al. The amputee mobility predictor: an instrument to assess determinants of the lower-limb amputee's ability to ambulate. Arch Phys Med Rehabil 2002; 83:613-627.

13. Grise MC, Gauthier-Gagnon C, Martineau GG. Prosthetic profile of people with lower extremity amputation: conception and design of a follow-up questionnaire. Arch Phys Med Rehabil 1993; 74:862-870. 


\section{CHAPTER 3}

14. Bland JM, Altman DG. Statistical methods for assessing agreement between two methods of clinical measurement. The Lancet 1986; 327:283-338.

15. Orendurff MS, Segal AD, Klute GK, McDowell ML, Pecoraro JA, Czerniecki JM. Gait efficiency using the C-Leg. J Rehabil Res Dev 2006; 43:239-246.

16. Seymour R, Engbretson B, Kott K, Ordway N, Brooks G, Crannell J, et al. Comparison between the C-leg microprocessor-controlled prosthetic knee and non-microprocessor control prosthetic knees: a preliminary study of energy expenditure, obstacle course performance, and quality of life survey. Prosthet Orthot Int 2007; 31:51-61.

17. Kahle JT, Highsmith MJ, Hubbard SL. Comparison of nonmicroprocessor knee mechanism versus C-Leg on Prosthesis Evaluation Questionnaire, stumbles, falls, walking tests, stair descent, and knee preference. J Rehabil Res Dev 2008; 45:1-14.

18. Williams RM, Turner AP, Orendurff $M$, Segal AD, Klute GK, Pecoraro J, et al. Does having a computerized prosthetic knee influence cognitive performance during amputee walking? Arch Phys Med Rehabil 2006; 87:989-994.

19. Gauthier-Gagnon C, Grisé M-C, Potvin D. Enabling factors related to prosthetic use by people with transtibial and transfemoral amputation. Arch Phys Med Rehabil 1999; 80:706-713.

20. Miller WC, Deathe AB, Speechley M. Lower extremity prosthetic mobility: a comparison of 3 selfreport scales. Arch Phys Med Rehabil 2001; 82:1432-1440.

21. Franchignoni F, Orlandini D, Ferriero G, Moscato TA. Reliability, validity, and responsiveness of the locomotor capabilities index in adults with lower-limb amputation undergoing prosthetic training. Arch Phys Med Rehabil 2004; 85:743-748.

22. van der Linde H, Geertzen JHB, Hofstad CJ, van Limbeek J, Postema K. Prosthetic prescription in the Netherlands: An observational study. Prosthet Orthot Int 2003; 27:170-178. 



$$
\operatorname{tin}
$$




\section{Chapter 4}

Functional added value of microprocessor-controlled prosthetic knee joints in daily life performance of Medicare functional classification level-2 amputees

P.J.R. Theeven, B. Hemmen, F. Rings, G. Meys, P.R.G. Brink, R.J.E.M. Smeets, H.A.M. Seelen / Rehabil Med 2011; 43:906-915

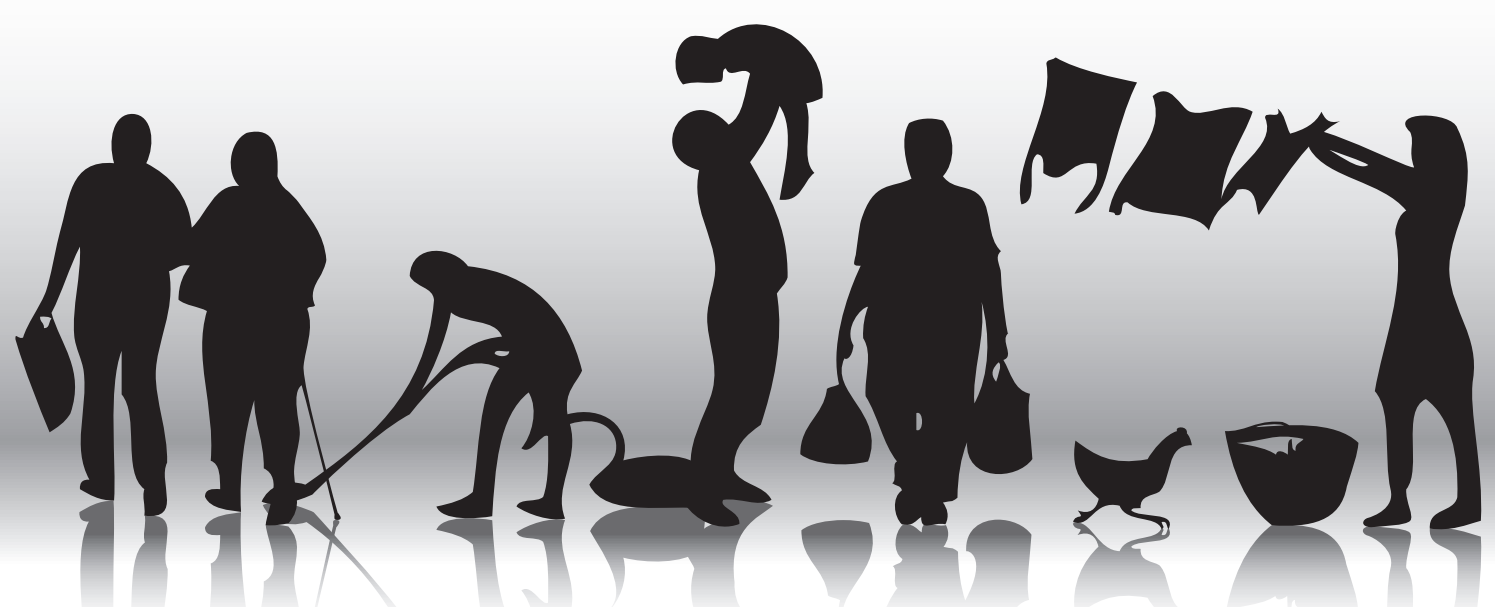




\section{Abstract}

Objective: To assess the effects of using a microprocessor-controlled prosthetic knee joint on the functional performance of activities of daily living in persons with an aboveknee leg amputation.

Design: Randomised cross-over trial.

Subjects: Forty-one persons with unilateral above-knee or knee disarticulation limb loss, classified as Medicare Functional Classification Level-2 (MFCL-2).

Methods: Participants were measured in 3 conditions, i.e. using a mechanically controlled knee joint and two types of microprocessor-controlled prosthetic knee joints. Functional performance level was assessed using a test in which participants performed 17 simulated activities of daily living (Assessment of Daily Activity Performance in Transfemoral amputees test). Performance time was measured and self-perceived level of difficulty was scored on a visual analogue scale for each activity.

Results: High levels of within-group variability in functional performance obscured detection of any effects of using a microprocessor-controlled prosthetic knee joint. Data analysis after stratification of the participants into 3 subgroups, i.e. participants with a 'low', 'intermediate' and 'high' functional mobility level, showed that the two higher functional subgroups performed significantly faster using microprocessor-controlled prosthetic knee joints.

Conclusion: MFCL-2 amputees constitute a heterogeneous patient group with large variation in functional performance levels. A substantial part of this group seems to benefit from using a microprocessor-controlled prosthetic knee joint when performing activities of daily living. 


\subsection{Introduction}

The introduction of increasingly expensive prosthetic components, such as microprocessorcontrolled prosthetic knee joints (MPKs), has led to greater demands for rehabilitation physicians and their teams to comprehensively justify prosthesis prescription to both health insurance companies and patients. Consequently, in-depth knowledge about the specific characteristics of MPKs and their potential effects on the patient's functioning is essential. The effects of different types of MPKs on the gait of amputees have been tested extensively, often focusing on the International Classification of Functioning, Disability and Health (ICF) level of 'body functions and structures' ${ }^{1}$, e.g. walking velocity, balance, energy consumption, cognitive load and gait symmetry ${ }^{2-7}$. Although important, it is also necessary to assess the complex effects of the MPK at the ICF levels of activity and participation, e.g. assessing the effects on sitting down and standing up, climbing stairs, or going to the supermarket, because measures at these levels better relate to the patients' daily life.

Currently, the assessment at the ICF activity and participation levels is often performed by using (self-report) questionnaires, resulting in subjective information on perceived performance, possibly obscuring information on actual performance. Theeven et al. ${ }^{8}$ introduced a novel test concept called Assessment of Daily Activity Performance in Transfemoral amputees (ADAPT), in which participants perform a set of standardized simulated activities of daily living ( $A D L)$, which amputees have indicated as being difficult to carry out while using a leg prosthesis. Theeven et al. ${ }^{8}$ showed that it was feasible to reliably and objectively assess the functional abilities of transfemoral amputees in performing ADL with ADAPT.

Several classification systems exist to assign specific codes to an amputee patient based on their functional status. The Mobis ${ }^{\circledR}$ mobility grades (9) $\left(m^{\circ} 1\right.$ to $\left.m^{\circ} 4\right)$ and the Medicare Functional Classification Level (MFCL) index ${ }^{10}$ (MFCL-0 to MFCL-4) are well-known classification systems intended for this purpose. A description of the MFCL grades is shown in Table I.

Most types of MPK are prescribed and reimbursed to amputees with a high functional level, i.e. MFCL-3 and MFCL-4, because the possibilities that an MPK offers are believed to better suit their functional abilities and prosthesis-related demands. However, as persons classified as MFCL-2 have had little or no access to MPKs, the possible benefit for this group of amputees remains unclear, thereby potentially denying them a suitable solution 
to their ambulation-related needs. Compared with persons classified as MFCL-3 or 4, persons classified as MFCL-2 are typically older, have a lower activity level, have more comorbidities, have reduced muscle strength and coordination, and are more prone to falling.

Table I. Medicare Functional Classification Level (MFCL) descriptions

\begin{tabular}{|c|c|c|}
\hline $\begin{array}{c}\text { HCFA } \\
\text { Modifier }\end{array}$ & & MFCL description \\
\hline ко & MFLC-0 - & $\begin{array}{l}\text { Does not have the ability or potential to ambulate or transfer safely with } \\
\text { or without assistance and a prosthesis does not enhance quality of life or } \\
\text { mobility. }\end{array}$ \\
\hline K1 & MFLC-1 - & $\begin{array}{l}\text { Has the ability or potential to use a prosthesis for transfers or ambulation } \\
\text { on level surfaces at fixed cadence. Typical of the limited and unlimited } \\
\text { household ambulator. }\end{array}$ \\
\hline K2 & MFLC-2 - & $\begin{array}{l}\text { Has the ability or potential for ambulation with the ability to traverse low- } \\
\text { level environmental barriers such as curbs, stairs, or uneven surfaces. } \\
\text { Typical of the limited community ambulator. }\end{array}$ \\
\hline K3 & MFLC-3 - & $\begin{array}{l}\text { Has the ability or potential for ambulation with variable cadence. Typical of } \\
\text { the community ambulator who has the ability to traverse most } \\
\text { environmental barriers and may have vocational, therapeutic, or exercise } \\
\text { activity that demands prosthetic utilization beyond simple locomotion. }\end{array}$ \\
\hline K4 & MFLC-4 - & $\begin{array}{l}\text { Has the ability or potential for prosthetic ambulation that exceeds the } \\
\text { basic ambulation skills, exhibiting high impact, stress, or energy levels, } \\
\text { typical of the prosthetic demands of the child, active adult, or athlete. }\end{array}$ \\
\hline$A=$ & rapin & ncing Administration \\
\hline
\end{tabular}

In MFCL-3 and MFCL-4 amputees the use of a MPK has been shown to improve persons' ability to walk faster, to negotiate stairs and obstacles, to walk downhill, and to walk on uneven terrain. In addition, using a MPK seems to reduce the number of stumbles and falls $2,4,6,11$. It is hypothesised that those features of an MPK targeted at providing maximal safety and functionality may also improve the functioning of MFCL-2 amputees. This study aimed to assess the effects of using an MPK on the functional ability level of persons classified as MFCL-2 to perform common ADL.

Several limitations of the MFCL classification are reported in the literature and are important to the present study. A lack of objective tools to assess a person's functional performance has been reported to impact negatively on the accuracy of the MFCL grade assigned to that person ${ }^{12,13}$. Also, the broad definition of MFCL levels may lead to high levels of variability within each functional level ${ }^{14}$. The clinical experience of rehabilitation physicians, prosthetists, physical therapists and occupational therapists further confirms these observations, particularly within the MFCL-2 population. In comparison with the groups with higher functional levels, the MFCL-2 population is often considered to be a 
heterogeneous group in which comorbidities and peripheral vascular disease are more prevalent. This group may also include former MFCL-3 amputees who, due to age or other causes, were assigned a lower MFCL grade after their physical function deteriorated. Therefore, large within-group variance regarding the functional performance is expected. Such a finding would be relevant, because the presence of large within-group variance may impede the detection of possible effects of using an MPK if only select users within the broad MFCL-2 population experience benefits from using it. Therefore, a further aim of this study is to examine within-group differences in an effort to explore this potential phenomenon further.

\subsection{Methods}

\section{Participant recruitment}

Eligible participants were identified from rehabilitation centres, hospitals and local prosthetic and orthotic care centres in the southern region of The Netherlands and north-eastern region of Belgium. Participants were considered suitable for participation in the study if they had undergone a transfemoral amputation or knee disarticulation, were classified as MFCL-2, were over 18 years of age, used a leg prosthesis fitted with a mechanically controlled knee joint daily, had finished rehabilitation following their amputation for at least one year, were able to walk at least $500 \mathrm{~m}$, and had no previous experience using an MPK. Persons were excluded in case of severe orthopaedic, rheumatologic, neurological or cardiovascular disease, in addition to the amputation; severe perceptual or cognitive disorders; or momentary skin problems of the residual limb. Participants were enrolled over a 3-year period. Approval was obtained from the medical ethics committee of the Rehabilitation Foundation Limburg, Hoensbroek, The Netherlands. Written informed consent was obtained from all persons prior to their participation.

\section{Study design}

Figure 1 represents a schematic overview of the randomised crossover study design. Participants were tested in 3 different prosthetic knee joint conditions: (i) with their current mechanically controlled knee joint, i.e. 3R80, 3R106, 3R60, 3R92 (Otto Bock, Vienna, Austria), Acphapend (Proteval, Valenton, France), Ultimate (Ortho Europe, Oxfordshire, UK), Total Knee, Mauch Knee (Össur, Reykjavik, Iceland), Graph-Lite (Teh Lin Prosthetics \& Orthopaedics, Kuala Lumpur, Malaysia) or manual locking knee; (ii) with a knee joint featuring a microprocessor-controlled stance and swing phase, i.e. $\mathrm{MPK}_{\mathrm{A}}\left(\mathrm{C}\right.$-leg ${ }^{\circledR}$ (Otto Bock, Vienna, Austria)), and (iii) with a knee joint featuring a microprocessor-controlled stance phase, i.e. $\mathrm{MPK}_{\mathrm{B}}$ (C-leg ${ }^{\circledR}$ Compact). 


\section{CHAPTER 4}

Baseline data $\left(t_{0}\right)$ were always collected in the mechanically controlled knee joint condition. Participants' performance using either MPK was compared with that using their mechanically controlled knee. The mechanical knee joint condition was therefore chosen as the base of comparison in the subsequent data analyses.

The order in which the MPKs were assigned to the participants was done by block randomisation by a blinded assessor (block size $=4$ ). Each MPK was fitted to the participant's existing socket and used by the participants for a 1-week period in their free-living environment. Fitting and alignment was done by an experienced certified prosthetist followed by a 2-hour 'familiarisation session' with a skilled physical therapist to set the appropriate software settings of the MPK and to familiarise the participants with using the MPK. At the end of this session, the decision was made whether the participant was capable enough to use the prosthesis safely and effectively in his home environment. If so, the participant returned home with the new prosthesis. If not, the participant was not allowed to continue in the study.

Participants returned to the prosthetist one day after the fitting of the MPK for possible prosthetic adjustments regarding alignment and software settings $\left(t_{1}\right.$ and $\left.t_{3}\right)$. Data were collected after each one-week period of home use, i.e. in the mechanical knee joint condition $\left(t_{0}\right)$ and in both MPK conditions $\left(t_{2}\right.$ and $\left.t_{4}\right)$.

Figure 1. Schematic overview of study design

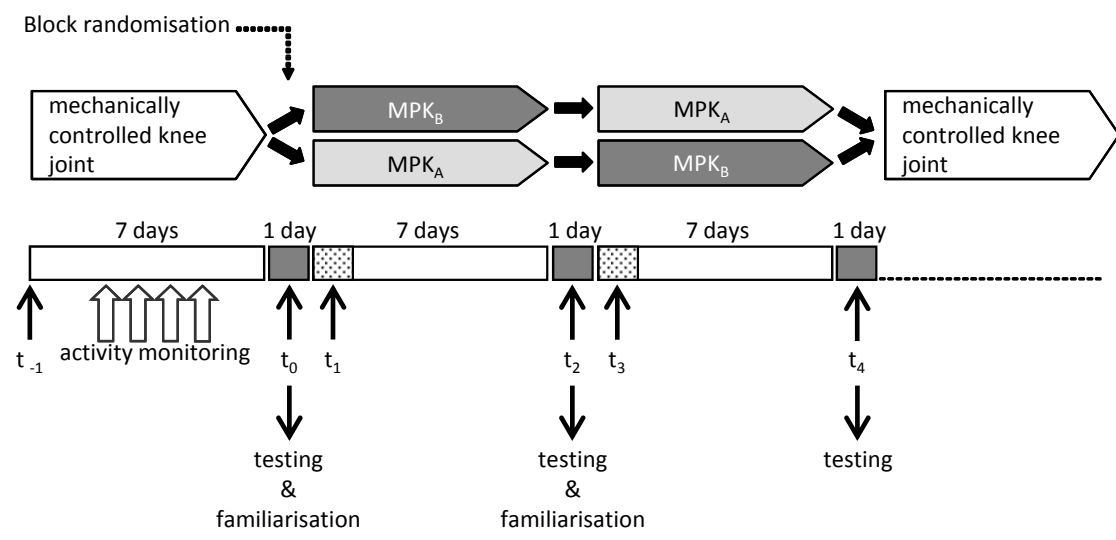

$\mathrm{MPK}_{A}$ : prosthetic knee joint featuring microprocessor-controlled stance and swing phase; $\mathrm{MPK}_{B}$ :

prosthetic knee joint featuring microprocessor-controlled stance phase and passive swing phase control. 


\section{Functional performance}

An ADAPT test circuit was composed, based on the concept developed by Theeven et al. ${ }^{8}$, to objectively assess the functional performance of the participants. This new ADAPT test circuit consisted of 11 circuit stations, in which 17 simulated daily activities were performed by the participants. These activities were chosen from two previous ADAPT test versions ${ }^{8}$, based on their psychometric properties. A description of the circuit stations is given in Table II.

For each activity the performance time was recorded and participants were asked to rate the perceived level of difficulty of all circuit stations on a visual analogue scale (VAS) from $0 \mathrm{~mm}$ (very easy) to $100 \mathrm{~mm}$ (very difficult). At the end of the study the participants were asked which type of knee joint they preferred in daily life.

An example of the ADAPT test results for 1 participant is given in Figure 2 . It shows a comparative overview of the differences in performance time on each of the ADAPT test activities for both $\mathrm{MPK}_{\mathrm{A}}$ and $\mathrm{MPK}_{\mathrm{B}}$ relative to the mechanically controlled prosthesis.

To be able to comprehensively interpret the results of the ADAPT test, the 17 activities were grouped into so-called activity subsets (AS). To determine the activity subsets, a statistical method called principal component analysis with varimax rotation ${ }^{15}$ was used. This method identified 3 different 'factors'. The corresponding ADAPT test activities were then divided into 3 subsets based on the values of the 'factor weights'. Each AS contains ADAPT test activities that share a certain underlying content similarity. The content similarity was identified as 'Standing activities requiring an adequate degree of balance' $\left(\mathrm{AS}_{1}\right)$, 'Activities requiring sitting down and standing up' $\left(\mathrm{AS}_{2}\right)$ and 'Ambulation activities heavily depending on the patient's prosthesis-related skills' $\left(\mathrm{AS}_{3}\right)$. Table III gives an overview of the activities in each AS.

\section{Stratification}

As indicated, large within-group variability in functional performance was expected in the MFCL-2 cohort, which might impede detection of possible effects of using an MPK. To reduce variance, participants were stratified into 3 subgroups, i.e. groups of MFCL2 amputees with either a 'low', 'intermediate' or 'high' functional level. Allocation to a particular subgroup was done by 3 independent experts (a physical therapist, a rehabilitation physician and a prosthetist) based on participants' daily activity level, mean comfortable walking speed, past medical history, psychosocial status and current physical condition. 
Table II. Description of the circuit stations of the Assessment of Daily Activity Performance in Transfemoral amputees test

\begin{tabular}{|c|c|c|}
\hline & Circuit station & Task description \\
\hline \multirow{3}{*}{1} & \multirow{3}{*}{ Supermarket } & $\begin{array}{l}\text { "easy": } 18 \text { low weight }(500 \mathrm{~g}) \text {, easy to handle objects have to be picked from } \\
\text { shelves at different heights and placed into a shopping trolley. Seven objects are } \\
\text { labelled with an " } A \text { ", } 6 \text { objects with a "B" and } 5 \text { objects with a " } C \text { ". }\end{array}$ \\
\hline & & $\begin{array}{l}\text { "moderate": } 4 \text { moderate weight ( } 2 \text { and } 5 \mathrm{~kg} \text { ) objects (labelled with a " } \mathrm{D} \text { ") have } \\
\text { to be picked from the shelves at different heights and placed into a shopping } \\
\text { trolley. }\end{array}$ \\
\hline & & $\begin{array}{l}\text { "difficult": } 2 \text { large and heavy ( } 6 \mathrm{~kg} \text { ) objects (labelled with an " } \mathrm{E} \text { ") have to be } \\
\text { picked from the shelves at different heights and placed into a shopping trolley. }\end{array}$ \\
\hline 2 & Shopping bags & $\begin{array}{l}\text { The } 18 \text { "easy" objects (described in circuit station } 1 \text { ) have to be loaded into } 3 \\
\text { shopping bags with corresponding labels " } A \text { ", " } B \text { ", " } C \text { ", that are placed on a } \\
\text { table. }\end{array}$ \\
\hline \multirow{3}{*}{3} & \multirow{3}{*}{ Kitchen cabinets } & $\begin{array}{l}\text { Unload the shopping bags into the kitchen cabinets of a height-adjustable } \\
\text { kitchen at different reaching heights. }\end{array}$ \\
\hline & & $\begin{array}{l}\text { "easy": put the } 18 \text { low weight objects into the designated cabinets labelled " } A \text { ", } \\
\text { " } B \text { " and " } C \text { ". Cabinets " } A \text { " and " } C \text { " are at eye level. Cabinet " } B \text { " is at knee level. }\end{array}$ \\
\hline & & $\begin{array}{l}\text { "difficult": put the } 5 \text { objects from cabinet "C" onto cabinet " } A \text { " (high) using a } \\
\text { two-step kitchen step. }\end{array}$ \\
\hline
\end{tabular}

\begin{tabular}{|c|c|c|}
\hline 4 & $\begin{array}{l}\text { Hanging out } \\
\text { laundry }\end{array}$ & $\begin{array}{l}\text { Pick up the towels } 1 \text { by } 1 \text { ( } 8 \text { in total) from a tray on the ground together with } \\
\text { two pins and hang them on the clothes line. The adjustable clothes line is set at } \\
\text { wrist level when arms are fully extended and raised above the head. }\end{array}$ \\
\hline 5 & Slalom & $\begin{array}{l}\text { Slalom while holding a serving tray with } 10 \text { table tennis balls (approximately } 32 \\
\text { m). }\end{array}$ \\
\hline 6 & $\begin{array}{l}\text { Get the remote } \\
\text { control }\end{array}$ & $\begin{array}{l}\text { Sit down, stand up, walk to the television set to pick up the remote control and } \\
\text { sit down again. } \\
\text { "easy": sit down on an armchair. } \\
\text { "moderate": sit down in the middle of a low sofa without using the armrests. }\end{array}$ \\
\hline 7 & Obstacle avoidance & Walk across the living room and avoid all the obstacles (e.g. toys) on the ground. \\
\hline 8 & Car & $\begin{array}{l}\text { Walk towards the car and get in at the passenger side (distance: } 4 \mathrm{~m} \text { ). Get out } \\
\text { and walk round the car once, get into and out of the car again and walk to the } \\
\text { place where you started the task. }\end{array}$ \\
\hline 9 & Theatre & $\begin{array}{l}\text { Walk sideways between two rows of chairs while holding a cup of water. Sit } \\
\text { down at the last chair, stand up and walk back to the start/finish line. }\end{array}$ \\
\hline 10 & $\begin{array}{l}\text { Stairs descent and } \\
\text { climb }\end{array}$ & $\begin{array}{l}\text { Walk down the stairs and then immediately up the stairs ( } 2 \text { flights of } 9 \text { threads } \\
\text { connected by an intermediate landing). } \\
\text { "easy": normal walking. } \\
\text { "moderate": walking combined with a cognitive dual task. }\end{array}$ \\
\hline 11 & $\begin{array}{l}\text { Hill descent and } \\
\text { climb }\end{array}$ & $\begin{array}{l}\text { Walk up and down a sloped road twice (length } 18 \mathrm{~m} \text {; height } 2.2 \mathrm{~m} \text { ). } \\
\text { "easy": normal walking. } \\
\text { "moderate": walking combined with a cognitive dual task. }\end{array}$ \\
\hline
\end{tabular}


Figure 2. Typical example of Assessment of Daily Activity Performance in Transfemoral amputees test results for one patient: overview of performance time on mechanically controlled knee joint compared with two types of microprocessor-controlled knee joints $\left(\mathrm{MPK}_{\mathrm{A}}\right.$ and $\left.\mathrm{MPK}_{\mathrm{B}}\right)$

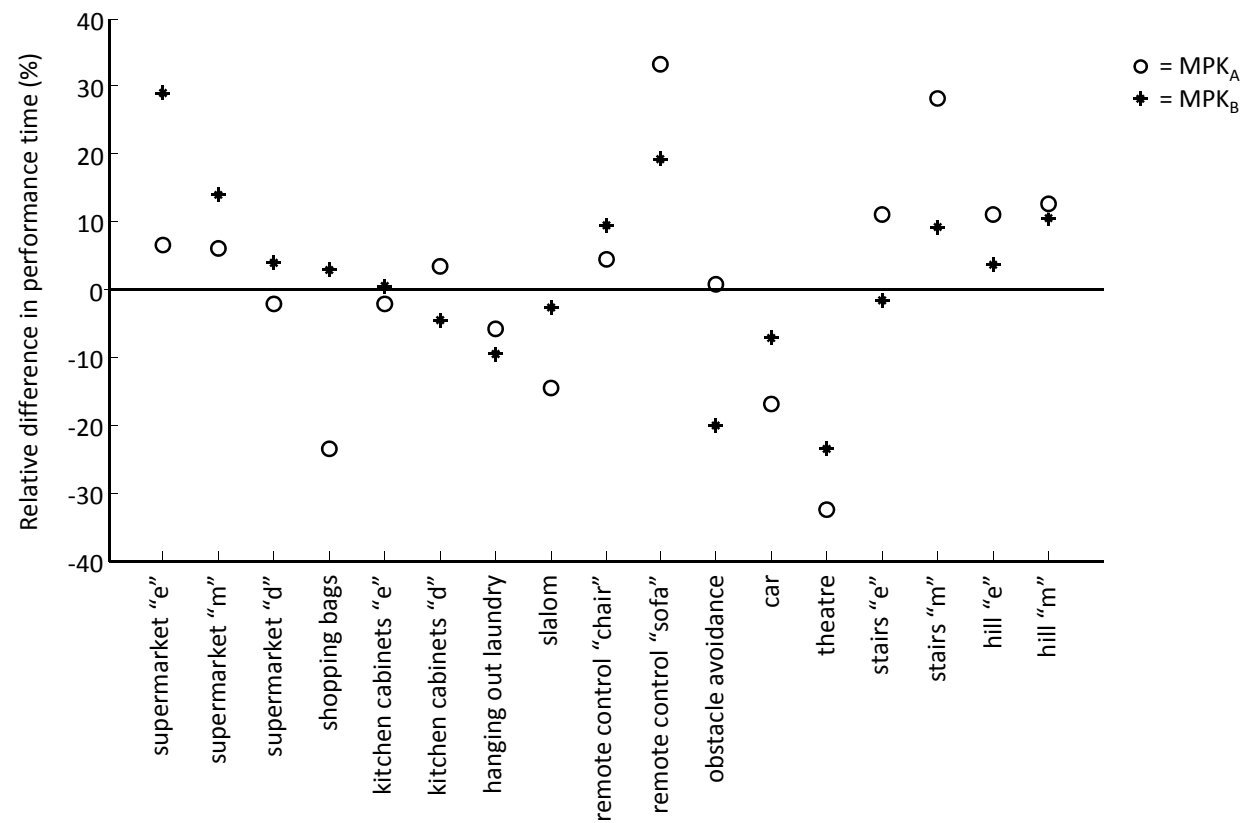

Performance on the mechanically controlled knee joint is set as the reference value to which the performance on the MPKs is compared (indicated by the horizontal line at $0 \%$ difference). Positive values illustrate a relative improvement in performance time while wearing an MPK compared with the performance with mechanically controlled prosthesis. Negative values indicate a relative deterioration in performance time on an MPK compared with the mechanically controlled prosthesis. MPK $K_{A}$ : prosthetic knee joint featuring microprocessorcontrolled stance and swing phase; $M P K_{B}$ : prosthetic knee joint featuring microprocessor-controlled stance phase and passive swing phase control; " $e$ ": easy; " $m$ ": moderate; " $d$ ": difficult.

The participants' daily activity level was monitored during one week in the mechanical knee joint condition with a uniaxial accelerometer (Actigraph, Pensacola, FL, USA) worn around the waist. The activity level was expressed as the number of times an acceleration was recorded or 'counts' per day. In addition, participants were asked to record their general daily activities in an activity diary. The activity diary provided descriptive information concerning the types of activity and daily routines in addition to the objective accelerometer data. Walking velocity was measured in the mechanically controlled knee joint condition using the two-minute walk test on an even surface ${ }^{16,17}$. The participants' past medical history, psychosocial status and physical condition were obtained from the patients' medical records. As the MPK conditions were the experimental conditions, and the mechanically controlled knee joint condition was the reference condition, both activity level and walking speed were measured in the latter condition. 


\section{CHAPTER 4}

Table III. Three activity subsets each representing content-similarity as indicated by factor weights in the principal component analysis of baseline data

\begin{tabular}{|c|c|c|}
\hline $\begin{array}{l}\mathrm{AS}_{1} \\
\text { Standing activities requiring an } \\
\text { adequate degree of balance }\end{array}$ & $\begin{array}{l}\mathrm{AS}_{2} \\
\text { Activities requiring sitting down } \\
\text { and standing up }\end{array}$ & $\begin{array}{l}\mathrm{AS}_{3} \\
\text { Ambulation activities heavily } \\
\text { depending on the patient's } \\
\text { prosthesis-related skills }\end{array}$ \\
\hline Supermarket "easy" & Get the remote control "easy" & Kitchen cabinets (difficult) \\
\hline Supermarket "moderate" & Get the remote control "moderate" & Slalom \\
\hline Supermarket "difficult" & Car & Obstacle avoidance \\
\hline Shopping bags & Theatre & Hill descent and climb \\
\hline Kitchen cabinets "easy" & & $\begin{array}{l}\text { Hill descent and climb with } \\
\text { cognitive dual task }\end{array}$ \\
\hline Hanging out laundry & & $\begin{array}{l}\text { Stair descent and climb } \\
\text { Stair descent and climb with } \\
\text { cognitive dual task }\end{array}$ \\
\hline
\end{tabular}

AS: activity subset.

The stratification was performed in two steps. Participants were first allocated to one of the subgroups 'high', 'intermediate' or 'low' based on their walking speed and activity level. Participants were assigned to subgroup 'high' if their walking speed was equal to or more than $4 \mathrm{~km} / \mathrm{h}$ and their activity level exceeded 100,000 counts/day. Participants were assigned to subgroup 'low' if their walking speed was less than $3 \mathrm{~km} / \mathrm{h}$ and their activity level was less than 65,000 counts/day. All other participants were allocated to subgroup 'intermediate'. In the second step, additional information about the participants (i.e. past medical history, psychosocial status, physical condition and information from the activity diary) was used to check and to further refine the primary stratification. In particular, participants with an activity level or walking speed close to the cut-off values were double-checked and if necessary reallocated to another subgroup if the clinical information strongly disagreed with the primary allocation $(n=3)$.

\section{Statistical analysis}

Data were assessed for both the total group of participants and for 3 subgroups of participants. Comparison of data between knee joint conditions included Friedman twoway analyses of variance by ranks test ${ }^{18}$. Multiple comparison included Wilcoxon signedrank tests for paired observations ${ }^{18}$. In case of the multiple comparison tests a Bonferroni correction was applied ${ }^{15}$. Possible differences between subgroups of participants were tested using the nonparametric Kruskal-Wallis one-way analysis of variance tests ${ }^{18}$. Multiple comparison included Mann-Whitney $U$ tests ${ }^{18}$. Data were statistically analysed using SPSS 16.0.1 (SPSS Inc, Chicago, IL, USA) and Matlab 7.2.0 (The MathWorks Inc., Natick, MA, USA). 


\subsection{Results}

Participants

From over 500 amputee patient records 103 eligible patients were identified. A total of 41 persons agreed to participate in the study. People of varying age, gender and physical condition declined the invitation to participate in this study for a number of reasons, such as having no interest in the study, travelling distance being too long, not getting the days off from work or no time to participate. Table IV shows an overview of the characteristics of the total group of participants and the assigned stratification (i.e. 'low', 'intermediate' or 'high'). Characteristics of participants by subgroup are also presented in Table IV.

Table IV. Participant characteristics for the total group and for all 3 subgroups 'high', 'intermediate' and 'low' MFCL-2

\begin{tabular}{|c|c|c|c|c|c|c|c|c|c|}
\hline $\begin{array}{l}\text { MFCL-2 } \\
\text { sub } \\
\text { group }\end{array}$ & $\begin{array}{l}\text { Gender } \\
\text { (n) }\end{array}$ & $\begin{array}{l}\text { Age } \\
\text { (years) }\end{array}$ & $\begin{array}{l}\text { Weight } \\
(\mathrm{kg})\end{array}$ & $\begin{array}{l}\text { Post- } \\
\text { amputation } \\
\text { time (years) }\end{array}$ & Amputat & ion aetiolo & ogy (n) & $\begin{array}{l}\text { Walking } \\
\text { velocity } \\
(\mathrm{km} / \mathrm{h})\end{array}$ & $\begin{array}{l}\text { Activity } \\
\text { level } \\
\text { (counts } \\
\text { /day) }\end{array}$ \\
\hline & $M F$ & $\begin{array}{l}\text { Mean } \\
\text { (SD) }\end{array}$ & $\begin{array}{l}\text { Mean } \\
\text { (SD) }\end{array}$ & Mean (SD) & Trauma & Vascular & Tumour & $\begin{array}{l}\text { Mean } \\
\text { (SD) }\end{array}$ & $\begin{array}{l}\text { Mean } \\
\text { (SD) }\end{array}$ \\
\hline Total & 228 & $\begin{array}{l}59.1 \\
(13.0)\end{array}$ & $\begin{array}{l}76.9 \\
(12.6)\end{array}$ & $21.5(18.2)$ & 23 & 6 & 1 & $3.4(0.7)$ & $\begin{array}{l}120070 \\
(57423)\end{array}$ \\
\hline Low & 5 & $\begin{array}{l}65.2 \\
(12.6)\end{array}$ & $\begin{array}{l}87.2 \\
(3.2)\end{array}$ & $20.3(19.6)$ & 3 & 3 & 0 & $2.5(0.4)$ & $\begin{array}{l}48292 \\
(12236)\end{array}$ \\
\hline $\begin{array}{l}\text { Inter- } \\
\text { mediate }\end{array}$ & 102 & $\begin{array}{l}61.0 \\
(10.0)\end{array}$ & $\begin{array}{l}75.3 \\
(14.0)\end{array}$ & $21.1(19.1)$ & 10 & 2 & 0 & $3.2(0.4)$ & $\begin{array}{l}113945 \\
(50304)\end{array}$ \\
\hline High & 75 & $\begin{array}{l}54.1 \\
(14.9)\end{array}$ & $\begin{array}{l}73.3 \\
(12.0)\end{array}$ & $22.4(18.1)$ & 10 & 1 & 1 & $4.0(0.5)$ & $\begin{array}{l}156102 \\
(44826)\end{array}$ \\
\hline
\end{tabular}

SD: standard deviation; MFCL-2: Medicare Functional Classification Level-2.

Twenty-eight of the 41 included participants completed the research protocol. In addition, two participants finished the tests using their mechanically controlled knee joint and only 1 of the two MPKs. The reasons these participants did not continue in the study were the onset of back pain $(n=1)$ and a high sense of insecurity using the MPK $(n=1)$. The other 11 participants dropped out at an earlier stage in the study, rendering an inadequate amount of data to include for further analysis. Reasons for dropping out of the study included: technical problems regarding the fit and alignment of the different knee joints $(n=4)$, inability to ambulate safely using the MPK after the familiarisation session $(n=3)$, physical problems due to overuse (e.g. skin disorders and muscle aching discomfort $(n=2))$, decease of a participant $(n=1)$ and the occurrence of a stroke $(n=1)$. Eight of the participants who dropped out had their amputations due to vascular problems and 3 participants were amputated due to trauma. 


\section{CHAPTER 4}

Assessment of Daily Activity Performance in Transfemoral amputees test:

performance times

Figure 3 represents the performance times of the total group on the 3 ADAPT test activity subsets (i.e. $\mathrm{AS}_{1}, \mathrm{AS}_{2}$ and $\mathrm{AS}_{3}$ ) in all 3 knee joint conditions (i.e. mechanical, $\mathrm{MPK}_{\mathrm{A}}$ and $\mathrm{MPK}_{\mathrm{B}}$ ). Large variations were found regarding the performance times in the 3 activity subsets. A significant decrease in performance time was found in activities of AS $_{1}$ for the MPK conditions $\mathrm{MPK}_{A}$ and $\mathrm{MPK}_{B}(\mathrm{p}=0.0001$ and $\mathrm{p}=0.002)$.

Comparing the results of the mechanical knee joint condition (baseline values) between the 3 subgroups of participants ('high', 'intermediate' and 'low') indicated that the $\mathrm{AS}_{1}$ activities were performed significantly faster by the participants in the subgroups 'high' and 'intermediate', compared with the participants in the subgroup 'low' ( $p=0.001$ and $p=0.007$, respectively). Performance times on the $\mathrm{AS}_{1}$ activities did not differ between subgroups 'high' and 'intermediate'. The $\mathrm{AS}_{2}$ activities were performed significantly faster by participants in the subgroups 'high' and 'intermediate' compared with participants assigned to subgroup 'low' ( $p=0.003$ and $p=0.015)$. In addition, participants assigned to subgroup 'high' performed the $\mathrm{AS}_{2}$ activities significantly faster than participants in subgroup 'intermediate' ( $p=0.013$ ). The observed differences in performance time on the activities in $\mathrm{AS}_{3}$ between the subgroups 'high' and 'low' just failed to attain significance after Bonferonni correction ( $p=0.025)$. The observed differences between the subgroups 'high' and 'intermediate' and between the subgroups 'intermediate' and 'low' did not attain a statistical significance level.

The participants in subgroup 'high' performed the activities in $\mathrm{AS}_{1}$ significantly faster in both the $\operatorname{MPK}_{A}(p=0.010)$ and the $\operatorname{MPK}_{B}(p=0.019)$ conditions compared with the mechanically controlled prosthesis condition. The performance times for the activities in $\mathrm{AS}_{2}$ for subgroup 'high' did not change in either the $\mathrm{MPK}_{\mathrm{A}}$ or the $\mathrm{MPK}_{\mathrm{B}}$ condition, compared with the mechanically controlled prosthesis condition. The observed difference in performance time for the activities in $\mathrm{AS}_{3}$ between the mechanically controlled prosthesis condition and the $\mathrm{MPK}_{\mathrm{A}}$ prosthesis condition did not attain statistical significance. In contrast, the difference between the mechanically controlled and $\mathrm{MPK}_{\mathrm{B}}$ condition for the $\mathrm{AS}_{3}$ activities was statistically significant $(\mathrm{p}=0.023)$.

Participants in subgroup 'intermediate' performed the activities in $\mathrm{AS}_{1}$ significantly faster in both the $\mathrm{MPK}_{\mathrm{A}}$ and $\mathrm{MPK}_{\mathrm{B}}$ prosthesis conditions compared with the mechanically controlled prosthesis condition $(p=0.004$ and $p=0.008)$. Participants from this subgroup 
also performed the $\mathrm{AS}_{2}$ activities significantly faster on $\mathrm{MPK}_{\mathrm{A}^{\prime}}$ compared with their mechanically controlled prosthesis for $(p=0.016)$. No difference in performance time was observed between the mechanically controlled prosthesis and $\mathrm{MPK}_{\mathrm{B}}$ conditions for activities in $\mathrm{AS}_{2}$ in the subgroup 'intermediate'. Participants classified as 'intermediate' showed no changes in performance times on the $\mathrm{AS}_{3}$ activities between any prosthesis condition.

The performance times of the participants in subgroup 'low' did not differ for any of the activity subsets between any prosthesis condition.

Assessment of Daily Activity Performance in Transfemoral amputees test:

perceived level of difficulty

The mean VAS scores reflecting the perceived level of difficulty of the ADAPT test activities are presented in Figure 4 for both the total group of participants and the subgroups of participants ('high', 'intermediate', and 'low'). In the total group, the perceived level of difficulty for activities in $\mathrm{AS}_{2}$ and $\mathrm{AS}_{3}$ was significantly lower in the $\mathrm{MPK}_{\mathrm{A}}$ condition compared with the mechanical knee joint condition $(p=0.023$ and $p=0.008)$. The perceived level of difficulty scores in the $\mathrm{MPK}_{\mathrm{B}}$ condition did not differ from the scores in the mechanical knee joint condition. The mean perceived level of difficulty scores per activity subset measured at $\mathrm{t}_{0}$ did not differ between the subgroups of participants.

For the subgroups 'high' and 'intermediate' there seems to be a trend, although not statistically significant, that the perceived level of difficulty in both MPK conditions is scored lower compared with the perceived level of difficulty in the mechanical knee joint condition for all activity subsets. The perceived level of difficulty scores of subgroup 'low' showed no significant differences in any of the activity subsets between the mechanically controlled and either $\mathrm{MPK}_{\mathrm{A}}$ or $\mathrm{MPK}_{\mathrm{B}}$ condition.

Out of the 29 participants who completed the knee joint preference questionnaire at the end of the study, 21 participants (high=10, intermediate $=7$, low=4) indicated preferring $\mathrm{MPK}_{\mathrm{A}^{\prime}} 7$ participants (high=2, intermediate=3, low=2) preferred $\mathrm{MPK}_{\mathrm{B}^{\prime}}$ and 1 participant (intermediate) preferred his own mechanically controlled prosthesis. 


\section{CHAPTER 4}

Figure 3. Boxplots of the mean performance times for each activity subset of the total group of participants and of the participants from the subgroups 'high', 'intermediate' and 'low' for all knee joint conditions
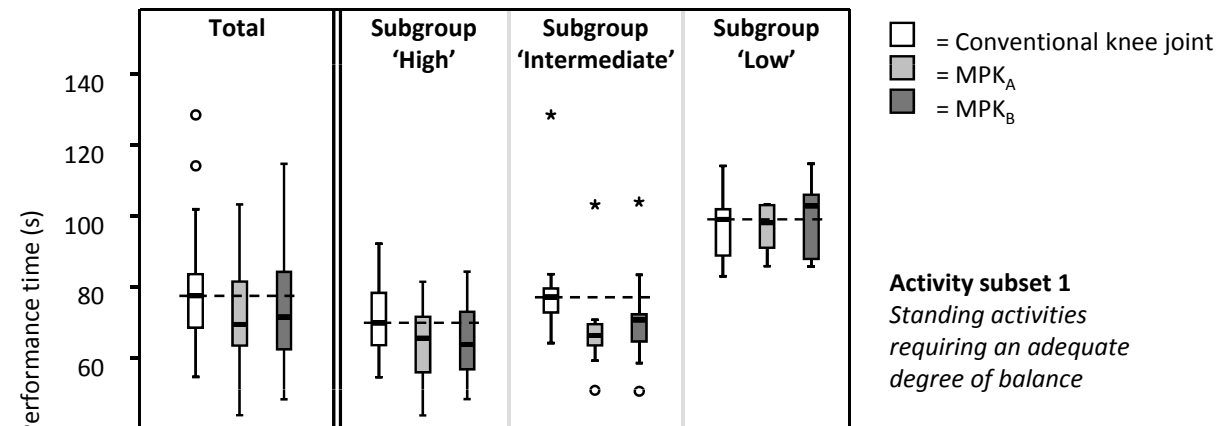

Activity subset 1

requiring an adequate

degree of balance

\section{Activity subset 2}

Activities requiring sitting down and standing up

Activity subset 3

Ambulation activities heavily depending on the patient's prosthesisrelated skills 
Figure 4. Mean perceived level of difficulty scores $(\mathrm{mm})$ for each of the activity subsets of the total group of participants and of the participants from the subgroups 'high', 'intermediate' and 'low' for all knee joint conditions

\begin{tabular}{|c|c|c|c|c|c|}
\hline 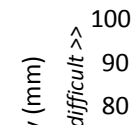 & Total & $\begin{array}{c}\text { Subgroup } \\
\text { 'High' }\end{array}$ & $\begin{array}{c}\text { Subgroup } \\
\text { 'Intermediate' }\end{array}$ & $\begin{array}{c}\text { Subgroup } \\
\text { 'Low' }\end{array}$ & $\begin{aligned} \square & =\text { Conventional knee joint } \\
\square & =\mathrm{MPK}_{\mathrm{A}} \\
\square & =\mathrm{MPK}_{\mathrm{B}}\end{aligned}$ \\
\hline
\end{tabular}

Activity subset 1

Standing activities requiring an adequate degree of balance

Activity subset $\mathbf{2}$

Activities requiring sitting down and standing up

Activity subset 3 Ambulation activities heavily depending on the patient's prosthesis-related skills

Figure 3 \& Figure 4. The dotted horizontal lines in each of the 3 Assessment of Daily Activity Performance in Transfemoral amputees test activity subsets illustrate the median value at baseline; MPK : prosthetic knee joint featuring microprocessor-controlled stance and swing phase; MPK $K_{B}$ prosthetic knee joint featuring microprocessor-controlled stance phase and passive swing phase control. 


\subsection{Discussion}

The aim of this study was to assess the effects of using an MPK on the level of functional ability to perform ADL in persons classified as MFCL-2. MPK $\mathrm{A}_{\mathrm{A}}$ and $\mathrm{MPK}_{\mathrm{B}}$ each seemed to improve the functional ability to perform standing activities that require adequate balance in the whole group of MFCL-2 amputees. Furthermore, the findings confirmed our expectations of large variation regarding the functional performance level within the group of MFCL-2 amputees. The stratification of persons with a comparable functional level within the MFCL-2 grade into 3 subgroups helped to refine the assessment of possible effects of using an MPK. Particularly the MFCL-2 amputees with either an 'intermediate' or 'high' functional level seemed to improve their ability to perform common daily activities using an MPK, while those amputees with a 'low' functional level did not appear to do so.

Very few studies have focused on the MFCL-2 population and on the possible effects of a MPK on daily functioning. Hafner \& Smith ${ }^{12}$ have reported that MFCL-2 amputees may benefit equally from the use of $\mathrm{MPK}_{\mathrm{A}}$ to those persons classified as MFCL-3. They investigated a cohort of MFCL-2 amputees with similar characteristics to those of the participants of the current study. In addition, findings of Hafner \& Smith ${ }^{12}$ and Kahle et al. ${ }^{2}$ indicated that several persons who were initially classified as MFCL-2 advanced to MFCL-3 when they used $\mathrm{MPK}_{\mathrm{A}}$. The results of the current study corroborate the findings of those previous investigations, but, additionally, allow for further differentiation of the effects of an MPK within this patient group. Because of the applied stratification of participants it has become clear that not all MFCL-2 amputees seem to benefit from using an MPK in daily life.

The MFCL classification is currently based on the subjective assessment by experienced clinicians of patient's actual ability or potential ability to accomplish his expected postrehabilitation daily function ${ }^{19}$. Applying this definition inherently leads to considerable variability within each functional level. This observation is further corroborated by the findings of the current study. Three subgroups were identified within the MFCL-2 cohort by using a method that incorporates the use of objective measures to help clinicians to describe a person's functional mobility level. At baseline, the 3 identified subgroups of patients showed significant differences in the level of functional ability to perform common daily activities, which may suggest the need for a more detailed classification system. 
For the participants in the subgroups 'intermediate' and 'high', both types of MPK led to significant improvements in their ability to perform activities, such as picking up objects from shelves at different heights and placing them in a shopping trolley, filling shopping bags with groceries, putting objects into kitchen cabinets and hanging out laundry on a clothes line (i.e. $\mathrm{AS}_{1}$ activities). Performing this type of activities typically requires an adequate degree of both static and dynamic balance, which is known to be reduced in lower limb amputees ${ }^{20}$. Often, amputees are less confident about their ability to maintain their balance when performing daily activities ${ }^{21}$, which, in turn, may have a strong effect on their level of mobility and participation ${ }^{22}$. Kaufman et al. ${ }^{3}$ previously reported MPK $_{A}$ to improve the level of balance and stability compared to using mechanically controlled knee joints in highly active amputees (MFCL-3 and MFCL-4). Our results suggest that the use of both $\mathrm{MPK}_{\mathrm{A}}$ and $\mathrm{MPK}_{\mathrm{B}}$ can also lead to increased performance in activities necessitating high balance levels in MFCL-2 amputees classified as either 'intermediate' or 'high'.

Activities that included sitting down and getting up from a chair in different settings, e.g. in a car, in a cinema, or in a living room (i.e. $\mathrm{AS}_{2}$ activities), were performed significantly faster only by the participants in subgroup 'intermediate'. The actively-controlled knee flexion damping available in both $\mathrm{MPK}_{\mathrm{A}}$ and $\mathrm{MPK}_{\mathrm{B}}$ should enable amputees to distribute their body weight more evenly over both legs when sitting down, reducing the load on the non-amputated leg and providing more stability. Participants in the subgroup 'high' did not perform these activities faster on either type of MPK, most likely because they already performed these activities at a speed that is maximal for them in the mechanically controlled knee joint condition.

The activities from $\mathrm{AS}_{3}$, which include more demanding ambulation activities, such as walking stairs, hill negotiation, obstacle avoidance in a confined space and slaloming while holding a tray, typically require adequate prosthesis-related skills and cognitive skills. Improvements in the performance of MFCL-2 amputees on some of the $\mathrm{AS}_{3}$ activities when using $\mathrm{MPK}_{\mathrm{A}^{\prime}}$, i.e. walking downhill and avoiding obstacles, have previously been reported by Hafner \& Smith ${ }^{12}$. Our results indicate that only the participants from the MFCL-2 subgroup 'high' seem to benefit from using $\mathrm{MPK}_{B}$ in performing this type of daily activities. It was expected that an improvement in the performance of the $\mathrm{AS}_{3}$ activities would also occur in the other subgroups, given the active stance phase control of both types of MPK providing high levels of safety and efficiency in these types of challenging activities. Although, in general, the participants were able to apply newly 


\section{CHAPTER 4}

learned performance strategies for the MPK, it remains unclear whether or not, after one week of use, they would also use these new strategies in more challenging conditions in which the full potential of the MPK would be required. Future research is required to investigate this.

The participants in MFCL-2 subgroup 'low' did not show an improvement in functional performance when using either type of MPK. However, neither the actual nor the perceived performance level during ADL did, on average, deteriorate in the members of subgroup 'low' after transitioning from a mechanically controlled knee joint to an MPK. A more compromised overall physical condition, in combination with lower balance confidence levels in participants in subgroup 'low' compared with the participants in the other subgroups may have contributed to this finding. Further research is necessary to assess whether an extended accommodation period on an MPK could lead to an improvement of the level in functional performance in amputees in subgroup 'low'.

As it was important to include the amputees' opinion about the use of an MPK, a subjective assessment was solicited (i.e. VAS questionnaire). However, in contrast to actual performance data, the level of variability of the participants' perceived performance level did not seem to improve after stratification. One of the reasons for this may be that a VAS is sensitive to changes in the participants' frame of reference, i.e. their perception of, for instance, the term 'poor' may change over time to 'moderate' because they have come to terms with a certain condition or state.

Although, statistically, no difference was found between both MPK conditions as to the level of functional performance, both types of MPK had different effects on the participants' individual functional performance level. Some participants from subgroup 'high' did not improve their functional performance when using an MPK, whereas participants from subgroup 'low' did improve their level of functional performance when using an MPK. Furthermore, some participants preferred $\mathrm{MPK}_{\mathrm{A}^{\prime}}$, some participants preferred $\mathrm{MPK}_{\mathrm{B}}$ and one person preferred his mechanically controlled prosthesis. These different examples of between-subject variability underline the need of individual assessment when using the ADAPT test for prosthesis selection and prescription purposes. One should not try to find a singular best prosthesis for an entire group of amputees, but rather use tests, like the ADAPT test, to personalise the choice, because each individual responds differently to a specific prosthesis ${ }^{4,13}$. 


\section{Considerations}

In the current study, persons who were classified as MFCL-2 participated. Approximately $20 \%$ of the research population acquired their amputation due to vascular reasons, which might not be fully representative for the total MFCL-2 population. Several vascular participants (designated to subgroup 'low') were not able to complete the study protocol due to their compromised physical condition. Cautious interpretation of the results of subgroup 'low' is therefore warranted.

No clear consensus exists concerning the optimal accommodation time for a new prosthetic component. English et al. ${ }^{23}$ reported that a one-week familiarisation period is adequate in clinical practice, but for research purposes, a familiarisation period of at least 3 weeks is recommended. Other studies report accommodation periods ranging from 1 to 33 weeks $2-5,11,12,24,25$. Nonetheless, significant improvements in functional performance levels were found in the present study in the 'intermediate' and 'high' subgroups after one week of use. This indicates that using an MPK may lead to shortterm effects related to an amputee's functional performance level.

\section{Future research}

The circuit stations that constituted the current ADAPT test were tested in a previous proof-of-concept study ${ }^{8}$. Given the nature of the ADAPT test, i.e. featuring representations of daily activities, the ecological validity of the test is considered promising. Part of our future research will be to further investigate and refine the psychometric properties of the ADAPT test. Also, research is planned to score the quality of performance, e.g. quantifying the amount of compensatory movements, accuracy, efficiency and smoothness of motion during task performance, in addition to measuring performance time.

In conclusion, the use of prosthetic knee joints featuring microprocessor-controlled stance and/or swing phase control has beneficial effects on the level of functional ability to perform common daily activities in part of the MFCL-2 population. This patient population has shown to be heterogeneous as to the level of functional mobility, functional outcome and the way persons perceive their own functional performance. This population may be further divided into subgroups of MFCL-2 amputees. Persons classified as MFCL-2 with either intermediate to high prosthesis-related abilities seem to have a functional benefit from using a MPK to perform ADL. 


\section{CHAPTER 4}

\subsection{Acknowledgements}

The authors would like to thank Sven Balk of Adelante Rehabilitation Centre for his valuable contribution to the physical therapy training sessions. We also would like to thank the prosthetists at Livit Orthopedie, Hoensbroek, The Netherlands for their support in fitting of the knee prostheses.

This study was supported by a grant provided by Otto Bock Healthcare GmbH, Vienna, Austria. Prior to the start of the investigation that has led to the current publication, it was contractually agreed between Adelante and the grant provider, that Adelante has the full and unrestricted right regarding: (i) the establishing of results of the investigation leading to scientifically corroborated conclusions; and (ii) the presentation of any result or conclusion resulting from the investigation, independent of any other party or grant provider. 


\subsection{References}

1. World Health Organisation. International Classification of Functioning, Disability and Health: ICF; 2001.

2. Kahle JT, Highsmith MJ, Hubbard SL. Comparison of nonmicroprocessor knee mechanism versus CLeg on Prosthesis Evaluation Questionnaire, stumbles, falls, walking tests, stair descent, and knee preference. J Rehabil Res Dev 2008; 45:1-14.

3. Kaufman KR, Levine JA, Brey RH, Iverson BK, McCrady SK, Padgett DJ, et al. Gait and balance of transfemoral amputees using passive mechanical and microprocessor-controlled prosthetic knees. Gait Posture 2007; 26:489-493.

4. Orendurff MS, Segal AD, Klute GK, McDowell ML, Pecoraro JA, Czerniecki JM. Gait efficiency using the C-Leg. J Rehabil Res Dev 2006; 43:239-246.

5. Segal $A D$, Orendurff MS, Klute GK, McDowell ML, Pecoraro JA, Shofer J, et al. Kinematic and kinetic comparisons of transfemoral amputee gait using C-Leg and Mauch SNS prosthetic knees. J Rehabil Res Dev 2006; 43:857-870.

6. Seymour R, Engbretson B, Kott K, Ordway N, Brooks G, Crannell J, et al. Comparison between the C-leg microprocessor-controlled prosthetic knee and non-microprocessor control prosthetic knees: a preliminary study of energy expenditure, obstacle course performance, and quality of life survey. Prosthet Orthot Int 2007; 31:51-61.

7. Williams $R M$, Turner AP, Orendurff $M$, Segal $A D$, Klute GK, Pecoraro J, et al. Does having a computerized prosthetic knee influence cognitive performance during amputee walking? Arch Phys Med Rehabil 2006; 87:989-994.

8. Theeven PJR, Hemmen B, Stevens CHC, IImer EC, Brink PRG, Seelen HAM. Feasibility of a new concept for measuring actual functional performance in daily life of transfemoral amputees. $J$ Rehabil Med 2010; 42:744-751.

9. Otto Bock Healthcare. MOBIS ${ }^{\circledR}$ - The Otto Bock Mobility System. [October 13, 2010]; Available from: http://www.ottobock.com/cps/rde/xchg/ob_com_en/hs.xsl/603.html.

10. Centers for Medicare and Medicaid Services. U.S. Department of Health and Human Services. HCFA Common Procedure Coding System (HCPCS). Springfield (VA): U.S. Department of Commerce, National Technical Information Service; 2001.

11. Hafner BJ, Willingham LL, Buell NC, Allyn KJ, Smith DG. Evaluation of function, performance, and preference as transfemoral amputees transition from mechanical to microprocessor control of the prosthetic knee. Arch Phys Med Rehabil 2007; 88:207-217

12. Hafner BJ, Smith DG. Differences in function and safety between Medicare Functional Classification Level-2 and -3 transfemoral amputees and influence of prosthetic knee joint control. J Rehabil Res Dev 2009; 46:417-433.

13. Gailey RS. Predictive outcome measures versus functional outcome measures in the lower limb am- 


\section{CHAPTER 4}

putee. J Prosthet Orthot 2006; 18:51-60.

14. Dudek NL, Khan OD, Lemaire ED, Marks MB, Saville L. Ambulation monitoring of transtibial amputation subjects with patient activity monitor versus pedometer. J Rehabil Res Dev 2008; 45:577-585.

15. Field A. Discovering statistics using SPSS. 2nd ed. London: SAGE publications; 2005.

16. Brooks D, Hunter JP, Parsons J, Livsey E, Quirt J, Devlin M. Reliability of the two-minute walk test in individuals with transtibial amputation. Arch Phys Med Rehabil 2002; 83:1562-1565.

17. Brooks D, Parsons J, Hunter JP, Devlin M, Walker J. The 2-minute walk test as a measure of functional improvement in persons with lower limb amputation. Arch Phys Med Rehabil 2001; 82:1478-1483.

18. Siegel S, Castellan J. Nonparametric statistics for the behavioral sciences. 2nd ed. New York: McGraw-Hill; 1988.

19. Medicare region C durable medical equipment prosthetics orthotic supplier (DMEPOS) manual. Colombia (SC): Palmetto GBA; 2005. p. 53.5-53.6.

20. Buckley JG, O'Driscoll D, Bennett SJ. Postural sway and active balance performance in highly active lower-limb amputees. Am J Phys Med Rehabil 2002; 81:13-20.

21. Miller WC, Speechley M, Deathe B. The prevalence and risk factors of falling and fear of falling among lower extremity amputees. Arch Phys Med Rehabil 2001; 82:1031-1037.

22. Miller $W C$, Deathe $A B$, Speechley $M$, Koval J. The influence of falling, fear of falling, and balance confidence on prosthetic mobility and social activity among individuals with a lower extremity amputation. Arch Phys Med Rehabil 2001; 82:1238-1244.

23. English RD, Hubbard WA, McElroy GK. Establishment of consistent gait after fitting of new components. J Rehabil Res Dev 1995; 32:32-35.

24. Kaufman KR, Levine JA, Brey RH, McCrady SK, Padgett DJ, Joyner MJ. Energy expenditure and activity of transfemoral amputees using mechanical and microprocessor-controlled prosthetic knees. Arch Phys Med Rehabil 2008; 89:1380-1385.

25. Klute GK, Berge JS, Orendurff MS, Williams RM, Czerniecki JM. Prosthetic intervention effects on activity of lower-extremity amputees. Arch Phys Med Rehabil 2006; 87:717-722. 



$$
\operatorname{tin}
$$




\section{Chapter 5}

Gait perturbation recovery of low-functional transfemoral amputees using microprocessor-controlled prostheses: perceived and actual performance

P.J.R. Theeven, B. Hemmen, R.P.J. Geers, P.R.G. Brink, R.J.E.M. Smeets, H.A.M. Seelen

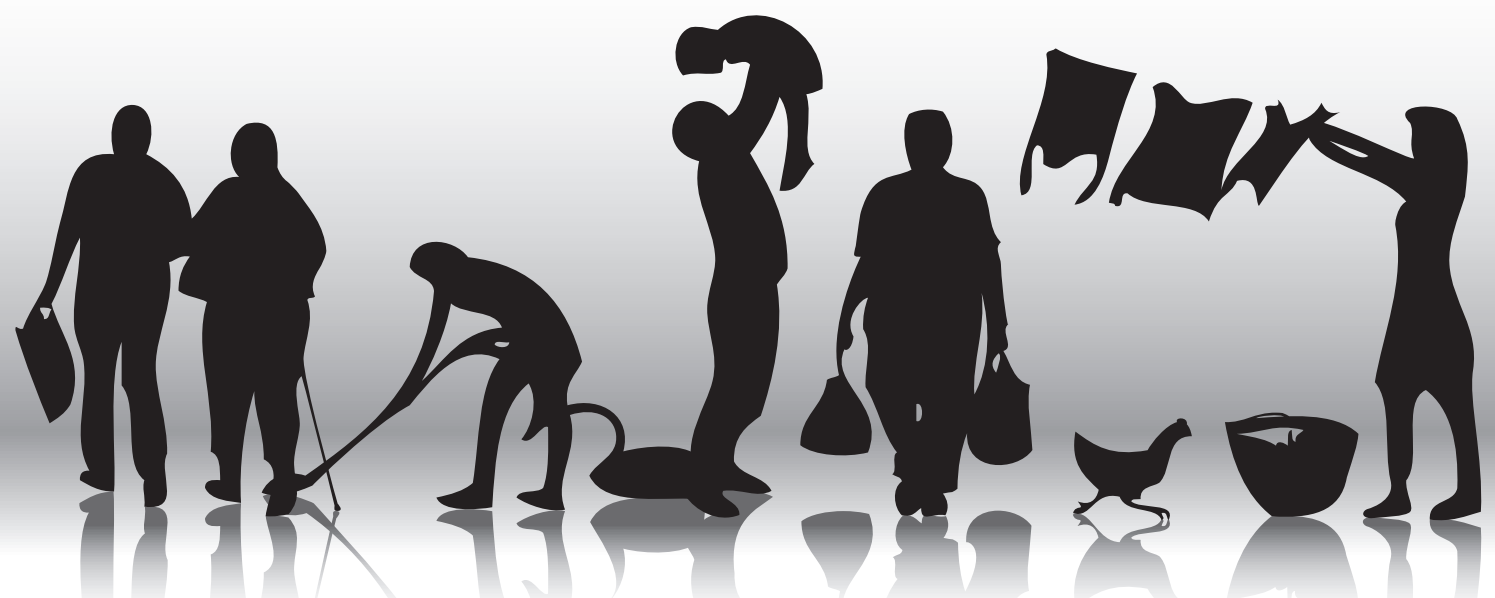




\section{Abstract}

Objective: Assessing the effects of microprocessor-controlled prosthetic knee joints on persons' actual and perceived level of performance of recovering from perturbations of gait.

Design: Cross-over design with assessor blinding.

Subjects/Participants: Twenty-nine persons with a unilateral transfemoral amputation or knee disarticulation classified as Medicare Functional Classification Level-2 (MFCL-2).

Methods: Four perturbation tests were performed, i.e. tripping, stopping abruptly, sidestepping abruptly, and stepping on an object. Subjects performed the tests using a mechanically controlled knee joint, a knee joint featuring a microprocessor-controlled stance and swing phase, and a knee joint featuring a microprocessor-controlled stance phase. Subjects' ability to recover following these perturbations was measured using video analyses. Participants' self-perceived performance concerning the perturbation recovery, and self-perceived level of stability of the prosthesis during perturbations was measured using questionnaires.

Results: Actual performance scores did not differ between knee joint conditions. Mean self-perceived performance scores demonstrated an increase of $7.6 \%-25.3 \%$ with the MPKs compared with the mechanically controlled knee joint.

Conclusion: MFCL-2 amputees recover similarly from a perturbation in gait when using an MPK or a mechanically controlled knee joint. However, they feel more capable to counteract the perturbations and experience improved stability of the prosthesis in situations with a high risk of falling. 


\subsection{Introduction}

Falls are highly prevalent among persons with a transfemoral amputation ${ }^{1,2}$ and may lead to serious physical injury. The absence of leg muscles and bone structures in the affected extremity and the associated reduction of somatosensory information complicate a fast recovery following, for example, a stumble during ambulation. Persons with an amputation who have a history of falls have an increased risk of developing a fear of falling ${ }^{2}$. Also, a high prevalence of fear of falling and/or a reduced balance confidence during prosthesis ambulation is reported ${ }^{2,3}$. Both falling and the fear of falling are considered major factors for decreased activity, mobility, and quality of life ${ }^{3,4}$.

Above-knee amputees who transitioned from a mechanically controlled knee joint to a microprocessor-controlled knee joint (MPK) have reported to perceive considerable improvements concerning their level of confidence, security, stability, and functional abilities to achieve activities of daily living ${ }^{5-9}$. These positive experiences of MPK users have been corroborated by the results of objective measurements ${ }^{8-15}$. Persons' everyday life activity level does not seem to be affected by using an MPK ${ }^{7,16,17}$. Regarding the safety aspects of using an MPK in everyday life, still very little information is available. In daily life, gait and balance are perturbed frequently, e.g. when tripping over a skew stone in the pavement. The active control of the flexion and/or extension resistance of an MPK may help prevent a sudden collapse of the knee from occurring at the moment of loading the prosthesis.

Furthermore, most research has been done in amputees classified in the higher functional levels, i.e. Medicare Functional Classification Level ${ }^{18}$ (MFCL) 3 and 4, whereas very little is known about the effects of an MPK in amputees with a lower functional level (MFCL-2). As MFCL-2 amputees generally have more co-morbidities and have a more compromised physical condition compared with the MFCL-3 and MFCL-4 amputees, they are more at risk of falling. It is important to further investigate whether the advantageous effects of an MPK on fall-related and balance-related outcome measures, as found in MFCL-3 and MFCL-4 amputees ${ }^{10,15,19}$, also apply to persons classified as MFCL-2.

The aim of the present study was to assess the possible effects of using two different types of MPKs on both the actual and perceived ability to recover from different types of gait perturbations in MFCL-2 amputees, who are normally fitted with a prosthesis featuring a mechanically controlled knee joint. It is hypothesized that, in MFCL-2 amputees, both types of MPK will assist in a more successful recovery from a stumble or sudden change 


\section{CHAPTER 5}

in walking direction than a knee joint with a mechanically controlled stance phase. It is also hypothesized that subjects perceive an increased level of stability and safety using the MPK in situations with a high risk of falling.

The authors have demonstrated in previously published work that considerable variability exists between persons classified as MFCL-2 with regard to their level of functional ability with the prosthesis ${ }^{9}$. As high levels of variability may obscure possible effects of the prosthetic intervention, we created three smaller, more homogenous subgroups. Results were analyzed for the total group and for the MFCL-2 subgroups. A similar approach was also implemented in the present study as the same group of participants is investigated here.

\subsection{Methods}

\section{Participants}

Participants were recruited from rehabilitation centres, hospitals and local prosthetic and orthotic care centres in the southern region of The Netherlands and north eastern region of Belgium. Each person was screened by a panel of experts, including a rehabilitation physician, a senior physiotherapist, and a senior prosthetist, to determine the person's MFCL level. Factors such as age, cause of amputation, physical condition, comorbidities, pain, and fear of falling were taken into account during classification.

The inclusion criteria were: having a transfemoral amputation or knee disarticulation; unanimously diagnosed by the screening panel as MFCL-2 amputee; over 18 years of age; daily use of a leg prosthesis fitted with a mechanically controlled knee joint; having completed rehabilitation for at least one year; ability to walk 500 meters a day; no previous experience using an MPK. Exclusion criteria were: severe additional orthopaedic, rheumatologic, neurological or cardiovascular disease which might hamper performance; severe perceptual or cognitive disorders; and/or skin problems of the stump.

Approval was obtained from the medical ethics committee of the Rehabilitation Foundation Limburg (currently: Adelante Rehabilitation Centre), Hoensbroek, The Netherlands. Written informed consent was obtained from the subjects prior to their participation.

\section{Study design}

Figure 1 represents a schematic overview of the double cross-over study design. 
Participants were tested in three different prosthetic knee joint conditions: (i) with their current mechanically controlled knee joint (3R80, 3R106, 3R60, 3R92 (Otto Bock, Vienna, Austria), Acphapend (Proteval, Valenton, France), Ultimate (Ortho Europe, Oxfordshire, UK), Total Knee, Mauch Knee (Össur, Reykjavik, Iceland), Graph-Lite (Teh Lin Prosthetics \& Orthopaedics, Kuala Lumpur, Malaysia) or manual locking knee); (ii) with a knee joint featuring a microprocessor-controlled stance and swing phase, i.e. MPK $_{A}$ (C-leg ${ }^{\circledR}$ (Otto Bock, Vienna, Austria), and (iii) with a knee joint featuring a microprocessorcontrolled stance phase, i.e. $\mathrm{MPK}_{\mathrm{B}}$ (C-leg ${ }^{\circledR}$ Compact (Otto Bock, Vienna, Austria).

Figure 1. Schematic overview of study design

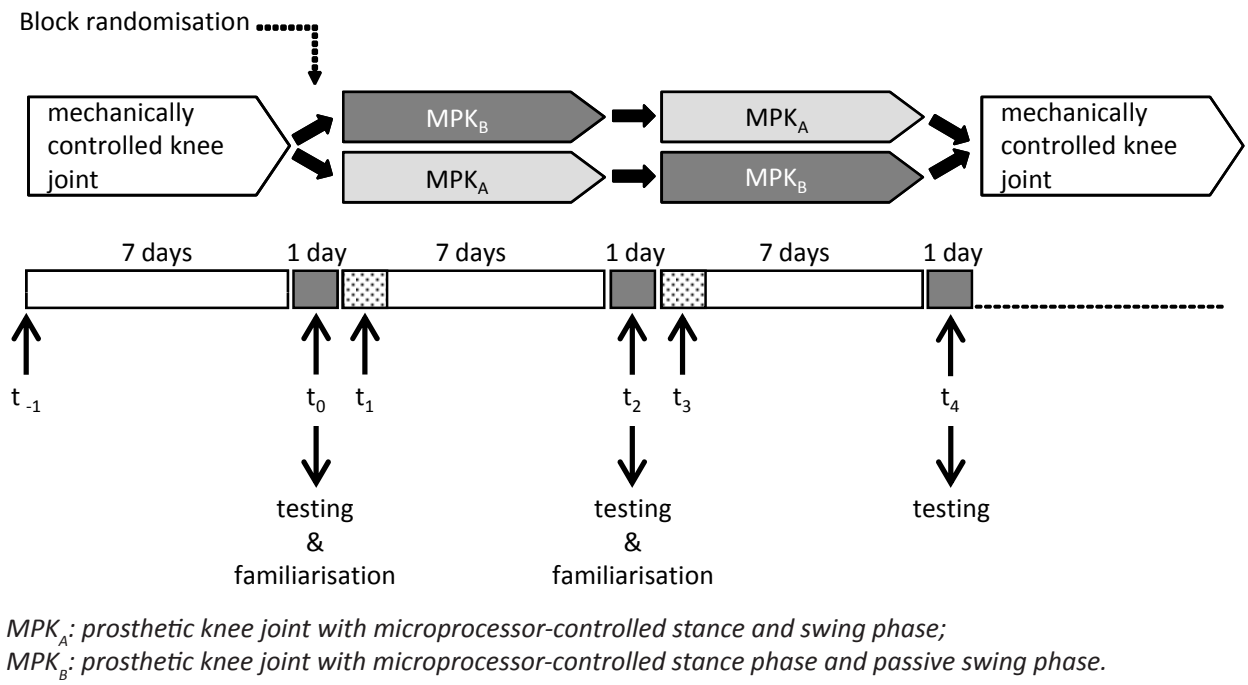

The mechanically controlled knee joint was always tested first and served as the baseline condition $\left(t_{0}\right)$. Participants' performance using either MPK was compared with these baseline values. Each person thus served as his or her own control. The order in which the MPKs were assigned to the participants was done by computer-generated block randomization (block size $=4$ ). The MPKs were fitted to the participant's existing socket by an experienced certified prosthetist. The MPK was set to the appropriate software settings and participants were familiarized with the MPK by a skilled physical therapist during a 2-hour period to ensure safe prosthesis use by the participant (at $t_{0}$ and $t_{2}$ ). At the end of this session, the therapist decided whether the participant was able to use the prosthesis safely in his home environment. If so, the participant returned home with the new prosthesis. If not, the participant was not allowed to continue in the study. One day after fitting the MPK participants returned to the prosthetist for possible prosthetic adjustments regarding alignment and software settings $\left(t_{1}\right.$ and $\left.t_{3}\right)$. Testing always took 


\section{CHAPTER 5}

place after a one-week period of home use, i.e. in the mechanical knee joint condition $\left(t_{0}\right)$ and in both MPK conditions $\left(t_{2}\right.$ and $\left.t_{4}\right)$.

\section{Intervention}

Participants had to react to various types of perturbations in their gait and to abrupt changes in walking direction during plain level walking. The induced perturbations and direction changes were based on a protocol reported by Blumentritt et al. ${ }^{19}$. The following perturbations were induced: 1 ) tripping, 2a) stopping abruptly, 2b) sidestepping abruptly and 3) unexpectedly stepping on an object. Figure 2a, 2b, $2 c$ and $2 d$ show schematic representations of the four tests. For safety reasons, participants wore a body harness attached to a low-resistance trolley on a ceiling-mounted rail during all tests.

Figure 2. Schematic representations of the four perturbation tests

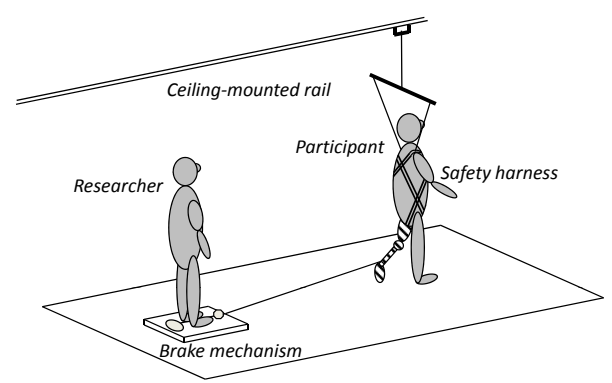

a. 'Tripping' test

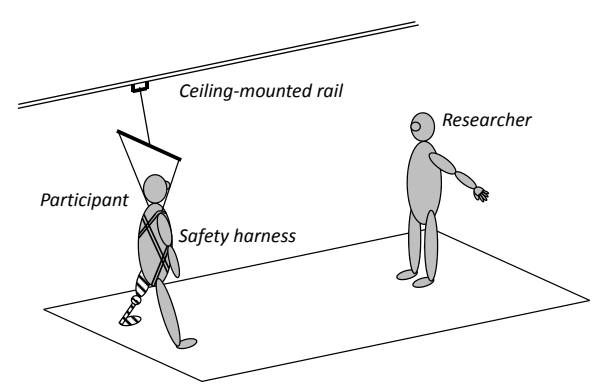

c. 'Abruptly sidestepping' test

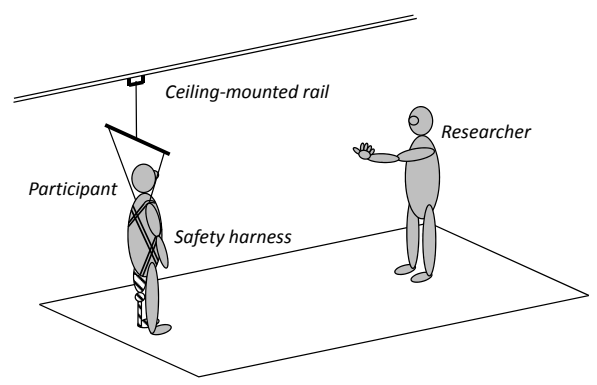

b. 'Abruptly stopping' test

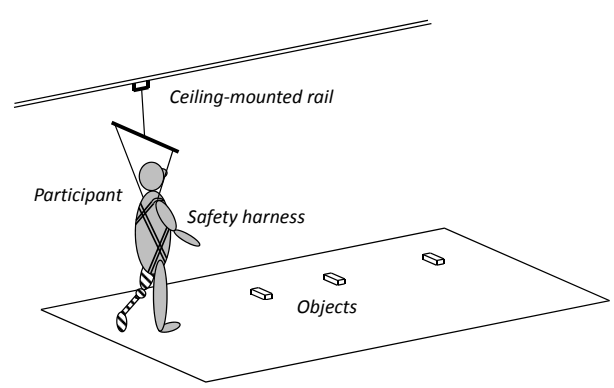

d. 'Stepping on object' test

\section{Tripping}

A cord was attached to the ankle adapter of the amputee's prosthetic leg. The researcher operated a braking mechanism to stop the cord momentarily during early swing phase of the participant's prosthetic leg (see Figure 2a). The cord was kept taut by a recoil spring that exerted a small constant force $( \pm 2 N)$, enabling constant high levels of 
responsiveness to induce a stumble. Trips were induced during multiple tests (minimally 2, maximally 5). The anticipation level was minimized by not inducing a trip during each test and by inducing the trips at random locations on the test track. Also, the researcher was positioned behind the subject to avoid possible visual cues.

\section{Stopping or sidestepping abruptly}

The participant walked towards the researcher positioned at the end of the test track (approximately $7 \mathrm{~m}$ ). During multiple tests (minimally 4, maximally 8 ) the researcher randomly hand-signalled the participant to either stop and stand with both feet parallel to one another (see Figure $2 \mathrm{~b}$ ), or to take a sidestep to the non-amputated side and stand with both feet parallel to one another (see Figure 2c). Hand signals were not given during each test to minimize anticipation. Signals were given during early swing phase of the participant's prosthetic leg.

\section{Unexpectedly stepping on an object}

Participants were asked to walk along the test track while keeping their attention focused on a fixed point on the wall in front of them, ignoring three blocks ( $215 \mathrm{~mm} \times 45 \mathrm{~mm} x$ $20 \mathrm{~mm}$ ) on the floor (see Figure $2 \mathrm{~d}$ ). The location of the blocks was varied with each test to ensure that the subject would unintentionally step on the object with the prosthetic leg (minimally 4, maximally 15). Only the tests in which the participants struck the object with the heel of the prosthetic foot were used for video analyses.

\section{Outcome measures}

Tests were recorded on video in standardized conditions and analyzed by two physical therapists blinded for knee joint condition. Assessor blinding for knee joint condition was accomplished by covering the knee joint and pylon with a skin-coloured nylon stocking. Participants' performance was scored on a newly developed performance assessment scale of 1 to 10 . Scoring was based on the amount of compensatory arm movement, the amount of trunk movement, the necessary number of recovery steps and fall occurrence (i.e. inability to recover). A score of 1 indicated an uncontrolled fall. A score of 10 indicated the subject recovered from the perturbation with little or no arm and trunk movement, and when normal gait was instantly resumed. A more detailed description of the video observation scale for the test 'tripping' is given in Table I. An average observed performance score for each of the four perturbation tests was calculated from both observer scores for each participant. The therapists also indicated the type of prosthesis they thought the subject was using in the video clips. Upon completion of all data acquisition, a blinding check was performed. 
Table I. Description of the video observation scale for perturbation test 'tripping'

\begin{tabular}{ll} 
Score & Description \\
\hline 1 & Uncontrolled fall. \\
\hline 3 & Near recovery that ends in a fall. \\
\hline 4 & $\begin{array}{l}\text { Recovery by support of the safety harness; maximal trunk flexion angle in the sagittal plane }>45^{\circ} ; \\
\text { excessive compensatory arm movement; more than } 3 \text { steps or hops necessary to come to a halt } \\
\text { before resuming gait. }\end{array}$ \\
\hline $\begin{array}{l}\text { Recovery by support of the safety harness; maximal trunk flexion angle in the sagittal plane }<45^{\circ} ; \\
\text { moderate compensatory arm movement; more than } 3 \text { steps or hops necessary to come to a halt } \\
\text { before resuming gait. }\end{array}$ \\
$\begin{array}{l}\text { Recovery without support of harness; maximal trunk flexion angle in the sagittal plane }<45^{\circ} ; \\
\text { excessive compensatory arm movement; more than } 3 \text { steps or hops necessary to come to a halt } \\
\text { before resuming gait. }\end{array}$ \\
$\begin{array}{l}\text { Recovery without support of harness; maximal trunk flexion angle in the sagittal plane }<45^{\circ} ; \\
\text { moderate compensatory arm movement; more than } 3 \text { steps or hops necessary to come to a halt } \\
\text { before resuming gait. }\end{array}$ \\
\hline 7 & $\begin{array}{l}\text { Recovery without support of harness; maximal trunk flexion angle in the sagittal plane }<45^{\circ} ; \\
\text { moderate compensatory arm movement; less than } 3 \text { steps or hops necessary to recover. }\end{array}$ \\
\hline 9 & $\begin{array}{l}\text { Recovery without support of harness; maximal trunk flexion angle in the sagittal plane }<45^{\circ} ; \text { little } \\
\text { compensatory arm movement; less than } 3 \text { steps or hops necessary to recover. }\end{array}$ \\
\hline 10 & $\begin{array}{l}\text { Recovery of without support of harness; maximal trunk flexion angle in the sagittal plane }<45^{\circ} ; \\
\text { moderate compensatory arm movement; normal gait is instantly resumed. }\end{array}$ \\
Recovery of perturbation with little or no arm and trunk movement. Normal gait is instantly \\
resumed.
\end{tabular}

The self-perceived quality of performance of recovering from a perturbation of gait was determined by posing the direct question "How would you rate your own performance of recovering after the perturbation?" for each type of perturbation. The self-perceived level of stability during the gait perturbation recovery was scored with the question "Please rate your feeling of stability on the prosthesis during the test" for each perturbation test. Both questions were answered on a 100-mm Visual Analogue Scale (VAS) ranging from 0 ('very poor') to 100 ('very good').

\section{Data analysis}

Subjects were stratified into three MFCL-2 subgroups, i.e. 'low', 'intermediate', and 'high', based on persons' self-selected walking speed ( 2 minute walk test), total activity level (accelerometry), and additional clinical information about the participants (e.g. past medical history, psychosocial status and current physical condition). Creating subgroups was a means to more intricately investigate the effects of using an MPK in the MFCL-2 population. A more detailed description of the stratification procedure is given elsewhere 9. All outcome measures were analysed for the total group and for three subgroups of participants using nonparametric statistics. Spearman's ranked correlation coefficients ${ }^{20}\left(r_{s}\right)$ were calculated to determine the level of agreement between the observed performance scores of both video raters. Alpha was set at 0.05 . 


\subsection{Results}

\section{Participants}

Forty-one persons agreed to participate in the study. The data of twenty-nine participants were analysed. For two of these participants data were only included for the mechanically controlled knee joint condition and one of the two MPK conditions. They did not complete the total study due to the onset of back pain with $\operatorname{MPK}_{A}(n=1)$ and a high sense of insecurity with $\operatorname{MPK}_{B}(n=1)$. An overview of the participant characteristics is presented in Table II. Eleven participants dropped out at an early stage in the study due to one of the following reasons: the participant's existing socket could not accommodate the MPK due to an incompatible attachment fitting $(n=4)$, the participant was not able to safely ambulate using the MPK after the 2-hour familiarization session $(n=3)$, the participant experienced physical discomfort after prolonged use of the prosthesis (e.g. skin lesions and extreme muscle ache) $(n=2)$, the participant suffered a stroke $(n=1)$, or the participant deceased from reasons unrelated to participating in the study $(n=1)$. The safety harness did not fit one participant, preventing him from participating in the perturbation tests.

Table II. Participant characteristics

\begin{tabular}{|c|c|c|c|c|c|c|c|c|c|c|}
\hline \multirow[t]{2}{*}{$\begin{array}{l}\text { MFCL-2 } \\
\text { subgroup }\end{array}$} & \multicolumn{2}{|c|}{$\begin{array}{l}\text { Gender } \\
\text { (n) }\end{array}$} & \multirow{2}{*}{$\begin{array}{l}\begin{array}{l}\text { Age } \\
\text { (years) }\end{array} \\
\text { Mean } \\
(S D)\end{array}$} & \multirow{2}{*}{$\begin{array}{l}\text { Weight } \\
(\mathrm{kg}) \\
\text { Mean } \\
(\mathrm{SD})\end{array}$} & \multicolumn{2}{|c|}{$\begin{array}{l}\text { Type of } \\
\text { amputation } \\
(n)\end{array}$} & \multirow{2}{*}{$\begin{array}{l}\text { Post- } \\
\text { amputation } \\
\text { time } \\
\text { (years) } \\
\text { Mean (SD) }\end{array}$} & \multicolumn{3}{|c|}{$\begin{array}{l}\text { Amputation aetiology } \\
(n)\end{array}$} \\
\hline & $\mathrm{M}$ & $\mathrm{F}$ & & & TA & KD & & Trauma & Vascular & Tumour \\
\hline Total & 22 & 7 & $\begin{array}{l}59.6 \\
(12.9)\end{array}$ & $\begin{array}{l}76.1 \\
(12.0)\end{array}$ & 23 & 6 & $21.1(18.4)$ & 22 & 6 & 1 \\
\hline Low & 5 & 1 & $\begin{array}{l}65.2 \\
(12.6)\end{array}$ & $\begin{array}{l}87.2 \\
(3.2)\end{array}$ & 5 & 1 & 20.3 (19.6) & 3 & 3 & 0 \\
\hline Intermediate & 10 & 1 & $\begin{array}{l}62.5 \\
(8.9)\end{array}$ & $\begin{array}{l}73.0 \\
(12.1)\end{array}$ & 8 & 3 & 20.2 (19.8) & 9 & 2 & 0 \\
\hline High & 7 & 5 & $\begin{array}{l}54.1 \\
(14.9)\end{array}$ & $\begin{array}{l}73.3 \\
(12.0)\end{array}$ & 10 & 2 & $22.4(18.1)$ & 10 & 1 & 1 \\
\hline
\end{tabular}




\section{CHAPTER 5}

\section{Observed perturbation recovery}

Mean perturbation recovery scores for all knee joint conditions of the total group and of the three subgroups are presented in Table III. The total group scores in neither of the two MPK knee joint conditions differed from the scores given in the conventional knee joint condition. Also, no differences in perturbation recovery scores were found between the mechanical knee joint condition and the MPK conditions in any of the three subgroups.

Table III. Overview of the mean observed perturbation performance scores for the different perturbation tests

\begin{tabular}{|c|c|c|c|c|c|c|c|c|c|c|c|c|}
\hline & \multicolumn{3}{|c|}{$\begin{array}{l}\text { Tripping } \\
\text { mean (SD) } \\
\end{array}$} & \multicolumn{3}{|c|}{$\begin{array}{l}\text { Stopping } \\
\text { mean (SD) }\end{array}$} & \multicolumn{3}{|c|}{$\begin{array}{l}\text { Sidestepping } \\
\text { mean (SD) }\end{array}$} & \multicolumn{3}{|c|}{$\begin{array}{l}\text { Stepping on object } \\
\text { mean (SD) }\end{array}$} \\
\hline & MCK & $\mathrm{MPK}_{\mathrm{A}}$ & $\mathrm{MPK}_{\mathrm{B}}$ & MCK & $\mathrm{MPK}_{\mathrm{A}}$ & $\mathrm{MPK}_{\mathrm{B}}$ & MCK & $\mathrm{MPK}_{\mathrm{A}}$ & $\mathrm{MPK}_{\mathrm{B}}$ & MCK & $\mathrm{MPK}_{\mathrm{A}}$ & $\mathrm{MPK}_{\mathrm{B}}$ \\
\hline $\begin{array}{l}\text { Total } \\
\mathrm{N}=29 \\
\end{array}$ & $\begin{array}{l}4.8 \\
(1.7) \\
\end{array}$ & $\begin{array}{l}5.0 \\
(1.8) \\
\end{array}$ & $\begin{array}{l}4.8 \\
(1.8) \\
\end{array}$ & $\begin{array}{l}6.5 \\
(1.5) \\
\end{array}$ & $\begin{array}{l}6.7 \\
(1.1) \\
\end{array}$ & $\begin{array}{l}6.8 \\
(1.0) \\
\end{array}$ & $\begin{array}{l}6.8 \\
(1.5) \\
\end{array}$ & $\begin{array}{l}7.1 \\
(1.0) \\
\end{array}$ & $\begin{array}{l}7.0 \\
(1.4) \\
\end{array}$ & $\begin{array}{l}6.9 \\
(1.1) \\
\end{array}$ & $\begin{array}{l}7.1 \\
(1.1) \\
\end{array}$ & $\begin{array}{l}7.1 \\
(1.1) \\
\end{array}$ \\
\hline $\begin{array}{l}\text { Low } \\
\mathrm{N}=6\end{array}$ & $\begin{array}{l}5.2 \\
(1.0) \\
\end{array}$ & $\begin{array}{l}4.6 \\
(2.1) \\
\end{array}$ & $\begin{array}{l}6.0 \\
(0.3) \\
\end{array}$ & $\begin{array}{l}6.4 \\
(1.2) \\
\end{array}$ & $\begin{array}{l}6.6 \\
(0.9) \\
\end{array}$ & $\begin{array}{l}6.6 \\
(0.7) \\
\end{array}$ & $\begin{array}{l}6.8 \\
(0.9) \\
\end{array}$ & $\begin{array}{l}6.7 \\
(1.0) \\
\end{array}$ & $\begin{array}{l}6.9 \\
(0.9) \\
\end{array}$ & $\begin{array}{l}6.2 \\
(1.4) \\
\end{array}$ & $\begin{array}{l}6.0 \\
(1.3) \\
\end{array}$ & $\begin{array}{l}6.3 \\
(0.9) \\
\end{array}$ \\
\hline $\begin{array}{l}\text { Intermediate } \\
\mathrm{N}=11\end{array}$ & $\begin{array}{l}5.1 \\
(1.5) \\
\end{array}$ & $\begin{array}{l}6.0 \\
(1.1) \\
\end{array}$ & $\begin{array}{l}4.9 \\
(1.9) \\
\end{array}$ & $\begin{array}{l}6.1 \\
(1.6) \\
\end{array}$ & $\begin{array}{l}7.2 \\
(0.7) \\
\end{array}$ & $\begin{array}{l}7.0 \\
(0.7) \\
\end{array}$ & $\begin{array}{l}6.8 \\
(1.1) \\
\end{array}$ & $\begin{array}{l}7.7 \\
(0.8) \\
\end{array}$ & $\begin{array}{l}7.2 \\
(1.1) \\
\end{array}$ & $\begin{array}{l}7.0 \\
(1.3) \\
\end{array}$ & $\begin{array}{l}7.4 \\
(0.8) \\
\end{array}$ & $\begin{array}{l}7.1 \\
(0.8) \\
\end{array}$ \\
\hline $\begin{array}{l}\text { High } \\
\mathrm{N}=12\end{array}$ & $\begin{array}{l}4.3 \\
(2.1) \\
\end{array}$ & $\begin{array}{l}4.5 \\
(2.0) \\
\end{array}$ & $\begin{array}{l}4.1 \\
(2.0) \\
\end{array}$ & $\begin{array}{l}6.8 \\
(1.4) \\
\end{array}$ & $\begin{array}{l}6.5 \\
(1.5) \\
\end{array}$ & $\begin{array}{l}6.8 \\
(1.3) \\
\end{array}$ & $\begin{array}{l}6.9 \\
(2.0)\end{array}$ & $\begin{array}{l}7.0 \\
(1.0)\end{array}$ & $\begin{array}{l}6.8 \\
(1.8)\end{array}$ & $\begin{array}{l}7.1 \\
(0.8) \\
\end{array}$ & $\begin{array}{l}7.5 \\
(1.0)\end{array}$ & $\begin{array}{l}7.5 \\
(1.1)\end{array}$ \\
\hline
\end{tabular}

$M P K_{A}$ : prosthetic knee joint with microprocessor-controlled stance and swing phase; MPK $K_{B}$ : prosthetic knee joint with microprocessor-controlled stance phase; MCK: mechanically controlled prosthetic knee joint; SD: standard deviation

The perturbation recovery scores given by the two therapists were in moderate agreement demonstrating an $r_{s}$ of 0.65 . Furthermore, the post-study blinding check indicated that the therapists' success rate of guessing the participants' type of knee joint did not deviate from normal chance.

Overall, a fall occurred in about $2 \%$ of all tests performed ( 8 out of 337 ). Two falls were sustained in the conventional knee joint condition, two falls in the $\mathrm{MPK}_{\mathrm{A}}$ condition and four falls in the $\mathrm{MPK}_{\mathrm{B}}$ condition. Seven out of the eight falls occurred during the test 'tripping', and one fall during the test 'sidestepping abruptly' on the conventional knee joint.

\section{Self-perceived perturbation recovery}

Mean scores of participants' perceived performance on the perturbation tests 'tripping', 'abruptly stopping' and 'abruptly sidestepping' for all knee joint conditions are presented in Table IV. 
Table IV. Overview of the mean self-perceived performance scores for the different perturbation tests

\begin{tabular}{llllllllll} 
& \multicolumn{1}{l}{$\begin{array}{l}\text { Tripping } \\
\text { mean (SD) }\end{array}$} & \multicolumn{3}{c}{$\begin{array}{l}\text { Stopping } \\
\text { mean (SD) }\end{array}$} & \multicolumn{3}{c}{$\begin{array}{l}\text { Sidestepping } \\
\text { mean (SD) }\end{array}$} \\
\hline & $\mathrm{MCK}$ & $\mathrm{MPK}_{\mathrm{A}}$ & $\mathrm{MPK}_{\mathrm{B}}$ & $\mathrm{MCK}$ & $\mathrm{MPK}_{\mathrm{A}}$ & $\mathrm{MPK}_{\mathrm{B}}$ & $\mathrm{MCK}$ & $\mathrm{MPK}_{\mathrm{A}}$ & $\mathrm{MPK}_{\mathrm{B}}$ \\
\hline Total & 69.2 & $81.4^{+}$ & 74.7 & 75.6 & $83.4^{+}$ & $82.9^{+}$ & 72.6 & $82.9^{+}$ & $81.0^{+}$ \\
$\mathrm{N}=29$ & $(17.1)$ & $(13.2)$ & $(18.0)$ & $(16.3)$ & $(13.0)$ & $(10.3)$ & $(15.9)$ & $(12.8)$ & $(11.4)$ \\
\hline & & & & & & & & & \\
\hline Low & 68.3 & 69.7 & 68.2 & 76.3 & 71.5 & 78.3 & 74.2 & 74.2 & 78.7 \\
$\mathrm{~N}=6$ & $(14.9)$ & $(18.6)$ & $(1.9)$ & $(13.9)$ & $(15.4)$ & $(8.1)$ & $(9.8)$ & $(16.1)$ & $(10.5)$ \\
\hline Intermediate & 73.0 & $87.7^{+}$ & 82.3 & 77.4 & $86.0^{*}$ & 84.5 & 77.8 & $88.0^{*}$ & 83.4 \\
$\mathrm{~N}=11$ & $(17.2)$ & $(9.2)$ & $(14.0)$ & $(15.5)$ & $(13.5)$ & $(12.1)$ & $(13.2)$ & $(12.7)$ & $(14.4)$ \\
\hline High & 66.2 & $82.0^{+}$ & 71.7 & 73.5 & $87.2^{+}$ & 83.9 & 67.0 & $83.0^{*}$ & 80.3 \\
$\mathrm{~N}=12$ & $(18.6)$ & $(9.4)$ & $(23.4)$ & $(19.0)$ & $(7.7)$ & $(9.7)$ & $(19.5)$ & $(9.4)$ & $(9.4)$ \\
\hline
\end{tabular}

$M P K_{A}$ : prosthetic knee joint with microprocessor-controlled stance and swing phase; MPK $:$ prosthetic knee joint with microprocessor-controlled stance phase; MCK: mechanically controlled prosthetic knee joint; SD: standard deviation; + significant difference in comparison with MCK condition ( $p \leq 0.01) ;{ }^{*}$ significant difference in comparison with MCK condition ( $p \leq 0.025)$

The mean self-perceived performance scores of the total group for the 'tripping' test, the 'abruptly stopping' test and the 'abruptly sidestepping' test were significantly higher (17.6\%, 10.3\%, and $14.2 \%$ increase, respectively) in the $\mathrm{MPK}_{\mathrm{A}}$ condition compared with the mechanically controlled knee joint condition. In the $\mathrm{MPK}_{\mathrm{B}}$ condition, mean values of the self-perceived performance scores were significantly higher than in the mechanically controlled knee joint condition for both the 'abruptly stopping' test and the 'abruptly sidestepping' test ( $9.7 \%$ and $11.6 \%$ increase, respectively), but not for the 'tripping' test. The self-perceived performance scores of participants in subgroup 'low' did not differ between knee joint conditions. The participants in subgroup 'intermediate' showed an $11.1 \%-20.1 \%$ ( $p \leq 0.025$ ) increase, and the participants in subgroup 'high' an increase of $18.6 \%-23.9 \%(p \leq 0.025)$ in perceived performance scores in the $\mathrm{MPK}_{\mathrm{A}}$ condition compared with the mechanically controlled knee joint condition across all perturbation tests. No differences in perceived performance scores were found between the $\mathrm{MPK}_{\mathrm{B}}$ condition and the mechanically controlled knee joint condition in any of the subgroups.

\section{Self-perceived level of stability}

An overview of the mean scores regarding the self-perceived level of stability is presented in Table V. Participants' mean values (total group) of the self-perceived level of stability scores with $\mathrm{MPK}_{\mathrm{A}}$ were significantly higher for all perturbation tests (10.0\%-18.9\%) in comparison with the scores in the mechanically controlled knee joint condition. Mean values of participants' self-perceived level of stability scores (total group) with $\mathrm{MPK}_{\mathrm{B}}$ 


\section{CHAPTER 5}

were significantly higher for the 'abruptly stopping' test, the 'abruptly sidestepping' test, and the 'stepping on an object' test (7.6\%, 12.9\%, and $15.2 \%$, respectively) compared with scores in the conventional knee joint condition. No difference was found in total group scores of the 'tripping' test between the $\mathrm{MPK}_{\mathrm{B}}$ and mechanically controlled knee joint conditions.

Table V. Overview of the mean self-perceived level of stability scores for the different perturbation tests

\begin{tabular}{|c|c|c|c|c|c|c|c|c|c|c|c|}
\hline & \multicolumn{3}{|c|}{$\begin{array}{l}\text { Tripping } \\
\text { mean (SD) }\end{array}$} & \multicolumn{3}{|c|}{$\begin{array}{l}\text { Stopping } \\
\text { mean (SD) }\end{array}$} & \multicolumn{3}{|c|}{$\begin{array}{l}\text { Sidestepping } \\
\text { mean (SD) }\end{array}$} & \multicolumn{2}{|c|}{$\begin{array}{l}\text { Stepping on object } \\
\text { mean (SD) }\end{array}$} \\
\hline & MCK & $\mathrm{MPK}_{\mathrm{A}}$ & $\mathrm{MPK}_{\mathrm{B}}$ & MCK & $\mathrm{MPK}_{\mathrm{A}}$ & $\mathrm{MPK}_{\mathrm{B}}$ & MCK & $\mathrm{MPK}_{\mathrm{A}}$ & $\mathrm{MPK}_{\mathrm{B}}$ & MCK & $\mathrm{MPK}_{\mathrm{A}} \mathrm{MPK}_{\mathrm{B}}$ \\
\hline $\begin{array}{l}\text { Total } \\
\mathrm{N}=29\end{array}$ & $\begin{array}{l}71.5 \\
(14.0)\end{array}$ & $\begin{array}{l}81.5^{\dagger} \\
(14.8)\end{array}$ & $\begin{array}{l}77.0 \\
(18.2) \\
\end{array}$ & $\begin{array}{l}73.4 \\
(15.8) \\
\end{array}$ & $\begin{array}{l}84.2^{+} \\
(13.5)\end{array}$ & $\begin{array}{l}82.9^{\dagger} \\
(10.5)\end{array}$ & $\begin{array}{l}76.0 \\
(15.1) \\
\end{array}$ & $\begin{array}{l}83.6^{\dagger} \\
(12.7)\end{array}$ & $\begin{array}{l}81.8^{*} \\
(12.2)\end{array}$ & $\begin{array}{l}70.3 \\
(19.6) \\
\end{array}$ & $\begin{array}{ll}83.6^{\dagger} & 81.0^{\dagger} \\
(11.7) & (12.3) \\
\end{array}$ \\
\hline $\begin{array}{l}\text { Low } \\
N=6\end{array}$ & $\begin{array}{l}72.3 \\
(12.2)\end{array}$ & $\begin{array}{l}69.7 \\
(20.4)\end{array}$ & $\begin{array}{l}73.7 \\
(8.4)\end{array}$ & $\begin{array}{l}65.7 \\
(18.5)\end{array}$ & $\begin{array}{l}73.0 \\
(16.9)\end{array}$ & $\begin{array}{l}76.8 \\
(11.0)\end{array}$ & $\begin{array}{l}75.3 \\
(10.9)\end{array}$ & $\begin{array}{l}74.2 \\
(19.0)\end{array}$ & $\begin{array}{l}74.7 \\
(13.2)\end{array}$ & $\begin{array}{l}64.0 \\
(24.3)\end{array}$ & $\begin{array}{ll}72.5 & 70.7 \\
(13.6) & (9.9)\end{array}$ \\
\hline $\begin{array}{l}\text { Intermediate } \\
\mathrm{N}=11\end{array}$ & $\begin{array}{l}74.0 \\
(14.9) \\
\end{array}$ & $\begin{array}{l}88.1^{\dagger} \\
(10.9)\end{array}$ & $\begin{array}{l}80.2 \\
(20.6) \\
\end{array}$ & $\begin{array}{l}78.3 \\
(13.3) \\
\end{array}$ & $\begin{array}{l}87.2^{*} \\
(13.2)\end{array}$ & $\begin{array}{l}83.6 \\
(13.0) \\
\end{array}$ & $\begin{array}{l}80.2 \\
(11.6) \\
\end{array}$ & $\begin{array}{l}87.6^{*} \\
(9.9)\end{array}$ & $\begin{array}{l}84.0 \\
(15.4) \\
\end{array}$ & $\begin{array}{l}75.1 \\
(16.4) \\
\end{array}$ & $\begin{array}{ll}87.3 & 83.5 \\
(10.5) & (15.7) \\
\end{array}$ \\
\hline $\begin{array}{l}\text { High } \\
\mathrm{N}=12\end{array}$ & $\begin{array}{l}68.8 \\
(14.7)\end{array}$ & $\begin{array}{l}82.0 \\
(11.6)\end{array}$ & $\begin{array}{l}76.0 \\
(20.5)\end{array}$ & $\begin{array}{l}72.9 \\
(16.3)\end{array}$ & $\begin{array}{l}87.3^{+} \\
(9.3)\end{array}$ & $\begin{array}{l}85.3 \\
(7.3)\end{array}$ & $\begin{array}{l}72.6 \\
(19.4)\end{array}$ & $\begin{array}{l}85.0 \\
(9.2)\end{array}$ & $\begin{array}{l}83.5^{*} \\
(7.5)\end{array}$ & $\begin{array}{l}68.8 \\
(20.4)\end{array}$ & $\begin{array}{ll}86.2^{*} & 84.5^{\dagger} \\
(8.3) & (6.4)\end{array}$ \\
\hline
\end{tabular}

$M P K_{A}$ : prosthetic knee joint with microprocessor-controlled stance and swing phase; MPK $:$ prosthetic knee joint with microprocessor-controlled stance phase; MCK: mechanically controlled prosthetic knee joint; SD: standard deviation

Participants in subgroup 'low' showed no differences in perceived stability scores between the mechanically controlled knee joint and any of the two MPKs.

Participants in subgroup 'intermediate' showed increased mean perceived stability scores for $\mathrm{MPK}_{\mathrm{A}}$ compared to the mechanically controlled prosthesis in the 'tripping' test, the 'abruptly stopping' test, and the 'abruptly sidestepping' test (19.1\%, $11.4 \%, 9.2 \%$, respectively; $\mathrm{p} \leq 0.025)$, but not in the 'stepping on an object' test. Participants in this subgroup showed no differences in stability scores between $\mathrm{MPK}_{\mathrm{B}}$ and the mechanically controlled knee joint.

In subgroup 'high' the mean perceived stability scores were increased in the $\mathrm{MPK}_{\mathrm{A}}$ condition on the 'stopping' and 'stepping on an object' tests $(19.8 \%$ and $25.3 \%$, respectively; $\mathrm{p} \leq 0.025)$. The stability scores on the 'sidestepping' and 'stepping on an object' tests were also increased for $\mathrm{MPK}_{\mathrm{B}}(15.0 \%$ and $22.8 \%$ respectively; $\mathrm{p} \leq 0.025)$. No differences were found in this subgroup between the mechanically controlled knee joint and the MPKs on the other tests. 


\subsection{Discussion}

This study aimed to assess the effects of two types of microprocessor-controlled prosthetic knee joints (MPKs) in MFCL-2 amputees on both their performed ability to recover from different types of induced gait perturbations, and on their self-assessed performance and sense of stability on the prosthesis during those perturbations. The recovery of the perturbations in gait did not seem to differ between the mechanically controlled knee joint and the MPKs. Yet participants report to feel more capable to successfully recover from gait perturbations and also experience increased levels of stability during situations with a high risk of falling.

Few studies have specifically investigated the effects of MPKs on safety aspects in amputees with a limited function level (MFCL-2). Hafner \& Smith ${ }^{21}$ reported a reduction in stumble frequency and the occurrence of falls in persons classified as MFCL-2 who use an MPK in comparison with a mechanically controlled knee joint. Also, Wetz et al. ${ }^{22}$ concluded that MFCL-2 subjects may benefit considerably from the static safety of the MPK. In terms of actual performance, our findings are not in agreement with the findings of these earlier studies. The MPKs do not seem to have an effect on persons' actual ability to (successfully) recover from a perturbation of gait in MFCL-2 amputees. On the other hand, their performance did not deteriorate either after one week of accommodation time with the MPK.

The occurrence of falls during the tests was very small (2\%). A considerably higher number of falls was expected to occur, because MFCL-2 amputees are typically older and show compromised muscle strength and coordination, which reduces their ability to successfully counteract a perturbation of gait ${ }^{23,24}$. Also, in two previous studies that used a similar protocol to test perturbation recovery in MFCL-3 and MFCL-4 amputees 19,25 , multiple uncontrolled falls occurred during the different perturbation tests. An explanation for the small number of falls in the present study may be that MFCL-2 amputees seem to respond differently to critical high-risk situations than amputees with higher functional levels. Possibly our participants performed the perturbation tests with a so-called 'cautious gait', common in older persons ${ }^{26}$. A cautious gait is characterised by a lower walking velocity, a smaller stride length and an increased double support time ${ }^{26}$. This optimises balance and increases the necessary response time to a perturbation of gait, thereby improving the chance to a successful recovery. This may have led to the similar performance in all three knee joint conditions. The supposition that MFCL-2 amputees may be more cautious ambulators than MFCL-3 or MFCL- 4 amputees is supported by 


\section{CHAPTER 5}

findings of Hafner \& Smith ${ }^{21}$. Their data show a mean frequency of stumbles and semicontrolled falls that is almost two times lower in persons classified as MFCL-2 compared with persons classified as MFCL-3.

The findings regarding persons' perceived perturbation recovery and perceived level of stability suggest that the MPK may positively influence balance confidence level of MFCL2 amputees. Miller et al. ${ }^{3}$ defined balance confidence as the belief that the individual has the capability to successfully perform an activity or action. Strong associations have been found between balance confidence and the level of mobility and societal participation 4, 27, 28. Fear-related activity avoidance can gradually lead to social isolation, a reduced physical condition, an increased risk of falling and, eventually, a further increase of the fear of falling ${ }^{29}$. Improving the MFCL-2 amputees' balance confidence level may therefore have major benefits for their quality of life. It might be expected that after extended use of the MPK, the increased self-confidence level causes the amputee to carry out daily activities he would normally avoid because of fear of falling. In turn, this may even further increase the confidence level and functional mobility level in MFCL-2 amputees.

The stratification of the group of participants into three subgroups has shown that especially participants in the subgroups 'intermediate' and 'high' reported significant improvements in self-assessed performance and stability on the perturbation tests, while the MPKs seemed to have no effects on self-assessed performance and stability in participants in subgroup 'low'. This corroborates previous findings of Theeven et al. ${ }^{9}$ who reported a similar trend of the effects of using an MPK with regard to persons' ability to perform activities of daily living.

\section{Study limitations}

The order of testing the MPKs was randomised, but participants always started the study with their mechanically controlled prosthesis. This design was chosen because it closely resembles current clinical practice in The Netherlands, where a patient is transitioned from his current prosthesis to a prosthesis featuring an MPK. As MFCL-2 amputees are typically not prescribed an MPK, their current prosthesis is often a prosthesis fitted with a mechanically controlled knee joint. The researchers realise that this approach may have introduced prior knowledge about the test procedures when walking with either one of the MPKs and thus may have influenced the results. However, participants performed each test only a limited number of times with a one week period between each knee joint. It seems unlikely that participants improved their muscle strength or motor responses as a result of repeated exposure to the tests. 
In addition, a subjective measure has been used to assess subjects' perceived performance, which may be susceptible to influences other than just the intended intervention. For instance, participants' expectations or prior knowledge about MPKs may have led them to exaggerate the benefits of the MPKs by giving answers that they consider to socially desirable. Blinding of participants regarding prosthesis condition would have eliminated this problem. However, this was not possible. During the familiarization session the different features of the MPKs had to be explained to enable subjects to use each MPK to its full potential and to ensure safe use outside the rehabilitation centre. Also, subjects would have undoubtedly noticed whether they were fitted with their own mechanically controlled knee joint or with an MPK, because, for example, in contrast to the mechanically controlled knee joint, the MPK has a battery that needs to be recharged every day. The perceived performance scores reported should therefore be interpreted with care.

The accommodation period of one week was relatively short for the participants and may have prevented them from using the MPK to its full potential. However, no clear consensus exists concerning the optimal accommodation time for a new prosthetic component. English et al. reported that a one-week familiarisation period is adequate in clinical practice, but for research purposes, a familiarisation period of at least 3 weeks is recommended ${ }^{30}$. Other studies comparing an MPK with a mechanically controlled prosthesis reported accommodation periods ranging from several minutes to 39 weeks $8,10,11,13,17,19,21,31-36$. Nonetheless, in the current study, participants already experienced differences regarding stability and self-perceived performance during recovery following gait perturbation after one week of using an MPK.

\section{Future research}

More sensitive measuring tools have to be used or developed in order to detect the possibly subtle differences in the whole body performance of amputees using either an MPK or a conventional knee joint. As more salient differences were expected prior to the start of this study, a video analysis method was chosen because of its general use in clinical practice and because it enables assessment of the whole body response, which suited the purpose of our study. Although the inter-rater reliability and assessor blinding were checked, further refinement of the video analysis method is, however, warranted. In conclusion, the present study has shown that persons classified as MFCL-2 show similar recovery responses to induced perturbations in gait with both a mechanically controlled prosthesis and a prosthesis fitted with an MPK. Nevertheless, using an MPK seemed to 


\section{CHAPTER 5}

increase persons' self-perceived ability to counteract a perturbation of gait and they feel more stable in critical situations compared with their mechanically controlled prosthesis.

\subsection{Acknowledgements}

The authors would specially like to thank Guido Meys of Adelante Rehabilitation Centre for his valuable contribution to the study. The support of Sven Balk during the physical therapy sessions is greatly appreciated. We would like to thank Frans Rings and his colleague prosthetists at Livit Orthopedie B.V., Hoensbroek, The Netherlands, for their support in fitting of the knee prostheses. 


\subsection{References}

1. Gauthier-Gagnon C, Grisé M-C, Potvin D. Enabling factors related to prosthetic use by people with transtibial and transfemoral amputation. Arch Phys Med Rehabil 1999; 80:706-713.

2. Miller WC, Speechley M, Deathe B. The prevalence and risk factors of falling and fear of falling among lower extremity amputees. Arch Phys Med Rehabil 2001; 82:1031-1037.

3. Miller WC, Speechley M, Deathe AB. Balance confidence among people with lower-limb amputations. Phys Ther 2002; 82:856-865.

4. Miller WC, Deathe $A B$, Speechley $M$, Koval J. The influence of falling, fear of falling, and balance confidence on prosthetic mobility and social activity among individuals with a lower extremity amputation. Arch Phys Med Rehabil 2001; 82:1238-1244.

5. Berry D, Olson MD, Larntz K. Perceived stability, function, and satisfaction among transfemoral amputees using microprocessor and nonmicroprocessor controlled prosthetic knees: a multicentre survey. J Prosthet Orthot 2009; 21:32-42.

6. Datta D, Howitt J. Conventional versus microchip controlled pneumatic swing phase control for transfemoral amputees: user's verdict. Prosthet Orthot Int 1998; 22:129-135.

7. Hafner BJ, Willingham LL, Buell NC, Allyn KJ, Smith DG. Evaluation of function, performance, and preference as transfemoral amputees transition from mechanical to microprocessor control of the prosthetic knee. Arch Phys Med Rehabil 2007; 88:207-217.

8. Kahle JT, Highsmith MJ, Hubbard SL. Comparison of nonmicroprocessor knee mechanism versus C-Leg on Prosthesis Evaluation Questionnaire, stumbles, falls, walking tests, stair descent, and knee preference. J Rehabil Res Dev 2008; 45:1-14.

9. Theeven PJR, Hemmen B, Rings F, Meys G, Brink PRG, Smeets RJEM, et al. Functional added value of microprocessor-controlled prosthetic knee joints in daily life performance of Medicare Functional Classification Level-2 amputees. J Rehabil Med 2011; 43:906-915.

10. Kaufman KR, Levine JA, Brey RH, Iverson BK, McCrady SK, Padgett DJ, et al. Gait and balance of transfemoral amputees using passive mechanical and microprocessor-controlled prosthetic knees. Gait Posture 2007; 26:489-493.

11. Orendurff MS, Segal AD, Klute GK, McDowell ML, Pecoraro JA, Czerniecki JM. Gait efficiency using the C-Leg. J Rehabil Res Dev 2006; 43:239-246.

12. Seymour R, Engbretson B, Kott K, Ordway N, Brooks G, Crannell J, et al. Comparison between the C-leg microprocessor-controlled prosthetic knee and non-microprocessor control prosthetic knees: a preliminary study of energy expenditure, obstacle course performance, and quality of life survey. Prosthet Orthot Int 2007; 31:51-61.

13. Segal AD, Orendurff MS, Klute GK, McDowell ML, Pecoraro JA, Shofer J, et al. Kinematic and kinetic comparisons of transfemoral amputee gait using C-Leg and Mauch SNS prosthetic knees. J Rehabil Res Dev 2006; 43:857-870. 


\section{CHAPTER 5}

14. Bellmann M, Schmalz T, BlumentrittS. Comparative biomechanical analysis of current microprocessorcontrolled prosthetic knee joints. Arch Phys Med Rehabil 2010; 91:644-652.

15. Highsmith MJ, Kahle JT, Bongiorni DR, Sutton BS, Groer S, Kaufman KR. Safety, energy efficiency, and cost efficacy of the C-Leg for transfemoral amputees: A review of the literature. Prosthet Orthot Int 2010; 34:362-377.

16. Theeven PJR, Hemmen B, Geers RPJ, Brink PRG, Smeets RJEM, Seelen HAM. Influence of advanced prosthetic knee joints on perceived performance and everyday life activity level of low-functional persons with a transfemoral amputation or knee disarticulation. J Rehabil Med 2012; 44:454-461.

17. Klute GK, Berge JS, Orendurff MS, Williams RM, Czerniecki JM. Prosthetic intervention effects on activity of lower-extremity amputees. Arch Phys Med Rehabil 2006; 87:717-722.

18. Centers for Medicare and Medicaid Services. U.S. Department of Health and Human Services. HCFA Common Procedure Coding System (HCPCS). Springfield (VA): U.S. Department of Commerce, National Technical Information Service; 2001.

19. Blumentritt S, Schmalz T, Jarasch R. The safety of C-leg: biomechanical tests. J Prosthet Orthot 2009; 21:2-15.

20. Field A. Discovering statistics using SPSS. 2nd ed. London: SAGE publications; 2005.

21. Hafner BJ, Smith DG. Differences in function and safety between Medicare Functional Classification Level-2 and -3 transfemoral amputees and influence of prosthetic knee joint control. J Rehabil Res Dev 2009; 46:417-433.

22. Wetz HH, Hafkemeyer U, Drerup B. Einfluss des C-Leg-Kniegelenk-Passteiles der Fa. Otto Bock auf die Versorgungsqualität Oberschenkelamputierter. Eine klinisch-biomechanische Studie zur Eingrenzung von Indikationskriterien [The influence of the C-leg knee-shin system from the Otto Bock Company in the care of above-knee amputees. A clinical-biomechanical study to define indications]. Orthopäde $2005 ; 34: 298-319$.

23. Pavol MJ, Owings TM, Foley KT, Grabiner MD. Influence of lower extremity strength of healthy older adults on the outcome of an induced trip. J Am Geriatr Soc 2002; 50:256-262.

24. Pijnappels $M$, Reeves ND, Maganaris CN, van Dieen JH. Tripping without falling; lower limb strength, a limitation for balance recovery and a target for training in the elderly. J Electromyogr Kinesiol 2008; 18:188-196.

25. Kaufman KR, Anderson $T$, Schneider G, Walsh $K$. Mechanisms of stumble recovery: nonmicroprocessor controlled compared to microprocessor-controlled prosthetic knees. The American Academy of Orthotics and Prosthetics 34th annual meeting and scientific symposium; 2008 February 27-March 1; Orlando (FL.), USA; 2008.

26. Giladi N, Herman T, Reider G, II, Gurevich T, Hausdorff JM. Clinical characteristics of elderly patients with a cautious gait of unknown origin. J Neurol 2005; 252:300-306.

27. Bertera EM, Bertera RL. Fear of falling and activity avoidance in a national sample of older adults in 
the United States. Health Soc Work 2008; 33:54-62.

28. Fletcher PC, Hirdes JP. Restriction in activity associated with fear of falling among community-based seniors using home care services. Age Ageing 2004; 33:273-279.

29. Delbaere K, Crombez G, Vanderstraeten G, Willems T, Cambier D. Fear-related avoidance of activities, falls and physical frailty. A prospective community-based cohort study. Age Ageing 2004; 33:368373.

30. English RD, Hubbard WA, McElroy GK. Establishment of consistent gait after fitting of new components. J Rehabil Res Dev 1995; 32:32-35.

31. Buckley JG, Spence WD, Solomonidis SE. Energy cost of walking: comparison of "intelligent prosthesis" with conventional mechanism. Arch Phys Med Rehabil 1997; 78:330-333.

32. Johansson JL, Sherrill DM, Riley PO, Bonato P, Herr H. A clinical comparison of variable-damping and mechanically passive prosthetic knee devices. Am J Phys Med Rehabil 2005; 84:563-575.

33. Kaufman KR, Levine JA, Brey RH, McCrady SK, Padgett DJ, Joyner MJ. Energy expenditure and activity of transfemoral amputees using mechanical and microprocessor-controlled prosthetic knees. Arch Phys Med Rehabil 2008; 89:1380-1385.

34. Petersen AO, Comins J, Alkjaer T. Assessment of gait symmetry in transfemoral amputees using C-leg compared with $3 R 60$ prosthetic knees. J Prosthet Orthot 2010; 22:106-112.

35. Taylor MB, Clark E, Offord EA, Baxter C. A comparison of energy expenditure by a high level transfemoral amputee using the Intelligent Prosthesis and conventionally damped prosthetic limbs. Prosthet Orthot Int 1996; 20:116-121.

36. Yokogushi K, Narita H, Uchiyama E, Chiba S, Nosaka T, Yamakoshi KI. Biomechanical and clinical evaluation of a newly designed polycentric knee of transfemoral prosthesis. J Rehabil Res Dev 2004; 41:675-681. 


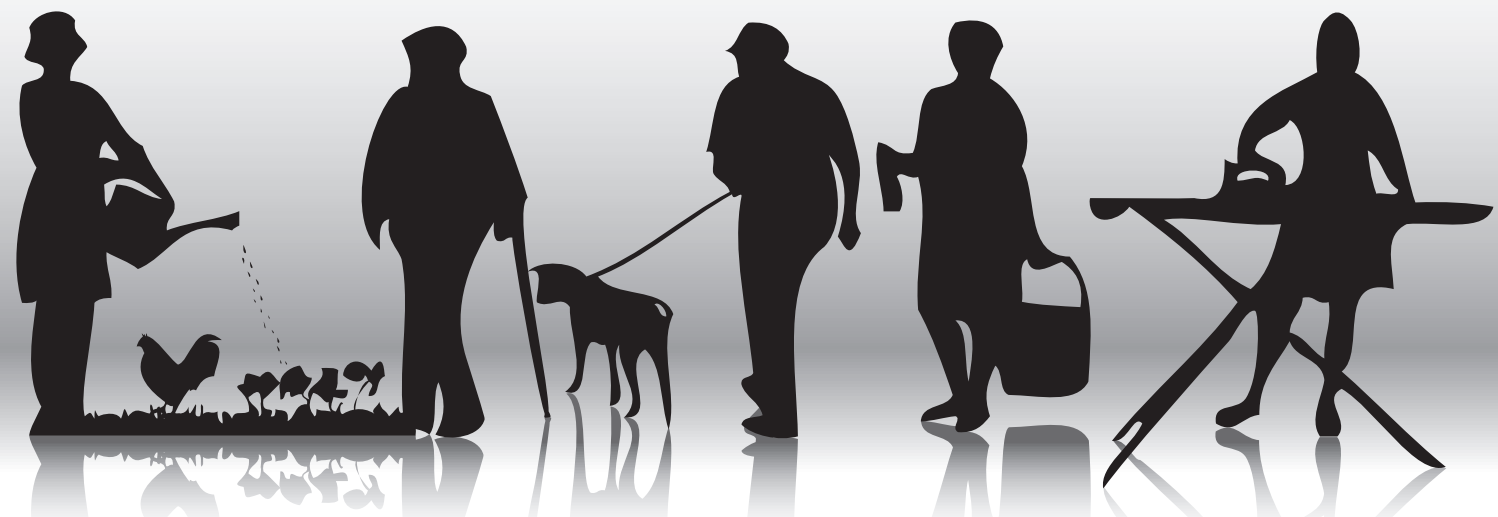




\section{Chapter 6}

Influence of advanced prosthetic knee joints on perceived performance and everyday life activity level of low-functional persons with a transfemoral amputation or knee disarticulation

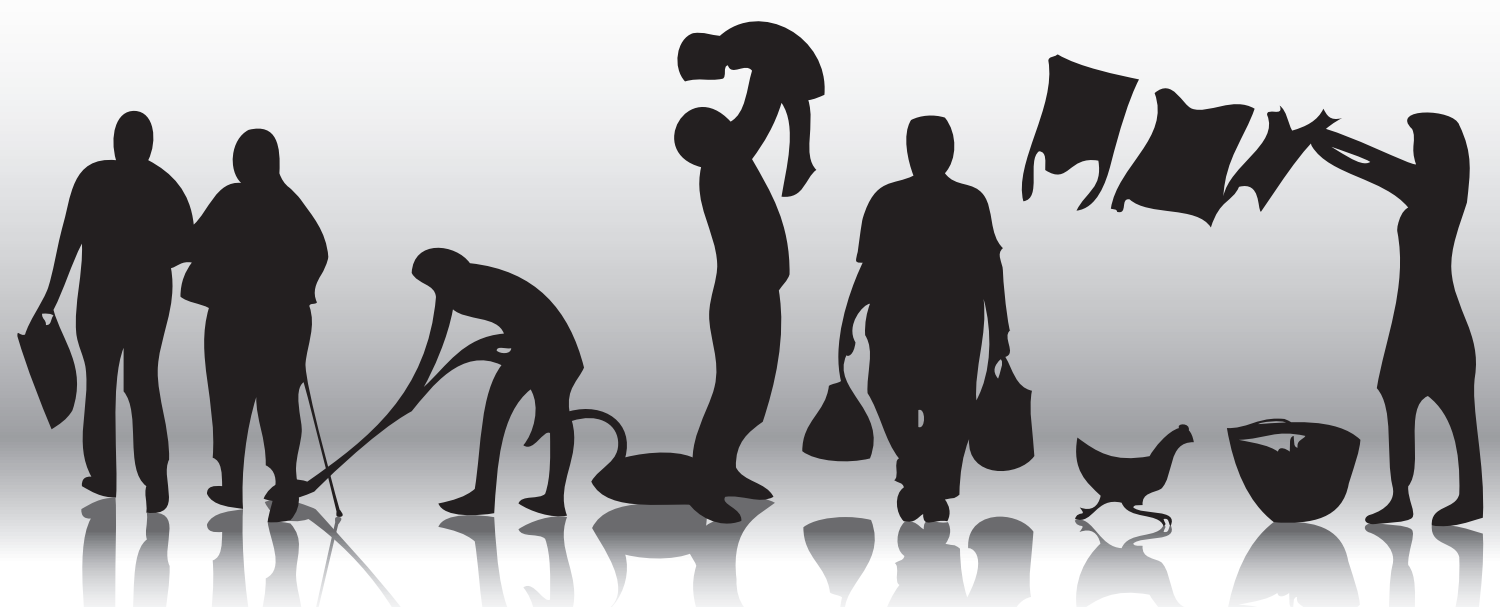




\section{Abstract}

Objective: To assess the effects of two types of microprocessor-controlled prosthetic knee joints (MPKs) on perceived performance and everyday life activity level.

Design: Randomized cross-over trial.

Subjects: Thirty persons with a unilateral above-knee amputation or knee disarticulation classified as Medicare Functional Classification Level-2.

Methods: Participants were measured in 3 conditions, i.e. using a mechanically controlled prosthesis, an MPK featuring a microprocessor-controlled stance and swing phase $\left(\mathrm{MPK}_{\mathrm{A}}\right)$, and an MPK featuring a microprocessor-controlled stance phase $\left(\mathrm{MPK}_{\mathrm{B}}\right)$. Subjects' perceived performance regarding prosthesis use was measured with the Prosthesis Evaluation Questionnaire. Subjects' activity level was quantified using accelerometry. As high within-group variability regarding subjects' functional performance was expected to impede detection of possible effects of an MPK, data were analysed for the total group and for 3 subgroups of participants.

Results: Participants' perception regarding ambulation, residual limb health, utility, and satisfaction with walking were significantly higher in the $\mathrm{MPK}_{\mathrm{A}}$ condition compared with the mechanical knee joint condition. Participants' activity level was similar in all knee joint conditions.

Conclusions: Although Medicare Functional Classification Level-2 amputees report benefitting in terms of their performance from using an MPK, this is not reflected in their actual daily activity level after one week of using an MPK. 


\subsection{Introduction}

Ambulating with a prosthetic limb is known to be a demanding task, both physically and mentally. Persons with a transfemoral amputation are less efficient ambulators in comparison with able-bodied persons, demonstrating a $27 \%-49 \%$ increased energy expenditure when walking at self-selected velocities. Moreover, the self-selected walking velocities of persons with an amputation are considerably lower ${ }^{1,2}$. The loss of motor control at the ankle and knee makes maintaining balance more difficult, which may reduce persons' sense of stability, safety and balance confidence ${ }^{3,4}$. In addition, due to the absence of somatosensory feedback from the amputated leg, persons with an aboveknee amputation have to rely on other stimuli (e.g. vision) to control the prosthesis during ambulation, which may interfere with their ability to concentrate on concurrent tasks ${ }^{5}$. In an attempt to decrease the physical or mental strain, persons with a leg amputation may alter, reduce, or avoid the performance of strenuous activities such as walking ${ }^{6,7}$. This eventually affects their level of participation in daily life ${ }^{3,8-10}$. This poses a problem, because activity avoidance may lead to further deterioration of a person's physical condition and eventually to additional loss of mobility ${ }^{9}$.

Manufacturers of microprocessor-controlled prosthetic knee joints (MPKs) generally claim that the continuous active control of the stance and/or swing phase featured in the MPK may help reduce the physical and mental load of walking with a prosthesis, thus enhancing the functional mobility of persons with an amputation. Much research has been performed to assess the effects of MPKs on persons' level of functioning. Many of the studies performed focused on the level of 'body function and structures', defined by the International Classification of Functioning, Disability, and Health (ICF) ${ }^{11}$. Only little is known about the effects of using an MPK at the ICF levels of activity and participation. Moreover, as outcome measures at the ICF level of body functions and structures typically measure actual performance, outcome measures at the ICF levels of activity and participation often have to rely on patients' perceived performance. The findings of studies that focused on actual performance, such as gait symmetry ${ }^{12-14}$, the level of energy efficiency of walking ${ }^{15-19}$, or the daily activity level ${ }^{20-22}$, are not always in agreement with findings concerning the perceived performance of persons who transitioned from a mechanically controlled knee joint to an MPK. They report increased ease of walking with the MPK ${ }^{23}$.

MPKs have been specially developed for persons with a high functional mobility level, i.e. persons who have been classified as Medicare Functional Classification Level-3 or -4 


\section{CHAPTER 6}

(MFCL-3 or MFCL-4) ${ }^{24}$ or Mobis ${ }^{\circledR}$ grade 3 or 4 (K3 or K4) ${ }^{25}$. Those persons have the ability or potential to ambulate with variable cadence and have the ability or potential to be involved in activities that demand prosthetic utilization beyond simple locomotion ${ }^{24}$. Very little is known about the effects of using an MPK in individuals with a lower functional mobility level (MFCL-2 or K2). These persons have the ability or potential to ambulate indoors and are able to overcome low-level environmental barriers (e.g. kerbs, stairs, or uneven surfaces) ${ }^{24}$.

The MFCL-2 population is seen by clinicians involved in amputation and prosthetics as being more heterogeneous regarding functional performance in comparison with persons with a higher functional level. This heterogeneity has recently been confirmed in a study by Theeven et al. ${ }^{26}$. Persons classified as MFCL-2 typically are older, have a more proximal level of amputation, have reduced muscle strength and coordination, have more comorbidities and are often amputated due to peripheral vascular disease. This group also includes individuals who were formerly classified as MFCL-3, but who, due to age or other medical causes, lost specific ambulation and prosthetic utilization skills, and hence were given a lower MFCL grade.

In 2004 an MPK with a microprocessor-controlled stance phase (C-leg ${ }^{\circledR}$ Compact, Otto Bock HealthCare, Vienna, Austria) was introduced particularly for individuals classified as MFCL-2. This MPK aimed to offer a high level of security to its user. The results of previous studies suggest that most persons with an amputation classified as MFCL-2 who use a prosthesis fitted with an MPK instead of a mechanically controlled knee joint show an increased level of functional ability to perform daily activities, fall less and may experience a higher sense of safety and stability in critical situations ${ }^{26-28}$. Although those findings suggest that an MPK may reduce the physical and mental strain of ambulating with a prosthesis in persons classified as MFCL-2, it is not known whether these advantageous effects will actually lead to these persons becoming more active in everyday life. In addition, it is important to take the perspective of persons with a leg amputation regarding prosthesis use into account when evaluating prosthetic components. Prosthesis use may be greatly influenced by the level of satisfaction with the prosthesis ${ }^{29}$.

The aim of this study was to investigate possible changes in perceived performance of persons classified as MFCL-2 who transition from a mechanically controlled prosthetic knee joint to an MPK. This study also assessed whether such a transition between 
prosthetic knee joints affects their everyday activity level. It is hypothesized that an MPK will reduce the physical and mental strain of ambulating with a prosthesis (as perceived by the participants), which in turn will encourage subjects to perform more activities during the day.

\subsection{Methods}

\section{Participants}

Eligible individuals $(n=103)$ were identified from patient records of rehabilitation centers, hospitals and prosthetic and orthotic care centers in the southern region of The Netherlands and north-eastern region of Belgium. Each person was screened by a panel of experts, including a rehabilitation physician, a senior physiotherapist, and a senior prosthetist, to determine the person's MFCL level. Factors such as age, cause of amputation, physical condition, comorbidities, pain, and fear of falling were taken into account during classification. Inclusion criteria were: unanimously diagnosed by the screening panel as MFCL-2; over 18 years of age; having a transfemoral amputation or knee disarticulation; daily use of a leg prosthesis fitted with a mechanically controlled knee joint; finished rehabilitation for at least one year; able to walk at least $500 \mathrm{~m}$ per day; no previous experience using an MPK. Exclusion criteria were: severe orthopedic, rheumatological, neurological or cardiovascular disease in addition to the amputation that might impede performance; severe perceptual or cognitive disorders; and/or skin problems of the stump.

Approval was obtained from the institutional medical ethics committee of the Rehabilitation Foundation Limburg (currently: Adelante Rehabilitation Centre), Hoensbroek, The Netherlands. Written informed consent was obtained from all subjects prior to their participation.

\section{Design}

A double crossover study design was used, in which participants were measured in 3 different prosthetic knee joint conditions, i.e. a mechanical knee joint condition and 2 different types of MPK conditions. In the mechanical knee joint condition, participants used their current, mechanically controlled knee joint (3R80, 3R106, 3R60, 3R92 (Otto Bock, Vienna Austria), Acphapend (Proteval, Valenton, France), Ultimate (Ortho Europe, Oxfordshire, UK), Total Knee, Mauch Knee (Össur, Reykjavik, Iceland), Graph-Lite (Teh Lin Prosthetics \& Orthopaedics, Kuala Lumpur, Malaysia) or manual locking knee). 


\section{CHAPTER 6}

The MPK conditions involved a knee joint with a microprocessor-controlled stance and swing phase (C-leg ${ }^{\circledR}$, Otto Bock) and a knee joint with a microprocessor-controlled stance phase (C-leg ${ }^{\circledR}$ Compact, Otto Bock). The MPK conditions are abbreviated as $\mathrm{MPK}_{\mathrm{A}}$ (C-leg) and $\mathrm{MPK}_{\mathrm{B}}$ (C-leg Compact), respectively.

The participants were assessed in each knee joint condition during a 1-week period in the participants' home and community environment. At the end of each week (at $t_{0}, t_{2}$, and $t_{4}$ ), participants' perceived performance and satisfaction with the prosthesis was assessed. The study design is illustrated in Figure 1.

Figure 1. Overview of the study design

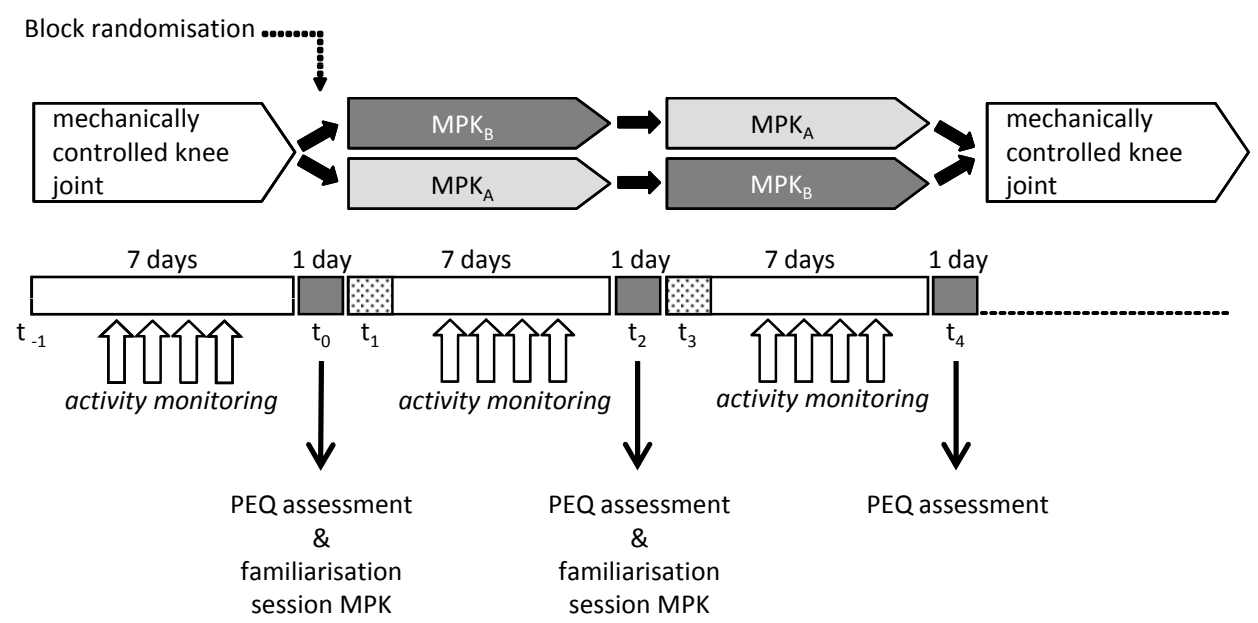

$M P K_{A}$ : prosthetic knee joint featuring microprocessor-controlled stance and swing phase; $M P K_{B}$ : prosthetic knee joint featuring microprocessor-controlled stance phase and passive swing phase control; PEQ: Prosthesis Evaluation Questionnaire.

Both types of MPK were fitted to the participant's existing socket by an experienced certified prosthetist and were aligned using the L.A.S.A.R. posture device (Otto Bock). Participants started the study on their mechanically controlled prosthesis $\left(t_{-1}\right)$ and the order in which the MPKs were subsequently assigned was determined by a computergenerated block randomization (block size $=4$ ). After fitting of the MPK $\left(t_{0}\right.$ and $\left.t_{2}\right) a$ skilled physical therapist gave a 2-hour 'familiarisation session' in which the appropriate software settings of the MPK were set and the participants were familiarized with using the MPK. At the end of this session the therapist assessed whether the participants were able to use the MPK safely in their home environment. If this was the case the participant 
returned home, fitted with his adapted prosthesis. If safe use was not possible, the participant was not allowed to continue in the study. Participants returned one day after fitting of the MPK for possible prosthetic adjustments regarding alignment and software settings $\left(t_{1}\right.$ and $\left.t_{3}\right)$. At $t_{4}$ the participant's prosthesis was returned to its original configuration.

\section{Measurements}

At the end of each test week the participants' perception about the use of an MPK in daily life was assessed using 6 out of the 9 validated, independent subscales of the Prosthesis Evaluation Questionnaire (PEQ) ${ }^{30}$, i.e. Ambulation (AM), Appearance (AP), Residual Limb health (RL), Sounds (SO), Utility (UT) and Well-being (WB). These subscales have shown moderate to strong levels of test-retest reliability (ICC ranges $0.79-0.90$ ) and validity ${ }^{30}$. The 3 other subscales of the PEQ (Frustration, Perceived Response and Social Burden) did not fit the scope of this study and were therefore not used. Furthermore, two additional individual questions of the PEQ concerning the participants' satisfaction about the prosthesis $\left(\mathrm{SA}_{\text {satpros }}\right)$ and the participants' satisfaction about walking with the prosthesis $\left(\mathrm{SA}_{\text {satwalk }}\right)$ were included. All questions were answered on a visual analogue scale from 0 to $100 \mathrm{~mm}$. A higher score corresponds with a more positive response.

The participants' activity level was recorded with a uniaxial accelerometer (GT1M, Actigraph, Pensacola, FL, USA) (dimensions: $38 \mathrm{~mm} \times 37 \mathrm{~mm} \times 18 \mathrm{~mm}$ ) during 3 oneweek periods. This type of accelerometer has shown adequate validity and sensitivity for use with both young and older persons ${ }^{31,32}$. The accelerometer was worn firmly around the waist on an adjustable belt during waking hours. The GT1M records accelerations ranging in magnitude from approximately 0.05 to $2.5 \mathrm{G}$. The analogue acceleration signal is subsequently digitized by a 12-bit converter at a rate of $30 \mathrm{~Hz}$ and band-limited to a frequency range that best detects human motion $(0.25-2.5 \mathrm{~Hz})$. The digitized acceleration values were summed over a 1-minute period and are expressed as so-called 'counts', which incorporate both the amount of accelerations and the magnitude of the accelerations. Participants also kept a small activity diary in which they recorded their general activities performed during the day.

\section{Data analysis}

Activity data were downloaded from the accelerometer at the end of each week with Actigraph software. The raw data were then processed using Matlab software (version 7.2.0, The MathWorks Inc, Natick, MA, USA). Bouts of activity were identified for each 


\section{CHAPTER 6}

day in the 3 prosthesis conditions. A bout of activity was defined as the number of minutes between the moment that the accelerometer signal exceeded a predetermined threshold value of 30 counts per minute to the moment that the signal dropped below that threshold value. This threshold value was chosen after inspecting the accelerometer signal during periods of rest, as was indicated by the participants in the activity diary (e.g. watching television in the evening). Small levels of activity recorded during these periods were likely to represent non-pertinent activities, such as repositioning oneself on the sofa.

Everyday life activity was assessed using the following outcome measures:

(i) 'up-time', i.e. the amount of time per day (minutes) that the participant wore the accelerometer; (ii) 'active-time', i.e. the portion of the up-time (\%) during which the participant performed bouts of activity; (iii) the total level of activity during the up-time (in so-called 'counts'); (iv) the mean number of bouts of activity during the up-time.

Theeven and co-workers ${ }^{26}$ have shown large between-subject variability in functional performance among persons classified as MFCL-2. As large variance may impede detection of possible effects of using an MPK, subjects were stratified into 3 subgroups, i.e. 'low', 'intermediate' and 'high' MFCL-2 subjects, based on persons' self-selected walking speed (2-min walk test) and total activity level (accelerometry) in combination with additional clinical information about the participants (e.g. past medical history, psychosocial status and current physical condition) analogous to the procedure described in more detail by Theeven et al. ${ }^{26}$. The data of the current study were analysed both for the total group of participants and for the 3 MCFL-2 subgroups.

\section{Statistics}

The level of activity in the mechanically controlled knee joint condition and both microprocessor-controlled knee joints conditions were compared using non-parametric statistics with alpha set at 0.05 . Multiple comparisons for related samples were performed using Wilcoxon signed-rank tests with Bonferroni correction ${ }^{33,34}$. Differences between MFCL-2 subgroups were assessed using Kruskal-Wallis tests and Mann-Whitney $U$ tests. Data were statistically analysed using SPSS 16.0.1 (SPSS Inc., Chicago, IL, USA).

\subsection{Results}

\section{Participants}

Of the 103 eligible subjects who were invited to participate in the study, 41 entered the 
study. Persons of various age, gender and with different causes for amputation declined the invitation for various reasons, such as, travelling distance being too long, no interest in participating in the study, not getting the time off work or having no time to participate. For 11 of the 41 participants insufficient data were collected to include in the final analyses, because they discontinued the study protocol at an early stage for one of the following reasons: the participant's existing socket could not accommodate the MPK due to an incompatible attachment fitting $(n=4)$, the participant was not capable to safely ambulating using the MPK after the 2-hour familiarisation session $(n=3)$, the participant experienced physical discomfort after prolonged use of the prosthesis (e.g. skin lesions and extreme muscle ache) $(n=2)$, the participant had a stroke $(n=1)$, or the participant deceased from reasons unrelated to participating in the study $(n=1)$.

The data of 30 participants were included in the final analyses. The characteristics of the total group of participants and of the 3 MCFL-2 subgroups are presented in Table I.

In two of the participants the accelerometer data for one of the MPK conditions were not available as these subjects did not complete the study protocol due to the occurrence of back pain $(n=1)$ or a high sense of insecurity using the MPK $(n=1)$. For one participant the accelerometer data of the two MPK prosthesis conditions were lost due to a technical error, but this subject's PEQ results were included in the analysis. One other participant did not complete the PEQ in the baseline condition and for that reason was not included in the PEQ analysis. However, his data was included in the analysis of the accelerometer data.

Table I. Characteristics of participants in the subgroups 'high', 'intermediate' and 'low'

\begin{tabular}{|c|c|c|c|c|c|c|c|c|c|c|c|c|}
\hline \multirow[t]{2}{*}{$\begin{array}{l}\text { MFCL-2 } \\
\text { subgroup } \\
\end{array}$} & \multicolumn{2}{|c|}{$\begin{array}{l}\text { Gender } \\
(n)\end{array}$} & \multirow{2}{*}{$\begin{array}{l}\begin{array}{l}\text { Age } \\
\text { (years) }\end{array} \\
\text { Mean } \\
\text { (SD) }\end{array}$} & \multirow{2}{*}{$\begin{array}{l}\text { Weight } \\
(\mathrm{kg}) \\
\text { Mean } \\
(\mathrm{SD})\end{array}$} & \multicolumn{2}{|c|}{$\begin{array}{l}\text { Type of } \\
\text { amputa- } \\
\text { tion }(n)\end{array}$} & \multirow{2}{*}{$\begin{array}{l}\text { Post- } \\
\text { amputation } \\
\text { time } \\
\text { (years) } \\
\text { Mean (SD) }\end{array}$} & \multicolumn{3}{|c|}{$\begin{array}{l}\text { Amputation } \\
\text { aetiology } \\
\text { (n) }\end{array}$} & \multirow{2}{*}{$\begin{array}{l}\text { Self-selected } \\
\text { walking } \\
\text { velocity } \\
(\mathrm{km} / \mathrm{h})\end{array}$} & \multirow{2}{*}{$\begin{array}{l}\text { Activity level } \\
\text { ('counts'/ } \\
\text { day) }\end{array}$} \\
\hline & $\mathrm{M}$ & $\mathrm{F}$ & & & TA & $\mathrm{KD}$ & & $\mathrm{Tr}$ & Va & Tu & & \\
\hline Total & 22 & 8 & $\begin{array}{l}59.1 \\
(13.0) \\
\end{array}$ & $\begin{array}{l}76.9 \\
(12.6) \\
\end{array}$ & 24 & 6 & $21.5(18.2)$ & 23 & 6 & 1 & $3.4(0.7)$ & $\begin{array}{c}117,852 \\
(57,982) \\
\end{array}$ \\
\hline Low & 5 & 1 & $\begin{array}{l}65.2 \\
(12.6) \\
\end{array}$ & $\begin{array}{l}87.2 \\
(3.2)\end{array}$ & 5 & 1 & $20.3(19.6)$ & 3 & 3 & 0 & $2.5(0.4)$ & $\begin{array}{l}48,322 \\
(10,926)\end{array}$ \\
\hline $\begin{array}{l}\text { Inter- } \\
\text { mediate }\end{array}$ & 10 & 2 & $\begin{array}{l}61.0 \\
(10.0) \\
\end{array}$ & $\begin{array}{l}75.3 \\
(14.0) \\
\end{array}$ & 9 & 3 & $21.1(19.1)$ & 10 & 2 & 0 & $3.2(0.4)$ & $\begin{array}{l}114,165 \\
(50,309) \\
\end{array}$ \\
\hline High & 7 & 5 & $\begin{array}{l}54.1 \\
(14.9)\end{array}$ & $\begin{array}{l}73.3 \\
(12.0)\end{array}$ & 10 & 2 & $22.4(18.1)$ & 10 & 1 & 1 & $4.0(0.5)$ & $\begin{array}{l}156,304 \\
(44,869)\end{array}$ \\
\hline
\end{tabular}

TA: transfemoral amputation; KD: knee disarticulation; SD: standard deviation; MFCL-2: Medicare Functional Classification Level-2 


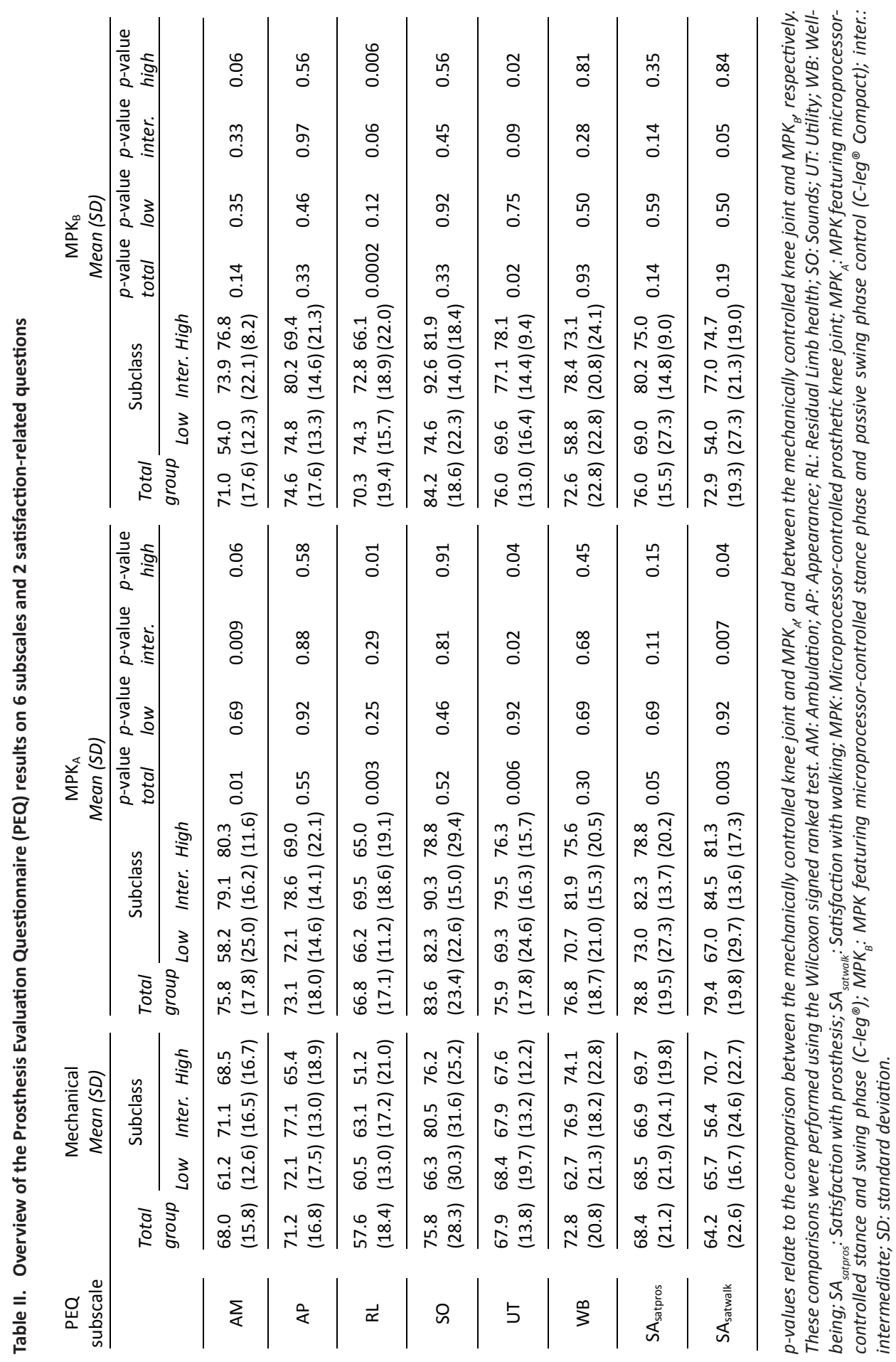




\section{Perceived performance}

The results on the different PEQ subscales are presented in Table II. The scores of the

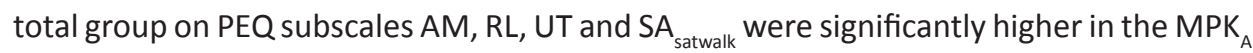
condition compared with the mechanically controlled knee joint condition. The scores on PEQ subscales RL and UT were significantly higher in the $\mathrm{MPK}_{\mathrm{B}}$ condition compared with the scores in the mechanically controlled knee joint condition. The scores in MCFL2 subgroup 'low' showed no statistically significant differences in PEQ subscale scores between knee joint conditions.

The scores on PEQ subscales AM, UT and SA $_{\text {satwalk }}$ were significantly higher $(p \leq 0.025)$ in the $\mathrm{MPK}_{\mathrm{A}}$ condition compared with the mechanically controlled knee joint condition for participants from the subgroup 'intermediate', but were not significantly different for the $\mathrm{MPK}_{\mathrm{B}}$ condition compared with the mechanically controlled knee condition. Participants in subgroup 'high' showed increased PEQ subscale scores in the $\mathrm{MPK}_{\mathrm{A}}$ condition compared with the mechanically controlled knee joint condition on scale RL and in the $\mathrm{MPK}_{\mathrm{B}}$ condition vs the mechanically controlled knee on scales RL and UT.

Figure 2. Boxplots of the mean daily up-time in all prosthetic knee joint conditions for both the total group and the 3 subgroups of participants

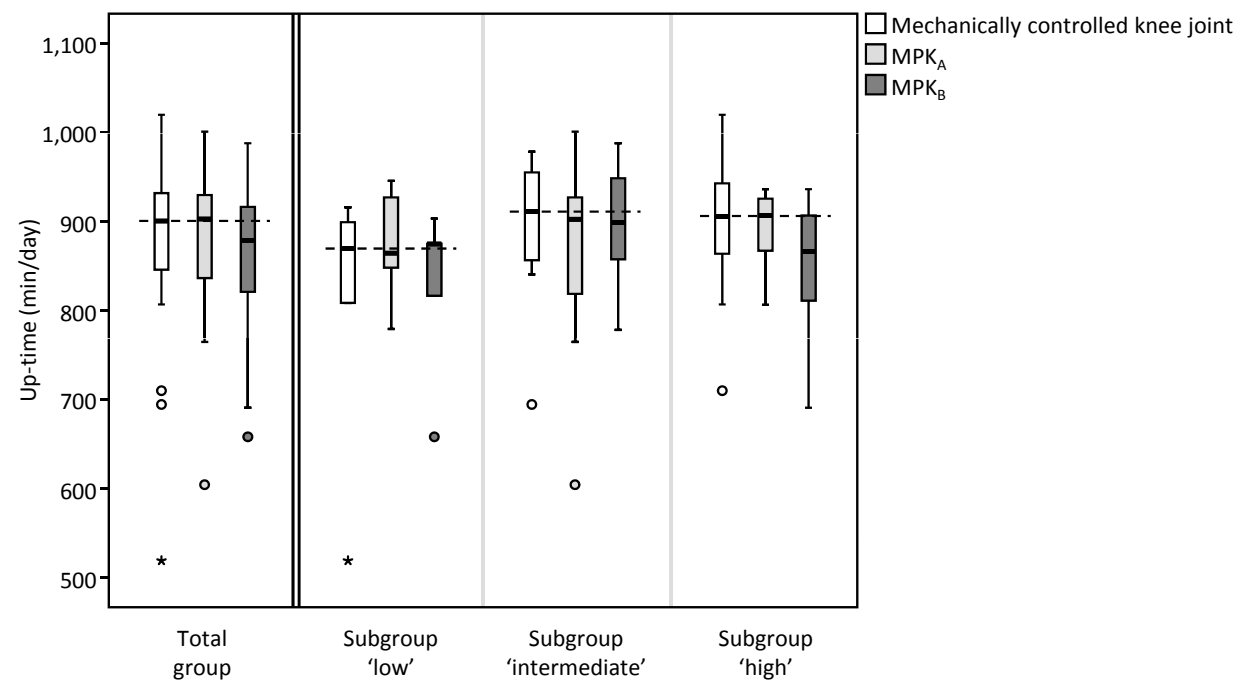

Up-time is the amount of time per day ( $\mathrm{min}$ ) that the participant wore the accelerometer. The dotted horizontal lines illustrate the median value of the mechanically controlled prosthesis condition $\left(t_{0}\right)$ for the particular group or subgroup; $M P K_{A}$ : prosthetic knee joint featuring microprocessor-controlled stance and swing phase; $M P K_{B}$ : prosthetic knee joint featuring microprocessor-controlled stance phase and passive swing phase control. 


\section{CHAPTER 6}

\section{Activity level}

The up-time results for all conditions and subgroups are presented in Figure 2. The differences in up-time between prosthetic knee joint conditions and the differences in up-time between subgroups did not reach statistical significance.

Figure 3 shows boxplots of the 'active time' for the total group of participants and for the subgroups 'low', 'intermediate' and 'high'. The differences in active time between the prosthetic knee joint conditions did not reach statistical significance levels in either the total group or in any of the subgroups. Active time in subgroup 'low' was less than the active time in subgroup 'high' $(p=0.008)$ in the mechanically controlled prosthesis condition. The difference in active time between the subgroups 'low' and 'intermediate' showed a trend in favour of the subgroup 'intermediate', but just failed to attain significance after Bonferroni correction $(p=0.020)$. No statistically significant difference was found between subgroups 'intermediate' and 'high' ( $p=0.184)$.

Figure 3. Mean amount of time (\%) that participants were active during their up-time

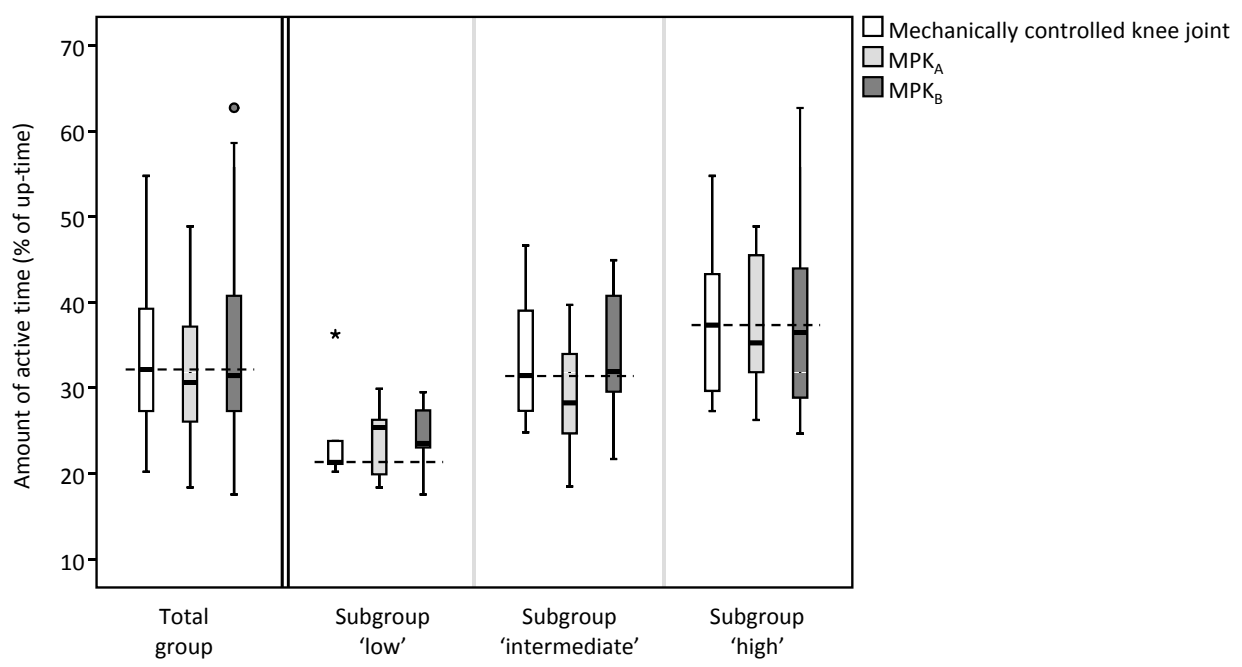

Active-time is the portion of the up-time (\%) during which the participant performed bouts of activity. The dotted horizontal lines illustrate the median value of the mechanically controlled prosthesis condition ( $\left.t_{0}\right)$ for the particular group or subgroup; $M P K_{A}$ : prosthetic knee joint featuring microprocessor-controlled stance and swing phase; $\mathrm{MPK}_{B}$ : prosthetic knee joint featuring microprocessor-controlled stance phase and passive swing phase control.

Figure 4 shows the results of the total level of activity per day. The total level of activity measured during the up-time in the mechanically controlled knee joint condition differed $(p \leq 0.017)$ between the participants of all 3 subgroups. The level of activity of the total group of participants did not differ between prosthetic knee joint conditions. Participants 
in subgroup 'intermediate' showed a reduction in the number of counts of activity per day (activity level) in the $\mathrm{MPK}_{\mathrm{A}}$ condition compared with the mechanically controlled knee joint condition ( $p=0.013$ ). No differences were found between knee joint conditions for participants in the other subgroups.

Figure 4. The level of total activity per day (counts/day)

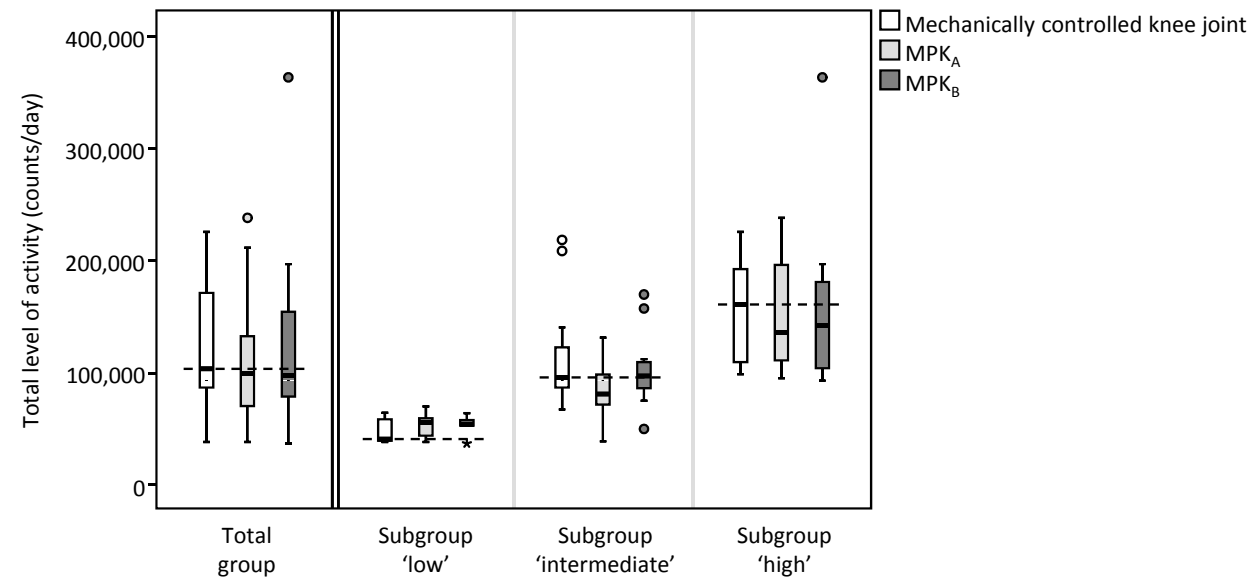

The dotted horizontal lines illustrate the median value of the mechanically controlled prosthesis condition $\left(t_{0}\right)$

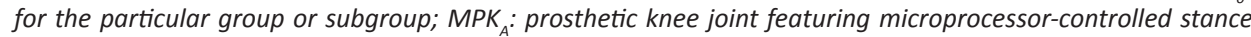
and swing phase; $M P K_{B}$ : prosthetic knee joint featuring microprocessor-controlled stance phase and passive swing phase control.

Figure 5. Mean number of bouts of activity per day

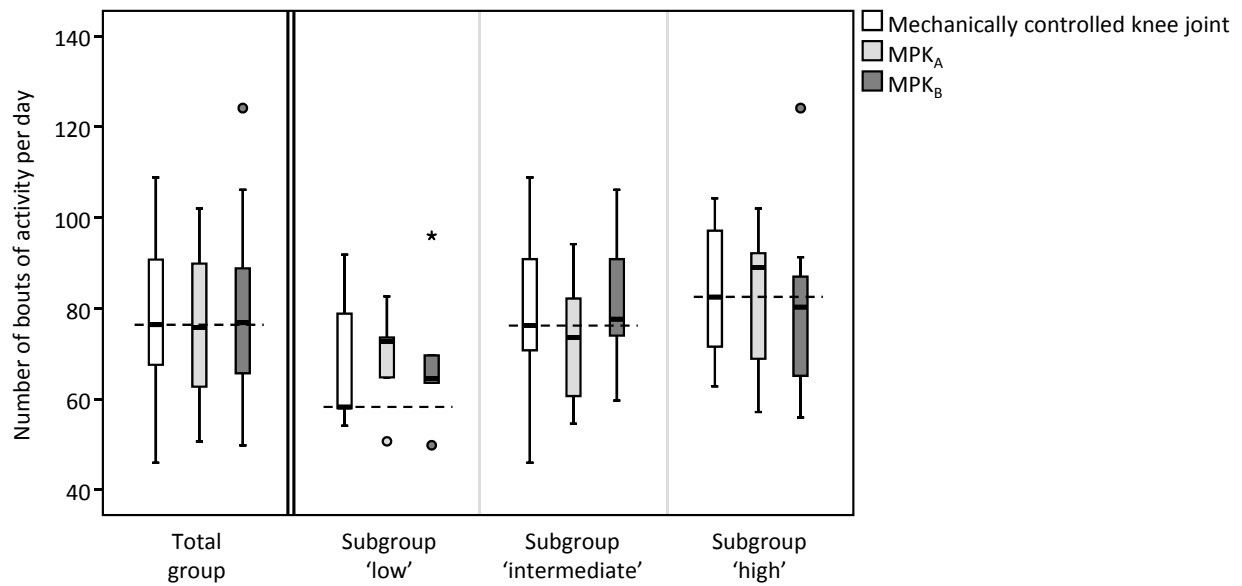

A bout of activity is the time between the moment that the accelerometer signal exceeded a predetermined threshold value of 30 counts per minute to the moment that the signal dropped below that threshold value. The dotted horizontal lines illustrate the median value of the mechanically controlled prosthesis condition ( $t_{0}$ ) for the particular group or subgroup; $M P K_{A}$ : prosthetic knee joint featuring microprocessor-controlled stance and swing phase; $M P K_{B}$ : prosthetic knee joint featuring microprocessor-controlled stance phase and passive swing phase control. 


\section{CHAPTER 6}

The mean number of bouts of activity per day for the whole group as well as for the 3 subgroups is shown in Figure 5 . The differences in the number of bouts of activity per day between prosthetic knee joint conditions and between the subgroups of participants did not reach statistical significance levels.

\subsection{Discussion}

The purpose of this study was to investigate the effects of using a leg prosthesis featuring an advanced prosthetic knee joint on both the self-assessed performance and the (actual) daily activity level of persons with a leg amputation who are classified as MFCL2. The results of the current study suggest that these persons perceive considerable improvements concerning their ability to ambulate with the prosthesis, their quality of walking, the condition of their residual limb, and the utility of the prosthesis, when they use a prosthesis fitted with an MPK (particularly an MPK that actively controls both the stance and swing phase) in comparison with a mechanically controlled prosthetic knee. Despite these self-assessed improvements their daily activity level remained unchanged after 1 week of use.

Only 3 studies ${ }^{26,27,35}$ were found in the literature that investigated the effects of an MPK explicitly in persons classified as MFCL-2. In an additional study by Kahle et al. ${ }^{36}$ a mixed group of individuals classified as MFCL-2 and MFCL-3 were investigated, but only total group data were reported. The characteristics of the MFCL-2 research population that was assessed in the current study were comparable to those reported by Hafner \& Smith ${ }^{27}$ in terms of age, post-amputation time, male to female ratio, and the ratio of amputations due to trauma and vascular disease. Compared with the MFCL-2 cohort studied by Wetz et al. ${ }^{35}$, the persons in our research population were slightly younger (59.1 vs 66.0 years) and included relatively more amputations due to trauma. Overall, the MFCL-2 population investigated in both the present study and in our previous work ${ }^{26}$ is considerably larger than in both other studies.

The PEQ results confirmed our hypothesis that subjects are more satisfied about their performance using the MPK compared with using their mechanically controlled knee. This is partly in agreement with the findings of Hafner \& Smith ${ }^{27}$ who found improved PEQ scores in the MPK condition for their MFLC-2 population. However, those differences failed to attain statistical significance in all of the PEQ subscales, possibly due to the small sample size $(n=8)$. 
Contrary to persons' perceived performance, the activity level of the total group of persons classified as MFCL-2 does not seem to be affected by the use of the MPK. Apparently, increasing the persons' potential to ambulate by fitting their prosthesis with an MPK, does not automatically stimulate them to be more active in daily life. It becomes increasingly clear in rehabilitation that actual performance and perceived performance are different constructs that are not necessarily related. Persons with a leg amputation have adapted their lifestyle in order to manage the functional limitations that come with the loss of a limb. Changing one's lifestyle instantaneously is difficult to accomplish. Regarding our research, an important factor that may have played a role here is that the subjects were not explicitly encouraged to perform more activities in daily life. For example, no cognitive behavioural training techniques have been used to stimulate persons to become more active. Introducing such an additional intervention would have obscured the design of the study. If subjects had been stimulated to perform at their maximal level, it is possible that more distinct differences between prosthesis conditions might have been found. However, the added value of measuring people in their everyday life would then have been lost.

Also, it should be considered that 2 hours of accommodation time and 1 week of home use might have been too short for the subjects to familiarize themselves with the adapted prosthesis. Perhaps a longer accommodation period led to different results, as subjects might be more able to use the MPKs to their full potential after a longer period of use. However, in studies with considerably longer periods of accommodation time on the MPK also no change in activity level (step count) was measured ${ }^{21,22}$, whereas results of the study by Kaufman et al. ${ }^{20}$ suggest otherwise. They reported significantly increased activity-related energy expenditure levels and concluded that persons with a transfemoral amputation using an MPK increased their daily physical activity level. Although in literature an average accommodation period between 12 and 18 weeks is reported ${ }^{14,19-21 \text {, }}$ $27,36,37$, no consensus exists on what the most optimal accommodation period should be. In the present study it has been shown that 2 hours of actively familiarizing the person with the newly fitted prosthetic knee joint proved to be adequate for most individuals to attain safe use of the prosthesis.

It is not uncommon in prosthesis research to stratify a group of subjects into subgroups. Legro et al. stratified subjects based on gender, age, presence or absence of comorbidities, level of amputation, and years since the amputation to test whether the PEQ could differentiate between those groups ${ }^{30}$. In the current study data were analysed for both the total group of included participants and 3 MFCL-2 subgroups. This approach was 


\section{CHAPTER 6}

chosen in an attempt to reduce the large variability in activity level among the total group. As large variability may obscure possible effects of using an MPK, the group of participants was stratified into 3 subgroups. A similar approach has been used in a previous study, which showed large variability in the level of functional ability of persons classified as MFCL-2 ${ }^{26}$. Although, the classification of participants into smaller subgroups indeed reduced the degree of dispersion regarding the subjects' activity level in the present study, a considerable amount of variability still remained. This indicates that not only between subgroups, but also within each subgroup the MPK seems to have diverse effects on the participants. This further supports our hypothesis that the group of persons classified as MFCL-2, as opposed to the MFCL-3 and MFCL-4 populations, is a more heterogeneous population. This also means that it is more difficult to make generalized statements about the effects of an MPK on the functioning of the 'typical' MFCL-2 patient. Therefore, determining whether a person classified as MFCL-2 may benefit from using an MPK in daily life should perhaps be done at the individual patient level.

\section{Study limitations}

It is noted that the perceived performance data might have been influenced by the expectations of the subjects about the benefits they would have when wearing an MPK. Although methodologically, blinding the subjects for prosthesis condition would have eliminated this issue, this was practically not possible. Participants would immediately notice the difference between their mechanically controlled prosthesis and an MPK (e.g. the MPK has to be recharged).

The accelerometer measured the accelerations of the participants' centre of mass. Although this merely quantifies the amount and intensity of the movements made, it does not provide information about the type of movements or about the quality with which the activities were performed. Perhaps, participants performed different types of activity that they were not able to do with their mechanically controlled prosthesis.

All subjects were tested with the accelerometer during 3 consecutive 1-week periods. Because the persons did not perform a fixed or predefined set of activities during each week of testing, it should be taken into account that other factors, apart from changing the prosthetic knee joint, may have influenced the activity level of the participants. To control for possible deviations within each weekly routine, a mean value of the accelerometer data over the 7-day period was calculated. To control for the occurrence of deviations between weekly routines is considered virtually impossible. Unfortunately, this is inherent to testing people in their home environment, i.e. outside the standardized laboratory setting. 
Classification of the total group of participants into 3 subgroups reduced within-group variance, but resulted in fairly small numbers of participants per subgroup. The results of the study should therefore be interpreted with care. Nevertheless, even with the current number of participants in each of the subgroups, this study is one of the largest studies to compare the effects of using an MPK with the effects of using a mechanically controlled knee joint ${ }^{15-20}$.

\section{Future research}

Advanced activity monitors, able to detect the specific nature of the performed bouts of activity (such as level walking, walking stairs, sitting, or bicycling), may provide more detailed information about changes in persons' quality of the performed activities in their free-living environment. This may provide more insight in the type of activities persons with a leg amputation tend to avoid in daily life and how the prosthesis configuration may affect that performance. In addition, a randomized controlled trial with prolonged followup measurements is necessary to investigate the long-term effects of using an MPK on activity level in persons classified as MFCL-2.

\section{Conclusions}

Persons with a transfemoral amputation or knee disarticulation, classified as MFCL2, perceive an improved ability to ambulate, are more satisfied with how they walk, experience an improved condition of the stump, and report increased utility when they use a prosthesis featuring an MPK compared with a mechanically controlled knee joint. However, these perceived benefits do not encourage these persons to increase their everyday activity level in the short term.

\subsection{Acknowledgements}

The authors would like to thank Guido Meys and Sven Balk of Adelante Rehabilitation Centre, Hoensbroek, The Netherlands, for supporting the participants during the accommodation sessions and familiarizing them to use the MPKs. The authors also thank the work of Frans Rings and his fellow prosthetists at Livit Ortopedie BV, Hoensbroek, The Netherlands, with fitting and aligning the prosthetic knee joints.

This study was supported by a grant provided by Otto Bock Healthcare GmbH, Vienna, Austria. Prior to the start of the investigation that has led to the current publication, it was contractually agreed between Adelante and the grant provider, that Adelante has the full and unrestricted right regarding: ( $i$ ) the establishing of results of the investigation leading to scientifically corroborated conclusions; and (ii) the presentation of any result or conclusion resulting from the investigation, independent of any other party or grant provider. 


\section{CHAPTER 6}

\subsection{References}

1. Gitter A, Czerniecki J, Weaver K. A reassessment of center-of-mass dynamics as a determinate of the metabolic inefficiency of above-knee amputee ambulation. Am J Phys Med Rehabil 1995; 74:332338.

2. Hoffman MD, Sheldahl LM, Buley KJ, Sandford PR. Physiological comparison of walking among bilateral above-knee amputee and able-bodied subjects, and a model to account for the differences in metabolic cost. Arch Phys Med Rehabil 1997; 78:385-392.

3. Miller $W C$, Deathe $A B$, Speechley $M$, Koval J. The influence of falling, fear of falling, and balance confidence on prosthetic mobility and social activity among individuals with a lower extremity amputation. Arch Phys Med Rehabil 2001; 82:1238-1244.

4. Miller WC, Speechley M, Deathe AB. Balance confidence among people with lower-limb amputations. Phys Ther 2002; 82:856-865.

5. Heller BW, Datta D, Howitt J. A pilot study comparing the cognitive demand of walking for transfemoral amputees using the Intelligent Prosthesis with that using conventionally damped knees. Clin Rehabil 2000; 14:518-522.

6. Bussmann JB, Grootscholten EA, Stam HJ. Daily physical activity and heart rate response in people with a unilateral transtibial amputation for vascular disease. Arch Phys Med Rehabil 2004; 85:240244.

7. Bussmann JB, Schrauwen HJ, Stam HJ. Daily physical activity and heart rate response in people with a unilateral traumatic transtibial amputation. Arch Phys Med Rehabil 2008; 89:430-434.

8. Bertera EM, Bertera RL. Fear of falling and activity avoidance in a national sample of older adults in the United States. Health Soc Work 2008; 33:54-62.

9. Delbaere K, Crombez G, Vanderstraeten G, Willems T, Cambier D. Fear-related avoidance of activities, falls and physical frailty. A prospective community-based cohort study. Age Ageing 2004; 33:368373.

10. Fletcher PC, Hirdes JP. Restriction in activity associated with fear of falling among community-based seniors using home care services. Age Ageing 2004; 33:273-279.

11. World Health Organisation. International Classification of Functioning, Disability and Health: ICF; 2001.

12. Jepson F, Datta D, Harris I, Heller B, Howitt J, McLean J. A comparative evaluation of the Adaptive knee and Catech knee joints: a preliminary study. Prosthet Orthot Int 2008; 32:84-92.

13. Petersen AO, Comins J, Alkjaer T. Assessment of gait symmetry in transfemoral amputees using C-leg compared with $3 R 60$ prosthetic knees. J Prosthet Orthot 2010; 22:106-112.

14. Segal $A D$, Orendurff MS, Klute GK, McDowell ML, Pecoraro JA, Shofer J, et al. Kinematic and kinetic comparisons of transfemoral amputee gait using C-Leg and Mauch SNS prosthetic knees. J Rehabil Res Dev 2006; 43:857-870. 
15. Schmalz T, Blumentritt S, Jarasch R. Energy expenditure and biomechanical characteristics of lower limb amputee gait: the influence of prosthetic alignment and different prosthetic components. Gait Posture 2002; 16:255-263.

16. Seymour R, Engbretson B, Kott K, Ordway N, Brooks G, Crannell J, et al. Comparison between the C-leg microprocessor-controlled prosthetic knee and non-microprocessor control prosthetic knees: a preliminary study of energy expenditure, obstacle course performance, and quality of life survey. Prosthet Orthot Int 2007; 31:51-61.

17. Chin T, Machida K, Sawamura S, Shiba R, Oyabu H, Nagakura $Y$, et al. Comparison of different microprocessor controlled knee joints on the energy consumption during walking in trans-femoral amputees: intelligent knee prosthesis (IP) versus C-leg. Prosthet Orthot Int 2006; 30:73-80.

18. Johansson JL, Sherrill DM, Riley PO, Bonato P, Herr H. A clinical comparison of variable-damping and mechanically passive prosthetic knee devices. Am J Phys Med Rehabil 2005; 84:563-575.

19. Orendurff MS, Segal AD, Klute GK, McDowell ML, Pecoraro JA, Czerniecki JM. Gait efficiency using the C-Leg. J Rehabil Res Dev 2006; 43:239-246.

20. Kaufman KR, Levine JA, Brey RH, McCrady SK, Padgett DJ, Joyner MJ. Energy expenditure and activity of transfemoral amputees using mechanical and microprocessor-controlled prosthetic knees. Arch Phys Med Rehabil 2008; 89:1380-1385.

21. Klute GK, Berge JS, Orendurff MS, Williams RM, Czerniecki JM. Prosthetic intervention effects on activity of lower-extremity amputees. Arch Phys Med Rehabil 2006; 87:717-722.

22. Hafner BJ, Willingham LL, Buell NC, Allyn KJ, Smith DG. Evaluation of function, performance, and preference as transfemoral amputees transition from mechanical to microprocessor control of the prosthetic knee. Arch Phys Med Rehabil 2007; 88:207-217.

23. Datta D, Howitt J. Conventional versus microchip controlled pneumatic swing phase control for transfemoral amputees: user's verdict. Prosthet Orthot Int 1998; 22:129-135.

24. Centers for Medicare and Medicaid Services. U.S. Department of Health and Human Services. HCFA Common Procedure Coding System (HCPCS). Springfield (VA): U.S. Department of Commerce, National Technical Information Service; 2001.

25. Otto Bock Healthcare. MOBIS ${ }^{\circledR}$ - The Otto Bock Mobility System. [accessed October 13, 2010]; Available from: http://www.ottobock.com/cps/rde/xchg/ob_com_en/hs.xsl/603.html.

26. Theeven PJR, Hemmen B, Rings F, Meys G, Brink PRG, Smeets RJEM, Seelen HAM. Functional added value of microprocessor-controlled prosthetic knee joints in daily life performance of Medicare Functional Classification Level-2 amputees. J Rehabil Med 2011; 43:906-915.

27. Hafner BJ, Smith DG. Differences in function and safety between Medicare Functional Classification Level-2 and -3 transfemoral amputees and influence of prosthetic knee joint control. J Rehabil Res Dev 2009; 46:417-433.

28. Burnfield JM, Eberly VJ, Gronely JK, PerryJ, Yule WJ, Mulroy SJ. Impact of stance phase microprocessor- 


\section{CHAPTER 6}

controlled knee prosthesis on ramp negotiation and community walking function in K2 level transfemoral amputees. Prosthet Orthot Int 2012; 36:95-104.

29. Murray CD, Fox J. Body image and prosthesis satisfaction in the lower limb amputee. Disabil Rehabil 2002; 24:925-931.

30. Legro MW, Reiber GD, Smith DG, del Aguila M, Larsen J, Boone D. Prosthesis evaluation questionnaire for persons with lower limb amputations: assessing prosthesis-related quality of life. Arch Phys Med Rehabil 1998; 79:931-8.

31. Focht BC, Sanders WM, P.H. B, Rejeskl WJ. Initial validation of the CSA activity monitor during rehabilitation exercise among older adults with chronic disease. J Aging Phys Activity 2003; 11:293304.

32. Patterson SM, Krantz DS, Montgomery LC, Deuster PA, Hedges SM, Nebel LE. Automated physical activity monitoring: validation and comparison with physiological and self-report measures. Psychophysl 1993; 30:296-305.

33. Field A. Discovering statistics using SPSS. 2nd ed. London: SAGE publications; 2005.

34. Siegel S, Castellan J. Nonparametric statistics for the behavioral sciences. 2nd ed. New York: McGraw-Hill; 1988.

35. Wetz HH, Hafkemeyer U, Drerup B. Einfluss des C-Leg-Kniegelenk-Passteiles der Fa. Otto Bock auf die Versorgungsqualität Oberschenkelamputierter. Eine klinisch-biomechanische Studie zur Eingrenzung von Indikationskriterien [The influence of the C-leg knee-shin system from the Otto Bock Company in the care of above-knee amputees. A clinical-biomechanical study to define indications]. Orthopäde $2005 ; 34: 298-319$.

36. Kahle JT, Highsmith MJ, Hubbard SL. Comparison of nonmicroprocessor knee mechanism versus C-Leg on Prosthesis Evaluation Questionnaire, stumbles, falls, walking tests, stair descent, and knee preference. J Rehabil Res Dev 2008; 45:1-14.

37. Kaufman KR, Levine JA, Brey RH, Iverson BK, McCrady SK, Padgett DJ, et al. Gait and balance of transfemoral amputees using passive mechanical and microprocessor-controlled prosthetic knees. Gait Posture 2007; 26:489-493. 



$$
\operatorname{tin}
$$




\section{Chapter 7}

General discussion

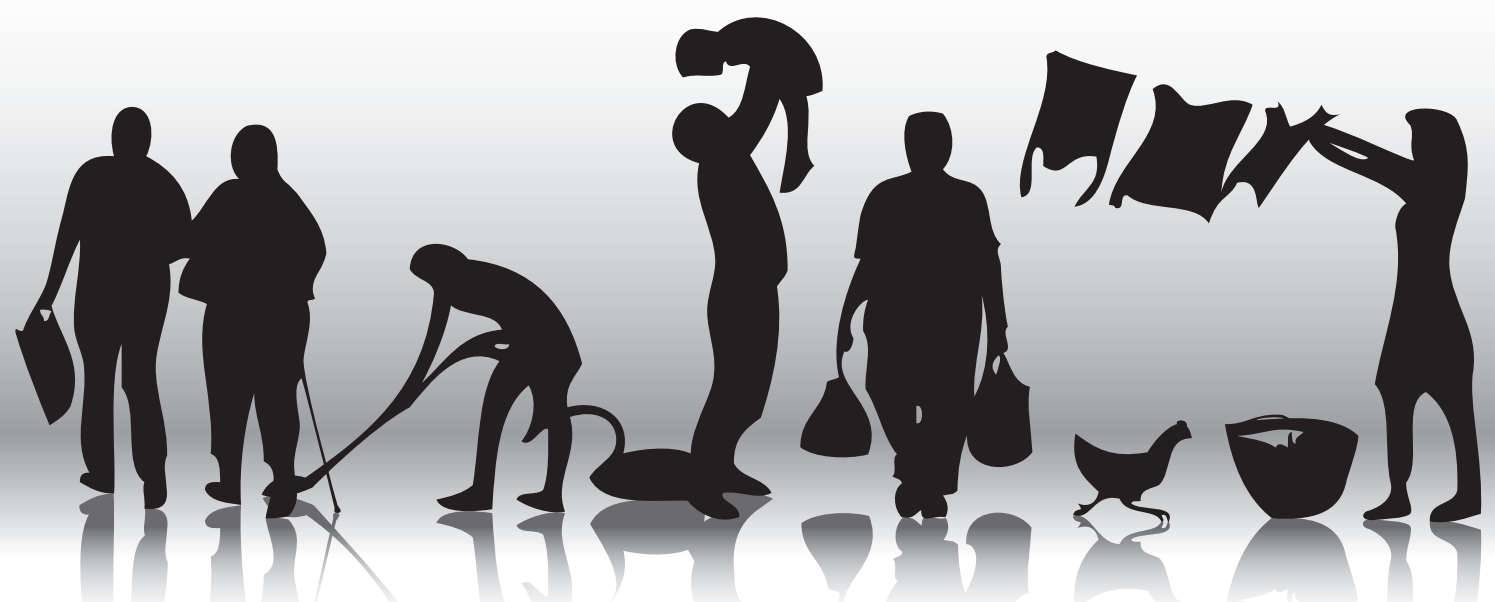




\section{CHAPTER 7}

\subsection{Scope and aim of this thesis}

Persons with a transfemoral amputation or knee disarticulation who are capable of standing and walking with a prosthesis are prescribed a prosthetic knee joint that should help them to reach and maintain an optimal level of functioning in daily life. Generally, the range of prosthetic knee joints are divided into mechanically controlled prosthetic knee joints and microprocessor-controlled prosthetic knee joints (MPKs). In order to make a sound decision, clinicians need reliable and objective scientific evidence concerning the effectiveness of the prosthetic knee joints currently available. The effects of MPKs have been investigated in many different domains. The International Classification of Functioning, Disability and Health (ICF) distinguishes between the three domains function, activity, and participation ${ }^{1}$. Clinical experts, like rehabilitation specialists, involved in the treatment of amputees often indicate that only limited evidence seems to be available concerning the effects of MPKs in the domains activity and participation. Objective information about the effects of an MPK in these domains is vital, because activity and participation are the prime areas in which amputees report to experience many problems. Moreover, effects of MPKs typically seem to have been investigated in amputees with a high functional level, whereas, in contrast, a relatively large portion of the amputee population has a low functional level. In this thesis it was hypothesized that the latter group of amputees may also benefit from using an MPK during their daily life pursuits.

The main goal of the present thesis was to assess whether persons with a unilateral transfemoral amputation or a knee disarticulation, who have a low functional level, i.e. Medicare Functional Classification Level-2 (MFCL-2), benefit from using an MPK regarding their level of functioning in everyday life. To this end, functioning was assessed from a patient's perspective, taking into consideration person's actual performance in daily life situations. Two important determinants of independence and quality of life were assessed, i.e. the functional ability to perform activities of daily living (ADL), and the functional ability to ambulate safely. In addition, it was assessed whether improvements on those determinants actually lead to increased daily activity levels.

General aims of the study were:

1. to review the measures that have been utilized to assess the effects of using an MPK, in comparison with a mechanically controlled knee joint, in each of the three ICF domains and to summarize the effects on the functioning of persons with a transfemoral amputation or knee disarticulation;

2. to assess the effects of using an MPK, in comparison with a mechanically controlled 
knee joint, in persons classified as MFCL-2, concerning:

(i) the functional ability to perform activities of daily living;

(ii) the functional ability to recover effectively from different types of perturbations in gait;

(iii) the influence on the daily activity level.

\section{Layout of the general discussion}

In this general discussion the main findings of this thesis will be presented. The clinical implications of these main findings and their interactions will be discussed subsequently. Several methodological and clinimetric issues that occurred and were resolved during the study will be discussed. Potential shortcomings in a number of domains will be given, as will areas in which future research should expand. Finally, the overall conclusions will be presented.

\subsection{Main research findings}

\section{Prior evidence on effectiveness of MPKs}

The first aim of the present thesis was to identify and structure the outcome measures in the literature that have been utilized to investigate the effects of using an MPK, in comparison with a mechanically controlled knee joint, on the amputee's functioning in each of the three ICF domains. Two important shortcomings as to the prior understanding of the effectiveness of MPKs were found based on the review in chapter 2.

Firstly, the majority $(\approx 77 \%)$ of all studies that investigated the effectiveness of using an MPK, relative to conventional mechanically controlled prostheses, included relatively young, fit, and active persons, who generally have a high functional level (i.e. a classification of at least MFCL-3). However, a considerable proportion of the population of lower limb amputees is over 65 years old and is amputated due to peripheral vascular problems ${ }^{2-4}$. Moreover, it is expected that, due to the ageing of the general population and the increasing prevalence of obesity and cardiovascular disease, the relative number of older persons with an amputation for vascular problems will further increase ${ }^{4}$. Amputees in this large subpopulation are typically classified as MFCL-2. However, only two studies ${ }^{5,6}$ were found that evaluated the effects of an MPK specifically in amputees classified as MFCL-2. The generalizability of the current scientific evidence on the effects of MPKs is therefore limited. Initially, manufacturers presumed that an MPK might only have advantageous effects on persons classified as MFCL-3 or MFCL-4, which may partly explain why so many studies focused on these latter patient populations. It may also 


\section{CHAPTER 7}

explain why MFCL-2 amputees are still not often prescribed an MPK. However, the review demonstrated that the assumption, that an MPK is not eligible for persons with a low functional level, is not supported by any scientific evidence currently available. As a result of the aforementioned lack of evidence, amputees classified as MFCL-2 are denied a prosthesis solution that might be advantageous to their level of functioning in daily life. Secondly, the effectiveness of an MPK regarding amputees' functioning is typically assessed in terms of clinical measures of impairment or function. However, the relationship between the amputee and his prosthesis is more complex. The framework of the ICF indicates that functioning is also determined in the domains of activity and participation $^{1}$. Very little evidence exists as to the effects of an MPK on the amputee's functioning in those domains, whereas such information is highly relevant to the amputees and clinicians. Moreover, the evidence that does exist on the effectiveness in the domains of activity and participation has been predominantly based on amputees' perceived performance, rather than on actual, objectively measured performance. This is in agreement with the results of earlier reviews on the evaluation of prosthetic prescription and rehabilitation in general ${ }^{7-9}$. It should be kept in mind that one of the main reasons to provide an above knee amputee with a prosthesis featuring a specific prosthetic knee joint is to enable that person to reach an optimal level of functioning in daily life. However, only little scientifically reported evidence existed as to whether the latter goal is actually reached.

In order for clinicians to be able to prescribe an MPK based on clinically relevant and reliable data, it is necessary that additional objective evidence is sought as to the effectiveness of MPKs in the domains of activity and participation, and especially as to the effectiveness of MPKs in MFCL-2 amputees. Whiteneck et al. ${ }^{10}$ argued that objectively measuring performance in the domain of ICF participation is impossible, as participation involves social interaction. The latter is impossible to measure under standardised conditions. Objective measurements should therefore first be performed in the domain of ICF activity using valid and reliable measuring tools.

In view of the aforementioned findings, it was necessary to search for eligible measuring tools that can be used to objectively assess the functional performance levels of amputees in the domain of ICF activity, in order to determine the functional added value of using MPKs relative to mechanically controlled prosthetic knee joints. 


\section{Measuring in the ICF activity domain}

The ability to perform activities of daily living ( $A D L)$ is an important predictor of quality of life ${ }^{11}$. Also, sustaining and/or improving this ability is one of the most important goals of elderly amputees ${ }^{12}$. Thus far, only very few studies have objectively assessed the differences between MPKs and mechanically controlled prosthetic knee joints in terms of the amputee's functional abilities to perform ADL (chapter 2). An important reason for this may be that only very few (validated) objective measuring tools have been available that can be used to measure actual performance of ADL in amputees, as was shown in a review by Condie et al. ${ }^{7}$. They also state that, although many measuring tools are available to measure prosthetic outcome in amputees, no gold standard seems to be available, and little agreement exists as to which measures to use and when they should be used. The Amputee Mobility Predictor (AMP) ${ }^{13}$ was the only test identified by Condie et al. ${ }^{7}$ that is both amputee-specific and objectively assesses the amputee's ability to perform a variety of basic mobility tasks. However, the AMP mainly measures several functional capabilities of the patient that underlie the ability to perform ADL (with or without a prosthesis), such as standing balance, sitting balance, and ability to rise from a chair, but not the performance of ADL itself. Based on the outcome of the AMP the patient's readiness or ability to ambulate with a prosthesis is then predicted ${ }^{13,14}$. One of the main aims of our study was to measure persons' actual performance of ADL. As such, the AMP is too limited and does not meet the requirements necessary to attain this goal. In our review (chapter 2 ) several tools gauging actual performance were reported, e.g. the Hill Assessment Index (HAI) and Stair Assessment Index (SAI) ${ }^{15,16}$. They allow assessment of the level of functional independence and technique used during negation of hills and stairs, respectively. Also, a standardized walking obstacle course (SWOC) ${ }^{17}$ and an outdoor obstacle course ${ }^{5,18}$ have been used to measure amputees' actual performance with the prosthesis. Unfortunately, each of these performance measures covers only a very limited range of functional skills, as opposed to the many activities associated with functional status (e.g. ability to sit, dress, drive a car, perform household or recreational activities) ${ }^{19}$. Moreover, the measuring tools on functional abilities identified in chapter 2 , seem to particularly focus on activities that underline the strengths of the MPK as to the active stance and swing phase control, instead of focusing on activities that people often need to perform and which may pose problems in everyday life. From the amputee's perspective, it is more important to be able to resume previous social roles (e.g. visiting the grandchildren), rather than to be able to, for example, walk 100 meters a few seconds faster. 
In view of the lack of eligible prosthetic outcome measures to objectively assess the functional ability to perform ADL, a novel measuring tool needed to be developed. One of the initial steps in our research has therefore been to develop such a tool, i.e. the ADAPT test. The ADAPT test has been developed using the perspective of the amputee. It is based on an elaborate list of activities and movements of which above-knee amputees have indicated that performing them in daily life poses problems and consequently hinders their daily pursuits. It has been shown in chapter 3 that it is feasible to objectively and reliably measure the functional ability of transfemoral amputees to perform common daily activities using the concept of simulated daily life situations (ADAPT). The ADAPT test is also able to detect differences in functional performance levels between amputees who are using different prosthetic knee joints (chapter 3 ). The ADAPT test configuration, which was utilized to assess the added value of MPKs in persons classified as MFCL-2 (chapter 4), consisted of activities with the best clinimetric properties, as described and tested in chapter 3. Important criteria that were taken into account during the composition of this ADAPT test were: Activities needed to be of adequate duration, because a short duration would lead to larger variances regarding performance time measurements when the test is performed multiple times (e.g. when assessing a patient several times during the course of his rehabilitation program); The number of different ways in which a participant can accomplish the activity needed to be as small as possible (also to minimize variance in performance time); The activity station needed to be highly sensitive to distinguish between performance levels.

Analogous to the search for a tool to objectively measure ADL, eligible measuring tools were also sought to determine persons' actual ability to ambulate safely. Falling and the fear of falling are considered major factors for decreased activity, mobility, and quality of life ${ }^{20,21}$. The ability to ambulate safely with an MPK, with reference to a mechanically controlled prosthetic knee joint, is typically assessed using measures on perceived performance (chapter 2). The perturbation protocol by Blumentritt et al. ${ }^{22}$ was the only tool identified that measures a person's actual performance as to safety during ambulation. This perturbation protocol was chosen to be used in the present thesis, because of a number of benefits in comparison with other perturbation protocols that are available ${ }^{23-25}$. The protocol of Blumentritt et al. includes several different situations with a high risk of falling, instead of focusing only on a tripping response. Moreover, the situations that are tested in this protocol may often occur in daily life, such as stumbling over a doorstep or over a skew stone in the pavement, having to stop abruptly for a fast approaching car, or unintentionally stepping on something. Furthermore, testing is 
performed during overground walking, which is perceived by participants as more realistic than treadmill walking. Also, treadmill walking leads to a different walking pattern ${ }^{26}$. The ecological validity of treadmill walking is therefore lower. However, a major disadvantage of the protocol of Blumentritt et al. is that the parameters assessed are typically function measures (kinematics/kinetics). For the present thesis, we were especially interested in persons' overall ability to perform the different perturbation tasks. That is why a novel, clinically based, performance scale was developed that enables the assessment of whole body performance, i.e. the combination of the amount of compensatory movements of the arms, the trunk, and the legs (number of steps/hops) to successfully recover from a perturbation in gait (chapter 5 ). This performance scale not only indicates whether subjects are able to perform the tasks (i.e. fall or no fall), it additionally provides information as to the quality of their performance (i.e. rating between 1 and 10 by a clinician).

In summary, after having established that little objective evidence was available regarding the effectiveness of MPKs in MFCL-2 amputees' daily life performance (ICF activity and participation), objective measuring tools were sought. As no eligible tools were available, the ADAPT test and a novel performance scale for the perturbation protocol were developed. With these tools, the main research question of the present thesis was subsequently answered.

\section{Functional added value of using an MPK in MFCL-2 amputees}

In chapters 4 through 6 the effects of two different types of MPKs on MFCL-2 amputees' performance of $A D L$, their ability to recover from perturbations of gait, and their daily activity level as measured with an accelerometer, have been assessed. The overall pooled group results on the different objective outcome measures suggest that using an MPK does not significantly contribute to improvement of the actual level of functioning of amputees classified as MFCL-2 after 1 week of accommodation time, relative to the use of a mechanically controlled prosthetic knee joint. Data on all main outcome measures demonstrated considerable levels of variability, suggesting large heterogeneity within the entire MFCL-2 group, possibly obscuring more refined effects of the MPKs. In anticipation of these large levels of variability within the MFCL-2 population, the possibility for stratification of the research population based on the baseline level of objective classification measures (i.e. mean comfortable walking speed, daily activity level, physical condition, past medical history, and psychosocial status) was incorporated in the initial study design. After stratifying the research population into three subgroups 


\section{CHAPTER 7}

(i.e. 'low', 'intermediate' and 'high'), the results on the ADAPT test clearly confirmed that the large heterogeneity of the MFCL-2 population had obscured the effects of the MPK. Particularly persons in the subgroups 'intermediate' and 'high' showed improved functional performance using an MPK as measured with ADAPT (chapter 4). Amputees in subgroup 'low' did not seem to benefit from using an MPK regarding the performance of ADL. The significant differences in functional performance levels (ADAPT test) and activity levels (accelerometer) at baseline (before the use of an MPK) between the three subgroups further confirm that the MFCL-2 population is indeed heterogeneous.

Amputees' performance on the perturbation tests while using the MPK was similar to their performance while using the mechanically controlled prosthetic knee joint. This was the case in all three subgroups. The same was true for amputees' activity level measured with an accelerometer. It seems that the participants were quickly able to adapt to the new prosthesis, as they were able to use the features of the MPK to such an extent that, for many participants, performance after just one week of use was already equivalent to their previous level of performance. Moreover, especially participants from the subgroups 'intermediate' and 'high', showed improved performance on most ADAPT test activities. An increase in the ability to perform ADL was achieved within a week, in contrast to the level to which gait perturbations could be adequately counteracted. This indicates that perturbation recovery is more difficult to learn and therefore may take more time to change. However, this can only be hypothesized and more research is needed in patients using the MPKs for a longer period of time.

In MFCL-3 and MFCL-4 amputees, an MPK showed significant advantages as to amputees' ability to overcome a perturbation of gait in comparison with a mechanically controlled prosthetic knee joint ${ }^{22,27}$. The discrepancy between those findings and the results in the present thesis may be explained by a higher degree of fear of falling among MFCL-2 amputees. Miller et al. ${ }^{28}$ have shown that fear of falling is pervasive among amputees. It is also known that the prevalence of fear of falling increases with age ${ }^{29,30}$. It can have negative consequences on measures of physical performance due to apprehension and anxiety that interfere with individuals' capacity to maximally challenge their abilities ${ }^{31}$. Moreover, a fear of falling is strongly associated with choosing a "cautious gait", which is characterised by a lower walking velocity, a smaller stride length and an increased double support time ${ }^{32}$. Adopting such a strategy optimises balance and increases the necessary response time to a perturbation of gait, which may explain the small number of actual falls occurred during all tests. It also makes it more difficult to observe considerable 
differences in performance. The possibility that MFCL-2 amputees are more cautious than MFCL-3 amputees is further underlined by Hafner \& Smith ${ }^{5}$. Despite the expectation that MFCL-2 amputees would fall more, due to their reduced physical capacity ${ }^{33,34}$, Hafner \& Smith ${ }^{5}$ demonstrated that the frequency of stumbles and semi-controlled falls in persons classified as MFCL-2 is almost two times lower compared with persons with a higher functional level. The findings of the present thesis suggest that providing participants with an MPK does not instantly change amputees' strategy in situations with a potential risk of falling.

In chapter 6 it was indicated that persons' daily activity level, as measured with the accelerometer, was similar in all three knee joint conditions. This is in agreement with the results of Klute et al. ${ }^{35}$ and Hafner et al. ${ }^{18}$ who also found no changes in the activity level of MFCL-3 amputees who were fitted with an MPK. The accelerometer used in the present study has been shown, in terms of responsiveness, to be suitable for detecting change in active time in older adults ${ }^{36,37}$. Analogous to the participants' performance on the perturbation tests (chapter 5), it appears that persons do not immediately change their daily activity level when provided an MPK. It was, for instance, expected that, due to the increased functional ability to perform ADL, persons would perform more activities per day, because they take on activities that they would not (dare to) perform with the mechanically controlled knee joint. However, an important reason why no differences were found in daily activity level between the three knee joint conditions may have been that persons with a leg amputation have adapted their lifestyle in order to manage the functional limitations inherent to the loss of a limb. Moreover, the participants in our study were not explicitly encouraged to perform more activities in daily life in order to prevent confounding of the effects of using the MPKs. If participants would have been stimulated to perform at their maximal level, possibly, more distinct differences between prosthesis conditions might have been found. However, the added value of measuring people in their 'normal' everyday life would then have been lost.

The main goal of the present thesis was to objectively measure amputees' actual performance in three different prosthesis conditions. Outcome measures on perceived performance were also included to assess the effects of an MPK, because it is wellrecognized that the patient's input in the prosthetic knee selection has a positive influence on successful outcomes ${ }^{38,39}$. Moreover, a person's level of (dis)satisfaction with the prosthesis is strongly related to the level of use of the prosthesis ${ }^{40,41}$. However, it has become increasingly clear that actual performance and perceived performance are 


\section{CHAPTER 7}

different constructs that need not be closely related per se. Overall, the results concerning perceived performance indicate that participants from the two MFCL-2 subgroups with the highest functional level experience the ADL activities to be less difficult to perform with the MPK. These persons reported to be more capable to overcome the perturbations using an MPK and indicated that the MPK felt more stable during those situations. Also, significant improvements were found as to the perceived performance and satisfaction with the MPK. In contrast, out of all outcome measures on amputees' actual functional performance, only the ability to perform ADL (ADAPT) improved with the MPK. It could be argued that the discrepancy between the results on perceived and actual performance is a result of the responsiveness of the measuring tools used to assess the subjects' ability to recover from a perturbation of gait and their daily activity level being insufficient to detect change in amputees' performance after only one week of using an MPK. An alternative explanation may be that perturbation and activity level need more time to change. Another explanation might be that the perceived performance measures cover other aspects than the ones that were used to assess actual performance outcome. To further elucidate this matter, more research is necessary.

The present study investigated two different types of MPKs. One of those prosthetic knee joints has been specially developed for the MFCL-2 patient population and aims to provide sufficient stability (i.e. $\mathrm{MPK}_{\mathrm{B}}$ ). Although a comparison between both MPKs was not included as an aim of the present thesis, an overview of the results suggest that no clear differences exist between $\mathrm{MPK}_{\mathrm{A}}$ and $\mathrm{MPK}_{\mathrm{B}}$ in terms of actual performance in the MFCL-2 population. Remarkably, patients' overall perceived performance was slightly higher with $\mathrm{MPK}_{\mathrm{A}}$. Additionally, most participants preferred $\mathrm{MPK}_{\mathrm{A}}$ when asked directly. From our data, no clear answer can be derived as to which MPK would be best for the MFCL-2 population. Individual performance assessment on either prosthesis type is recommended here.

\subsection{Clinical implications of main research findings}

In this thesis it is shown that in a large part of the group of MFCL-2 amputees an MPK may positively affect a person's functional ability to perform ADL, may increase his sense of safety and confidence with the prosthesis, and may increase his perceived performance and satisfaction with the prosthesis after one week of MPK use. These findings are in agreement with other studies that focused on the effects of MPKs in MFCL-2 amputees $5,6,42$, and thereby further confirm that an MPK is an eligible prosthesis solution for this amputee subpopulation. In addition to the other studies, the present thesis has shown 
that the MFCL-2 population is a heterogeneous group that can be further differentiated into smaller subgroups. Subsequently, it has been demonstrated that not all amputees classified as MFCL-2 seem to benefit from an MPK in the short term. Particularly persons with the lowest functional level within the MFCL-2 population did not show an improvement in either their actual or their perceived performance. This suggests that amputees require a minimum level of physical ability in order to be able to use the distinct features in the MPK to such an extent, that it may lead to an improved level of functioning.

Initially, the manufacturers of MPKs recommended prescription of MPKs for amputees with a high functional level (MFCL-3 or MFCL-4). Our results indicate that several amputees classified as MFCL-2 may have been wrongfully denied an MPK as a prosthesis solution, as it has shown to improve their level of functioning in daily life. In the Dutch (preliminary) guidelines for Amputation and Prosthesiology ${ }^{43}$ it is stated that the selection and prescription of prosthetic components should be based more on clinical studies rather than solely on the product information provided by the manufacturers. The evidence that has been collected in the present thesis further underlines the importance of this viewpoint.

The large between-subject variability in the outcome measures indicates that the MFCL-2 population is a heterogeneous patient group. An important reason for this heterogeneity is that the different MFCL levels are too broadly defined. Moreover, no clear objective measuring tools have been delineated to help clinicians with assigning amputees to a particular MFCL level. Classification is consequently based on subjective measures. Several authors ${ }^{14,44}$ have argued that a more accurate classification system is necessary for prosthetic knee joint prescription. They have also developed alternative methods, such as the functional level assessment system 'Galileo' ${ }^{44}$, which is a novel classification method that assigns persons to a K-level between 0.0 and 4.9 using a StepWatch activity monitor (Orthocare Innovations LLC., Oklahoma City, OK, USA). Also, the Amputee Mobility Predictor has been suggested as a tool to objectively classify persons to a specific K-level ${ }^{14}$. However, we have shown that even after refining the classification of MFCL-2 amputees based on objective parameters, considerable variation in performance levels remain within each subgroup. Consequently, generalized statements about the effects of an MPK on the functioning of the 'typical' MFCL-2 patient are difficult to make. One should not try to find a singular best prosthesis for an entire group of amputees, but rather use objective tests, like the ADAPT test, to personalize the choice. 


\section{CHAPTER 7}

The MFCL level that is assigned to an amputee primarily determines which prosthetic knee joints are available to him. A major problem with this method of prosthesis prescription is that the prosthetic knee joint that is chosen affects the amputees' functional level. Kahle et al. ${ }^{45}$ and Hafner \& Smith ${ }^{5}$ have indicated that several persons who were initially classified as MFCL-2 (fitted with a mechanically controlled prosthetic knee joint) showed an improvement in their functional performance level when they used an MPK, to such an extent, that they advanced to MFCL-3. This example underpins that selecting a prosthetic knee joint solely on a persons' MFCL level may not be the best method of prescribing a prosthetic knee joint.

In view of the shortcomings of prescribing a prosthetic knee joint based on the amputee's assigned MFCL level, it is recommended to use an alternative approach that is based on individual performance assessment. A pre-selection of prosthetic knee joints should be made based on the experience and expertise of the rehabilitation team, current scientific evidence, and clinical knowledge about the patients (medical history, activity level, mental capacity, current physical fitness, psychosocial status). The selected prosthetic knee joints should then successively be fitted to the amputee's prosthesis, followed by an accommodation time of at least one week, including prosthesis training that addresses fear of falling and which may further optimize functioning with the prosthesis. The final decision for a prosthetic knee joint should then be made based also on actual performance results on the ADAPT test for each of the prosthetic knee joints. An individual patient profile should be composed using ADAPT test results (see chapter 4) in combination with information on, for instance, the amputee's home environment and preferred activities. This procedure has already been implemented as a standard protocol for the prescription of prosthetic knee joints (particularly for MPKs) in Adelante Rehabilitation Centre and has been well-received by the health insurance companies. By using this approach, prosthesis prescription may become more efficient, more client-centered, and evidencebased. Also, the end result, i.e. the patient's performance in daily life and subsequently his participation, will be optimized further. It is important to realize that the procedure proposed here is deduced from the protocol that has been used in the present thesis. This procedure may be applied to experienced prosthetic ambulators, whereas choosing a prosthetic knee joint for an amputee who will receive his first prosthesis probably requires an alternative approach.

Currently, the (preliminary) Dutch guidelines for amputation and prosthesiology state that the rehabilitation physician is responsible for determining amputees' intended use 
and possible level of functioning with a prosthesis, which is expressed as a specific K-level (similar to MFCL). A strong point in this guideline is the recommendation to focus on the person's intended or expected activity and participation during the assessment of functioning. However, the guidelines do not clearly state how the rehabilitation physician should assess the amputee's level of functioning. The guidelines also state that a followup evaluation of the prosthesis should be performed after six months. The ADAPT test is a suitable tool to objectively evaluate persons' functional abilities in both instances of the prescription process.

A health care innovation project was performed at the department of Amputation, Traumatology, and Orthopedics of Adelante Rehabilitation Centre to investigate the feasibility of implementing the ADAPT test as an evaluative tool to monitor physical training progress. Based on the experiences of the therapists who have used this test, it became clear that, in order for this test to be suitable to incorporate into the current clinical practice, several practical changes need to be implemented. The most important change is that the time to complete the ADAPT test needs to be reduced. In the current form (17 activities), an experienced prosthesis user needs about 30 to 45 minutes to complete the total ADAPT test, including the perceived performance questionnaires. Patients who are just starting to walk with a prosthesis, especially patients with peripheral vascular disease, needed at least 2 hours to fully complete the test. Given the compromised endurance and physical condition of most amputees, the load of performing the ADAPT test may be too high. To accomplish a reduction in time for the administering of the test, the number of activities in the test needs to be reduced. Activity stations with activities that encompass similar movements (e.g. reaching overhead to hang up laundry or to place an object into an upper kitchen cabinet) may be identified and combined into one activity. This would also save in the space needed as test area. A second option is to choose a limited number of activities from the available set that best suit the individual's home environment or preferred daily activities. This creates the possibility to compose a highly personalized test for each patient, focused on those aspects of functioning that are relevant to the amputee in his daily life environment. In both cases, additional research is needed to re-evaluate the psychometric properties of the test.

\subsection{Methodological considerations}

The main association with persons who are classified as MFCL-2, in relation to amputees classified as MFCL-3 or MFCL-4, is that MFCL-2 amputees are typically older ( $>65$ years) and are more likely to have vascular problems that have led to their amputation. The 


\section{CHAPTER 7}

mean age of the participants in the present study was about 60 years. Approximately $20 \%$ of them had their amputation due to vascular problems. The fact that a relatively small portion of the group of our participants had vascular problems and the mean of the group of subjects was under 65 years seems untypical for MFCL-2 patients. It should be noted that persons with a dysvascular amputation have a poor prognosis, including a high reamputation rate ${ }^{46}$, and a high mortality rate $(\approx 30 \%)$ within the first 6 to 12 months after amputation ${ }^{46,47}$. All participants were extensively screened and classified as MFLC-2 by three rehabilitation experts (i.e. a senior rehabilitation physician, a senior physiotherapist and a senor prosthetist) prior their entry into the study. Also, the characteristics of our MFCL-2 research population such as age, post-amputation time, and the ratio of amputations due to trauma and vascular disease generally concur with previous studies that included MFCL-2 amputees ${ }^{5,6,42}$. It is important to realize that age and cause of amputation do not solely determine a persons' functional level. Fear of falling, confidence, skin condition, pain, socket fit, length of the residual limb, and physical condition are all additional factors that contribute to a person's level of functioning with the prosthesis.

Stratification of the group of participants resulted in three relatively small subgroups, which consequently reduced the power to detect the possible effects of the MPKs within each subgroup. Particularly, the sample size of the subgroup containing amputees with the lowest functional level was limited. This subgroup mainly consisted of amputees due to vascular problems, who demonstrated a more reduced physical condition in comparison with amputees who were amputated due to other causes (trauma, tumour). They were physically less able to perform all the necessary tests within one day that were included in the study protocol. Moreover, before the start of the study the available pool of persons with an amputation due to vascular problems who were eligible for participation was already limited. The small sample sizes in the subgroups warrant some caution regarding the extrapolation of the results as to the effects of an MPK towards the general population of MFCL-2 patients.

The order in which the two MPKs have been tested was randomized, whereas amputees were always tested first in the mechanically controlled prosthetic knee joint condition. Due to this approach the increased performance on the ADAPT test in the MPK condition may have occurred because of a training effect. However, the circuit stations consist of common daily activities and have therefore been performed many times before participating in the study. Effects have occurred because participants were more familiar 
with how to perform the different activities. These effects were minimized by elaborately explaining the procedures and by introducing practice trials prior to actual testing. Randomizing all three knee joint conditions would have possibly prevented such bias. However, no persons classified as MFCL-2 who already used an MPK were available in The Netherlands at the start of the study. Participants would have had to be familiarized with all three knee joints first, before it was possible to randomly allocate the three testing sessions. The long time commitment for the participants that is inherent to such a design was expected to reduce the number of amputees willing to participate. Additional practical considerations, such as the additional time and financial resources necessary to implement such an approach, also led to the decision for the design that has been used in the current thesis.

The accommodation phase in the present thesis was set at one week, so not to deter potential participants from joining the study by long lasting commitments to the study. Also, providing patients with an MPK for an extended period of time, familiarizing them with the new component, and then returning their mechanically controlled prosthetic knee joint was considered unethical. Compared to other comparative studies, one week may have been relatively short. It may have prevented participants to be able to use the MPK to its full potential. English et al. ${ }^{48}$ reported that a one-week familiarisation period is adequate in clinical practice, but for research purposes, a familiarisation period of at least three weeks is recommended. However, this recommendation was based on accommodation after changing from a polycentric unit with hydraulic swing control to one with friction swing control. No clear consensus seems to exist concerning the optimal accommodation time for an MPK. Other studies comparing an MPK with a mechanically controlled prosthesis reported accommodation periods ranging from several minutes to 39 weeks $^{5,22,35,45,49-57}$. In the current study, participants' performance after one week with the MPKs was already at a similar level as compared with the mechanically controlled prosthetic knee joint. In fact, significant differences were found in both actual and perceived performance on various outcome measures after one week of using an MPK. As was discussed in chapter 2 , measuring in the domain of ICF activity and ICF participation is considered a rather uncharted terrain. As a result, new measuring tools (i.e. ADAPT test and the performance observation scale for the perturbation tests) needed to be developed and were implemented in order to attain the research goals. For the ADAPT test, the validity and test-retest reliability have been assessed in two separate test configurations. However, other clinimetric properties, such as sensitivity to change, need to be further investigated. 


\section{CHAPTER 7}

Multiple measures have been used to assess subjects' perceived performance. Using self-report measures may be inaccurate, because of, for instance, potential recall bias and social desirability effects. Participants' expectations or prior knowledge about MPKs may have triggered them to (consciously or unconsciously) exaggerate their perceived performance on the MPKs. The results on the different tools on perceived performance should therefore be interpreted with care. Blinding of participants regarding prosthesis condition would have eliminated this problem. However, this was not possible from a practical perspective. During the familiarization session the different features of the MPKs had to be explained to enable subjects to use each MPK to its full potential and to ensure safe use outside the rehabilitation centre. Also, subjects would have undoubtedly noticed whether they were fitted with their own mechanically controlled knee joint or with an MPK. Also, in contrast to the mechanically controlled knee joint, the MPK has a battery that needs to be recharged every day.

The underlying concept of the ADAPT test is that a decrease in performance time of an activity indicates improved ability to perform that particular task. Measuring performance time is inexpensive, simple, and easy to interpret. However, it does not provide information about the quality of the performance. Such information would lead to a more detailed assessment of persons' functional abilities. Developing such a quality assessment tool is highly recommended for future research. In order to monitor the level of activities during daily life, the amount and intensity of the movements made were quantified by using accelerometers, but no information was provided as to the type of movements or about the quality with which the activities were performed. Activity monitors have been developed that enable detection of a number of different types of tasks (such as walking, cycling, standing, sitting, and lying) performed under standardized conditions and during well-delineated time segments ${ }^{58-60}$. However, those devices have not shown yet to be capable to reliably detect various other common ADL activities and tasks that are performed by an individual during his (non-standardized) daily routine. Objectively monitoring the type and quality of activities in the home situation seems to be fairly limited thus far.

\subsection{Recommendations for future research}

This thesis has shown that tools, aimed at objectively measuring the patients' performance in the ICF domains activity and participation, should be further developed and assessed in future research. For instance, tools to assess the quality of performance of ADL (e.g. quantifying the amount of compensatory movements, accuracy, efficiency and 
smoothness of motion during task performance, in addition to measuring performance time), as well as to determine the type of activities that are performed by amputees using a leg prosthesis in their own living environment, need to be further developed. Such tools are vital to assess the effectiveness of prosthetic components.

It has been demonstrated in the present thesis that MFCL-2 amputees are quickly able to function with the MPK at a level that was at least equivalent to their previous performance level with the mechanically controlled prosthetic knee joint. In our study participants did not receive any form of training aimed to improve their functioning with the prosthesis and the tests used were not designed to encourage participants to perform at their maximal ability. The effects of the MPK on persons' functioning as measured in our study may be considered as minimum effects of the MPKs. The next step in determining the functional added value of using MPKs in MFCL-2 amputees should be to provide participants with comprehensive training sessions and a longer accommodation phase in which the participants learn how to use the MPK to its full potential. Consequently, this may provide evidence as to the maximum effects of using an MPK in MFCL-2 amputees. The selection of prosthetic knee joints should be based on individual patient assessment, using objective data from performance tests such as the ADAPT test. This recommendation is based on the results of participants who are experienced prosthesis users and who were capable of performing all tests. The feasibility of using the ADAPT test to support the selection of a patient's first prosthetic knee joint after amputation needs to be further investigated.

In order for the ADAPT test to become clinically feasible and an aid in the selection of prosthetic components for individual patients, further refinements are necessary. It should be investigated whether reducing the number of activities incorporated in the current test affects its sensitivity to detect differences in functional ability of patients. Moreover, future research should focus on further improving the possibility to personalize the ADAPT test for each subject by, for instance, choosing a specific number of activities from a "library" of independently validated activity stations. This would enable a unique ADAPT test configuration that would closely resemble the subject's home situation. Also, activity stations that better relate to less experienced prosthesis users need to be developed.

Additional research should focus on further improving the perturbation protocol and the observational performance scale. The primary focus should lie on reducing the level of 
patient's anticipation to a perturbation of gait to minimize the effects of, for instance, fear of falling on the recovery response following an induced stumble, thereby further improving validity of the perturbation protocol. Moreover, treatment programs to reduce the fear of falling should be developed and should be incorporated in the training sessions mentioned above.

\subsection{Final conclusions}

The MFCL-2 population is a heterogeneous group, in which at least three MFCL-2 subgroups can be identified. Persons in the MFCL-2 subgroups with an intermediate or high functional level benefit from using an MPK, with regard to improved ADL performance, after only one week of home use and two hours of familiarization, whereas patients who have a low MFCL-2 functional level do not.

The use of an MPK does not lead to changes in recovery responses of MFCL-2 amputees to induced perturbations of gait after a short period of use. Nevertheless, persons indicate to feel safer and more confident in their abilities with the MPK during situations with a high risk of falling, and amputees are more satisfied with their overall performance with the MPK. However, neither the positive effects on persons' perceived performance and safety during ambulation, nor the improved performance of ADL, seem to encourage patients to become more active in daily life after one week of using an MPK.

New measuring tools have been developed that enable objective testing of the amputee's actual performance with a prosthesis in the ICF domain activity. These tools enable clinicians to further fine-tune prescription of prosthetic devices, therapy, and evaluation of therapy outcome. 


\subsection{References}

1. World Health Organisation. International Classification of Functioning, Disability and Health: ICF; 2001.

2. Kiwa Prismant. Landelijke Medische Registratie [National Medical Registration]. [Accessed December 30, 2011]; Available from: http://cognosserver.prismant.nl/cognos7/cgi-bin/ppdscgi.cgi?DC=Q\&E=/ Prisma-Landelijke-LMR/Landelijke+LMR-informatie+-+Verrichtingen.

3. Rommers GM, Vos LD, Groothoff JW, Schuiling CH, Eisma WH. Epidemiology of lower limb amputees in the north of The Netherlands: aetiology, discharge destination and prosthetic use. Prosthet Orthot Int 1997; 21:92-99.

4. Ziegler-Graham K, MacKenzie EJ, Ephraim PL, Travison TG, Brookmeyer R. Estimating the prevalence of limb loss in the United States: 2005 to 2050. Arch Phys Med Rehabil 2008; 89:422-429.

5. Hafner BJ, Smith DG. Differences in function and safety between Medicare Functional Classification Level-2 and -3 transfemoral amputees and influence of prosthetic knee joint control. J Rehabil Res Dev 2009; 46:417-433.

6. Wetz HH, Hafkemeyer U, Drerup B. Einfluss des C-Leg-Kniegelenk-Passteiles der Fa. Otto Bock auf die Versorgungsqualität Oberschenkelamputierter. Eine klinisch-biomechanische Studie zur Eingrenzung von Indikationskriterien [The influence of the C-leg knee-shin system from the Otto Bock Company in the care of above-knee amputees. A clinical-biomechanical study to define indications]. Orthopäde 2005; 34:298-319.

7. Condie E, Scott H, Treweek S. Lower limb prosthetic outcome measures: a review of the literature 1995 to 2005. J Prosthet Orthot 2006; 18:13-45.

8. Cumming JC, Barr S, Howe TE. Prosthetic rehabilitation for older dysvascular people following a unilateral transfemoral amputation. Cochrane Database Syst Rev 2006; CD005260.

9. van der Linde H, Hofstad CJ, Geurts AC, Postema K, Geertzen JH, van Limbeek J. A systematic literature review of the effect of different prosthetic components on human functioning with a lower-limb prosthesis. J Rehabil Res Dev 2004; 41:555-570.

10. Whiteneck G, Dijkers MP. Difficult to measure constructs: conceptual and methodological issues concerning participation and environmental factors. Arch Phys Med Rehabil 2009; 90:S22-S35.

11. Weiss GN, Gorton TA, Read RC, Neal LA. Outcomes of lower extremity amputations. J Am Geriatr Soc 1990; 38:877-883.

12. Schoppen T, Boonstra A, Groothoff JW, de Vries J, Goeken LN, Eisma WH. Physical, mental, and social predictors of functional outcome in unilateral lower-limb amputees. Arch Phys Med Rehabil 2003; 84:803-811.

13. Gailey RS, Roach KE, Applegate EB, Cho B, Cunniffe B, Licht S, Maguire M, Nash MS. The amputee mobility predictor: an instrument to assess determinants of the lower-limb amputee's ability to ambulate. Arch Phys Med Rehabil 2002; 83:613-627. 


\section{CHAPTER 7}

14. Gailey RS. Predictive outcome measures versus functional outcome measures in the lower limb amputee. J Prosthet Orthot 2006; 18:51-60.

15. Buell NC, Willingham LL, Allyn KJ, Hafner BJ, Smith DG. Evaluation of gait style to ascend and descend stairs for lower limb amputees. Proceedings of the 11th World Congress of the International Society of Prosthetics and Orthotics; Hong Kong; 2004.

16. Buell NC, Willingham LL, Allyn KJ, Hafner BJ, Smith DG. Evaluation of gait style for hill descent for lower limb amputees. Proceedings of the 11th World Congress of the International Society of Prosthetics and Orthotics; Hong Kong; 2004.

17. Seymour R, Engbretson B, Kott K, Ordway N, Brooks G, Crannell J, Hickernell E, Wheeler K. Comparison between the C-leg microprocessor-controlled prosthetic knee and non-microprocessor control prosthetic knees: a preliminary study of energy expenditure, obstacle course performance, and quality of life survey. Prosthet Orthot Int 2007; 31:51-61.

18. Hafner BJ, Willingham LL, Buell NC, Allyn KJ, Smith DG. Evaluation of function, performance, and preference as transfemoral amputees transition from mechanical to microprocessor control of the prosthetic knee. Arch Phys Med Rehabil 2007; 88:207-217.

19. Stratford PW, Kennedy D, Pagura SM, Gollish JD. The relationship between self-report and performance-related measures: questioning the content validity of timed tests. Arthritis Rheum 2003; 49:535-540.

20. Miller WC, Deathe $A B$, Speechley $M$, Koval J. The influence of falling, fear of falling, and balance confidence on prosthetic mobility and social activity among individuals with a lower extremity amputation. Arch Phys Med Rehabil 2001; 82:1238-1244.

21. Miller WC, Speechley M, Deathe AB. Balance confidence among people with lower-limb amputations. Phys Ther 2002; 82:856-865.

22. Blumentritt S, Schmalz T, Jarasch R. The safety of C-leg: biomechanical tests. J Prosthet Orthot 2009; 21:2-15.

23. Pijnappels $M$, Bobbert MF, van Dieen JH. Contribution of the support limb in control of angular momentum after tripping. J Biomech 2004; 37:1811-1818.

24. Eng JJ, Winter DA, Patla AE. Strategies for recovery from a trip in early and late swing during human walking. Exp Brain Res 1994; 102:339-349.

25. Hofstad CJ, van der Linde H, Nienhuis B, Weerdesteyn V, Duysens J, Geurts AC. High failure rates when avoiding obstacles during treadmill walking in patients with a transtibial amputation. Arch Phys Med Rehabil 2006; 87:1115-1122.

26. Warabi T, Kato M, Kiriyama K, Yoshida T, Kobayashi N. Treadmill walking and overground walking of human subjects compared by recording sole-floor reaction force. Neurosci Res 2005; 53:343-348.

27. Kaufman KR, Anderson T, Schneider G, Walsh K. Mechanisms of stumble recovery: non-microprocessor controlled compared to microprocessor-controlled prosthetic knees. Proceedings of the The 
American Academy of Orthotics and Prosthetics 34th annual meeting and scientific symposium; Orlando, FL., USA; 2008.

28. Miller WC, Speechley M, Deathe B. The prevalence and risk factors of falling and fear of falling among lower extremity amputees. Arch Phys Med Rehabil 2001; 82:1031-1037.

29. Bertera EM, Bertera RL. Fear of falling and activity avoidance in a national sample of older adults in the United States. Health Soc Work 2008; 33:54-62.

30. Scheffer AC, Schuurmans MJ, van Dijk N, van der Hooft T, de Rooij SE. Fear of falling: measurement strategy, prevalence, risk factors and consequences among older persons. Age Ageing 2008; 37:1924.

31. Maki BE, Holliday PJ, Topper AK. Fear of falling and postural performance in the elderly. J Gerontol 1991; 46:M123-M131.

32. Giladi N, Herman T, Reider G, II, Gurevich T, Hausdorff JM. Clinical characteristics of elderly patients with a cautious gait of unknown origin. J Neurol 2005; 252:300-306.

33. Pavol MJ, Owings TM, Foley KT, Grabiner MD. Influence of lower extremity strength of healthy older adults on the outcome of an induced trip. J Am Geriatr Soc 2002; 50:256-262.

34. Pijnappels M, Reeves ND, Maganaris CN, van Dieen JH. Tripping without falling; lower limb strength, a limitation for balance recovery and a target for training in the elderly. J Electromyogr Kinesiol 2008; 18:188-196.

35. Klute GK, Berge JS, Orendurff MS, Williams RM, Czerniecki JM. Prosthetic intervention effects on activity of lower-extremity amputees. Arch Phys Med Rehabil 2006; 87:717-722.

36. Gardiner PA, Clark BK, Healy GN, Eakin EG, Winkler EA, Owen N. Measuring older adults' sedentary time: reliability, validity, and responsiveness. Med Sci Sports Exerc 2011; 43:2127-2133.

37. Focht BC, Sanders WM, P.H. B, RejeskI WJ. Initial validation of the CSA activity monitor during rehabilitation exercise among older adults with chronic disease. J Aging Phys Activity 2003; 11:293-304.

38. Boone DA, Coleman KL. Use of the Prosthesis Evaluation Questionnaire (PEQ). J Prosthet Orthot 2006; 18:68-79.

39. Legro MW, Reiber GD, Smith DG, del Aguila M, Larsen J, Boone D. Prosthesis evaluation questionnaire for persons with lower limb amputations: assessing prosthesis-related quality of life. Arch Phys Med Rehabil 1998; 79:931-938.

40. Phillips B, Zhao H. Predictors of assistive technology abandonment. Assist Technol 1993; 5:36-45.

41. Riemer-Reiss ML, Wacker RR. Factors associated with assistive technology discontinuance among individuals with disabilities. J Rehabil 2000; 66:44-50.

42. Burnfield JM, Eberly VJ, Gronely JK, Perry J, Yule WJ, Mulroy SJ. Impact of stance phase microprocessor-controlled knee prosthesis on ramp negotiation and community walking function in K2 level transfemoral amputees. Prosthet Orthot Int 2012; 36:95-104.

43. Nederlandse Vereniging van Revalidatieartsen (VRA). Conceptrichtlijn Amputatie en Prothesiolo- 
gie Onderste Extremiteit [Concept Guidelines Amputation and Prosthesiology Lower Extremities]. Available from: http://www.cbo.nl/Downloads/1347/conceptrichtlijn\%20amputatie_definitieve\%20 versie\%20voor\%20commentaar_11\%20mei\%202011.pdf.

44. Orthocare Innovations LLC. Stepping beyond K-levels: the Functional Level Assessment System. [accessed March 3, 2011]. Available from: http://www.orthocareinnovations.com/galileo/pdf/GalileoWhitepaper01-04-11.pdf.

45. Kahle JT, Highsmith MJ, Hubbard SL. Comparison of nonmicroprocessor knee mechanism versus CLeg on Prosthesis Evaluation Questionnaire, stumbles, falls, walking tests, stair descent, and knee preference. J Rehabil Res Dev 2008; 45:1-14.

46. Dillingham TR, Pezzin LE, Shore AD. Reamputation, mortality, and health care costs among persons with dysvascular lower-limb amputations. Arch Phys Med Rehabil 2005; 86:480-486.

47. Bo Ebskov L. Dysvascular amputations and long-term survival in a 20-year follow-up study. Int J Rehabil Res 2006; 29:325-328.

48. English RD, Hubbard WA, McElroy GK. Establishment of consistent gait after fitting of new components. J Rehabil Res Dev 1995; 32:32-35.

49. Buckley JG, Spence WD, Solomonidis SE. Energy cost of walking: comparison of "intelligent prosthesis" with conventional mechanism. Arch Phys Med Rehabil 1997; 78:330-333.

50. Johansson JL, Sherrill DM, Riley PO, Bonato P, Herr H. A clinical comparison of variable-damping and mechanically passive prosthetic knee devices. Am J Phys Med Rehabil 2005; 84:563-575.

51. Kaufman KR, Levine JA, Brey RH, Iverson BK, McCrady SK, Padgett DJ, Joyner MJ. Gait and balance of transfemoral amputees using passive mechanical and microprocessor-controlled prosthetic knees. Gait Posture 2007; 26:489-493.

52. Kaufman KR, Levine JA, Brey RH, McCrady SK, Padgett DJ, Joyner MJ. Energy expenditure and activity of transfemoral amputees using mechanical and microprocessor-controlled prosthetic knees. Arch Phys Med Rehabil 2008; 89:1380-1385.

53. Orendurff MS, Segal AD, Klute GK, McDowell ML, Pecoraro JA, Czerniecki JM. Gait efficiency using the C-Leg. J Rehabil Res Dev 2006; 43:239-246.

54. Petersen AO, Comins J, Alkjaer T. Assessment of gait symmetry in transfemoral amputees using C-leg compared with $3 R 60$ prosthetic knees. J Prosthet Orthot 2010; 22:106-112.

55. Segal AD, Orendurff MS, Klute GK, McDowell ML, Pecoraro JA, Shofer J, Czerniecki JM. Kinematic and kinetic comparisons of transfemoral amputee gait using C-Leg and Mauch SNS prosthetic knees. J Rehabil Res Dev 2006; 43:857-870.

56. Taylor MB, Clark E, Offord EA, Baxter C. A comparison of energy expenditure by a high level transfemoral amputee using the Intelligent Prosthesis and conventionally damped prosthetic limbs. Prosthet Orthot Int 1996; 20:116-121.

57. Yokogushi K, Narita H, Uchiyama E, Chiba S, Nosaka T, Yamakoshi KI. Biomechanical and clinical 
evaluation of a newly designed polycentric knee of transfemoral prosthesis. J Rehabil Res Dev 2004; 41:675-681.

58. Grant PM, Ryan CG, Tigbe WW, Granat MH. The validation of a novel activity monitor in the measurement of posture and motion during everyday activities. Br J Sports Med 2006; 40:992-997.

59. Pitta F, Troosters T, Spruit MA, Decramer M, Gosselink R. Activity monitoring for assessment of physical activities in daily life in patients with chronic obstructive pulmonary disease. Arch Phys Med Rehabil 2005; 86:1979-1985.

60. Roy SH, Cheng MS, Chang SS, Moore J, De Luca G, Nawab SH, De Luca CJ. A combined sEMG and accelerometer system for monitoring functional activity in stroke. IEEE Trans Neural Syst Rehabil Eng 2009; 17:585-594. 


$$
\operatorname{tin}
$$


Summary

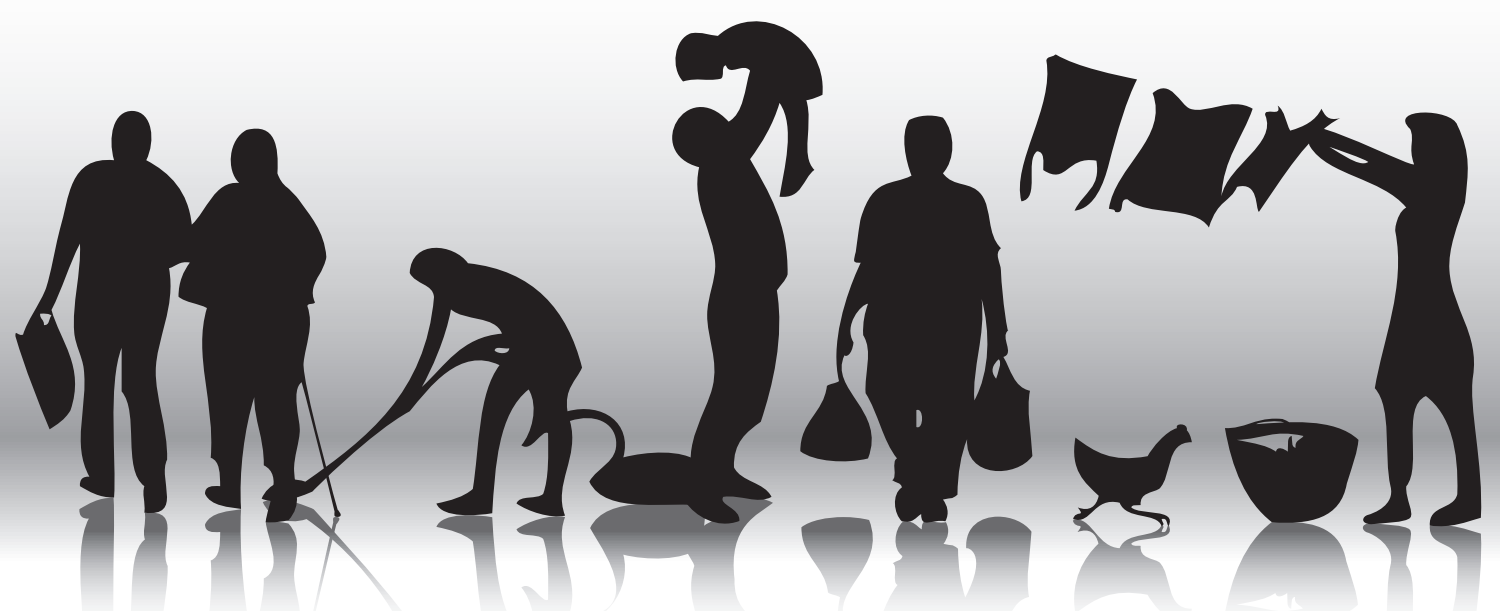




\section{Summary}

The prosthetic knee joint is an important part of a leg prosthesis, because it greatly contributes to the extent to which patients with a transfemoral amputation or knee disarticulation are able to ambulate efficiently and safely. The wide variety of prosthetic knee joints available is generally divided in mechanically controlled prosthetic knee joints and microprocessor-controlled prosthetic knee joints (MPKs). It is the task of the clinician to select the prosthetic knee joint that helps the patient to achieve and maintain an optimal level of functioning in daily life. In order for the clinicians to make a sound decision, they need reliable and objective scientific evidence concerning the effectiveness of the prosthetic knee joints regarding all three domains of functioning, as described by the International Classification of Functioning, Disability and Health (ICF), i.e. function, activity, and participation. Especially objective information regarding the effects of an MPK on persons' performance in the domains activity and participation is vital, because these are the main areas in which amputees report to experience many problems. Also, the effectiveness of an MPK should be investigated in all subpopulations of patients with an above-knee amputation of which it is reasonable to assume they might benefit from an MPK. These subpopulations may be distinguished using the Medicare Functional Classification Levels (i.e. MFCL-0 through MFLC-4), which reflects the amputee's abilities or potential abilities with the prosthesis. Currently, an MPK is still typically prescribed only to MFCL-3 and MFCL-4 amputees. However, prior to the start of our investigation we expected that MFCL-2 amputees might also benefit from using an MPK.

The main aim of the present thesis was to systematically assess the effects of using an MPK, in comparison with a mechanically controlled knee joint, in persons classified as MFCL-2, on their functional ability to perform activities of daily living, their functional ability to recover effectively from different types of perturbations in gait, and their daily activity level. In addition, the measures that have been utilized thus far to assess the effects of using an MPK have been reviewed and structured according to the three ICF domains.

Studies that compared patients' performance with an MPK in relation to a mechanically controlled prosthetic knee joint were identified and systematically reviewed in chapter 2 . The main outcome measures of 31 studies were extracted and subsequently structured according to the ICF framework. Also, the effects of MPKs on amputees' functioning were presented concisely. The majority (70\%) of all outcome measures identified, describing the effects of an MPK on a person's actual performance with the prosthesis, covered ICF function level, whereas only $27 \%$ of the measures on actual performance targeted ICF activity and none of the objective measures identified in the review targeted ICF 
participation. Moreover, the evidence available about the effects of MPKs on persons' functioning cannot be generalised for the entire population of persons with an aboveknee amputation, as testing of MPKs has, in the majority of cases, been performed in healthy, fit, and active persons who are relatively young. In our review it was concluded that scientifically valid evidence regarding the performance of persons with an MPK in everyday life is limited. Research should specifically focus on ICF activity and participation level of the functioning of MFCL-2 amputees to increase the understanding of the possible functional added value of MPKs.

The limited evidence as to the effects of MPKs on the patient's functioning in the ICF domain activity, as well as the absence of eligible tools to objectively measure performance in this domain, indicated the need for the development of a new measuring tool. The development of such a new tool that objectively measures functional performance of activities of daily living (ADL) has been described in chapter 3. This Assessment of Daily Activity Performance in Transfemoral amputees (ADAPT) test is a test circuit consisting of different circuit stations that comprise simulated representations of ADL tasks that are perceived by amputees as difficult to perform in daily life. The feasibility of implementing a concept of objectively assessing functional abilities of transfemoral amputees in daily life performance into a new measuring tool (i.e. the ADAPT test) was investigated. To this end, proof of principle was sought by investigating the discriminant validity and the level of reproducibility in two test versions of the ADAPT test. In most of the ADAPT test activities a clear difference was found between the performance of amputees that used an MPK and amputees that used a mechanically controlled prosthetic knee joint. It was concluded that the ADAPT test was adequately able to detect differences in functional performance levels between the two groups of prosthesis users. As to the test-retest reliability, only small differences in the mean differences in performance time between the first and second measurement were found, whereas all correlation coefficients exceeded 0.80 , with the exception of 1 activity. In $75 \%$ of all circuit stations the correlation coefficient was even greater or equal to 0.90. Results from the BlandAltman analyses showed no specific trend between mean time scores on the one hand and test-retest differences in time scores on the other hand. The ADAPT test results were also compared with the scores on the Locomotor Capabilities Index (LCI). LCl scores were maximal in $70 \%$ of the participants, indicating a ceiling effect. In contrast, the ADAPT test results showed clear differences per circuit station, even in those patients in which the $\mathrm{LCl}$ score was maximal. The results of this study indicated that it is feasible to objectively measure functional abilities in daily life in transfemoral amputees using the concept of simulated daily life situations. 
The functional added value of MPKs regarding the performance of ADL has been assessed in MFCL-2 amputees using the ADAPT test (chapter 4). Participants were measured in three conditions, i.e. while using a mechanically controlled knee joint, an MPK with an adaptive stance and swing phase control $\left(\mathrm{MPK}_{\mathrm{A}}\right)$, and an MPK with an adaptive stance phase and mechanically controlled swing phase $\left(\mathrm{MPK}_{\mathrm{B}}\right)$. For each activity of the ADAPT test, the performance time was measured and the self-perceived level of difficulty was scored on a Visual Analogue Scale. The time to perform activities that require adequate postural balance improved in both $\mathrm{MPK}_{\mathrm{A}}$ and $\mathrm{MPK}_{\mathrm{B}}$ knee joint conditions in the whole group of MFCL-2 amputees. Furthermore, a large between-subject variability in performance times on the ADAPT test was observed, which confirmed our expectations that the MFCL-2 population is a heterogeneous group. However, as this large variability was expected to obscure possible effects of the MPKs on amputees' performance, stratification of the research group into three subgroups was performed. This led to a more intricate overview of the effects of the MPKs. As a result, it became clear that particularly the MFCL-2 amputees with either an intermediate or high functional level improved their ability to perform ADL when using an MPK, whereas amputees with a low functional level did not. A more compromised overall physical condition, in combination with lower balance confidence levels in participants of the latter group may explain this phenomenon.

In chapter 5 the effectiveness of $\mathrm{MPK}_{\mathrm{A}}$ and MPK $\mathrm{B}_{\mathrm{B}}$ as to MFCL-2 amputees' ability to recover from four different types of induced gait perturbations, their self-assessed performance, and their sense of stability on the prosthesis during those perturbations, were investigated. Each amputee was recorded on video during all perturbation tests and his recovery response was subsequently rated by two independent expert physiotherapists, using a newly developed performance assessment scale. Only the participants who were classified in the intermediate and high MFCL-2 subgroups reported feeling more capable to successfully recover from gait perturbations and also experienced increased levels of stability during situations with a high risk of falling. However, the recovery of the perturbations in gait did not seem to differ between the mechanically controlled knee joint condition and the MPK conditions. MFCL-2 amputees seem to respond differently to critical high-risk situations than amputees with higher functional levels (MFCL-3 or MFCL4). A possible explanation may be that our participants performed the perturbation tests with a so-called "cautious gait", common in older persons. With a cautious gait balance is optimised and the necessary response time to successfully overcome the perturbation is elongated. As to the perturbation testing in the present thesis it is recommended to develop and use more sensitive measuring tools in order to detect the possibly subtle 
differences in the performance of amputees using either an MPK or a conventional knee joint.

The effects of using an MPK, in comparison with a mechanically controlled prosthetic knee joint, on the daily activity level of MFCL-2 amputees has been described in chapter 6. Participants' activity level was assessed in the participants' home and community environment using accelerometry. Also, participants' perception about the use of the prosthetic knee joints was assessed using the Prosthesis Evaluation Questionnaire (PEQ). The MFCL-2 amputees perceived an improved ability to ambulate, were more satisfied with how they walked, experienced an improved residual limb health, and reported an increased level of physical comfort when using a prosthesis featuring an MPK. However, these perceived benefits did not encourage these persons to increase their everyday activity level after one week of using the MPK. Apparently, improving an MFCL-2 amputee's potential to ambulate by fitting his prosthesis with (for instance) an MPK, does not automatically stimulate him to be more active in daily life. These persons have adapted their lifestyle in order to manage the functional limitations that come with the loss of a limb. Changing one's lifestyle instantaneously is difficult to accomplish.

In Chapter 7 a comprehensive overview of the main findings of the present research has been provided and the clinical implications of the results have been discussed. In general, our research has shown that a considerable part of the MFCL-2 population benefits from using an MPK in terms of improved actual performance of ADL, an increased sense of safety and confidence with the prosthesis, as well as an improved perceived performance after one week of MPK use. This suggests that many MFCL-2 amputees may have been unduly denied an MPK as a prosthesis solution. It has also become clear that the MFCL-2 population is a heterogeneous group, which may be partly explained by the fact that the original MFCL levels have been too broadly defined and that no objective measuring tool has been delineated to help assign amputees to the MFCL levels. Even after refining the classification of MFCL-2 amputees, using our subclassification, considerable variation in performance levels remained in each subgroup. It is therefore recommended to use objective tests, such as the ADAPT test, to select prosthetic knee joints based on individual performance assessment. The tools that have been developed in the present studies to objectively measure a patient's performance with a prosthesis in the ICF domain activity, as well as the evidence that has been provided concerning the effectiveness of MPKs in MFCL-2 amputees, may assist clinicians to further fine-tune the prescription of prosthetic knee joints. 


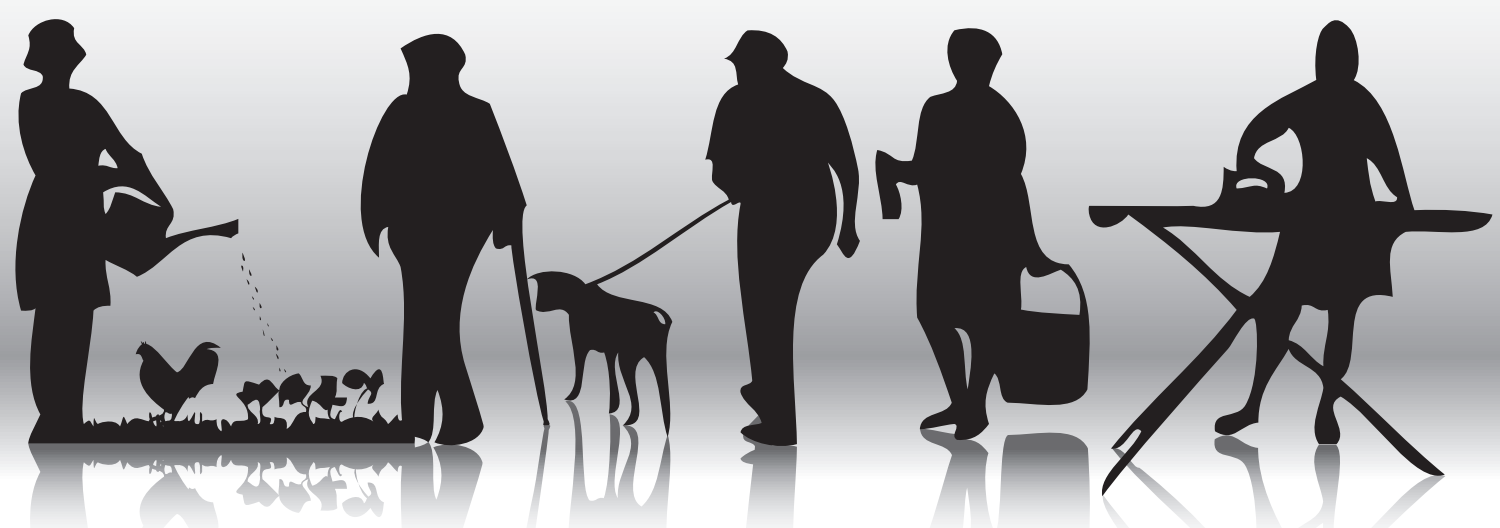


Samenvatting

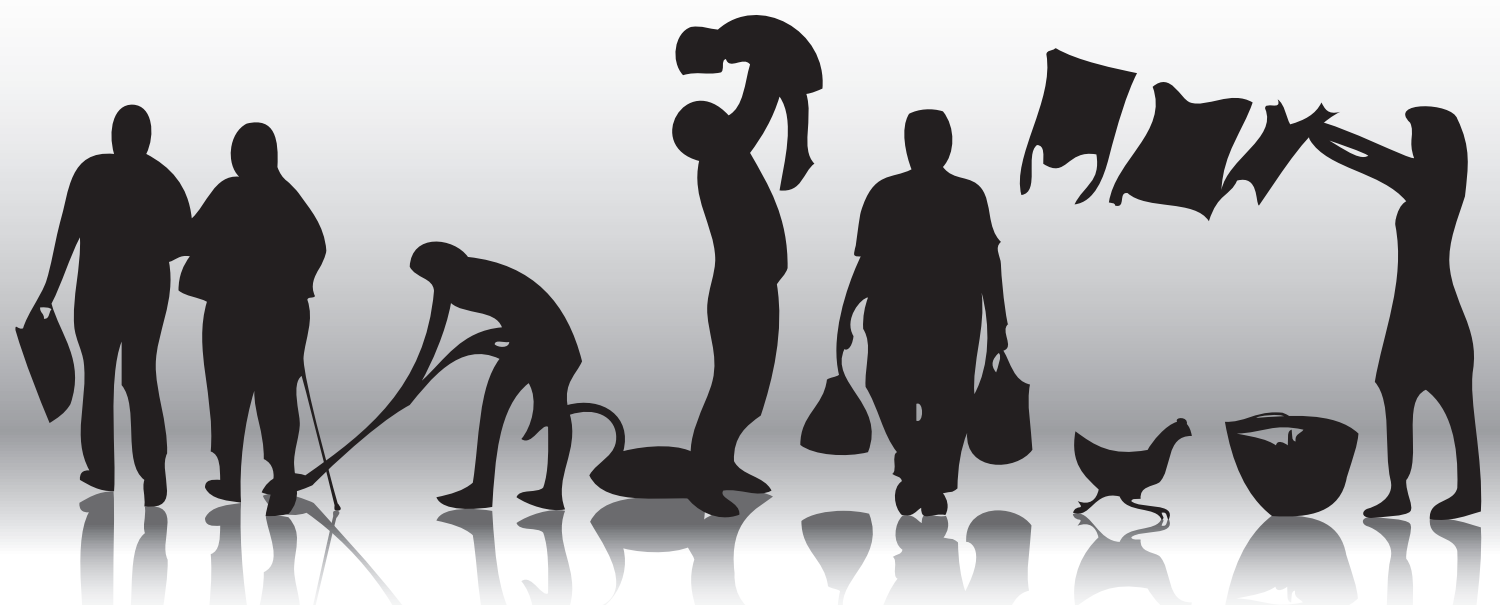




\section{Samenvatting}

$\mathrm{Na}$ een beenamputatie kan de patiënt een beenprothese voorgeschreven krijgen. Het kniescharnier is een belangrijk onderdeel van een beenprothese. Het levert een belangrijke bijdrage aan de mate waarin patiënten met een transfemorale amputatie of een knie exarticulatie in staat zijn zich efficiënt en veilig voort te bewegen. Het grote aantal verschillende kniescharnieren is ruwweg onder te verdelen in twee groepen, i.e. kniescharnieren waarbij de overgang van standfase naar zwaaifase (en omgekeerd) mechanisch geregeld is en kniescharnieren waarbij deze overgangen elektronisch worden geregeld (de zogenaamde microprocessorgestuurde kniescharnieren, kortweg MPKs). Binnen de groep amputatiepatiënten worden doorgaans verschillende deelpopulaties onderscheiden op basis van het mobiliteitsniveau van de patiënt. De Medicare Functional Classification Levels (MFCL-0 tot en met MFCL-4) zijn een voorbeeld van een systeem om amputatiepatiënten te classificeren. De MFCL classificatie gebeurt op basis van prothesegerelateerde vaardigheden of potentiële vaardigheden van een amputatiepatiënt.

Het is de taak van de revalidatiearts om uit het grote aanbod aan kniescharnieren juist dat kniescharnier te selecteren waarmee de patiënt uiteindelijk een optimaal niveau van functioneren in het dagelijks leven kan bereiken en kan behouden. Willen clinici een goed onderbouwde beslissing kunnen nemen wat betreft de keuze voor een MPK, dan hebben zij betrouwbare en objectief getoetste, wetenschappelijke informatie nodig ten aanzien van de effectiviteit van MPKs. Het is hierbij ten eerste van belang dat deze informatie betrekking heeft op alle drie de domeinen van het menselijk functioneren, i.e. 'functie', 'activiteit' en 'participatie'. Deze domeinen zijn beschreven in de International Classification of Functioning, Disability and Health (ICF). Met name objectieve informatie betreffende de effecten van een MPK op het functioneren van patiënten in de domeinen 'activiteit' en 'participatie' is zeer belangrijk. Amputatiepatiënten geven aan dat zij vooral in deze twee domeinen veel problemen ondervinden als gevolg van hun amputatie of hun beenprothese. Ten tweede is het belangrijk dat deze informatie betrekking heeft op alle deelpopulaties van amputatiepatiënten waarvan het aannemelijk is dat de patiënten binnen die groep baat zouden kunnen hebben bij het gebruik van een MPK. Met behulp van de informatie ten aanzien van deze deelpopulaties informatie zou duidelijk moeten worden welke patiënten voordeel kunnen hebben van een MPK, en welke patiënten niet. Tot nu toe is onderzoek naar de effectiviteit van MPKs voornamelijk uitgevoerd binnen de groep amputatiepatiënten met een hoge mobiliteitsgraad (MFCL-3 en MFCL-4). De hoeveelheid (getoetste) informatie ten aanzien van de effectiviteit van MPKs voor personen binnen de MFCL-2 subpopulatie, daarentegen, was minimaal. 
Het huidige onderzoek had als primair doel het systematisch evalueren van de effecten die een MPK heeft op het fysiek functioneren van amputatiepatiënten binnen de MFCL-2 subpopulatie. Het gebruik van een MPK is in dit onderzoek vergeleken met conventionele, mechanisch gestuurde kniescharnieren. Hierbij is onderzocht wat de invloed is van een MPK op de functionele vaardigheden van patiënten ten aanzien van algemene dagelijkse levensverrichtingen ( $A D L)$. Ook is geëvalueerd wat de effecten zijn van het gebruik van een MPK op de manier waarop patiënten omgaan met verschillende verstoringen van het lopen. Verder is onderzocht wat de invloed is van een MPK op het dagelijks activiteitenniveau van patiënten.

De eerste stap in deze thesis was om in de huidige wetenschappelijke literatuur na te gaan hoe tot nu toe de effectiviteit van MPKs, in vergelijking met mechanisch gestuurde kniescharnieren, is geëvalueerd. In hoofdstuk 2 zijn 31 studies geïdentificeerd waarin de effecten zijn onderzocht van zowel een MPK als een mechanisch gestuurd kniescharnier op het functioneren van de patiënt. De belangrijkste uitkomstmaten van deze studies zijn geëxtraheerd en vervolgens gestructureerd volgens het ICF model. Ook is een beknopt overzicht gegeven van de resultaten van de verschillende studies. De meerderheid $(70 \%)$ van alle geïdentificeerde uitkomstmaten die gericht waren op het daadwerkelijk functioneren van de patiënt met zijn prothese, hadden betrekking op het ICF domein 'functie'. Slechts $27 \%$ van de uitkomstmaten was gericht op het ICF domein 'activiteit' en geen enkele van deze uitkomstmaten had betrekking op het ICF domain 'participatie'. Bovendien had de informatie ten aanzien van de effecten van MPKs betrekking op slechts een beperkt deel van de totale populatie van mensen met een amputatie door of boven de knie. MPKs waren vooral getest bij gezonde, fitte, actieve personen, die relatief jong zijn. Patiënten die geclassificeerd zijn als MFCL-2 waren veelal buiten beschouwing gelaten, hoewel deze groep patiënten een relatief grote deelpopulatie van amputatiepatiënten is. De effecten van een MPK op het functioneren van deze deelpopulatie waren dan ook vrijwel onbekend. Uit de verrichte review kan geconcludeerd worden dat het wetenschappelijk bewijs betreffende het functioneren in het dagelijks leven van patiënten met een MPK zeer beperkt is. Onderzoek zou zich specifiek moeten richten op de ICF domeinen 'activiteit' en 'participatie' om zo de mogelijke meerwaarde van een MPK op het dagelijks functioneren van patiënten met een prothese beter te kunnen begrijpen. Ook de MFCL-2 deelpopulatie moet meer aandacht krijgen in onderzoek ten aanzien van MPKs. 
Gegeven de beperkte evidentie wat betreft de effecten van MPKs op het functioneren van amputatiepatiënten binnen het ICF domein 'activiteit', evenals het geconstateerde gebrek aan mogelijke instrumenten om de prestaties van patiënten in dit domein objectief te meten, was het noodzakelijk om een nieuw meetinstrument te ontwikkelen. In hoofdstuk 3 is deze ontwikkeling van een nieuw meetinstrument dat het uitvoeren van ADL door mensen met een bovenbeenamputatie op een objectieve manier kan meten, beschreven. Dit meetinstrument, genaamd 'Assessment of Daily Activity Performance in Transfemoral amputees (evaluatie van de uitvoering van dagelijkse activiteiten bij transfemorale amputatiepatiënten), afgekort ADAPT, is een testcircuit dat bestaat uit verschillende stations. Bij ieder station voert de patiënt één of meer ADL taken uit. Deze taken zijn gekozen aan de hand van de resultaten van eerder onderzoek naar de problemen die amputatiepatiënten ondervinden in het dagelijks leven. Doordat de patiënt de ADL taken daadwerkelijk moet uitvoeren, is het mogelijk om objectieve informatie te verzamelen ten aanzien van de functionele vaardigheden van transfemorale amputatiepatiënten. Enkele psychometrische eigenschappen van de ADAPT test zijn geëvalueerd, zoals het vermogen van de test om te discrimineren tussen mensen met een verschillend vaardigheidsniveau en de test-hertest betrouwbaarheid. Personen die gebruik maakten van een MPK waren duidelijk sneller in het uitvoeren van de verschillende onderdelen van de ADAPT test dan de personen die gebruik maakten van een mechanisch gestuurd kniescharnier. De ADAPT test lijkt voldoende in staat is om verschillen in vaardigheidsniveau te detecteren die het gevolg zijn van het type kniescharnier dat door de persoon gebruikt wordt. Ten aanzien van de test-hertest betrouwbaarheid werden slechts kleine verschillen gevonden in de gemiddelde uitvoeringstijden tussen de eerste en de tweede keer dat de betreffende activiteiten werden uitgevoerd. Een sterke relatie is gevonden tussen de eerste en de tweede meting (correlatiecoëfficiënt $\geq 0.80$ ) op alle ADAPT activiteiten, met uitzondering van 1 activiteit. Voor 75\% van alle teststations was deze relatie zelfs zeer sterk (correlatiecoëfficiënt $\geq 0.90$ ). Om de betrouwbaarheid verder te testen is tevens gekeken naar de mate van overeenstemming tussen de eerste en de tweede meting met behulp van Bland-Altman analyses. De Bland-Altman analyses gaven voor alle ADAPT teststations aan dat de eerste meting en de tweede meting in overeenstemming met elkaar waren over het gehele spectrum van gemeten scores. De ADAPT testresultaten zijn ook vergeleken met de scores op de Locomotor Capabilities Index (LCI). De LCl scores gaven een duidelijk plafondeffect aan, namelijk $70 \%$ van de deelnemers behaalde een maximale score. De ADAPT testresultaten lieten daarentegen duidelijke verschillen per teststation zien, zelfs bij de patiënten die op de LCl maximaal scoorden. Op basis van de resultaten van deze studie is geconcludeerd dat het mogelijk is om functionele dagelijkse 
vaardigheden van transfemorale amputatiepatiënten objectief te meten, gebruikmakend van het concept van gesimuleerde ADL taken.

De functionele meerwaarde van MPKs wat betreft de uitvoering van ADL is onderzocht met behulp van de ADAPT test in MFCL-2 amputatiepatiënten (hoofdstuk 4). Deelnemers werden gemeten in drie prothesecondities, namelijk condities waarin de deelnemers gebruik maakten van een mechanisch gestuurd kniescharnier, een MPK met een adaptieve standfase-en zwaaifasesturing $\left(\mathrm{MPK}_{A}\right)$, en een MPK met een adaptieve standfasesturing en een mechanische zwaaifaseregeling $\left(\mathrm{MPK}_{\mathrm{B}}\right)$. Per ADAPT testactiviteit werd de tijd gemeten die nodig was om de taak uit te voeren. Ook werd de zelfervaren moeilijkheidsgraad door de deelnemers gescoord op een visuele analoge schaal. Activiteiten waarbij voldoende stabalans nodig is, werden gemiddeld significant sneller uitgevoerd in beide MPK condities in vergelijking met de mechanische protheseknieconditie. Verder is een grote variabiliteit waargenomen tussen proefpersonen wat betreft de uitvoeringstijden op de ADAPT test. Dit bevestigde onze verwachtingen dat de populatie MFCL-2 patiënten een heterogene groep zou zijn. Het probleem bij grote heterogeniteit is dat eventuele effecten van de MPKs op het functioneren van de patiënt verhuld kunnen worden door de grote variabiliteit tussen proefpersonen. De deelnemersgroep werd daarom gestratificeerd over drie subgroepen, i.e. groepen deelnemers met respectievelijk een laag, gemiddeld en hoog functioneel niveau. Op deze manier kon een verfijnder overzicht van de effecten van de MPKs verkregen worden. De uiteindelijke resultaten laten zien dat een MPK leidt tot een verbeterd vermogen om ADL uit te voeren bij MFCL-2 patiënten met een gemiddeld of hoog functioneel niveau. Dit in tegenstelling tot de patiënten met een laag functioneel niveau, bij wie geen verschillen werden gemeten tussen prothesecondities. Dit fenomeen zou verklaard kunnen worden door de lagere lichamelijke conditie in combinatie met een verminderd niveau van vertrouwen in de prothese bij de mensen in deze laatste groep.

In hoofdstuk 5 is de effectiviteit van $\mathrm{MPK}_{\mathrm{A}}$ en $\mathrm{MPK}_{\mathrm{B}}$ onderzocht wat betreft het vermogen van de MFCL-2 patiënten om vier verschillende typen verstoringen van hun looppatroon op te vangen (struikelen, plotseling moeten stoppen, plotseling een stap zijwaarts moeten zetten, en onverwacht op een obstakel stappen). Ook hun zelfervaren prestaties en hun gevoel van stabiliteit op de prothese tijdens deze perturbaties zijn onderzocht. De manier waarop de proefpersoon omging met de verschillende perturbaties werd beoordeeld door twee onafhankelijke experts aan de hand van videobeelden van de testen. Aan de prestatie van de patiënt werd een score toegekend variërend van een 
1 (val) tot en met een 10 (perfect opgevangen). De resultaten wijzen uit dat alleen de deelnemers uit de subgroepen met een gemiddeld en hoog functioneel niveau zich beter in staat achten om de verstoring tijdens het lopen succesvol op te vangen met de MPK ten opzichte van een mechanisch gestuurde kniescharnier. Ook vonden de deelnemers uit deze twee subgroepen dat de MPKs tijdens de perturbatietesten meer stabiliteit gaven dan de prothese met het mechanisch gestuurde kniescharnier. Ten aanzien van het daadwerkelijk opvangen van de verschillende verstoringen van het looppatroon werden geen verschillen waargenomen tussen knieprothesecondities. In voorgaande onderzoeken met MFCL-3 en MFCL-4 patiënten werden daarentegen wel duidelijke verschillen waargenomen tussen MPKs en mechanisch gestuurde kniescharnieren tijdens vergelijkbare perturbatietesten. MFCL-2 patiënten lijken anders te reageren op situaties met een hoog valrisico. Een mogelijke verklaring hiervoor zou kunnen zijn dat onze deelnemers de testen hebben uitgevoerd met een zogenaamde "voorzichtige gang", dat veel voorkomt bij oudere personen. Door voorzichtiger te lopen wordt de balans geoptimaliseerd en wordt de tijd verlengd die nodig is om de verstoring tijdens het lopen succesvol op te vangen. Wat betreft de perturbatietesten adviseren wij om sensitievere meetinstrumenten te ontwikkelen en te gebruiken. De ogenschijnlijk subtiele effecten die een prothesekniescharnier heeft op de manier waarop amputatiepatiënten omgaan met perturbaties van het looppatroon, kunnen dan mogelijk beter worden gedetecteerd.

De effecten van het gebruik van een MPK, in vergelijking met een mechanisch gestuurd kniescharnier, op het dagelijkse activiteitenniveau van MFCL-2 amputatiepatiënten is beschreven in hoofdstuk 6. Het activiteitenniveau van de deelnemers is gemeten in de eigen leefomgeving van de patiënten met behulp van accelerometrie. Ook zijn de ervaringen van de deelnemers over het gebruik van de verschillende prothese kniescharnieren geregistreerd met behulp van de Prosthesis Evaluation Questionnaire (prothese evaluatie vragenlijst) (PEQ). De MFCL-2 amputatiepatiënten gaven aan dat zij beter in staat waren om met de prothese te lopen die voorzien was van een MPK. Ook waren zij meer tevreden met de manier waarop zij liepen. Bovendien rapporteerden zij een betere stompconditie en een hoger niveau van lichamelijk comfort. Echter, ondanks dat de patiënten deze voordelen van de MPK hebben ervaren, heeft dat niet geleid tot een verhoging van hun dagelijkse activiteitenniveau na één week gebruik van de MPK. Blijkbaar is het verhogen van het potentieel functioneren van gebruikers van een beenprothese door de prothese te voorzien van een MPK, niet automatisch een stimulans voor de patiënt om meer actief te zijn in het dagelijks leven. Deze personen hebben blijkbaar in de jaren na hun amputatie hun levensstijl aangepast aan de functionele beperkingen die 
het gevolg waren van de amputatie. Het is moeilijk gebleken om iemands levensstijl op korte termijn te veranderen. De effecten van het gebruik van een MPK zullen daarom ook op de lange termijn bekeken moeten worden in de toekomst.

In hoofdstuk 7 is een uitgebreid overzicht gegeven van de belangrijkste bevindingen van het huidige onderzoek en zijn de klinische implicaties van deze bevindingen bediscussieerd. Door middel van het onderzoek dat in deze thesis gerapporteerd wordt, is aangetoond dat MFCL-2 patiënten met een gemiddeld of hoog functioneel niveau baat kunnen hebben bij het gebruik van een MPK. Bij deze patiënten leidde het gebruik van een MPK tot verbeterde prestaties van ganggerelateerde $A D L$ in vergelijking met mechanisch gestuurde kniescharnieren. Bovendien leidde het gebruik van een MPK tot een groter gevoel van vertrouwen en veiligheid bij voornoemde patiënten, alsook een toename in de zelfervaren prestaties, zelfs na één week gebruik van een MPK.

Tot op heden werden MPKs voornamelijk voorgeschreven aan amputatiepatiënten met een hoog functioneel niveau (MFCL-3 en MFCL-4). Patiënten met een lager functioneel niveau (MFCL-2) kregen vooral een mechanisch gestuurde kniescharnier voorgeschreven, omdat een MPK een minder grote meerwaarde zou hebben voor het dagelijks functioneren van deze patiënten. De bevindingen van dit proefschrift tonen aan dat een aanzienlijk gedeelte van de groep MFCL-2 patiënten (namelijk MFCL-2 patiënten met een gemiddeld en hoog functioneel niveau), eigenlijk toch een MPK voorgeschreven hadden moeten krijgen als protheseoplossing. Verder is in dit proefschrift evidentie aangedragen dat de populatie van MFCL-2 patiënten een heterogene groep is. Een verklaring hiervoor zou kunnen zijn dat de oorspronkelijke MFCL niveaus te breed zijn gedefinieerd en dat geen eenduidig, objectief meetinstrument is toegekend om te helpen bij het toewijzen van patiënten aan een bepaald MFCL niveau. Zelfs nadat de classificatie van MFCL-2 patiënten verder verfijnd was met behulp van onze subclassificatie, bleef een aanzienlijke variabiliteit bestaan in de prestatie tussen patiënten binnen iedere subgroep. Daarom zouden testen, zoals de ADAPT test, gebruikt moeten worden, zodat op basis van individuele prestaties van de patiënt een prothesekniescharnier geselecteerd kan worden. In het uitgevoerde onderzoek zijn meetinstrumenten ontwikkeld om het functioneren van een patiënt in het ICF domein 'activiteit' objectief te meten. Ook is evidentie aangereikt betreffende de effectiviteit van MPKs bij MFCL-2 patiënten. Deze bevindingen kunnen clinici helpen bij het voorschrijven van prothesekniescharnieren. 


$$
\operatorname{tin}
$$




\section{Dankwoord}

"Vele handen maken licht werk". Deze uitdrukking is zeker van toepassing op mijn promotieonderzoek. Vele mensen hebben mij gesteund en geholpen de afgelopen periode. Mede dankzij hun hulp is dit proefschrift tot stand gekomen. Graag wil ik via deze weg dan ook iedereen hartelijk bedanken die betrokken is geweest bij mijn promotie. Ontzettend bedankt!

Een aantal personen wil ik graag in het bijzonder bedanken voor hun bijdrage.

Henk, bij jou is het allemaal begonnen. Je hebt me destijds, toen ik nog 'groen' en 'nat achter de oren' was, benaderd met de vraag of ik dit promotieonderzoek wilde uitvoeren. Gezien onze eerdere prettige samenwerking tijdens mijn Bachelor stage bij het voormalige iRv en SRL, hoefde ik niet lang te aarzelen om hiermee in te stemmen. De afgelopen jaren heb je me met veel raad en daad bijgestaan. Altijd stond je deur voor me open en kon ik bij je terecht met mijn vragen. Met oneindig veel geduld heb je mijn stukken nagekeken en van een kritische noot voorzien. Hoewel termen als 'KO2MUW', 'hmmm...', en 'TBS' me soms tot wanhoop hebben gedreven, hebben zij ervoor gezorgd dat de kwaliteit van het proefschrift het juiste peil bereikte. Deze typische termen (waar ik overigens nog een hele rij van kan opnoemen) zijn onlosmakelijk met jou verbonden en ik zal ze waarschijnlijk nooit meer vergeten. Henk, ik heb het ontzettend fijn gevonden dat jij mijn mentor en copromotor bent geweest en ik wil je daarom bij deze bedanken voor al je hulp. Hopelijk kruisen onze wegen elkaar nog eens in de toekomst.

Bea, samen met Henk heb jij dit promotieonderzoek leven ingeblazen en heb je me onder je hoede genomen. Jouw onnavolgbare enthousiasme werkte erg aanstekelijk en ook jij hebt me veel geleerd de afgelopen periode. Ondanks je overvolle agenda vond je toch steeds de tijd om op vrijdagochtend met me van ideeën te wisselen. Je hielp me er steeds weer even aan herinneren om naast de onderzoekskant ook het klinisch perspectief niet uit het oog te verliezen. Ik ben er trots op dat ik je eerste promovendus mocht zijn. Hopelijk heeft het je niet te veel afgeschrikt om nog velen promovendi na mij te begeleiden.

Rob, hoewel je in een later stadium van mijn promotietraject bent ingestapt in de rol van promotor en hoogleraar Revalidatiegeneeskunde, bracht je frisse blik op de materie en je opbouwende kritiek geregeld nieuwe stof tot nadenken. Ik kon er altijd van op aan dat je mijn artikelen snel en zorgvuldig beoordeelde, wat ik als zeer prettig heb ervaren. Ik wil je graag danken voor alle tijd en moeite die je in me geïnvesteerd hebt. 
Peter, je hebt me vooral in het begin van mijn promotieonderzoek met veel wijze raad bijgestaan, wat het onderzoek zeker ten goede is gekomen. Hoewel je gedurende het promotietraject wat meer op de achtergrond bent gebleven, is je hulp en ondersteuning zeker niet onopgemerkt gebleven. Hartelijk dank hiervoor!

Ook wil ik graag een woord van waardering richten tot de leden van de beoordelingscommissie, prof. dr. M. Hesselink, Prof. dr. G. Schurink, Prof. dr. J. Geertzen, Prof. dr. H. Stam, Prof. dr. R. de Bie, voor het kritisch beoordelen van mijn proefschrift.

Zonder bereidwillige deelnemers aan alle onderzoeken is een promotie onmogelijk. Graag wil ik alle deelnemers hartelijk danken voor de tijd en vele moeite die jullie belangeloos geïnvesteerd hebben in dit onderzoek. Mede dankzij het enthousiasme waarmee jullie al die keren naar Hoensbroek zijn gekomen en de inzet die jullie hebben getoond, kan ik terugkijken op een hele bijzondere tijd.

Tijdens dit onderzoek heb ik het geluk gehad om nauw samen te mogen werken met de fysiotherapeuten van de afdeling Amputatie en Traumatologie van Adelante Revalidatiecentrum. Allen hartelijk dank voor jullie hulp, tijd en steun. In het bijzonder een speciaal woord voor Sven en Guido. Jullie hebben een sleutelrol gehad in het onderzoek. Met volle overgave hebben jullie de deelnemers wegwijs gemaakt op hun nieuwe prothese. Jullie expertise als fysiotherapeut op het gebied van amputatie en prothesiologie heeft ertoe geleid dat dit onderzoek succesvol kon worden afgerond. Sven, daarnaast was je natuurlijk ook in een later stadium bij het onderzoek betrokken in je rol als manager bedrijfsvoering van het Kenniscentrum. Ik wil jullie ontzettend bedanken voor alle hulp.

Ook een zeer belangrijke rol binnen dit onderzoek was weggelegd voor de orthopedisch instrumentmakers van Livit Orthopedie. leder van jullie heeft mij wel op een bepaalde manier geholpen tijdens dit onderzoek, waarvoor dank. Graag wil ik Frans in het bijzonder noemen. Ondanks de dagelijkse hectiek van de werkplaats, bleef jij altijd de rust zelve en vond je steeds weer de tijd om mij te woord te staan en te helpen in het onderzoek. Met veel vakkundigheid heb je de protheses van de deelnemers aan het onderzoek voorzien van een C-leg. Ook wanneer de protheseknie niet 'gewoon' om te wisselen was, vond jij wel een manier om het toch voor elkaar te krijgen. Frans, graag wil ik bij deze mijn waardering uitspreken voor wat jij allemaal voor me hebt gedaan de afgelopen jaren. Bedankt! 
Esther en Caroline wil ik graag bedanken voor de rol die zij hebben gespeeld in het ontwikkelen en evalueren van de ADAPT test. Zonder jullie goede voorwerk was dit onderzoek niet mogelijk geweest.

I wish to express my gratitude to Andreas Kannenberg. Thank you for all the time and effort you have invested in me and in this project. I appreciate you making all those long trips to Hoensbroek in order to engage in several fruitful discussions regarding the progress and findings of our research.

Uiteraard wil ik ook het woord richten tot al mijn (oud-)collega's van het Adelante Kenniscentrum. Mede dankzij jullie kan ik terug kijken op een geweldige tijd. Dank allemaal voor alle hulp en de talloze leuke dingen die we samen hebben meegemaakt. Een extra woord van dank wil ik richten tot Richard voor al zijn technische hulp en ondersteuning tijdens dit project. Tijdens mijn tijd in Hoensbroek is het Kenniscentrum verschillende keren van locaties gewisseld. Hierdoor heb ik ook het geluk gehad dat ik in de loop der tijd met vele leuke collega's een kantoor heb mogen delen. Graag wil ik mijn (oud-)kamergenoten Ananda, Annemie, Annick, Ivan, Rachma, Ryanne, Veronique, en Vera danken voor een hele leuke tijd en tevens mijn excuses aanbieden voor de keren dat ik jullie van het werk heb gehouden (bijvoorbeeld tijdens de uitbraak van het USD-virus in het Kenniscentrum...). Ook mijn overburen Albère en Pascalle wil ik bedanken. De vrolijke noot die jullie steeds weer brachten met $z$ 'n tweeën hield de moed erin en de lachspieren op peil. Ook de heldinnen van het secretariaat Jolanda, Veronique en Margareth wil ik hartelijk danken voor alle ondersteuning. En hoewel ze uit het oog is, maar niet uit het hart hoort Irma ook zeker in dit rijtje thuis.

Aan mijn paranimfen Ivan en Ananda:

Ivan, samen hebben we lange tijd een bureau gedeeld. Tussen de dolle pret door hebben we toch tijd gevonden om een proefschrift te schrijven. Je hebt vorig jaar het promotiestokje aan me doorgegeven, maar ik hoop dat je de andere kant nog even vast wilt houden tot je taak als paranimf erop zit. Naast een gewaardeerde collega, ben je ook een goede vriend geworden. Ik ben zeer vereerd je aan mijn zijde te hebben tijdens de verdediging van mijn proefschrift. Bedankt voor alle hulp en steun tijdens de laatste loodjes. Dit is zeer gewaardeerd!

Ananda, vanaf het eerste moment dat je in het Kenniscentrum terecht bent gekomen, hebben je nuchtere no-nonsense instelling en ongeëvenaarde vechtersmentaliteit me veel respect ingeboezemd. Tijdens onze vele gesprekken over de belangrijke dingen des levens heb je veel zaken voor me in een nieuw perspectief weten te plaatsen. Ontzettend 
bedankt voor de leuke tijd! Ook voor jou geldt dat ik enorm blij ben dat je me als paranimf ter zijde wilt staan op de grote dag.

Mijn familie wil ik graag bedanken voor alle steun die ze me geboden hebben tijdens de afgelopen tijd. Mam, bedankt dat je altijd voor me klaar hebt gestaan en me de mogelijkheden hebt geboden om mij te kunnen ontwikkelen. Dankzij jou ben ik op dit punt kunnen komen. Dankjewel!!! Mijn broers Jan en Maurice, jullie wil ik enorm bedanken voor alle steun die jullie me hebben geboden. Fons, Netty, Camiel en Michel, ook jullie wil ik hartelijk danken voor alle hulp tijdens de afgelopen tijd.

Ook al mijn vrienden wil ik graag bedanken. Op de juiste momenten brachten jullie de ontspanning die nodig was om weer verder te kunnen. Helaas heb ik jullie de afgelopen maanden niet zo heel veel meer kunnen zien vanwege alle werkzaamheden. Hopelijk komt daar snel weer verandering in.

Het beste heb ik tot het laatste bewaard, mijn lieve schatten Esther en Enora. Esther, de afgelopen jaren hebben we heel veel samen meegemaakt. In de periode van mijn promotieonderzoek, zijn we op de Volmolen gaan wonen en hebben deze de afgelopen jaren van boven tot onder verbouwd, we zijn getrouwd en hebben ons eerste kindje samen gekregen. Ondertussen was jij ook nog aan het studeren en vervolgens aan een nieuwe baan begonnen. Je had misschien het idee dat je niet zo heel veel voor me kon doen ten aanzien van dit proefschrift, maar ik kan met zekerheid zeggen dat het zonder jou nooit was gelukt. Het laatste jaar was erg moeilijk, maar jij hebt ons erdoor gesleept met je eeuwige positivisme en praktische aanpak. Langzaam hebben we ons leven weer op de rit en vanuit de grond van mijn hart wil ik je dan ook bedanken voor alles wat je tot nu toe voor me hebt gaan. En nu het proefschrift is voltooid, kunnen we ons volledig gaan richten op ons tweede wereldwondertje dat in februari het levenslicht zal zien. Enora, ik ben ontzettend trots dat ik jouw papa mag zijn. Die mooie glimlach die je me telkens weer schenkt is onbetaalbaar. Je was de beste motivatie om hard door te werken en nu het proefschrift klaar is, krijg je weer alle aandacht van me die je zo ontzettend verdient.

Daar het zeker niet mijn bedoeling is om mensen te vergeten in dit dankwoord, wil ik graag afsluiten met een stukje naar de beroemde woorden van Walter de Donder: "Iedereen die een steentje heeft bijgedragen tijdens de afgelopen periode, BEDANKT! ledereen die geen steentje heeft bijgedragen tijdens deze periode, OOK BEDANKT!" 


$$
\operatorname{tin}
$$


About the author

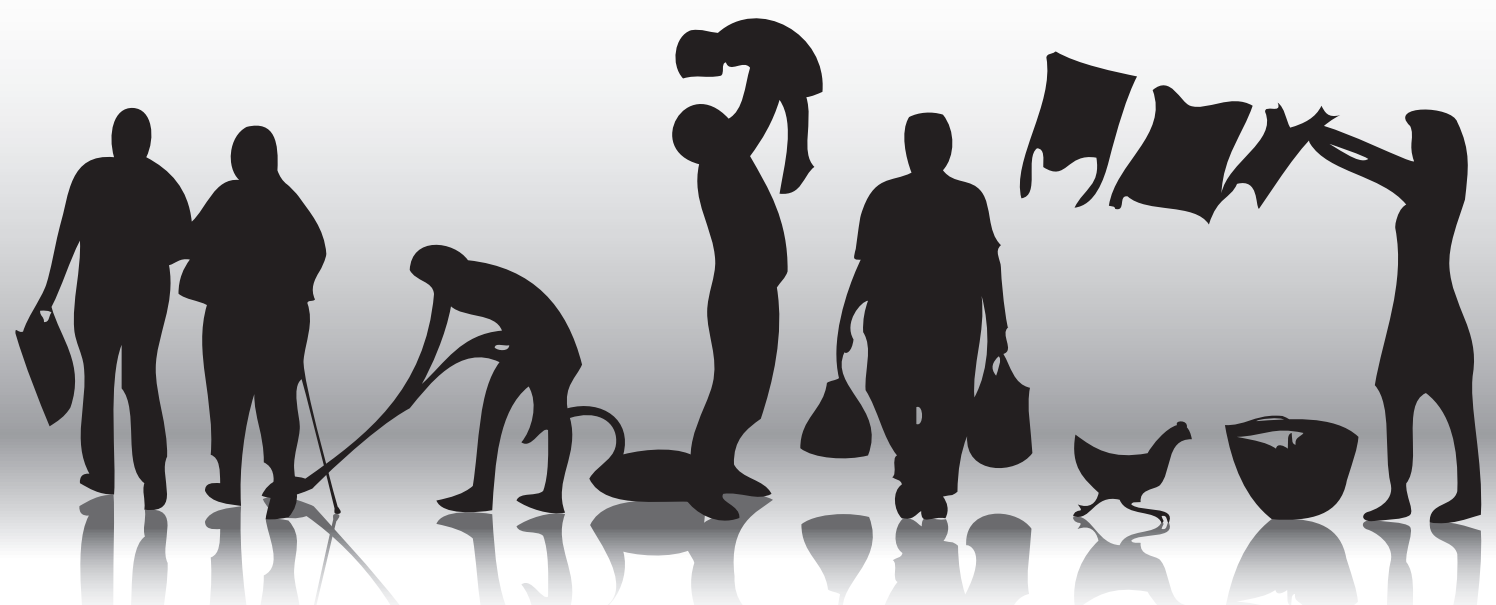




\begin{abstract}
About the author
Patrick Theeven was born on January 2, 1982 in Sittard, The Netherlands. He attended secondary education at 'Trevianum' in Sittard, from which he graduated in 2000 . He then studied Technical Engineering and Management at the University of Technology in Eindhoven. In 2002 he made a switch from Eindhoven to Maastricht University where he studied General Health Sciences. Here he followed the minor Bioregulation and Health and majored in Human Movement Sciences. In 2005 he obtained his Bachelor's degree and in 2006 received his Master's degree, both in Human Movement Sciences at Maastricht University. In November 2006 he was appointed as a PhD researcher at Rehabilitation Foundation Limburg (currently: Adelante Rehabilitation Centre) on the project 'Functional added value of prostheses with an electronically controlled stance and/or swing phase for persons with a unilateral transfemoral amputation, a hip or a knee disarticulation - a clinical study'. This study has resulted in this thesis. He was also affiliated with research school CAPHRI, department of Rehabilitation Medicine at Maastricht University. During the period of being a PhD student, he married Esther van Hinsberg in May 2009 and welcomed his firstborn daughter Enora in August 2011. Since August 2012, he works as a researcher and lecturer at the Fontys University of Applied Sciences in Eindhoven.
\end{abstract}





$$
\operatorname{tin}
$$


Publications

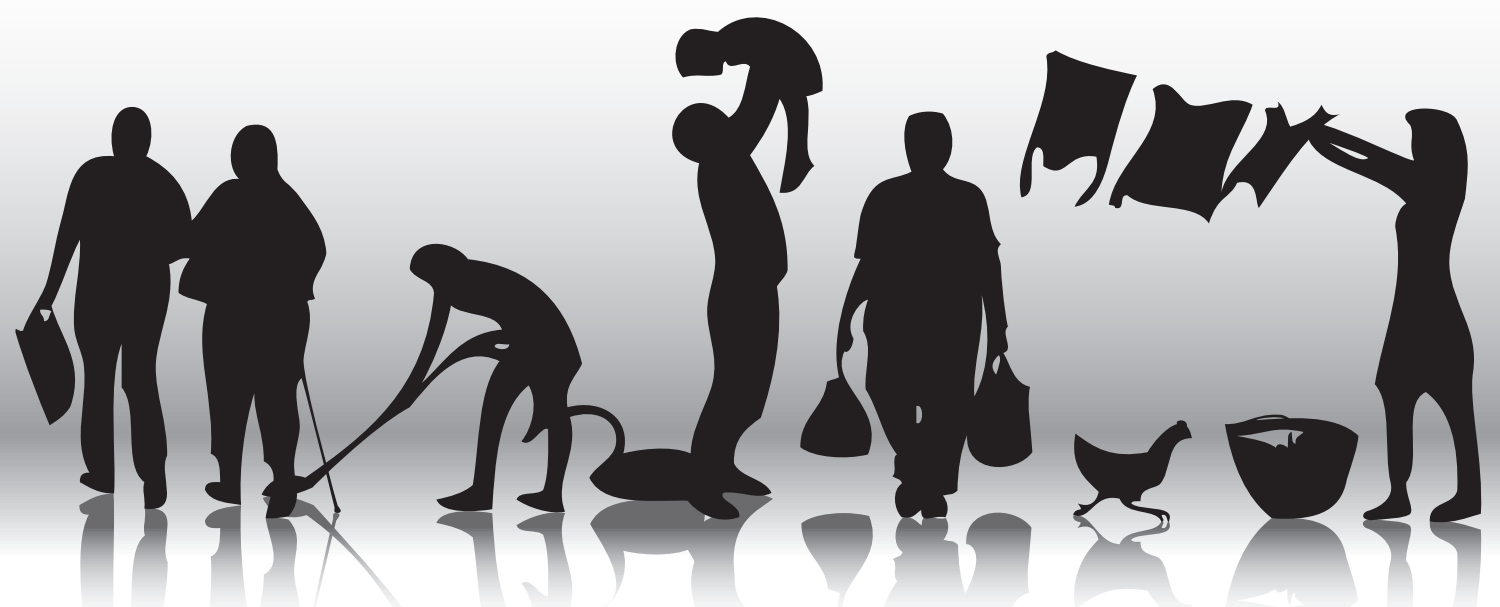




\section{Publications}

International journal publications

- Theeven P, Hemmen B, Stevens C, Ilmer E, Brink P, Seelen H. Feasibility of a new concept for measuring actual functional performance in daily life of transfemoral amputees. J Rehabil Med 2010; 42: 744-751.

- Theeven P, Hemmen B, Rings F, Meys G, Brink P, Smeets R, Seelen H. Functional added value of microprocessor-controlled knee joints in daily life performance of Medicare Functional Classification Level-2 amputees. J Rehabil Med 2011; 43: 906915.

- Theeven P, Hemmen B, Geers R, Meys G, Brink P, Smeets R, Seelen H. Influence of advanced prosthetic knee joints on perceived performance and everyday life activity level of low-functional persons with a transfemoral amputation or knee disarticulation. J Rehabil Med 2012; 44: 454-461.

- Theeven P, Hemmen B, Geers R, Brink P, Smeets R, Seelen H. Gait perturbation recovery of low functional transfemoral amputees using microprocessor-controlled prostheses: perceived and actual performance. (Submitted).

- Theeven P, Hemmen B, Brink R, Smeets, R, Seelen H. Measures and procedures utilized to determine the added value of microprocessor-controlled prosthetic knee joints. (Submitted).

\section{National publications}

- $\quad$ Theeven P, C-leg voor dagelijks gebruik. Dialoog 2009; 7: 38-39

\section{Peer reviewed conference publications}

- Theeven P, Hemmen B, Geers R, Balk S, Rings F, Brink P, Seelen H. Effects of electronically controlled prosthetic knee hinges on performance of common daily activities. 16th European Congress of Physical and Rehabilitation Medicine 3-6 June 2008, Bruges, Belgium.

- Theeven P, Hemmen B, Geers R, Balk S, Rings F, Brink P, Seelen H. Effects of electronically controlled prosthetic knee hinges on performance of common daily activities. VRA Congress, 30-31 October, 2008, Ermelo, The Netherlands.

- Theeven P, Hemmen B, Geers R, Meys G, Rings F, Brink P, Seelen H. Evaluation of daily performance in upper leg amputees using electronically and non-electronically controlled prosthetic knee hinges. 22nd Congress of the International Society for Biomechanics, July 5-9, 2009, Cape Town, South Africa. 
- Theeven P, Hemmen B, Geers R, Meys G, Rings F, Brink P, Seelen H. Functional added-value of microprocessor-controlled knee joints on daily life performance in Medicare Functional Classification Level-2 amputees. 13th World Congress of the International Society for Prosthetics and Orthotics, May 10-15, 2010, Leipzig, Germany.

- Theeven P, Hemmen B, Geers R, Meys G, Rings F, Brink P, Seelen H. Recovery from a trip in transfemoral Medicare Functional Classification Level 2 amputees using different prosthetic knee hinges. 13th World Congress of the International Society for Prosthetics and Orthotics, May 10-15, 2010, Leipzig, Germany. 
